\title{
ChARACTERIZATION OF MICROBIAL
}

\section{COMMUNITIES IN CARBONATE SEDIMENTS}

\author{
Dissertation \\ for the award of the degree \\ "Doctor rerum naturalium" \\ of the Georg-August-Universität Göttingen \\ within the doctoral program of the \\ Göttingen Graduate School for Neurosciences, Biophysics, and \\ Molecular Biosciences (GGNB)
}

submitted by

Avril Jean Elisabeth von Hoyningen-Huene

from Offenbach am Main

Göttingen, 2021 


\section{Thesis Committee:}

Prof. Dr. Rolf Daniel, Department of Genomic and Applied Microbiology, Institute of Microbiology and Genetics, Georg-August-Universität Göttingen

PD Dr. Michael Hoppert, Department of General Microbiology, Institute of Microbiology and Genetics, Georg-August-Universität Göttingen

Prof. Dr. Gernot Arp, Geobiology Group, Geoscience Centre - GZG, Georg-AugustUniversität Göttingen

\section{Members of the examination board:}

Referee: Prof. Dr. Rolf Daniel, Department of Genomic and Applied Microbiology, Institute of Microbiology and Genetics, Georg-August-Universität Göttingen

$2^{\text {nd }}$ Referee: PD Dr. Michael Hoppert, Department of General Microbiology, Institute of Microbiology and Genetics, Georg-August-Universität Göttingen

\section{Further members of the examination board:}

Prof. Dr. Gernot Arp, Geobiology Group, Geoscience Centre - GZG, Georg-AugustUniversität Göttingen

Prof. Dr. Stefanie Pöggeler, Department of Genetics of Eukaryotic Microorganisms, Institute of Microbiology and Genetics, Georg-August-Universität Göttingen

Prof. Dr. Kai Heimel, Department of Molecular Microbiology and Genetics, Institute of Microbiology and Genetics, Georg-August-Universität Göttingen

Jun.-Prof. Dr. Jan de Vries, Department of Applied Bioinformatics, Institute of Microbiology and Genetics, Georg-August-Universität Göttingen 


\begin{tabular}{|l|}
\hline LIVE THE WORK! \\
LIVE THE WALK! \\
LIVE TAKA! \\
LIVE THE GREN! \\
Takamaka Camp, Aldabra \\
\hline
\end{tabular}




\section{Table of contents}

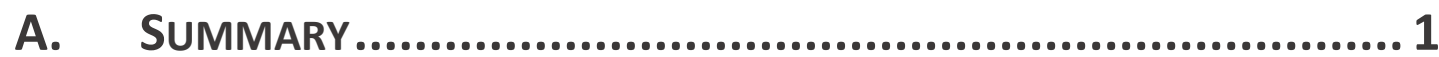

B. GeNERAL INTRODUCTION .............................................. 3

1. Microbial communities in global (carbonate) sediments ............ 3

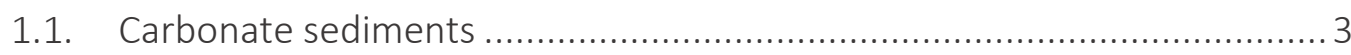

1.2. Global microbial players in the marine environment .............................. 4

2. Marine biogeochemical cycling and carbonate precipitation ..... 7

2.1. Global biogeochemical cycles...........................................................

2.2. Carbonate precipitation in the environment ………............................. 9

2.3. Biogenic carbonate precipitation …………………........................... 10

2.4. Microbial metabolism and the link to carbonate precipitation .................12

2.5. Detection of microbial communities and biogeochemical processes in

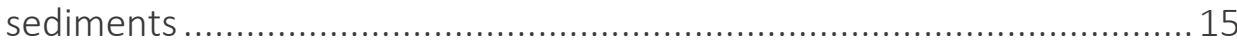

3. Study sites: Lake Neusiedl and Aldabra Atoll .......................... 17

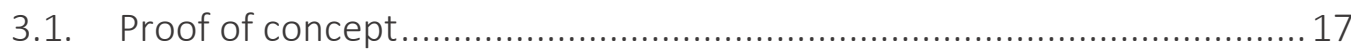

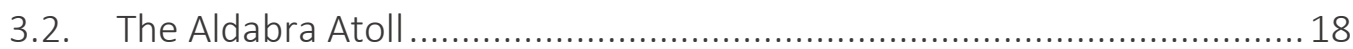

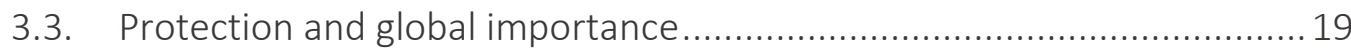

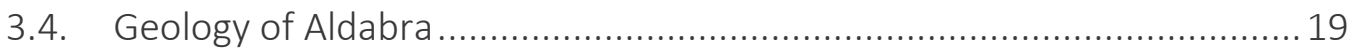

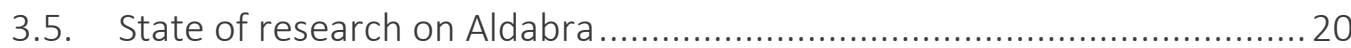

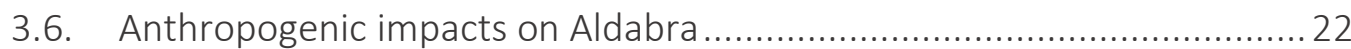

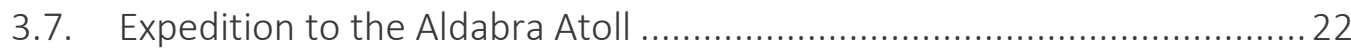

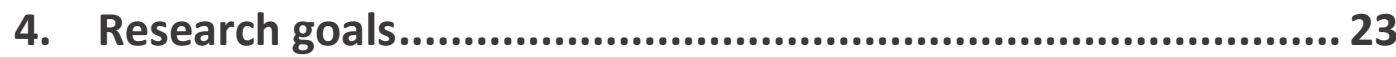

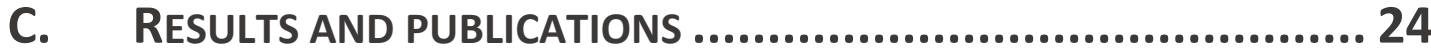

1. Bacterial succession along a sediment porewater gradient at Lake Neusiedl in Austria .............................................................. 25

2. Authigenic formation of $\mathrm{Ca}-\mathrm{Mg}$ carbonates in the shallow alkaline Lake Neusiedl, Austria ........................................................ 33

3. Total and active bacterial communities, porewater dynamics and time: a cross-sectional study of Aldabra Atoll sediments......... 56

Supplement: 84

4. Pontibacillus sp. ALD_SL1 and Psychroflexus sp. ALD_RP9, two novel moderately halophilic bacteria isolated from sediment and water from the Aldabra Atoll, Seychelles. 
Supplement:

5. Aldabras' hypersaline pools: metagenomic insights into lithifying and unlithifying environments...................................... 121

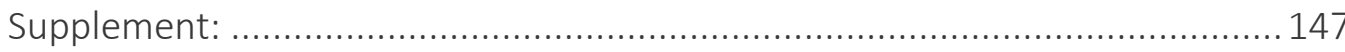

D. GenERAL DISCUSSION .......................................... 150

1. Microbiome of the Aldabra Atoll ..................................... 151

1.1. Sampling sites on the Aldabra Atoll ............................................... 151

1.2. Carbonate sand flats in the lagoon of Aldabra .................................... 151

1.3. Biogeochemical cycling in carbonate mud and silt............................. 154

2. Carbonate precipitation and diagenesis.......................... 157

2.1. Precipitation, diagenesis, and microbes........................................... 157

2.2. Precipitation in the water column: Lake Neusiedl............................... 158

2.3. Precipitation and dissolution in sand and sediment: Aldabra Lagoon.... 160

2.4. Precipitation in microbial mats and stromatolites: Aldabras' landlocked

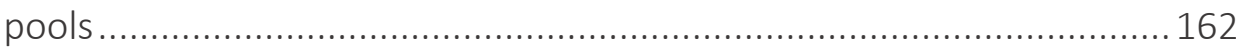

2.5. Role of the water column in carbonate precipitation at Westpool D and

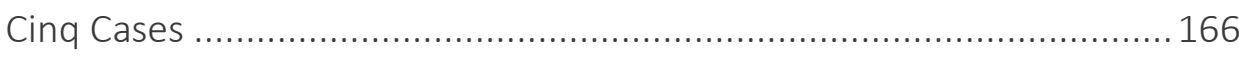

3. Sediment microbial communities and contamination........... 167

3.1. Method-based biases and contaminations ....................................... 168

3.2. Environmental pollution and microbial community response ............... 169

3.3. Clinically relevant microbial pollution ............................................... 170

4. Conclusion \& Outlook.............................................. 171

5. References .......................................................... 172

E. APPENDIX............................................................. 187

1. Supplement............................................................ 187

1.1. Supplementary Data Chapter B.1 Figure 1 ..................................... 187

1.2. Supplementary Data Chapter D.1 Figure 6 ..................................... 187

2. Publications \& Conference participations ........................... 192

3. Acknowledgements .................................................. 193

4. Curriculum Vitae............................................................... 195 


\section{A. SUMmARY}

Microbial communities in carbonate sediments from the alkaline Lake Neusiedl and the Aldabra Atoll were characterized. The aim was to determine the microbial community composition and function in the context of their contribution to biogeochemical cycles and carbonate precipitation. Total DNA and RNA were extracted from sediment and water samples. 16S ribosomal RNA genes and transcripts were amplified and sequenced to determine the bacterial community composition. Metagenomes were assembled from selected sampling sites to determine the functional potential encoded within the microbial community. Detailed insights into bacterial genomes and metabolism were gained through isolation and characterisation of two novel bacterial species derived from Aldabra.

The first sampling campaign represents the proof-of-concept study at Lake Neusiedl (Chapter C.1 \& C.2). In this study the sampling procedure for the push-cores and water column was established. Bacterial 16S rRNA genes were amplified from the total DNA, sequenced, and analysed. The results showed that freshwater picoplanktonic Alphaproteobacteria and Actinobacteriota were abundant in the water column (Chapter C.1). Together with Synechococcales sheaths they may provide nucleation sites for carbonate precipitation in the water column. The sediment followed the standard biogeochemical succession and showed signs of diatom dissolution (Chapter C.2). This was linked to high abundance of heterotrophic Gammaproteobacteria and fermenting Chloroflexota, which likely contributed to maintaining the neutral $\mathrm{pH}$ and supported the dissolution process.

The main sampling campaign to the Aldabra Atoll took place at the end of the dry season in November 2017. Sediment cores and water samples were taken at three sampling sites in the lagoon and one pool at the island rim (Chapter C.3). The bacterial community composition was identified using both 16S rRNA genes and transcripts, covering both present and past members of the community. The sampling sites Cinq Cases and Westpool D were selected for direct metagenome sequencing and analysis, as these were landlocked pools with a history of stromatolites (Chapter C.5). The sand sediment was oxic with low bacterial diversities and dominant Pseudomonas. The surface was covered by a slightly lithified crust, potentially linked to tidally induced carbonate oversaturation and precipitation driven by the activity of Gloeocapsopsis 
(Chapter C.3). In the mud and silt sediments bioturbation and tidal mixing led to a mixed surface and sulphate reduction zone. These were followed by atypical low bacterial phylogenetic diversity zones with high proportions of Gammaproteobacteria. Their onset was linked to changes in redox conditions, sediment age and available organic material (Chapter C.3). This was supported by results from the analysis of abundant metagenome-assembled genomes (MAGs) of the low-diversity zones at Cinq Cases. The MAGs harboured key genes for aerobic metabolism and denitrification (Chapter C.5). MAGs and 16S rRNA genes from Westpool D suggested that a biofilm comprising Gloeocapsa, Salinivibrio and Francisella is responsible for biologically induced carbonate precipitation of the local stromatolites. The unlithified microbial mat at the bottom of the pond harboured Cyanobium and Arthrospira, indicating that only specific Cyanobacteria support carbonate precipitation (Chapter C.5).

To identify novel bacteria and provide information on the vast majority of uncultured taxa, we enriched halophilic members of the bacterial community. Two isolates were selected and characterized both physiologically and genomically (Chapter C.4). Pontibacillus sp. ALD_SL1 was isolated form the mudflat of the South Lagoon and exhibited a high relative abundance (30\%) in the active bacterial community of the water column at Cinq Cases. Psychroflexus sp. ALD_RP9 was isolated from the bacterial bloom at Westpool D. Its ability to form extensive EPS to protect itself from salt and solar radiation may result in binding $\mathrm{Ca}^{2+}$-ions. Upon EPS degradation, local increase of $\mathrm{Ca}^{2+}$ and rearrangement of the EPS residues support the nucleation of carbonates.

This study encompasses the first characterization of microbial communities from the Aldabra Atoll using amplicon, metagenome, and genome analyses. The study highlights the different modes of carbonate precipitation, which can occur in the lacustrine and lagoonal environments. It also provides a basis for in-depth analysis of individual members of the community and their involvement in sediment biogeochemical cycling. 


\section{B. General InTRODUCTION}

\section{Microbial communities in global (carbonate) sediments}

\subsection{Carbonate sediments}

Prokaryotes, more precisely bacteria and archaea are the dominant lifeforms in sediments, able to withstand harsh environmental conditions. They are the main drivers of organic matter degradation, recycling, and biogeochemical cycling. Sediments containing more than $50 \% \mathrm{CaCO}_{3}$ are defined as carbonate sediments (Smith, 1998). They form through inorganic precipitation in the water column or by deposition of carbonate shells and skeletons over time. After deposition, the sediment carbonates can change in structure through environmental and microbial alteration, a process termed diagenesis (Montañez and Crossey, 2018). This leads to recrystallisation, lithification and cementation, leading to limestone formation (Smith, 1998). In the tropics, carbonate sediments occur mainly in shallow waters in the shape of coral reefs, coastal and intertidal mud and ooid deposits. Popular examples are the Bahamian ooid shoals (Diaz et al., 2013), extensive coral reef systems (Rusch and Gaidos, 2013), or atolls and lagoons, such as Kiritimati (Schmitt et al., 2019; Schneider et al., 2013) and Aldabra (this thesis). North and South of the tropics, carbonate sediments are mainly formed of calcareous skeletons of foraminifera, bryozoans and molluscs, and undergo stronger mixing, dissolution and diagenesis (Nelson, Keane and Head, 1988). In the deep-sea, carbonates dissolve as they pass the lysocline (Berger and Wefer, 2009). The lysocline occurs at the water depth where carbonate-ion concentrations in the water column switch from saturation to undersaturation. Depending on temperature, pressure, and $\mathrm{pH}$, this depth is variable, however, it occurs increasingly below a water depth of 3,000 m (Bickert, 2009). Vast carbonate deposits occur in the deep sea, yet deposition rates are exceptionally slow. The sediment is formed by marine (planktonic) snow and is referred to as calcareous ooze (Smith, 1998). In addition to marine carbonate sediments, saline marine and lacustrine ponds and alkaline lakes can contain carbonate sediments (Fussmann et al., 2020, Chapter C.2) or carbonate deposits in form of microbialites (Russell et al., 2014) and stromatolites (Casaburi et al., 2016). Freshwater deposits are not common but can be found along karst water creeks and caves as, e.g.: tufa (Schneider et al., 2015). 
Depending on the environmental conditions, as well as the microbial communities, these environments are shaped through different modes of precipitation and dissolution, which will be discussed in Chapter 2 .

\subsection{Global microbial players in the marine environment}

Microbial communities are a key component to understanding the processes and alteration of sediments. Global sediment bacterial communities are dominated by a few phyla. Of 89 phyla listed in the SILVA database, six are regarded as global key marine taxa (Figure 1). Proteobacteria, including Alpha-, Gamma- and Deltaproteobacteria (now Desulfobacterota) are the most prevalent. They can be found in almost all sediments, ranging from freshwater lakes and rivers to the deep sea (Figure 1) and throughout the ocean (Sunagawa et al., 2015). As a main component of global bacterial communities, they drive the nutrient exchange within the ecosystem.

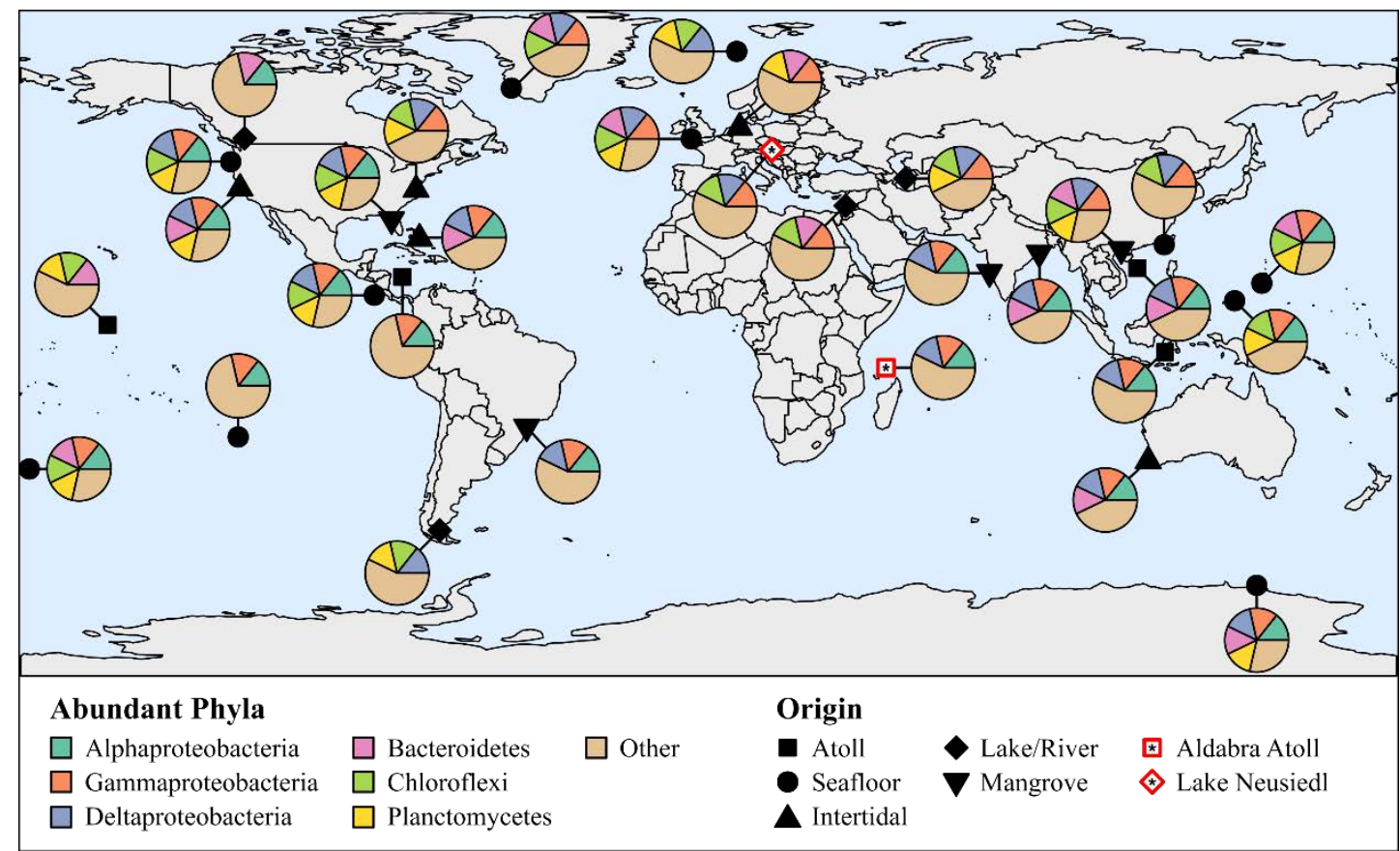

Figure 1. Main globally distributed bacterial phyla based on $16 \mathrm{~S}$ rRNA gene amplicon studies in sediments of different origin. The pie charts were generated in $\mathrm{R}$ using the package rworldmap v. 1.3-6 and are based on the six most abundant bacterial phyla in the studies listed in Appendix 1.1.

Alphaproteobacteria are less prevalent in sediments but dominate the global water column (Sunagawa et al., 2015). For instance, the SAR11 clade or Pelagibacterales are the most abundant bacteria in the oceans and are highly adapted to oligotrophic conditions (Brown et al., 2012). Many Alphaproteobacteria harbour 
bacteriochlorophylls (i.e., Rhodobacteraceae) to support their energy metabolism and are abundant in sun-exposed microbial mats, sediments and sea water (Brinkhoff, Giebel and Simon, 2008; Pohlner et al., 2017, Chapter C.3, C.5). In the sediment and soil environment, members of the Rhizobiales live as nitrogen fixers in root nodules or in root-association (Kuypers, Marchant and Kartal, 2018).

Gammaproteobacteria harbour a large variety of taxa with different metabolic capabilities. Members of this class include sulphur oxidizing Beggiatoales and Chromatiales (purple sulphur bacteria), facultatively anaerobic and potentially pathogenic Enterobacterales, ammonia oxidizing Nitrosococcales, as well as the ubiquitous Pseudomonadales including both Pseudomonas and Halomonas (formerly Oceanospirillales). In marine sediments the sulphur oxidizing taxa represent a main component of dark carbon fixation from organic matter (Dyksma et al., 2016). The Enterobacterales include the well-known gut bacterium Escherichia coli, but also opportunistic and ubiquitous Vibrio and Photobacterium, which are often found in association with marine fauna (Chimetto et al., 2008; Urbanczyk, Ast and Dunlap, 2011). Gammaproteobacteria are key players in global nitrogen cycling, as they produce ammonia from organic matter, are able to nitrify, denitrify and fix nitrogen under variable oxygen conditions (Kuypers, Marchant and Kartal, 2018).

Deltaproteobacteria, recently reclassified as Desulfobacterota, are an abundant phylum in anoxic sediments. Members of this phylum are key sulphate reducers, most of which can also ferment organic substrates to $\mathrm{CO}_{2}$ or acetate (Waite et al., 2020). With decreasing permeability of sediments, they show increasing relative abundances (Probandt et al., 2017). Their activity can be traced through monitoring of sulphate and total sulphides in the sediment, which culminates in a sulphate reduction zone (Jørgensen and Kasten, 2006). As high-molecular-weight organic matter is initially broken down by aerobic and anaerobic macro- and microfauna in the surface sediments, sulphate reducers use the released short-chained organic carbons, e.g.: acetate and formate, as electron donors (Jørgensen and Kasten, 2006; Wasmund, Mußmann and Loy, 2017). By fermenting short-chained organic carbons to $\mathrm{CO}_{2}$ they carry out the last step within the organic matter degradation chain. In addition to the classical sulphate reducing taxa, Desulfobacterota also harbour the Desulfobulbaceae known as cable bacteria, which can set up electron transport between the oxic and the 
anoxic sediment. Along their cell chains, or cables, they oxidize sulphide in the anoxic environment while reducing oxygen at the sediment surface (Burdorf et al., 2016).

Another prominent group are the Bacteroidetes, which are abundant in the water column and flourish during the first stages of decaying phytoplankton blooms (Alderkamp, Sintes and Herndl, 2006; Wemheuer et al., 2015). As r-strategists, they show fast doubling rates in response to blooms, attaching to algal particles to degrade the high-molecular-weight organic matter and particularly sulphated polysaccharides (Teeling et al., 2012 and references therein). In surface sediments they are less abundant than in the water column, particularly in studies based on 16S rRNA gene transcripts (Zhang et al., 2014; Chapter C.3). This indicates that they may have sedimented from the water column and may no longer be as metabolically active as they would be during a bloom.

The only currently known phylum to harbour bacteria with the ability to anaerobically oxidize ammonia to di-nitrogen gas (anammox, Candidatus Brocadiae) are the Planctomycetes. Anammox bacteria are an essential contributor to the nitrogen cycle (Kartal et al., 2013). Most members of this phylum, however, follow a facultatively anaerobic, free-living heterotrophic lifestyle and reach peak abundances in marine surface sediments in association with micro- and macro-algae (Wiegand, Jogler and Jogler, 2018). It is assumed that they survive by scavenging and degrading macromolecules from phototrophs and algae which they attach to. This ability allows them to be one of the first organic matter degraders along the carbon cycling chain in sediments and results in peak abundances during algal blooms (Wiegand, Jogler and Jogler, 2018 and references therein). They are therefore major competitors of Bacteroidetes in the water column. In the sediments they likely replace Bacteroidetes as dominant macromolecule degraders (Probandt et al., 2017).

Chloroflexota are a poorly described phylum containing anaerobic fermenters and green non-sulphur bacteria. Members of the phylum have been found to accumulate in wastewater treatment plants (Petriglieri et al., 2018), lake (HoyningenHuene et al., 2019) and river (Hug et al., 2013) sediments, and microbial mats (Schneider et al., 2013), where they are the dominant anaerobic degraders of organic matter. In intertidal sediments they are less abundant in relation to other phyla (Figure 1). 
Archaea occur ubiquitously alongside bacterial communities yet remain largely uncultivated. With recent advances in single-cell sequencing and the assembly of genomes from metagenomes (MAGs), our knowledge of archaea has considerably expanded (Baker et al., 2020). The marine water column harbours mainly Marine Groups I, II and III archaea, the first of which belong to the Thaumarchaeota and the latter two belonging to the Euryarchaeota (Zhang et al., 2015). Members of Marine Group II are associated with the photic zone and coastal surface waters where they can degrade particulate organic matter and gain energy through a photoheterotroph lifestyle (Rinke et al., 2019), sharing a niche with Bacteroidetes. The Euryarchaeota currently contain the most cultured representatives ranging from methanogens and anaerobic methane oxidizers (ANME) to aerobic halo-, acido- and thermophiles, and photoheterotrophs (Baker et al., 2020 and references therein). In coastal sediments Euryarchaeota and Candidatus Bathyarchaeota are the prevalent community members (Starnawski et al., 2017; Wang et al., 2020). Candidatus Bathyarchaeota occur mainly in anoxic environments, where they are able to degrade recalcitrant organic matter, fix $\mathrm{CO}_{2}$ and gain energy through methanogenesis (Baker et al., 2020 and references therein). Oxic marine sediments can harbour high relative abundances of ammonia oxidizing Thaumarchaeota, which can cope with low amount of ammonia and oligotrophic conditions to support their nitrifying activity (Pester, Schleper and Wagner, 2011; Wemheuer et al., 2019).

\section{Marine biogeochemical cycling and carbonate precipitation}

\subsection{Global biogeochemical cycles}

In the previous chapter marine sediment and water environments were introduced with regard to the dominant bacterial and archaeal taxa. Through their metabolism they are key drivers of the global biogeochemical cycles. The cycles describe the biological (biogenic) and geochemical (abiogenic) journey of key elements including carbon, nitrogen, sulphur, hydrogen and oxygen (Hilairy E. H., 2018). Abiogenic processes include geothermal and atmospheric processes, such as tectonics or weathering. Biogenic processes are determined by aerobic and anaerobic metabolic cycles which both produce and degrade organic matter (Falkowski, Fenchel and Delong, 2008). During oxygenic and anoxygenic photosynthesis energy is generated using water, or 
sulphur compounds as electron donors, while $\mathrm{CO}_{2}$ is fixed as organic matter. The generated organic matter is later degraded by aerobic and anaerobic heterotrophs (Dupraz et al., 2009). Different heterotrophic taxa can stepwise degrade large- to small-molecular-weight organic matter forming distinct microbial successions in the environment.

As the biogeochemical cycles are determined by the availability of different elements, they usually occur in zones (Figure 2). In the water column, oxygen and light availability determine the community structure and metabolism of the surface zone and deep chlorophyll maximum. As the oceans are mostly oligotrophic, biogeochemical cycling relies on photosynthesis as the main carbon-fixing process. Phytoplankton blooms are hotspots for diverse microbial communities, which live freely or in particle association on the produced organic matter using both aerobic and anaerobic respiration (Decho and Gutierrez, 2017; Giovannoni and Stingl, 2005). Anaerobes may survive in oxygen minimum zones, or by forming particle attachments and living in the central oxygen depleted parts of particles (Bertagnolli and Stewart, 2018; Decho and Gutierrez, 2017). Each particle by itself can harbour a complex nutrient cycle depending on the specialization of the associate members and the metabolic flexibility of many marine taxa (Moran, 2015). Particles and detritus from the marine food chain sink to the seafloor as marine snow, thereby supplying the light-depleted meso- and bathypelagic zone with nutrients (Decho and Gutierrez, 2017).

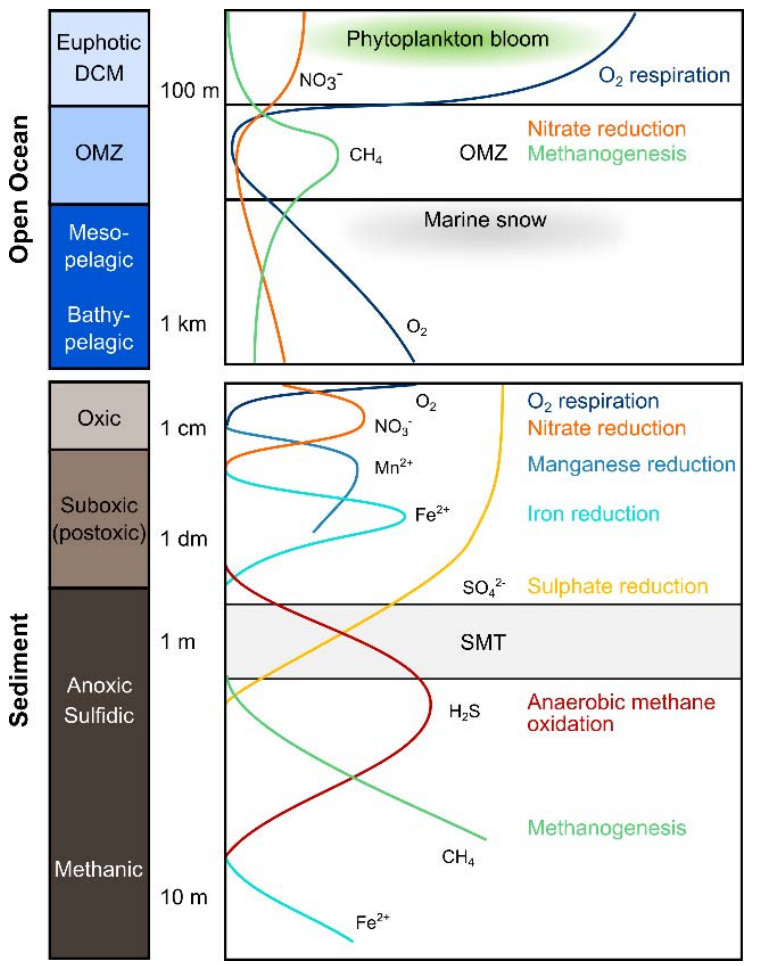

Figure 1. Water column and sediment biogeochemical zonation adapted from (Bertagnolli and Stewart, 2018; Löscher et al., 2016) and (Jørgensen, Findlay and Pellerin, 2019; Jørgensen and Kasten, 2006). Abbreviations: DCM: Deep chlorophyll maximum, OMZ Oxygen minimum zone. Adapted and reused with permissions from Springer Nature (Springer eBook license: 5172951031127) and Elsevier (Geochimica et Cosmochimica Acta license: 5172960259869) 
In sediments the succession of biogeochemical zones was schematically determined by Jørgensen and Kasten (2006, Figure 2). Starting with a surface zone, the availability of oxygen and sunlight determine the community structure of aerobic heterotrophs and phototrophs, similarly to the water column. When oxygen or nitrate are present in this zone, sulphur oxidizing (SOX) bacteria utilize sulphide and other sulphur compounds as an energy source. They replenish available sulphate and contribute to sediment detoxification (Wasmund, Mußmann and Loy, 2017). The surface zone is followed by a sulphate reduction (SR) zone where sulphate reducing bacteria (SRB) reduce sulphate and sulphur compounds to hydrogen sulphide. Part of the released hydrogen sulphide reacts with iron to form black FeS-precipitates in the sediment, thereby acting as a sulphur sink (Jørgensen, 2019). The SR zone transitions via a sulphate-methane-transition zone to the methanic zone, where methanogenic archaea live alongside syntrophs and methanotrophs (Jørgensen and Kasten, 2006). As the different metabolic pathways drive and are driven by environmental conditions, changes in these can lead to both precipitation and dissolution of calcium carbonates.

\subsection{Carbonate precipitation in the environment}

The precipitation of calcium carbonate $\left(\mathrm{CaCO}_{3}\right.$ or carbonate in the following) is dependent on the equilibrium and solubility of its components $\left(\mathrm{Ca}^{2+}, \mathrm{CO}_{3}{ }^{2-}\right)$ in the environment and its overall saturation. The saturation of a solution can be assessed through the saturation index $(\mathrm{SI})$, which is calculated from the ion activity product (IAP) and the solubility product of the mineral ( $\left.\mathrm{K}_{\text {mineral }}\right)$ (Reimer and Arp, 2011):

$$
S I=\log \left(\mathrm{IAP} / \mathrm{K}_{\text {mineral }}\right)
$$

In the environment carbonates can precipitate as soon as the solution becomes saturated. In biofilms inhibition by EPS only allows calcite to precipitate when it exceeds a ten-fold super saturation $\left(\mathrm{SI}_{\text {calcite }}>1.0\right)$ (Arp, Reimer and Reitner, 2001). During mineralization the environmental equilibrium of carbonate is mainly dependent on the addition or removal of $\mathrm{CO}_{2}$ from the system and can be formulated as (Mann, 2001):

$$
\mathrm{Ca}^{2+}+2 \mathrm{HCO}_{3}{ }^{-} \leftrightarrows \mathrm{CaCO}_{3}+\mathrm{CO}_{2}+\mathrm{H}_{2} \mathrm{O}
$$

Shifts in the equilibrium can either occur through physicochemical processes from the outside (abiogenic) or biological processes (biogenic) from within the system. 
Environmental changes in temperature and pressure, for instance, can cause extensive degassing of $\mathrm{CO}_{2}$ and evaporation, thereby shifting the equilibrium and inducing fresh abiotic precipitation (Figure 3). Alternatively, carbonate can abiotically precipitate in supersaturated environments, such as hypersaline or alkaline lakes and brines (Riding and Awramik, 2000).

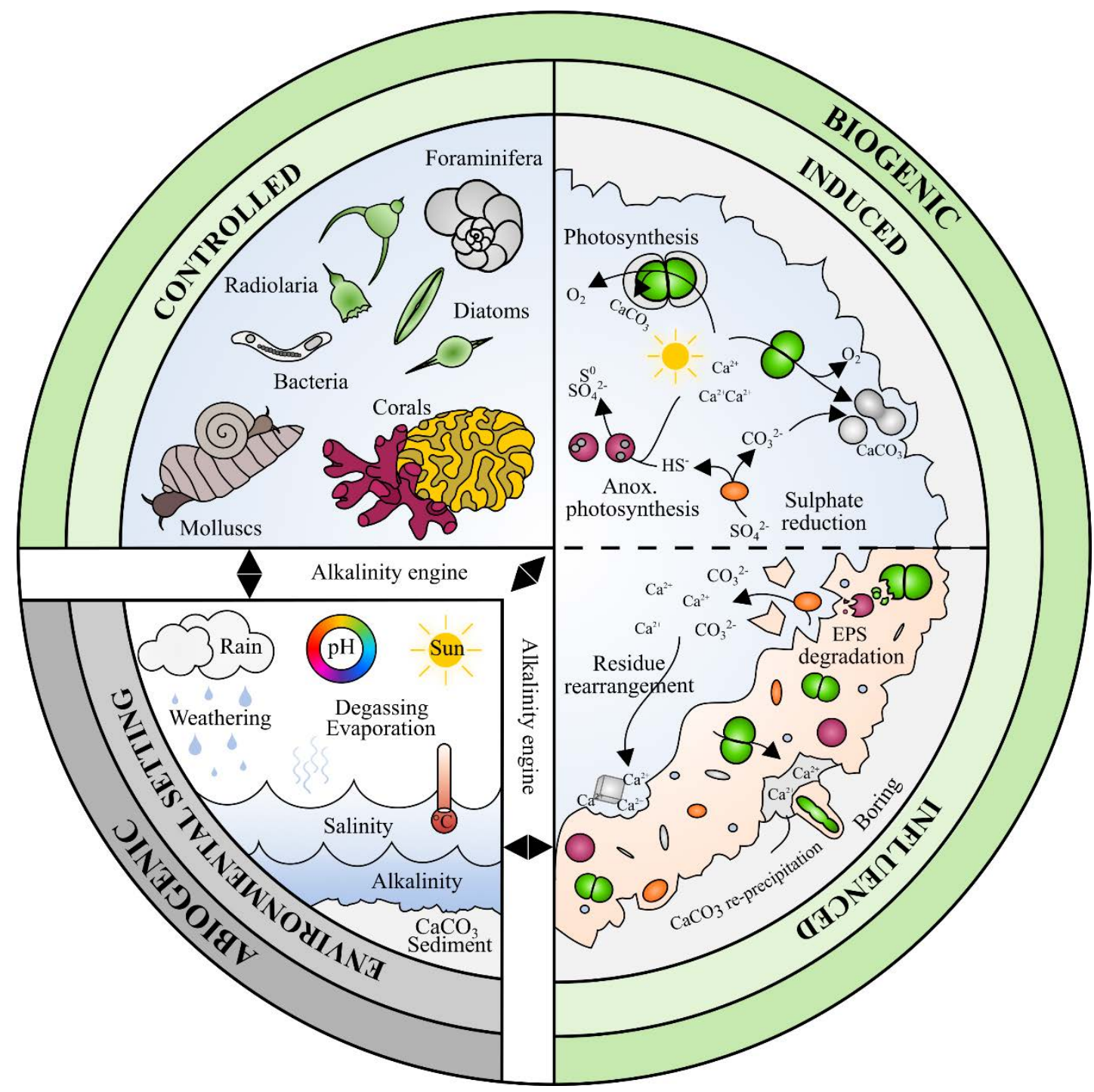

Figure 3. Modes of abiotic and biogenic carbonate precipitation in the environment.

\subsection{Biogenic carbonate precipitation}

Biogenic carbonate precipitation can be subdivided into three categories: biologically controlled, induced, and influenced precipitation (Dupraz et al., 2009 and references therein, Figure 3). Biologically controlled carbonate precipitation occurs when, for instance echinoderms, molluscs, sponges and corals, form a protective carbonate shell or calcareous skeleton (Mann, 2001). On the microbiological scale, controlled 
precipitation is utilized by i.e.: protozoan Foraminifera, ostracods (Mann, 2001), and some bacteria, such as Achromatium which form carbonate inclusions (Monteil et al., 2021 and references therein). Importantly, carbonate precipitation in this category is usually an essential component of the organism.

Biologically induced and biologically influenced carbonate precipitation occur as a result of the direct or indirect interaction of microbes with their environment and cannot clearly be separated (Figure 3). As a starting point, the environment (extrinsic factors) determines the conditions for a given microbial community. The community, in turn, changes the physicochemical parameters of its immediate surroundings through their metabolism (intrinsic factors) (Figure 3). This interaction forms a cycle called the alkalinity engine (Dupraz et al., 2009), leading to favourable conditions for carbonate precipitation. These conditions are dependent on the dissolved inorganic carbon (DIC), $\mathrm{pH}$ and alkalinity (the buffering capacity of water, Dickson, 1992; Gallagher et al., 2012) and the availability of nucleation sites. Nucleation sites can be provided by microbial cells, both alive and dead, as well as their extrapolymeric substances (EPS)(Gallagher et al., 2012). The status of the cell in terms of viability is one of the key differences between biologically induced and biologically influenced carbonate precipitation. For biologically induced precipitation, cells are required to be alive and metabolically active, while this is not the case for biologically influenced precipitation where cells and cell components act as nucleation sites (Dupraz et al., 2009).

During biologically induced precipitation, live cells actively change their environment with their auto- or heterotroph metabolism (Figure 3). Oxygenic and anoxygenic photosynthesis are autotroph pathways, which fix $\mathrm{CO}_{2}$ into organic carbon, thereby increasing the $\mathrm{pH}$ in their environment. If the surrounding conditions are high in $\mathrm{Ca}^{2+}$ and low in DIC, this can induce precipitation around the cells (Arp, Reimer and Reitner, 2001). Organic matter produced during the carbon fixation process is broken down stepwise by heterotrophs during aerobic and anaerobic respiration. In the first instance, this is a destructive process for carbonates, as excess $\mathrm{H}^{+}$and organic acids lower the $\mathrm{pH}$ and cause carbonate dissolution. This, in turn, can create a knockon effect where the dissolution of environmental carbonates and organic matter breakdown funnel $\mathrm{Ca}^{2+}$ and $\mathrm{HCO}_{3}^{-}$ions back into the system. In this case, local $\mathrm{pH}$, 
alkalinity, and saturation can rise to levels suitable for precipitation (Dupraz et al., 2009).

Biologically influenced precipitation relies on microbial cells and their components to act as nucleation sites (Dupraz et al., 2009). It can therefore also be a by-product of heterotrophic metabolism, which is involved in the organic matter degradation. Extracellular polymeric substances (EPS) play a key role within this process. EPS are composed of a mixture of high and low molecular weight organic polymers, which consist of polysaccharides and glycoproteins with anionic residues (Chamizo et al., 2020; Decho and Gutierrez, 2017). They act as carbon storage and are produced by microbial cells to provide protection. Further, they allow attachments as well as biofilm- and inter-cell-connectivity. Microbial communities can create a micro-environment with altered rates of diffusion and retention of nutrients, as well as a space for inter-cell communication, DNA-exchange and extracellular degradation of nutrients, by utilizing EPS (Decho and Gutierrez, 2017). Importantly for carbonate precipitation, EPS anionic residues can bind positively charged ions, such as $\mathrm{Ca}^{2+}$ and $\mathrm{Mg}^{2+}$, thereby reducing their free environmental saturation. EPS and its multitude of components are considered as key nucleation sites, however, while cells are alive their metabolism and irregular free acidic residues should counteract any precipitation (Arp, Reimer and Reitner, 2001). When EPS is in a state of degradation, it can happen that sterically blocked residues randomly rearrange to form a lattice. If the environment is saturated with $\mathrm{Ca}^{2+}$ at the same time, this lattice can act as the starting point for precipitation (Arp, Reimer and Reitner, 2001).

\subsection{Microbial metabolism and the link to carbonate precipitation}

As described in the previous section, microbial metabolism may support the precipitation of carbonate in the environment. A variety of metabolic pathways have been linked to precipitation and dissolution (Table 1). The major metabolic pathways in microbial mats and hypersaline lakes are photosynthesis and sulphate reduction (Baumgartner et al., 2006; Glunk et al., 2011). As Aldabra harbours similar environmental conditions, these will be described in more detail below. In deep marine sediments and seep environments carbonate precipitation can occur linked to the anaerobic oxidation of methane coupled to the reduction of sulphate (Table 1, Reeburgh, 2007). Aerobic and anaerobic heterotrophy usually favours dissolution of 
carbonates as the degradation of organic matter releases $\mathrm{CO}_{2}$ and organic acids, which have a $\mathrm{pH}$ lowering effect. Sulphide oxidation also lowers the $\mathrm{pH}$ by oxidizing hydrogen sulphide to sulphate and releasing hydrogen. In both cases the increase in $\mathrm{pH}$ will shift the carbonate equilibrium towards dissolution (Visscher and Stolz, 2005). Some pathways, such as ureolysis and denitrification have been explored with regard to bioremediation of limestone (Muynck et al., 2013) or in the anaerobic high-pressure subsurface (Martin et al., 2013). Their mode of action relies on the local increase of $\mathrm{pH}$ and alkalinity through their metabolic activity, thereby favouring precipitation in an artificially $\mathrm{Ca}^{2+}$ saturated environment (Martin et al., 2013).

Table 1. Microbial metabolic processes favouring precipitation (blue) or dissolution (red) of calcium carbonates. The asterisks indicate precipitation observed under laboratory conditions. Abbreviations: PSB: purple sulphur bacteria, ABC bacteria: aerobic bacteriochlorophyllcontaining, ANME: anaerobic methanotrophic.

\begin{tabular}{|c|c|c|c|c|}
\hline $\begin{array}{l}\text { Metabolic } \\
\text { Process }\end{array}$ & Taxon & Formula & $\mathrm{pH}$ & Source \\
\hline $\begin{array}{l}\text { Oxygenic } \\
\text { Photosynthesis }\end{array}$ & Cyanobacteria & $\begin{array}{l}2 \mathrm{HCO}_{3}^{-}+\mathrm{Ca}^{2+} \\
\rightarrow\left[\mathrm{CH}_{2} \mathrm{O}\right]+\mathrm{CaCO}_{3}+\mathrm{O}_{2}\end{array}$ & 仓 & $\begin{array}{c}\text { (Dupraz et } \\
\text { al., 2009; } \\
\text { Visscher and } \\
\text { Stolz, 2005) }\end{array}$ \\
\hline $\begin{array}{l}\text { Anoxygenic } \\
\text { Photosynthesis }\end{array}$ & $\begin{array}{l}\text { PSB (e.g., } \\
\text { Chromatiaceae) }\end{array}$ & $\begin{array}{l}3 \mathrm{HCO}_{3}^{-}+\mathrm{Ca}^{2+}+\mathrm{HS}^{-} \\
\rightarrow 2\left[\mathrm{CH}_{2} \mathrm{O}\right]+\mathrm{CaCO}_{3}+\mathrm{SO}_{4}^{2-}\end{array}$ & 个 & $\begin{array}{l}\text { (Visscher and } \\
\text { Stolz, 2005) }\end{array}$ \\
\hline \multirow{2}{*}{$\begin{array}{l}\text { Sulphate } \\
\text { Reduction }\end{array}$} & \multirow{2}{*}{$\begin{array}{l}\text { Desulfobacterota: } \\
\text { Desulfovibrio }\end{array}$} & $\begin{array}{l}4 \mathrm{CHO}_{2}^{-}+\mathrm{SO}_{4}^{2-}+\mathrm{H}_{2} \mathrm{O} \\
\rightarrow 4 \mathrm{HCO}_{3}^{-}+\mathrm{HS}^{-}+\mathrm{OH}^{-}\end{array}$ & 仓 & \multirow{2}{*}{$\begin{array}{l}\text { (Gallagher et } \\
\text { al., 2012) }\end{array}$} \\
\hline & & $\begin{array}{l}2 \mathrm{C}_{2} \mathrm{H}_{6} \mathrm{O}+3 \mathrm{SO}_{4}^{2-}+ \\
\rightarrow 4 \mathrm{HCO}_{3}^{-}+3 \mathrm{HS}^{-}+ \\
\quad 2 \mathrm{H}_{2} \mathrm{O}+\mathrm{H}^{+}\end{array}$ & $\sqrt{n}$ & \\
\hline $\begin{array}{l}\text { Sulphide } \\
\text { Oxidation }\end{array}$ & $\begin{array}{l}\text { PSB, } \\
\text { Desulfobulbaceae: } \\
\text { Candidatus } \\
\text { Electrothrix }\end{array}$ & $\begin{array}{l}3 \mathrm{HS}^{-}+4 \mathrm{O}_{2}+\mathrm{HCO}_{3}^{-}+\mathrm{CaCO}_{3} \\
\rightarrow 2\left[\mathrm{CH}_{2} \mathrm{O}\right]+\mathrm{SO}_{4}{ }^{2-}+\mathrm{Ca}^{2+}\end{array}$ & $\sqrt{7}$ & $\begin{array}{c}\text { (Dupraz et } \\
\text { al., 2009; } \\
\text { Trojan et al., } \\
\text { 2016; } \\
\text { Visscher and } \\
\text { Stolz, 2005) }\end{array}$ \\
\hline \multirow[b]{2}{*}{ Denitrification* } & \multirow[b]{2}{*}{ Halomonas } & $\begin{array}{l}\mathrm{CH}_{2} \mathrm{O}+\mathrm{NO}_{3}^{-}+\mathrm{H}^{+} \\
\rightarrow \mathrm{HCO}_{3}^{-}+\mathrm{H}_{2} \mathrm{O}+\mathrm{N}_{2}\end{array}$ & 个 & $\begin{array}{c}\text { (Martin et al., } \\
\text { 2013) }\end{array}$ \\
\hline & & $\begin{array}{l}5 \mathrm{CH}_{2} \mathrm{O}+4 \mathrm{NO}_{3}^{-}+\mathrm{CaCO}_{3} \\
\rightarrow 6 \mathrm{HCO}_{3}^{-}+2 \mathrm{~N}_{2}+ \\
\quad 2 \mathrm{H}_{2} \mathrm{O}+\mathrm{Ca}^{2+}\end{array}$ & $\sqrt{n}$ & $\begin{array}{l}\text { (Visscher and } \\
\text { Stolz, 2005) }\end{array}$ \\
\hline
\end{tabular}




\begin{tabular}{|c|c|c|c|c|}
\hline Ureolysis* & $\begin{array}{l}\text { Bacillus sphaericus, } \\
\text { Sporosarcina } \\
\text { pasteurii }\end{array}$ & $\begin{array}{l}\mathrm{CO}\left(\mathrm{NH}_{2}\right)_{2}+2 \mathrm{H}_{2} \mathrm{O} \\
\rightarrow 2 \mathrm{NH}_{4}^{+}+\mathrm{CO}_{3}^{2-}\end{array}$ & 仓 & $\begin{array}{l}\text { (Muynck et } \\
\text { al., 2013; } \\
\text { Stocks- } \\
\text { Fischer, } \\
\text { Galinat and } \\
\text { Bang, 1999) }\end{array}$ \\
\hline Fermentation & Chloroflexota & $\begin{array}{l}3\left[\mathrm{CH}_{2} \mathrm{O}\right]+\mathrm{CaCO}_{3}+\mathrm{H}_{2} \mathrm{O} \\
\rightarrow 2 \mathrm{HCO}_{3}^{-}+\mathrm{Ca}^{2+}+\mathrm{C}_{2} \mathrm{H}_{6} \mathrm{O}\end{array}$ & $\sqrt{n}$ & $\begin{array}{l}\text { (Dupraz et } \\
\text { al., 2004; Hug } \\
\text { et al., 2013) }\end{array}$ \\
\hline $\begin{array}{l}\text { Aerobic } \\
\text { Respiration }\end{array}$ & $\begin{array}{l}\text { ABC bacteria: } \\
\text { Roseobacter } \\
\text { denitrificans }\end{array}$ & $\begin{array}{l}{\left[\mathrm{CH}_{2} \mathrm{O}\right]+\mathrm{CaCO}_{3}+\mathrm{O}_{2}} \\
\rightarrow 2 \mathrm{HCO}_{3}{ }^{-}+\mathrm{Ca}^{2+}\end{array}$ & $\sqrt{ }$ & $\begin{array}{l}\text { (Dupraz et } \\
\text { al., 2004; } \\
\text { Imhoff and } \\
\text { Hiraishi, } \\
\text { 2005) }\end{array}$ \\
\hline $\begin{array}{l}\text { Anaerobic } \\
\text { Methane } \\
\text { Oxidation }\end{array}$ & $\begin{array}{l}\text { Desulfosarcina, } \\
\text { ANME archaea }\end{array}$ & $\begin{array}{l}\mathrm{CH}_{4}+\mathrm{SO}_{4}{ }^{2-} \\
\rightarrow \mathrm{CaCO}_{3}+\mathrm{H}_{2} \mathrm{~S}+\mathrm{H}_{2} \mathrm{O}\end{array}$ & 仓े & $\begin{array}{l}\text { (Boetius et } \\
\text { al., 2000; } \\
\text { Reeburgh, } \\
\text { 2007) }\end{array}$ \\
\hline $\begin{array}{l}\text { Aerobic } \\
\text { Methane } \\
\text { Oxidation }\end{array}$ & $\begin{array}{l}\text { Methylococcaceae, } \\
\text { Methylocystaceae }\end{array}$ & $\begin{array}{l}\mathrm{CH}_{4}+2 \mathrm{O}_{2} \\
\rightarrow \mathrm{CO}_{2}+2 \mathrm{H}_{2} \mathrm{O}\end{array}$ & $\sqrt{ }$ & $\begin{array}{l}\text { (Bowman, } \\
\text { 2006; } \\
\text { Reeburgh, } \\
\text { 2007) }\end{array}$ \\
\hline
\end{tabular}

Cyanobacteria are the classical example for involvement in biologically induced carbonate precipitation. Many Cyanobacteria acquire carbonate sheaths due to their photosynthetic activity, which removes $\mathrm{CO}_{2}$ and $\mathrm{HCO}_{3}{ }^{-}$and releases $\mathrm{CO}_{3}{ }^{2-}$ and $\mathrm{OH}^{-}$ ions into their immediate surroundings, i.e., EPS sheaths, thereby locally increasing $\mathrm{pH}$ and alkalinity (Couradeau et al., 2012). In the water column this is suggested to supply carbonate crystals which can be shed, while in microbial mats Cyanobacteria acquire calcified sheaths preserving them as microfossils on the long-term (Riding, 2006). Whether the sheath is actively acquired, or a by-product of the cyanobacterial metabolism under certain environmental conditions is not yet fully understood. Both possibilities have been discussed in literature including its function as protective sheath, buffering agent of the carbon concentration machinery, or metabolic sideproduct ultimately blocking the cells access to sunlight and photosynthesis (Kamennaya et al., 2012). Cyanobacteria are not only important for carbonate precipitation regarding their sheath formation, but also in early diagenesis due to their endolithic activity. Endolithic cyanobacteria bore into the limestone by locally removing $\mathrm{Ca}^{2+}$-ions and extruding them from the area, thereby causing localised 
dissolution. Their boreholes may be refilled by their own or other photosynthetic activity, thereby creating the first stages of diagenetic alteration to the bored carbonate grain (Garcia-Pichel, Ramírez-Reinat and Gao, 2010). The ability to produce boreholes is not only limited to bacteria but is commonly also seen in heterotroph fungi and algae, which bore through dissolution or mechanical force (Gleason et al., 2017; Littler and Littler, 2011).

Special attention has been paid to sulphate reducing bacteria (SRB), as they are one of the metabolically most active heterotrophs in coastal sediments and precipitation zones of microbial mats (Gallagher et al., 2012; Jørgensen and Kasten, 2006). Sulphate reducers are at the end of the organic matter degradation chain, degrading small organic compounds, such as ethanol, acetate and lactate which are formed during respiration and fermentation, to the end-product $\mathrm{CO}_{2}$ (Wasmund, Mußmann and Loy, 2017). Depending on the electron donor utilised by SRB, the amounts of $\mathrm{HCO}_{3}{ }^{-}, \mathrm{CO}_{2}$ and $\mathrm{H}^{+}$-ions released by their metabolism vary. Generally, the production of $\mathrm{CO}_{2}$ by heterotrophs including SRB should lead to a decrease in $\mathrm{pH}$ and, thus, dissolution of carbonates. If hydrogen or formate are used as electron donors, their activity will, however, lead to a net increase in alkalinity, thus favouring carbonate precipitation (Gallagher et al., 2012). While the latter mechanism is an example for induced precipitation, SRB can also trigger biologically influenced carbonate precipitation as they, and other heterotrophs, release inorganic carbon and $\mathrm{Ca}^{2+}$ during organic matter degradation (Dupraz et al., 2009).

Overall whether carbonate precipitation or dissolution occurs is determined by net increase or decrease in $\mathrm{pH}$ and alkalinity by microbial community activities, as well as the availability of $\mathrm{Ca}^{2+}$, shifting the carbonate equilibrium either way. Shifts in community type and carbonate equilibrium may not only occur laterally with depth or sediment type, but also diurnally in a sunlight-dependent manner (Baumgartner et al., 2006).

\subsection{Detection of microbial communities and biogeochemical processes in sediments}

A series of approaches exist to determine the interplay between microbial communities and sediment (carbonate) geochemistry. Microbe-focussed approaches vary from enrichment, cultivation, and characterisation of individual members (Chapter C.4), 
over the taxonomic and metabolic assessment of microbial communities through marker genes and detection of their metabolic products (i.e., $\mathrm{SO}_{4}{ }^{2-}, \mathrm{NH}_{4}{ }^{+}, \sum \mathrm{H}_{2} \mathrm{~S}, \mathrm{PO}_{4}{ }^{3-}$ , Chapter C.3), to metagenomic sequencing of the entire communities and in-silico reconstruction of their metabolism (Chapter C.5). The enrichment and characterization of microbes from environmental samples can provide new information on as-of-yet uncultured species. This information can be added to existing databases to provide more context about these taxa. While isolation of specific taxa can give detailed insight into their metabolic capabilities, marker genes and metagenomics focus on the broad community setup. As to date only about $0.5 \%$ of non-human associated microbes have been cultured under laboratory conditions (Lloyd et al., 2018), the latter aims to understand the environment from a reverse approach. Metagenomics utilize large datasets in the form of DNA sequences to investigate the functional potential of a microbial community from a gene-centred perspective (Frioux et al., 2020). In addition, in-silico genomes, also called metagenome assembled genomes or MAGs, are assembled to provide context for the functional annotation. The metagenomic reads or assembled MAGs are decorated with taxonomic and gene-functional information from the large available databases, in order to provide an initial understanding of the microbes and their metabolism for which isolates are not yet available (Frioux et al., 2020). This approach has led to the discovery and description of a large number of uncultured taxa called the candidate phyla radiation (CPR) (Hug et al., 2016). The marker-gene approach can be used in a taxonomy and partly in a metabolism directed manner. For instance, 16S rRNA gene sequencing is used to taxonomically identify bacteria and archaea to describe the taxonomic community composition (Knight et al., 2018). In addition, functional information can be inferred by connecting taxonomic information with data on cultured representatives and available genomes (Wemheuer et al., 2020). However, it should be kept in mind, that the approach is only as good as the available references and their origin, leading to an overrepresentation on information linked to human-associated biota (Lloyd et al., 2018). While the $16 \mathrm{~S}$ rRNA gene is used for taxonomic and general community member identification, sequencing of other marker genes, i.e.: $d s r$ genes, can capture specific metabolic groups of interest, in this example sulphate reducers (Wagner et al., 2005).

The approaches to characterize the microbial community are complemented by geochemical analyses of the sediment, water column and/or porewater. These measure 
the overall environmental conditions, i.e.: temperature, $\mathrm{pH}$, salinity, and underlying geochemistry, e.g.: total organic and inorganic carbon (TOC, TIC), $\mathrm{C} / \mathrm{N}$ ratio, carbonate compound saturation (aragonite, calcite, gypsum, etc.), describing the microbial habitat. In addition, metabolic end-products, such as $\mathrm{O}_{2}, \mathrm{CO}_{2}, \mathrm{SO}_{4}{ }^{2-}$ and $\mathrm{NH}_{4}{ }^{+}$, indicate the on-going metabolic processes (Chapters C.2 and C.3). Together, the geochemical and microbiological data can corroborate each other's findings, forming a snapshot of the sedimentary environment at the time of sampling.

\section{Study sites: Lake Neusiedl and Aldabra Atoll}

\subsection{Proof of concept}

Two independent sampling campaigns were undertaken to study different carbonate sediment environments. The first campaign to Lake Neusiedl in Austria was the proofof-concept study (Chapters C.2 and C.3) for the second expedition to the Aldabra Atoll, Seychelles (Chapters C.3, C.4 and C.5). Lake Neusiedl is a large steppe-lake at the border of Austria and Hungary (Figure 4.A). The shallow alkaline lake receives its water input from precipitation transported by rivers from the surrounding catchment area (Soja et al., 2013). Its sediments consist of high magnesium calcite (HMC), calcite and protodolomite (Fussmann et al., 2020). The formation of the sedimentary calcite components, particularly proto-dolomite and dolomite, have been the subject of previous studies (Boros et al., 2014; Müller, Irion and Förstner, 1972; Schroll and Wieden, 1960). The lake is of economic importance to the region, as it is a popular holiday location and national park. The anthropogenic impact on the lake is monitored on a regular basis by analysing water quality (Magyar et al., 2013), and assessing pathogen load (Hatvani et al., 2018; Pretzer et al., 2017) and pollutants (Jirsa et al., 2014; Krachler et al., 2018). The fine-grained carbonate mud and shallow water levels presented an ideal opportunity to establish our sampling procedures and methodology. In addition, the proof-of-concept study provided insight into a closed saline, but nonmarine system in opposition to the open marine lagoon and landlocked saline pools of Aldabra. 


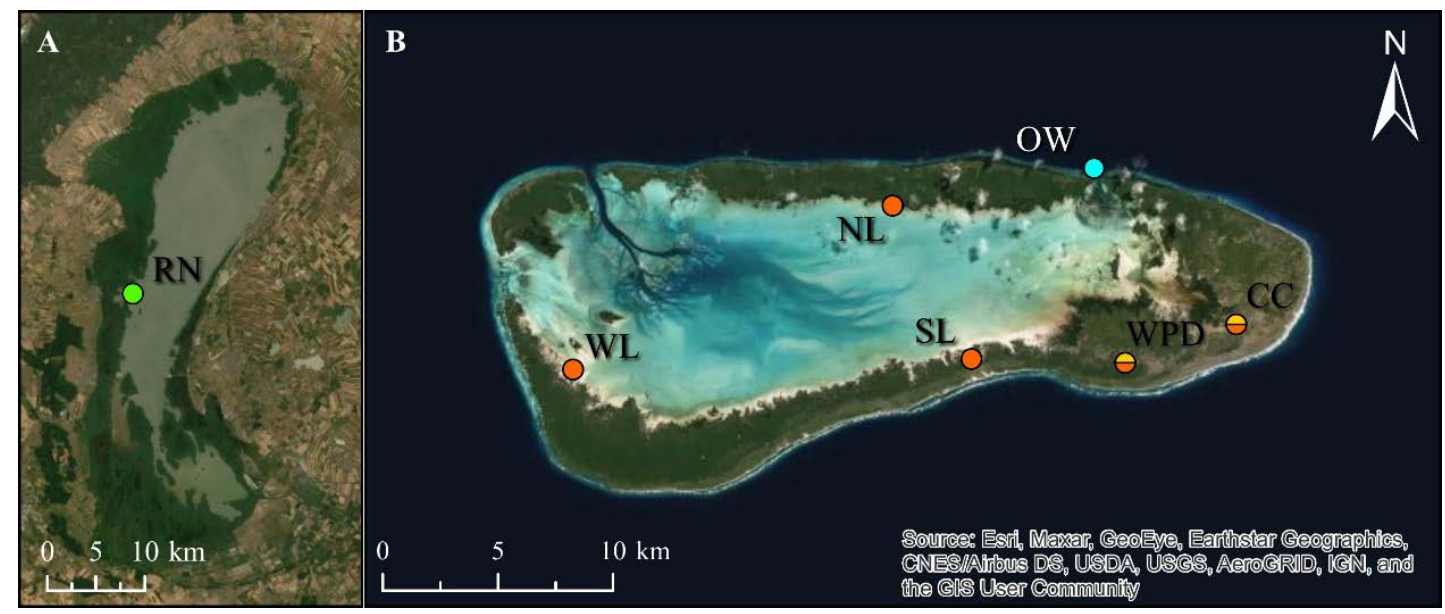

Figure 4. Main sampling sites at Lake Neusiedl, Austria (A) and the Aldabra Atoll, Seychelles (B). A: The sampling site at Lake Neusiedl in the bay of Rust (RN, green). B: Sampling sites on Aldabra: West Lagoon (WL), North Lagoon (NL), South Lagoon (SL), the pool system Cinq Cases (CC) and the unnamed Westpool D (WPD). Orange: sampling sites used for $16 \mathrm{~S}$ rRNA sequencing, blue: ocean water reference, yellow: sampling sites with metagenomes. The scale bars indicate $10 \mathrm{~km}$ of distance. Both images face north, as indicated by the compass arrow. The map was plotted in ArcGis Maps using ESRI world imagery and the sources in the bottom right corner.

\subsection{The Aldabra Atoll}

The main part of this thesis is centred on the Aldabra Atoll. Situated in the Indian Ocean, approximately $420 \mathrm{~km}$ North-West of Madagascar at $9^{\circ} 24^{\prime} \mathrm{S}$ and $46^{\circ} 22^{\prime} \mathrm{E}$, it is the outermost island of the Seychelles, roughly 1,000 km away from the capital Victoria on Mahé (Figure 4.B). The atoll consists of an island rim of four islands, Grand Terre, Malabar, Picard and Polymnie, surrounding a 34 by $15 \mathrm{~km}$ large lagoon. Aldabra covers a surface of $365 \mathrm{~km}^{2}, 203 \mathrm{~km}^{2}$ of which are attributed to the lagoon and $162 \mathrm{~km}^{2}$ to the island rim (Hamylton et al., 2018). It is situated within the tropics just south of the equator. The climate is consistently warm at temperatures between 24 and $28^{\circ} \mathrm{C}$ and an average yearly rainfall of $975 \mathrm{~mm}$. Rainfall is determined by two seasons, the wet north-west monsoon (November-April) and the dry south-east monsoon (May-October). Over the past 30 years, the atoll has been subjected to more severe dry periods and a tripling in drought frequency has been observed (Haverkamp et al., 2017). 


\subsection{Protection and global importance}

The push to protect the Aldabra Atoll began with scientific and public protest amid plans for the establishment of a British-US American military base. This triggered a reconnaissance expedition in 1966 with investigations into the unique ecology, describing it as "one of the last relatively undisturbed elevated-limestone island ecosystems in the world"(Stoddart, 1968, p. 63). "There was general agreement that to build a military airfield on the atoll would be a biological disaster" (Stoddart, 1968, p. 65). After military plans were disbanded for economic reasons, Aldabra was leased and maintained by the Royal Society between 1967-1979 to protect its unique flora and fauna. Since 1979 the Seychelles Islands Foundation (SIF) maintains the atoll. This includes maintenance of the research station, eradication, and monitoring programmes, as well as external scientific projects. Ultimately this led to Aldabra gaining UNESCO protection status in 1982 (Braithwaite, 2020). Nowadays Aldabra is inhabited only by SIF staff, visiting researchers and tourists, which rarely exceed 20 persons at a time. This means, that Aldabras' large range of endemic species can flourish protected from a direct anthropogenic impact.

\subsection{Geology of Aldabra}

The elevated atoll sits atop a volcanic seamount. It consists of layers of reef limestone which were deposited during sea level high stands during different interglacial intervals. The most recent submersion occurred approximately $125 \mathrm{kyr}$ BP, suggesting that the present flora and fauna established itself following this event (Thomson, Walton and A., 1972). The deposited limestones recrystallized and cemented to varying degrees, retaining visible remnants of the former coral and molluscan inhabitants (Braithwaite, Taylor and Kennedy, 1973). Most of the surface limestone consists of highly karstic, sharp reef rock, also termed champignon. In some areas flatter, smooth limestone, termed platin, forms shallow basins, which are periodically filled with water (Fryer, 1911; Stoddart et al., 1971). The shallow water and extensive mangrove vegetation along the inner rim sustain a diverse ecosystem. This shapes the present-day sediment, which consists of organic detritus, shell debris, carbonate mud and sand (Chapter C.3). 


\subsection{State of research on Aldabra}

The Aldabra Atoll harbours diverse biomes, which were extensively studied in the 1960's - 1970's by the Royal Society's multi-phase Aldabra expedition (Griffin, 1974). These studies form the basis for all ongoing research to date and cover all biomes from the lagoon to the champignon rim. The lagoon harbours extensive seagrass beds, macroalgal assemblages on carbonate sand and coral reefs, which are replenished with fresh sea water by the strong tidal currents (Hamylton, Hagan and Doak, 2012). The seagrass meadows are the home of the last colony of dugongs (Dugong dugon) in the Indian Ocean (Hamylton, Hagan and Doak, 2012). The edge of the lagoon is characterized by intertidal flats consisting of fine sand and silt with high amounts of organic matter, rimmed by dense Avicennia and Lumnitzera mangrove forests (Hamylton, Spencer and Hagan, 2012). In some areas, the mangroves remain submerged at all times, thereby providing protection and nutrients for large schools of fish and sea turtles (Haupt, 2020). The intertidal flats harbour a rich fauna of molluses, crustaceans, and other invertebrates (Farrow, 1971; Hughes and Gamble, 1977; Kensley, 1988), which sustain the endemic bird population. Large parts of the sediment are covered by blue-green algal (cyanobacteria) crusts and mats, which consist mainly of Scytonema sp. and Microcoleus chtonoplastes. Thin crusts and laminar stromatolites were found in few places in the lagoon harbouring Microcoleus and Schizothrix. Sediment surfaces are often covered by pink phototrophic bacteria (Chromatiaceae) with occasional blooms in intertidal pools (Potts and Whitton, 1977, 1980). On the coarse carbonate sands, they were observed to follow a horizontal zonation with decreasing proximity to the mangrove edge. The transition from brown pennate diatoms, via blue-green algae to pink Chromatium cover occurred along a decrease in redox values (Eh) towards the mangrove (Potts and Whitton, 1979a).

The high mangroves in the north lagoon house extensive seabird colonies and breeding grounds for red-footed boobies (Sula sula) and frigatebirds (Fregata minor/ariel) (Diamond, 1971). Mangroves change to dense shrubbery on the karstic island rim. Any soil cover on Aldabra is very shallow with an acidic $\mathrm{pH}$ (Potts and Whitton, 1979b). The vegetation is characterized by the so-called tortoise turf (Grubb, 1971) and mixed scrubs including, Fimbristylis cymosa, Pemphis acidula, Ochna ciliata, and tree stands of different Cyperus species and Calophyllum inophyllum 
(Gibson and Phillipson, 1983). Apart from the shrubbery and karstic overhangs, almost no shade is available on the islands, which are the home to some 100,000 giant tortoises (Aldabrachelys gigantea) (Bourn et al., 1999) and endemic birds, such as the Aldabra Drongo (Dicrurus aldabranus) and flightless Aldabra rail (Dryolimnus cuvieri aldabranus) (van de Crommenacker et al., 2016).

Depressions in the karstic and platin limestone form pools, whose water levels depend on the rainy season or underground connections to the ocean and lagoon (Braithwaite et al., 1989). Some pools with marine connections harbour upside-down jellyfish and crustaceans, however fish are absent (Drew, 1972). The conditions in the pools vary strongly throughout the year. During the rainy and early dry season fresh to brackish water conditions were measured (Donaldson and Whitton, 1977), which turned increasingly saline during the dry season (Braithwaite et al., 1989), leading to the observed moderately hypersaline conditions in this study (Chapters C.3, C.4, and C.5). Accordingly, water levels encountered during the present expedition were extremely low. In some cases, even prominent pools, such as Bassin Profond with a former water depth of up to $2 \mathrm{~m}$ (Braithwaite et al., 1989), were virtually dried out. In addition to seasonal fluctuation of the pools, their chemistry is influenced by birds, crabs and tortoises, which drink, bathe and defecate in these, and can cause increasing levels of ammonia and phosphate (Donaldson, 1978; Chapter C.3). Previous research on the pools has centred around $\mathrm{pH}, \mathrm{Eh}$, nitrogen fixation and their diurnal changes in relation to local blue-green algae and Chromatium species (Donaldson, 1978; Potts and Whitton, 1979a). Further, three large pools (Bassin Profond, Bassin Mackenzie and Cinq Cases) where described for their stromatolites and the conditions leading to their development (Braithwaite et al., 1989). The stromatolites were covered by filamentous green algae, such as Chladophora and Rhizoclonium. On and within the stromatolite surface layers Pleurocapsa, Dichothrix gypsophila, Entophysalis and Schizothrix were identified morphologically, although their sheaths were only locally preserved. Further, sulphur oxidizing Beggiatoa and Thiothrix as well as pink gelatinous phototrophs were observed as parts of the stromatolite surface mat. Although the algal and cyanobacterial communities were closely associated with stromatolites, the precipitation of these was not linked to microbial activity (Braithwaite et al., 1989). 


\subsection{Anthropogenic impacts on Aldabra}

The Aldabra Atoll has remained largely unaffected by a direct anthropogenic impact due to the protection and preservation efforts of the last decades. This also includes eradication programmes targeting introduced invasive bird species (van de Crommenacker et al., 2016), as well as goats (Bunbury et al., 2018), feral cats, rats, and various insects (Range to Reef Environmental, 2016). Increasingly, however, Aldabra waters and shores are being inundated with marine plastic debris and litter brought in from the surrounding continents by the Indian Ocean currents. The waste consists mainly of buoys and ghost nets from the fishing industries (Burt et al., 2020), as well as large quantities of flip flops and plastic bottles (Figure 5). A clean-up project was able to remove around 25 tonnes of the estimated 500 tonnes of waste from some of the outer beaches and karst (Burt et al., 2020). The lagoon of Aldabra is relatively protected from the large debris, however, the impact of marine litter or smaller debris and microplastics has not been assessed.

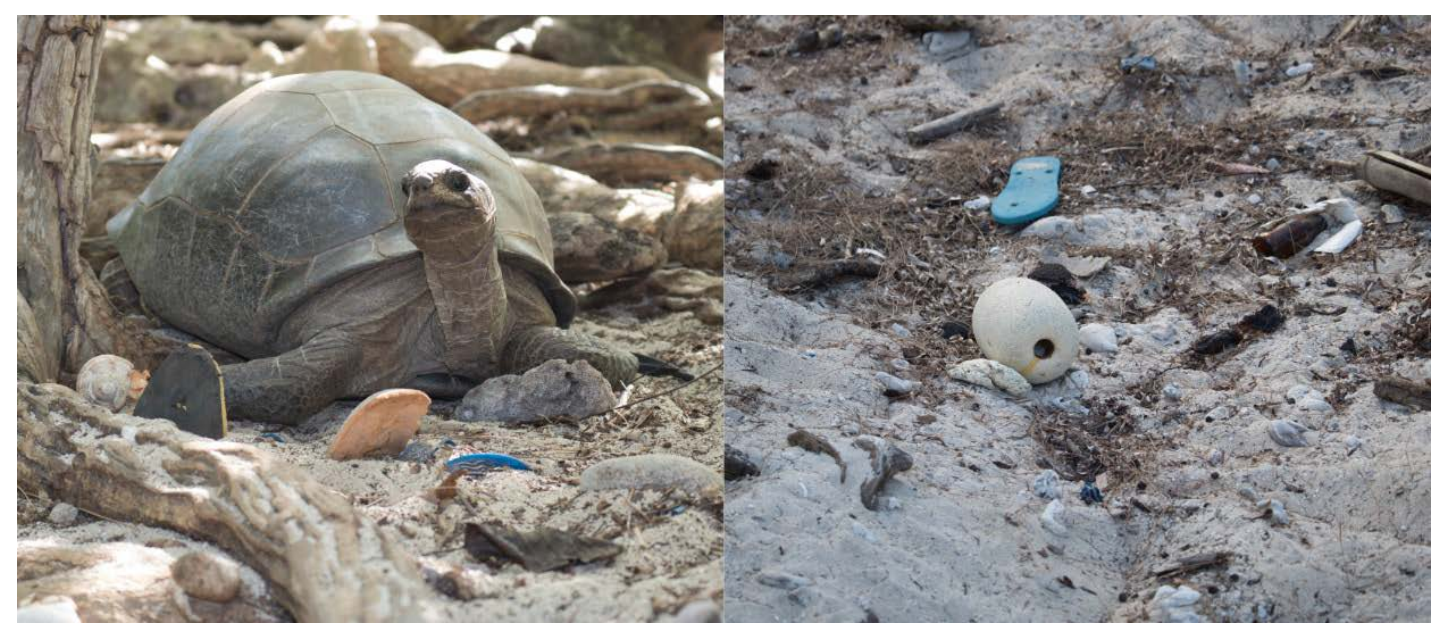

Figure 5. Plastic pollution at Anse Cedres on the outer coast of the Aldabra Atoll.

\subsection{Expedition to the Aldabra Atoll}

The main sampling campaign to the Aldabra Atoll took place in November 2017. During the 21-day stay on the Atoll 500 samples for microbial community analysis were taken at 15 different sampling sites. The majority of the samples comprised sediments from 30-50 cm deep push cores. Further samples included biofilms, microbial mats, whale cadaver, tortoise faeces and water samples. The main sampling locations were the four sediment coring sites (West Lagoon WL, North Lagoon NL, South Lagoon SL, Cinq Cases CC), and a landlocked moderately hypersaline pool 
(Westpool D WPD a.k.a. Ronny's Pool) with stromatolites (Figure 4). Samples were taken during multiple field trips, which were extremely dependent on the tidal fluctuations. Detailed descriptions of the samples and sampling procedures can be found in Chapter C.1, C.3 and C.5.

\section{Research goals}

This research project set out to determine the microbial and geochemical composition in carbonate sediments and to assess any diagenetic changes encountered in these. The proof-of-concept study was designed to test the sampling and analysis methodology and create a basis for comparison to the main study site Aldabra. Microbial communities at Aldabra were last investigated some 30-40 years ago. The studies focused on blue-green algae highlighting the main cyanobacteria and purple-sulphur bacteria on Aldabra. A key component of this research was the determination of rates of nitrogen fixation in microbial mats throughout the atoll. Shortcomings were highlighted in identifying specific cyanobacterial taxa, due to the lack of an accurate classification system and methods at the time (Donaldson, 1978; Potts, 1977). Using metagenomic complemented with cultivation-based approaches, we aimed to shed light on the to-date untapped diverse microbial communities in the different sediment settings, as well as similar microbial mats and biofilms. The project was approached from a top-down sequence-based standpoint using taxonomic profiling of both the total (DNA-based) and active (RNA-based) bacterial community, as well as metagenome sequencing. In addition, an isolation-based approach was used to identify and characterize novel bacterial isolates both physiologically and genomically. The data were completed by detailed porewater and geochemical characterization of the local sediments and waters. This is the first study on microbial communities of the Aldabra Atoll using a combination of next-generation sequencing and biogeochemistry to provide an in-depth analysis of the microbial roles in the unique environments of Aldabra. 
C. Results and publications 


\section{BACTERIAL SUCCESSION ALONG A SEDIMENT POREWATER GRADIENT AT LAKE NEUSIEDL IN AUSTRIA}

Avril Jean Elisabeth von Hoyningen-Huene ${ }^{1}$, Dominik Schneider ${ }^{1}$, Dario Fussmann ${ }^{2}$, Andreas Reimer ${ }^{2}$, Gernot Arp ${ }^{2}$, Rolf Daniel ${ }^{1}$

Scientific Data (30 August 2019), 6, Article number: 163

https://doi.org/10.1038/s41597-019-0172-9

\section{Affiliations}

${ }^{1}$ Genomic and Applied Microbiology and Göttingen Genomics Laboratory, Institute of Microbiology and Genetics, Georg-August-University Göttingen, Göttingen, Germany

${ }^{2}$ Geobiology, Faculty of Geosciences and Geography, Georg-August-University Göttingen, Göttingen, Germany

\section{Author contributions:}

Conceived and designed the study: RD, GA, AH

Performed the experiments: AH, DF, AR

Analysed the data: AH, DS, DF, AR

Wrote the paper: AH, DS, DF, AR, GA, RD 


\section{SCIENTIFIC DATA}

OPEN

\section{DATA DESCRIPTOR}

Received: 8 March 2019

Accepted: 26 July 2019

Published online: 30 August 2019

\section{Bacterial succession along a} sediment porewater gradient at Lake Neusiedl in Austria

\author{
Avril Jean Elisabeth von Hoyningen-Huene $\mathbb{D}^{1}$, Dominik Schneider ${ }^{1}{ }^{1}$, Dario Fussmann ${ }^{2}$, \\ Andreas Reimer ${ }^{2}$, Gernot Arp $\mathbb{D}^{2}$ \& Rolf Daniel $\mathbb{D I}^{1}$
}

We provide bacterial 16S rRNA community and hydrochemical data from water and sediments of Lake Neusiedl, Austria. The sediments were retrieved at $5 \mathrm{~cm}$ intervals from $30-40 \mathrm{~cm}$ push cores. The lake water community was recovered by filtration through a 3.0/0.2 $\mu \mathrm{m}$ filter sandwich. For 16S rRNA gene amplicon-based community profiling, DNA was extracted from the sediment and filters and the bacterial V3-V4 regions were amplified and sequenced using a MiSeq instrument (Illumina). The reads were quality-filtered and processed using open source bioinformatic tools, such as PEAR, cutadapt and VSEARCH. The taxonomy was assigned against the SILVA SSU NR 132 database. The bacterial community structure was visualised in relation to water and porewater chemistry data. The bacterial community in the water column is distinct from the sediment. The most abundant phyla in the sediment shift from Proteobacteria to Chloroflexota (formerly Chloroflexi). Ammonium and total alkalinity increase while sulphate concentrations in the porewater decrease. The provided data are of interest for studies targeting biogeochemical cycling in lake sediments.

\section{Background \& Summary}

Lake Neusiedl is the largest, seasonally evaporative lake in western Europe covering an area of approximately $315 \mathrm{~km}^{21}$. Its sediments show high contents of authigenic high magnesium calcite and poorly ordered dolomite, which have been the focus of multiple studies on sediment formation, geochemistry and water level ${ }^{1-4}$. There is a strong economic interest in the lake and the surrounding national parks due to their recreational value $e^{1,5}$. Thus, the lake's water quality, including potential pathogenic microbes, is monitored on a regular basis ${ }^{6-9}$. Nevertheless, the bacterial community composition of water and sediment remains largely unexplored, particularly in relation to the lakes' hydrochemistry.

Soft sediment push-cores were taken in the bay of Rust in August 2017 (Fig. 1a). Two 30-40 cm cores were used for bacterial community analysis and one for porewater extraction and analysis. The water (core supernatant) was filtered through a 3.0 and $0.2 \mu \mathrm{m}$ filter sandwich. All samples for bacterial community analysis were stored in RNAprotect Bacteria Reagent (Qiagen, Hilden, Germany) for transport. The reagent was removed by centrifugation from the samples prior to storage at $-80^{\circ} \mathrm{C}$. Metagenomic DNA was extracted from $0.25 \mathrm{~g}$ of sediment or one third of a filter. Subsequently, the V3-V4 region of bacterial 16S rRNA genes were amplified using primers described by Klindworth et al. ${ }^{10}$. After purification with magnetic beads, the amplicons were sequenced, yielding a total of 6,044,032 raw paired-end reads. Bioinformatic processing of the data included quality-filtering and base pair correction of overlapping regions (fastp), read-merging (PEAR), primer clipping (cutadapt), size-selection, dereplication, denoising and chimera removal (VSEARCH). After taxonomic assignment 2,263,812 high-quality $16 \mathrm{~S}$ rRNA gene sequences remained in the dataset ${ }^{11}$. Amplicon sequence variants ${ }^{12}$ (ASVs) with $100 \%$ sequence identity were screened with BLASTn against the SILVA SSU 132 NR database for taxonomic assignment. The ASV abundance table ${ }^{13}$ was used for visualisation of the bacterial community. Total alkalinity (TA) was determined by titration. Major cations and anions were measured by ion-chromatography and ICP-MS was used to determine trace element content. Nutrient concentrations and total sulphide were assessed

${ }^{1}$ Genomic and Applied Microbiology and Göttingen Genomics Laboratory, Institute of Microbiology and Genetics, Georg-August-University Göttingen, Göttingen, Germany. ${ }^{2}$ Geobiology, Faculty of Geosciences and Geography, Georg-August-University Göttingen, Göttingen, Germany. Correspondence and requests for materials should be addressed to R.D. (email: rdaniel@gwdg.de) 

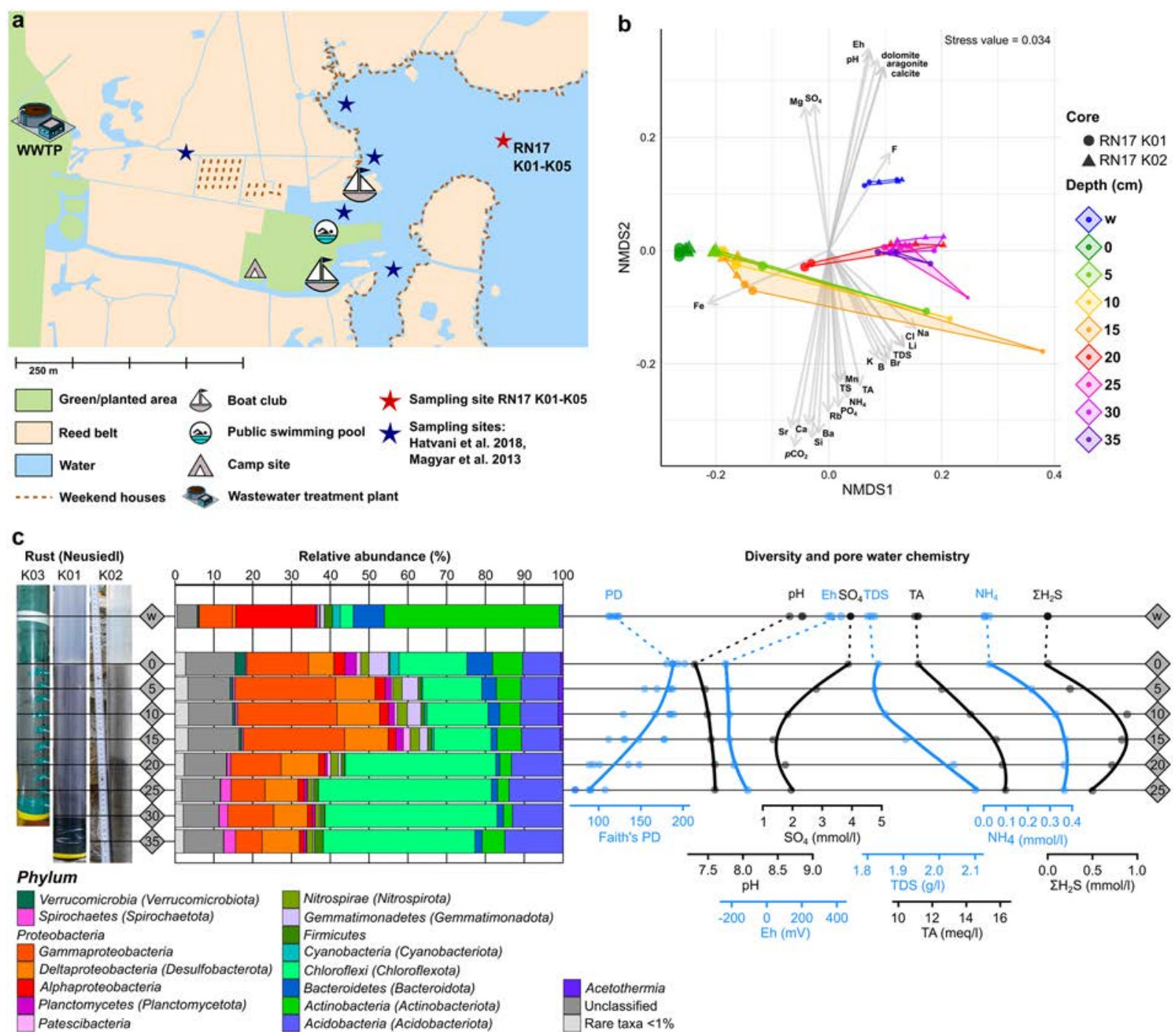

Relative abundance (\%)
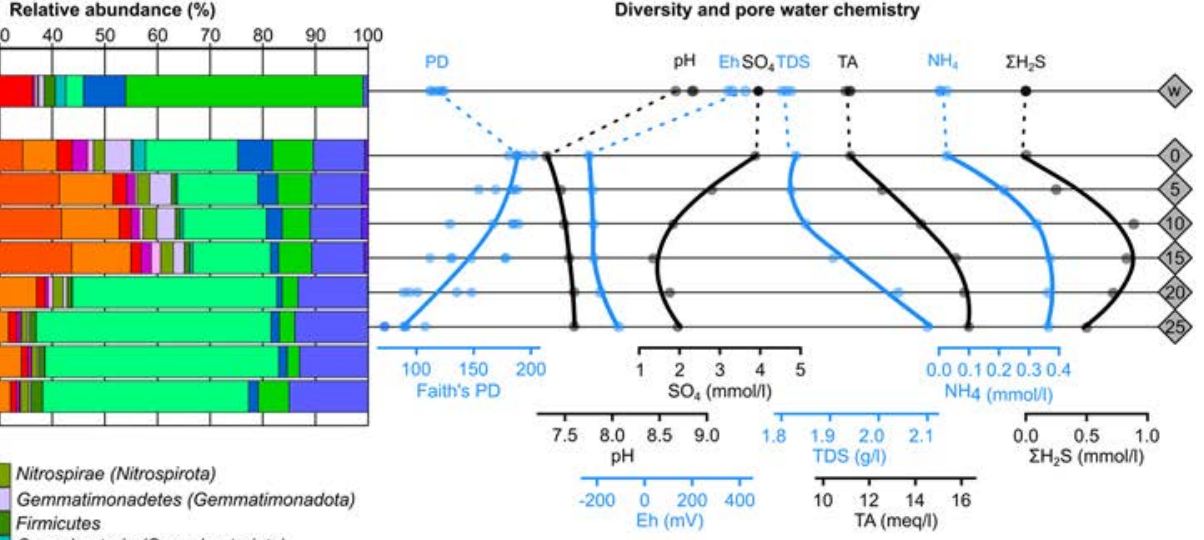

Nitrospirae (Nitrospirota) Gemmatimonadetes (Gemmatimonadota) Firmicutes

Cyanobacteria (Cyanobacteriota)

Chloroflexi (Chloroflexota)

Bacteroidetes (Bacteroidota)

Actinobacteria (Actinobacteriota)

Acidobacteria (Acidobacteriota)

Rare taxa $<1 \%$

Fig. 1 Sampling site in the bay of Rust, NMDS and depth profiles of the bacterial community composition and porewater properties. (a) Sampling site of this study (red star) and previous studies (blue stars). Markers for anthropogenic influences, such as a wastewater treatment, holiday houses (brown dashed lines) and recreational sites (pool, boat club, camp site) are indicated by pictograms or dashed lines. (b) Non-metric multidimensional scaling (NMDS) of bacterial communities $(\mathrm{n}=47)$ with the environmental fit $(\mathrm{p}<0.01)$ of porewater properties (grey arrows) based on a weighted generalized UniFrac analysis using the vegan package incorporated into ampvis $2^{51,57}$. Depths are indicated in $\mathrm{cm}$ or $\mathrm{w}$ (water column) and triangles or circles indicate the sediment core. (c) Sampling depths of the sediment cores (Rust Neusiedl RN-K01 and RN-K02) for bacterial community analysis. Each bacterial phylum depicted here comprises more than $1 \%$ relative abundance of the bacterial community in at least one sample. All other amplicon sequence variants (ASVs) are summarized as rare taxa and those with a taxonomic match below 95\% sequence identity were summarized as "Unclassified". The phylum Proteobacteria is shown at class level (Alpha-, Gamma-, Deltaproteobacteria). Names in brackets indicate revised phylum classifications according to Parks et al. ${ }^{28}$. The phylogenetic diversity (Faith's PD) was calculated based on the rarefied community (5,873 reads per sample) and a midpoint-rooted phylogenetic tree. Indicators for microbial activity in the porewater chemistry were selected and depicted as profiles of up to $25 \mathrm{~cm}$ depth.

photometrically ${ }^{14}$. Porewater chemistry and bacterial community composition were analysed in intervals of 5 $\mathrm{cm}^{15}$ (Fig. 1c).

The bacterial community composition and diversity as well as the porewater chemistry of the sediment are distinct from the water column and change gradually with depth (Fig. 1b). The water column has a lower phylogenetic diversity than the top sediment layers (Fig. 1c) and is dominated by aquatic Actinobacteria (hgcl clade) ${ }^{16-20}$ and freshwater Alphaproteobacteria (SAR11 clade III) ${ }^{16,21-25}$ with relative abundances of more than $40 \%$ and up to $20 \%$ (Figs $1 \mathrm{c}$ and 2). The uppermost sediment layer is the most diverse and harbours the largest number of associated genera (Fig. 2). It shares community members of water and sediment, such as Synechococcus or the algae-associated Phaeodactylibacter ${ }^{26,27}$. The phylogenetic diversity (Fig. 1c) and associated genera (Fig. 2) 


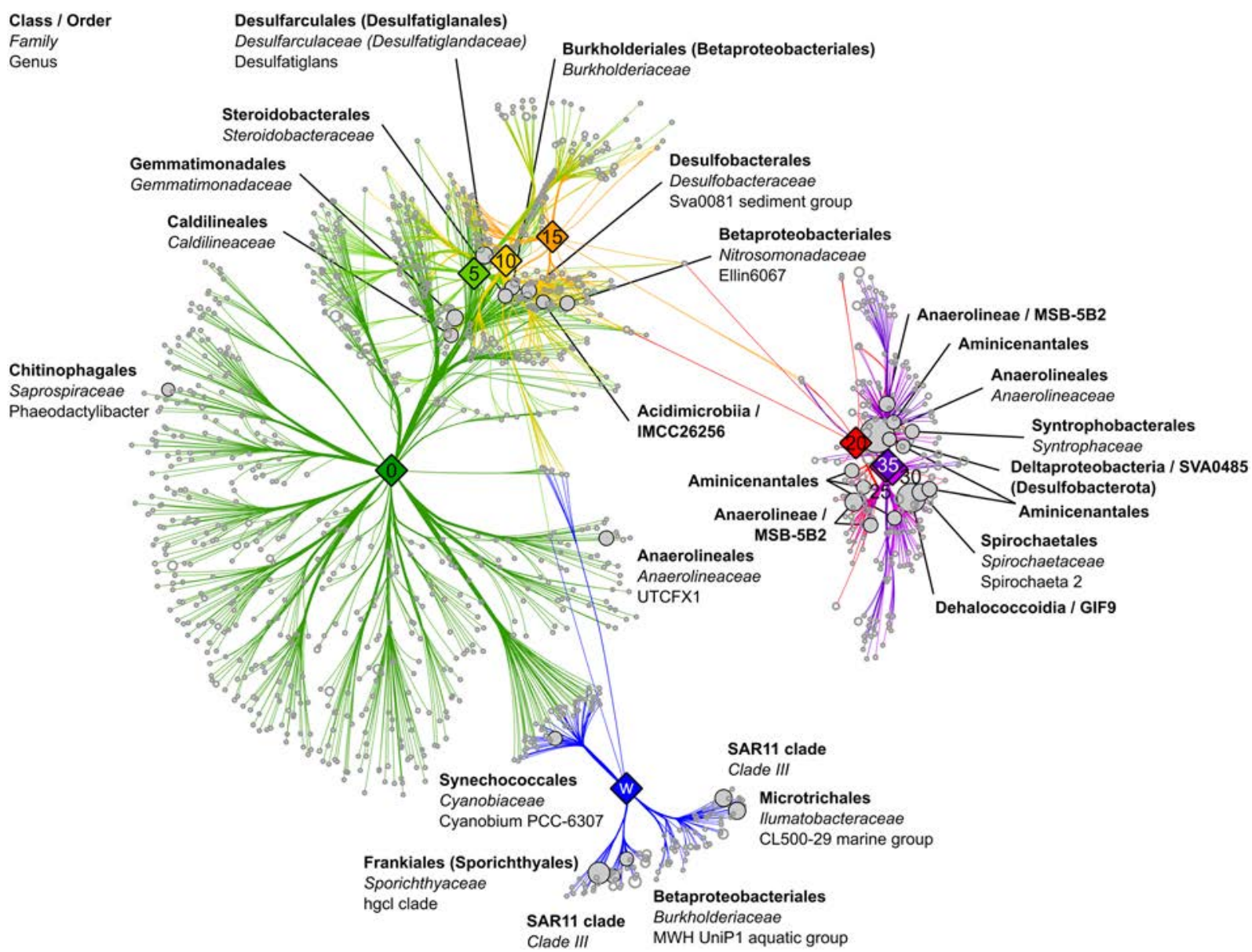

Fig. 2 Bacterial genera associated with the different depths of the sediment cores and water column. The association network was calculated with the indicspecies ${ }^{54}$ package in $\mathrm{R}$ and visualised in Cytoscape with an edge-weighted spring embedded layout. Branch lengths indicate the phi correlation coefficient. Each light grey circle indicates a bacterial genus associated $(\mathrm{p}<0.001)$ with the depth it is connected to. The 30 most abundant genera are indicated by filled circles and named up to the point where the classification turns to uncultured. Revised names according to Parks et al. ${ }^{28}$ are indicated in brackets. Average relative abundance of each genus among all samples is indicated by the circle size. Each sampling depth is indicated by a filled diamond shape containing the depth in $\mathrm{cm}$ or $\mathrm{w}$ (water column).

in the sediment decrease gradually with depth until approximately $20 \mathrm{~cm}$. Members of the Proteobacteria and Chloroflexota ${ }^{28}$ are dominant in the sediment community, which shifts from 15-35\% Gammaproteobacteria in the top $15 \mathrm{~cm}$ to approximately $40 \%$ Chloroflexota below $15 \mathrm{~cm}$. Notably, the upper sediment layers harbour sulphate-reducing bacteria, such as Desulfobacteraceae and Desulfarculaceae ${ }^{29-32}$ (Fig. 2). The decline in sulphate, increase in total sulphide $\left(\mathrm{SH}_{2} \mathrm{~S}\right)$ and low redox potential also indicate sulphate reduction (Fig. 1c). Below $15 \mathrm{~cm}$ the bacterial community is associated with Anaerolineae, Aminicenantales and Dehalococcoidia (Fig. 2). Members of these taxa are known fermenters, organohalide respirators and hydrocarbon degraders ${ }^{33-35}$. Increasing degradative processes are indicated by the increase in ammonium and total alkalinity (Fig. 1c).

The bacterial community of Lake Neusiedl has mainly been studied with regard to potential pathogens ${ }^{6,9}$. Here, Enterobacteriaceae, more specifically Escherichia/Shigella, but not Vibrionaceae were detected with a relative abundance of up to $10 \%$ at almost all depths in the sediment, but not in the water column. While they indicate an anthropogenic impact on the sediment, the bacteria detected are based on DNA amplification and may not be metabolically active. This data may contribute to studies identifying the sampling site as hotspot for faecal pollu$\operatorname{tion}^{6,7}$ (Fig. 1a). Further, this survey forms a basis for studies targeting biogeochemical cycling in alkaline lakes.

\section{Methods}

Sediment sampling at Lake Neusiedl, Austria. Three soft sediment push-cores (RN-K01/K02/K03) covering 30 to $40 \mathrm{~cm}$ depth were sampled in close lateral distance to each other at the bay of Rust $\left(16^{\circ} 42^{\prime} 33.635^{\prime \prime} \mathrm{E}\right.$, $47^{\circ} 48^{\prime} 12.929^{\prime \prime} \mathrm{N}$ ) at Lake Neusiedl, Austria in August of 2017. PVC coring tubes (Uwitec, Mondsee, Austria) of $60 \mathrm{~cm}$ length and $63 \mathrm{~mm}$ diameter (RN-K01/K03) or $100 \mathrm{~cm}$ and $50 \mathrm{~mm}$ diameter (RN-K02) were manually pushed into the sediment at the sampling site. A rubber plug was applied to the top of the coring tube to create a partial vacuum, which allowed retrieval of the sediment. After allowing the sediment to settle on 
cores RN-K01 and K02, $600 \mathrm{ml}$ core supernatant (water column) was filtered through a $3.0 \mu \mathrm{m}$ polycarbonate (Merck, Darmstadt, Germany) and $0.2 \mu$ m polyethersulfone (Sartorius, Göttingen, Germany) filter sandwich. Subsequently, filters were immediately stored in RNAprotect Bacteria Reagent (Qiagen, Hilden, Germany). Sampling of the sediment for community analysis occurred under exclusion of the outer $1 \mathrm{~cm}$ of sediment, which is in contact with the walls of the coring tubes. RN-K01/K02 were sampled in triplicate at every $5 \mathrm{~cm}$ of depth. RN-K02 was sampled at a higher resolution (every 2.5) as the sediment showed finer lamination. Every triplicate was immediately mixed with RNAprotect Bacteria Reagent (Qiagen, Hilden, Germany) and kept at ambient temperature in a cool box with freezer elements for transport. Before storage, samples were centrifuged at $3,220 \times g$ for $15 \mathrm{~min}$ and the clear supernatant containing the RNAprotect Bacteria Reagent discarded. Samples were stored at $-80^{\circ} \mathrm{C}$. Core RN-K03 and the core supernatant were stored in the cool and dark until analytical chemical analysis.

DNA extraction and amplification of bacterial 16S rRNA genes. DNA was extracted from $0.25 \mathrm{mg}$ of sediment from each sample of RN-K01/K02 using the MoBio Power Soil Kit (MoBio, CA, USA) with minor modifications. For this purpose, sediments were thawed on ice and homogenized to disrupt any layering caused by the previous centrifugation step. Subsequently, $0.25 \mathrm{mg}$ were transferred into bead-beating tubes supplied by the manufacturer. DNA from the water column (core supernatant) was extracted by cutting one third of the frozen filter sandwiches into small pieces in the bead-beating tubes. After the addition of SDS-containing Solution C1, cells were mechanically disrupted with a FastPrep (MP Biomedicals, Eschwege, Germany) at $6.5 \mathrm{~m} / \mathrm{s}$ for 20 s. After disruption, the DNA was extracted according to manufacturer's instructions. Subsequently, DNA was eluted twice in $50 \mu$ of prewarmed DEPC-treated water ${ }^{36}$. Bacterial $16 \mathrm{~S}$ rRNA genes were amplified by PCR with forward and reverse primers published by Klindworth et al. ${ }^{10}$ and added adapters for MiSeq sequencing (underlined) (D-Bact0341-b-S-17, TCGTCGGCAGCGTCAGATGTGTATAAGAGACAG CCTACGGGNGGCWGCAG; S-D-Bact0785-a-A-21, GTCTCGTGGGCTCGGAGATGTGTATAAGA GACAGGACTACHVGGGTATCTAATCC). PCR reactions were performed in a total volume of $50 \mu$ l containing $10 \mu \mathrm{l}$ of five-fold GC Buffer (Thermo Scientific, Waltham, MA, USA), 5\% DMSO, $0.2 \mathrm{mM}$ of forward and reverse primer, $200 \mu \mathrm{M} \mathrm{dNTPs}, 0.2 \mathrm{mM} \mathrm{MgCl}_{2}, 1 \mathrm{U}$ Phusion High-Fidelity DNA polymerase (Thermo Scientific, Waltham, MA, USA) and 20-25 ng template DNA. The PCR mixture was denatured for $1 \mathrm{~min}$ at $98^{\circ} \mathrm{C}$ and then subjected to 25 cycles at $98^{\circ} \mathrm{C}$ for $45 \mathrm{~s}, 45 \mathrm{~s}$ at $60^{\circ} \mathrm{C}$, and $30 \mathrm{~s}$ at $72^{\circ} \mathrm{C}$, followed by a final extension at $72^{\circ} \mathrm{C}$ for $5 \mathrm{~min}$. Negative controls were prepared without template and positive controls with genomic E. coli DH5 $\alpha$ DNA as template. PCR reactions for each sample were performed in triplicate. PCR triplicates were pooled in equal amounts in order to minimize amplification bias, concentrated and purified with MagSi-NGS Prep magnetic beads as recommended by the manufacturer (Steinbrenner, Wiesenbach, Germany). After the final washing step, the beads were air-dried and DNA eluted in $30 \mu \mathrm{l}$ of elution buffer EB (Qiagen, Hilden, Germany). Purified PCR products were quantified and sequenced as described by Schneider et al. ${ }^{37}$ using a MiSeq instrument and v3 chemistry (Illumina, San Diego, CA, USA).

Bioinformatic processing of 16S rRNA gene amplicons. Paired-end sequencing data from the Illumina MiSeq were quality-filtered with fastp ${ }^{38}$ (version 0.19.4) using default settings with the addition of an increased per base phred score of 20 , base pair corrections by overlap (-c), as well as $5^{\prime}$ - and $3^{\prime}$-end read trimming with a sliding window of 4 , a mean quality of 20 and minimum sequence size of $50 \mathrm{bp}$. After quality control, the paired-end reads were merged using $\operatorname{PEAR}^{39}$ (version 0.9.11) and primers clipped using cutadapt ${ }^{40}$ (version 1.18 ) with default settings. Sequences were then processed using VSEARCH ${ }^{41}$ (v2.9.1). This included sorting and size-filtering of the paired reads to $\geq 300 \mathrm{bp}$ (--sortbylength --minseqlength 300), dereplication (--derep_fulllength). Dereplicated amplicon sequence variants (ASVs) were denoised with UNOISE3 using default settings (--cluster_unoise - minsize 8) and chimeras were removed (--uchime3_denovo). An additional reference-based chimera removal was performed (--uchime_ref) against the SILVA SSU NR database (version 132). Raw reads were mapped to ASVs (--usearch_global-id 0.97). The taxonomy was assigned using BLAST 2.7.1 $+{ }^{42}$ against the SILVA SSU 132 NR database with an identity of at least $95 \%$ to the query sequence resulting in a total of 21,009 $\mathrm{ASVs}^{43}$.

Bacterial community analysis. For data evaluation all samples from the $5 \mathrm{~cm}$ intervals were analysed. Additional samples taken due to the finer lamination of one core were not considered in the presented analysis but are available in the dataset ${ }^{44}$. Sequences comprising extrinsic domains, eukaryotes and archaea were removed from the ASV table using grepl, a base $\mathrm{R}$ function (version 3.4.4). A phylogenetic tree was generated by aligning all sequences of the filtered dataset with MAFFT $^{45}$ at a maximum of 100 iterations. The tree was calculated using FastTree 2.1.7 (OpenMP) ${ }^{46}$, saved in newick format and midpoint rooted using FigTree ${ }^{47}$ (version 1.4.4).

The dataset was analysed in $\mathrm{R}^{48}$ (version 3.4.4) and RStudio ${ }^{49}$ (version 1.1.456). Depth profiles in the form of bar and line charts were generated with ggplot $2^{50}$ (version 3.1.0) using standard R packages. Alphadiversity indices and species richness were calculated with the ampvis $2^{51}$ package (version 2.4.1) and Faith's phylogenetic diversity with picante ${ }^{52}$ (version 1.7) and the midpoint-rooted tree ${ }^{15}$. For this purpose, 16 samples with a read count below 5,000 were excluded from the diversity analysis (RN17_K1_DNA_Bac_2a, 3a, 5a, 6a, RN17_K2_ DNA_Bac_5a-c, 7a-c, 9a-c, 11a-c). All other samples were rarefied in ampvis 2 to 5,873 reads. For the visualisation in bar charts, the mean of all replicates from both cores was used to account for the variance at the sampling sites. The non-metric multidimensional scaling (NMDS) matrix was calculated using the ASV table and phylogenetic tree in a weighted generalized UniFrac analysis using the ampvis2 package (version 2.4.1) including the package GUniFrac $^{53}$ (version 1.1). Environmental fit of the metadata were also calculated and plotted onto the NMDS if $\mathrm{p}<0.01$. An association network of the bacterial community was calculated using the indicspecies ${ }^{54}$ package (version 1.7.6) with the multipatt function and the r.g species-site group association function for calculation of the association strength. The significance cut-off for the phi coefficient was set to $\mathrm{p}<0.001$. The network was 
visualised in Cytoscape (version 3.5.1) with an edge-weighted spring-embedded layout using weight as the force and average abundance as the circle size.

Water column and porewater analysis. For hydrochemical analysis, capped and tightly sealed sediment cores, including the supernatant water column above, were stored upright in the cool and dark until analytical investigation 5 days after sampling. Core supernatants were collected in $250 \mathrm{ml}$ polyethylene (PE) bottles for anion, nutrient, and total alkalinity determination. For cation analysis, a $50 \mathrm{ml}$ aliquot of the supernatants was filtered through $0.7 \mu \mathrm{m}$ diameter membrane filters (Merck, Darmstadt, Germany) into a PE-bottle and acidified with $100 \mu \mathrm{HNO}_{3}$ (suprapure, Merck, Darmstadt, Germany). Physicochemical parameters of the core supernatants were measured using a WTW Multi 3430 device equipped with a WTW Tetracon 925 conductivity probe, a WTW FDO 925 probe for dissolved $\mathrm{O}_{2}$, a Schott Pt 61 redox electrode, and a WTW Sentix 940 electrode for temperature and $\mathrm{pH}$, which was calibrated against standard $\mathrm{pH}$-buffers 7.010 and 10.010 (HI6007 and HI6010, Hanna Instruments, Vöhringen, Germany). Total alkalinity (TA) was determined via titration using a hand-held titration device and $1.6 \mathrm{~N} \mathrm{H}_{2} \mathrm{SO}_{4}$ cartridges (Hach, Loveland, $\mathrm{CO}$, USA).

Redox potential (Eh) and $\mathrm{pH}$ gradients were measured through boreholes directly in the sediment core using a portable WTW 340i pH meter equipped with an Inlab Solids Pro pH-electrode (Mettler Toledo, Gießen, Germany) and a Pt 5900A redox electrode (SI Analytics, Mainz, Germany). Porewater was extracted from core RN-K03 using $5 \mathrm{~cm}$ CSS Rhizon samplers (Rhizosphere, Wageningen, Netherlands). Immediately after extraction, aliquots were fixed with $\mathrm{Zn}$-acetate for determination of total sulphide or acidified with suprapure $\mathrm{HNO}_{3}$ for analysis of main cations and trace elements. Porewater alkalinity was immediately determined by titration with cartridges (Hach, Loveland, CO, USA) containing self-prepared $0.01 \mathrm{n} \mathrm{HCl}$ as titrant. An aliquot for determination of nutrients and anions was stored in the cool and dark until subsequent analysis. Total sulphide $\left(\mathrm{\Sigma H}_{2} \mathrm{~S}\right)$ and nutrient concentrations $\left(\mathrm{NH}_{4}, \mathrm{NO}_{2}, \mathrm{PO}_{4}, \mathrm{SiO}_{2}\right)$ were measured by photometric methods according to Grasshoff et al. ${ }^{14}$, using an SI Analytics Uviline 9400 spectrophotometer within a few days after extraction.

Major cation $(\mathrm{Ca}, \mathrm{Mg}, \mathrm{Na}, \mathrm{K}$ and $\mathrm{Li})$ and anion $\left(\mathrm{Cl}, \mathrm{F}, \mathrm{Br}\right.$ and $\left.\mathrm{SO}_{4}\right)$ concentrations of all water samples (porewaters, water column) were analysed by ion chromatography with non-suppressed and suppressed conductivity detection, respectively (Metrohm 820 IC/Metrosep C3-250 analytical column, Metrohm 883 Basic IC/Metrohm ASupp5-250 analytical column). ICP-MS (ICAP-Q, Thermo Fisher, Waltham, MA, USA) was used to determine $\mathrm{Sr}, \mathrm{Ba}, \mathrm{Fe}, \mathrm{Mn}, \mathrm{Rb}$ and $\mathrm{B}$, as well as control for the cation determination by ion chromatography. Total dissolved salts (TDS) were calculated as the sum of all measured cations and anions. The chemical analysis was completed within two weeks after extraction with the analytical accuracy of all methods exceeding $1.5 \%{ }^{15}$.

All measured values were processed by the PHREEQC software package, version $3^{55}$, using the phreeqc.dat and wateqf4.dat databases in order to calculate ion activities and $p \mathrm{CO}_{2}$ (partial pressure of $\mathrm{CO}_{2}$ ) of the water samples and mineral saturation states. The saturation indices of all mineral phases are given as $\log \left(\mathrm{IAP} / \mathrm{K}_{\mathrm{SO}}\right)$ where IAP denotes the ion activity product and $\mathrm{K}_{\mathrm{SO}}$ is the solubility product of the corresponding mineral (solid phase).

\section{Data Records}

The 16S rRNA gene paired-end raw reads were deposited to the National Center for Biotechnology Information Sequence Read Archive (SRA) and can be found under the accession number PRJNA507590 (Bio Project 507590/ SRP171602). This BioProject contains 63 samples and 126 zipped FASTQ files, which were processed using the CASAVA software (Illumina, San Diego, CA, USA) ${ }^{44}$. The processing included demultiplexing and adapter removal from the sequences. The following files have been deposited at figshare: a FASTA file with the assigned ASV sequences after bioinformatic processing ${ }^{56}$; the ASV count table with taxonomic assignments ${ }^{13}$, the read statistics before, during and after bioinformatic processing ${ }^{11}$; the metadata, porewater chemical data and alphadiversity metrics of each sample ${ }^{15}$. The individual files may also be accessed through a figshare collection ${ }^{43}$.

\section{Technical Validation}

For microbial community analysis the layers $(2.5-5 \mathrm{~cm})$ of both soft sediment push-cores were sampled in three technical replicates to allow for the microbial heterogeneity at each depth. The PCR reactions were run in three technical replicates per sample and PCR products were pooled equimolar. Negative controls without DNA template and positive controls with genomic E. coli DH5 $\alpha$ DNA as template were also performed. Correct amplicon size was determined on a $0.8 \%$ agarose gel. PCR triplicates per sample were pooled in equimolar amounts for amplicon sequencing to minimize possible PCR bias. Physiochemical data were measured with calibrated probes and ions and nutrients were measured against IC and nutrient standards from Merck (Darmstadt, Germany) and Honeywell Fluka (Charlotte, NC, USA). The analytical accuracy of all methods exceeded $1.5 \%$.

\section{References}

1. Soja, G., Züger, J., Knoflacher, M., Kinner, P. \& Soja, A.-M. Climate impacts on water balance of a shallow steppe lake in Eastern Austria (Lake Neusiedl). J. Hydrol. 480, 115-124 (2013).

2. Kogelbauer, I. \& Loiskandl, W. Characterization of sediment layer composition in a shallow lake: from open water zones to reed belt areas. Hydrol. Earth Syst. Sci. 19, 1427-1438 (2015).

3. Müller, G., Irion, G. \& Förstner, U. Formation and diagenesis of inorganic Ca-Mg carbonates in the lacustrine environment. Naturwissenschaften 59, 158-164 (1972).

4. Schroll, E. \& Wieden, P. Eine rezente Bildung von Dolomit im Schlamm des Neusiedler Sees. Tschermaks Mineral. und Petrogr. Mitteilungen 7, 286-289 (1960).

5. Whitman, R. L. \& Nevers, M. B. Foreshore sand as a source of Escherichia coli in nearshore water of a Lake Michigan beach. Appl. Environ. Microbiol. 69, 5555-5562 (2003).

6. Hatvani, I. G., Kirschner, A. K. T., Farnleitner, A. H., Tanos, P. \& Herzig, A. Hotspots and main drivers of fecal pollution in Neusiedler See, a large shallow lake in Central Europe. Environ. Sci. Pollut. Res. 25, 28884-28898 (2018).

7. Magyar, N. et al. Application of multivariate statistical methods in determining spatial changes in water quality in the Austrian part of Neusiedler See. Ecol. Eng. 55, 82-92 (2013). 
8. Jirsa, F., Pirker, D., Krachler, R. \& Keppler, B. K. Total mercury in sediments, macrophytes, and fish from a shallow steppe lake in eastern Austria. Chem. Biodivers. 11, 1263-1275 (2014).

9. Pretzer, C. et al. High genetic diversity of Vibrio cholerae in the European lake Neusiedler See is associated with intensive recombination in the reed habitat and the long-distance transfer of strains. Environ. Microbiol. 19, 328-344 (2017).

10. Klindworth, A. et al. Evaluation of general $16 \mathrm{~S}$ ribosomal RNA gene PCR primers for classical and next-generation sequencingbased diversity studies. Nucleic Acids Res. 41, 1-11 (2013).

11. von Hoyningen-Huene, A. et al. $16 \mathrm{~S}$ rRNA gene sequence processing statistics and biosample accession numbers. figshare. https:// doi.org/10.6084/m9.figshare.8948813.v1 (2019).

12. Callahan, B. J., McMurdie, P. J. \& Holmes, S. P. Exact sequence variants should replace operational taxonomic units in marker-gene data analysis. ISME J. 11, 2639-2643 (2017).

13. von Hoyningen-Huene, A. et al. ASV counts and taxonomic assignments PRJNA507590/SRP171602. figshare. https://doi. org/10.6084/m9.figshare.8832458.v3 (2019).

14. Grasshoff, K., Kremling, K. \& Ehrhardt, M. Methods of seawater analysis. (John Wiley \& Sons, 2009).

15. von Hoyningen-Huene, A. et al. Lake Neusiedl sample metadata and porewater properties. figshare. https://doi.org/10.6084/ m9.figshare.8948906.v1 (2019).

16. Aguilar, P., Dorador, C., Vila, I. \& Sommaruga, R. Bacterioplankton composition in tropical high-elevation lakes of the Andean plateau. FEMS Microbiol. Ecol. 94, 1-9 (2018).

17. Warnecke, F., Amann, R. \& Pernthaler, J. Actinobacterial $16 \mathrm{~S}$ rRNA genes from freshwater habitats cluster in four distinct lineages. Environ. Microbiol. 6, 242-253 (2004).

18. Tandon, K. et al. Bacterial community in water and air of two sub-alpine lakes in Taiwan. Microbes Environ. 33, 120-126 (2018).

19. Newton, R. J., Jones, S. E., Eiler, A., McMahon, K. D. \& Bertilsson, S. A guide to the natural history of freshwater lake bacteria. Microbiol. Mol. Biol. Rev. 75, 14-49 (2011).

20. Neuenschwander, S. M., Ghai, R., Pernthaler, J. \& Salcher, M. M. Microdiversification in genome-streamlined ubiquitous freshwater Actinobacteria. ISME J. 12, 185-198 (2018).

21. Herlemann, D. P. R., Woelk, J., Labrenz, M. \& Jürgens, K. Diversity and abundance of "Pelagibacterales" (SAR11) in the Baltic Sea salinity gradient. Syst. Appl. Microbiol. 37, 601-604 (2014).

22. Brown, M. V. et al. Global biogeography of SAR11 marine bacteria. Mol. Syst. Biol. 8, 1-13 (2012).

23. Zhang, Y., Zhao, Z., Dai, M., Jiao, N. \& Herndl, G. J. Drivers shaping the diversity and biogeography of total and active bacterial communities in the South China Sea. Mol. Ecol. 23, 2260-2274 (2014).

24. Llirós, M. et al. Bacterial community composition in three freshwater reservoirs of different alkalinity and trophic status. PLoS One 9, el16145 (2014)

25. Eiler, A. et al. Tuning fresh: radiation through rewiring of central metabolism in streamlined bacteria. ISME J. 10, 1902-1914 (2016).

26. Flombaum, P. et al. Present and future global distributions of the marine Cyanobacteria Prochlorococcus and Synechococcus. PNAS 110, 9824-9829 (2013).

27. Lei, X. et al. Phaeodactylibacter luteus sp. nov., isolated from the oleaginous microalga Picochlorum sp. Int. J. Syst. Evol. Microbiol. 65, 2666-2670 (2015).

28. Parks, D. H. et al. A standardized bacterial taxonomy based on genome phylogeny substantially revises the tree of life. Nat. Biotechnol. 36, 996-1004 (2018).

29. Schneider, D., Arp, G., Reimer, A., Reitner, J. \& Daniel, R. Phylogenetic Analysis of a Microbialite-Forming Microbial Mat from a Hypersaline Lake of the Kiritimati Atoll, Central Pacific. PLoS One 8, e66662 (2013).

30. Diaz, M. R. et al. Functional gene diversity of oolitic sands from Great Bahama Bank. Geobiology 12, 231-249 (2014).

31. Broman, E., Sjöstedt, J., Pinhassi, J. \& Dopson, M. Shifts in coastal sediment oxygenation cause pronounced changes in microbial community composition and associated metabolism. Microbiome 5, 1-18 (2017).

32. Reyes, C. et al. Bacterial communities potentially involved in iron-cycling in Baltic Sea and North Sea sediments revealed by pyrosequencing. FEMS Microbiol. Ecol. 92, 1-14 (2016).

33. Hug, L. A. et al. Community genomic analyses constrain the distribution of metabolic traits across the Chloroflexi phylum and indicate roles in sediment carbon cycling. Microbiome 1, 1-17 (2013).

34. Dombrowski, N., Seitz, K. W., Teske, A. P. \& Baker, B. J. Genomic insights into potential interdependencies in microbial hydrocarbon and nutrient cycling in hydrothermal sediments. Microbiome 5, 1-13 (2017).

35. Kadnikov, V. V., Mardanov, A. V., Beletsky, A. V., Karnachuk, O. V. \& Ravin, N. V. Genome of the candidate phylum Aminicenantes bacterium from a deep subsurface thermal aquifer revealed its fermentative saccharolytic lifestyle. Extremophiles 23, 189-200 (2019).

36. Schneider, D., Wemheuer, F., Pfeiffer, B. \& Wemheuer, B. Extraction of total DNA and RNA from marine filter samples and generation of a cDNA as universal template for marker gene studies. In Metagenomics: Methods and Protocols (eds Streit, W. R. \& Daniel, R.) Ch.2 (Humana Press, 2017).

37. Schneider, D. et al. Gut bacterial communities of diarrheic patients with indications of Clostridioides difficile infection. Sci. Data 4, 170152 (2017)

38. Chen, S., Zhou, Y., Chen, Y. \& Gu, J. fastp: an ultra-fast all-in-one FASTQ preprocessor. Bioinformatics 34, i884-i890 (2018).

39. Zhang, J., Kobert, K., Flouri, T. \& Stamatakis, A. PEAR: a fast and accurate illumina paired-end read merger. Bioinformatics 30 , 614-620 (2014)

40. Martin, M. Cutadapt removes adapter sequences from high-throughput sequencing reads. EMBnet. journal 17, 10-12 (2011).

41. Rognes, T., Flouri, T., Nichols, B., Quince, C. \& Mahé, F. VSEARCH: a versatile open source tool for metagenomics. PeerJ 4, e2584 (2016).

42. Altschul, S. F. et al. Basic local alignment search tool. J Mol Biol 215, 403-410 (1990).

43. von Hoyningen-Huene, A. et al. Bacterial succession along a sediment porewater gradient at Lake Neusiedl in Austria. figshare. https://doi.org/10.6084/m9.figshare.c.4569482.v3 (2019).

44. NCBI Sequence Read Archive, https://identifiers.org/insdc.sra:SRP171602 (2019).

45. Katoh, K. \& Standley, D. M. MAFFT multiple sequence alignment software version 7: improvements in performance and usability. Mol. Biol. Evol. 30, 772-780 (2013).

46. Price, M. N., Dehal, P. S. \& Arkin, A. P. FastTree 2 - approximately maximum-likelihood trees for large alignments. PLoS One 5, e9490 (2010).

47. Rambaut, A. FigTree - tree figure drawing tool. Institute of Evolutionary Biology, University of Edinburgh, http://tree.bio.ed.ac.uk/ software/figtree/ (2018).

48. R Core Team. R: A language and environment for statistical computing. $R$ Foundation for Statistical Computing, https://www.Rproject.org/ (2019).

49. RStudio Team. RStudio: integrated development for R. RStudio Inc., http://www.rstudio.com/ (2016)

50. Wickham, H. ggplot2: elegant graphics for data analysis. (Springer-Verlag, 2016).

51. Andersen, S. K., Kirkegaard, R. H., Karst, S. M. \& Albertsen, M. ampvis2: an R package to analyse and visualise 16S rRNA amplicon data. bioRxiv 1-2, https://doi.org/10.1101/299537 (2018).

52. Kembel, S. W. et al. Picante: R tools for integrating phylogenies and ecology. Bioinformatics 26, 1463-1464 (2010). 
53. Chen, J. et al. Associating microbiome composition with environmental covariates using generalized UniFrac distances. Bioinformatics 28, 2106-2113 (2012).

54. De Cáceres, M. \& Legendre, P. Associations between species and groups of sites: indices and statistical inference. Ecology 90 3566-3572 (2009).

55. Parkhurst, D. L. \& Appelo, C. A. J. Description of input and examples for PHREEQC version 3-a computer program for speciation, batch-reaction, one-dimensional transport, and inverse geochemical calculations. In U.S. Geological Survey Techniques and Methods Book 6 Ch. A43, https://pubs.usgs.gov/tm/06/a43/ (2013).

56. von Hoyningen-Huene, A. et al. ASV sequences PRJNA507590/SRP171602. figshare. https://doi.org/10.6084/m9.figshare.7808324.v5 (2019).

57. Oksanen, J. et al. vegan: community ecology package, https://cran.r-project.org/package=vegan (2018).

\section{Acknowledgements}

This study was funded by the German research foundation (DFG) in the framework of the research unit "CHARON" (subproject TP7: DA 374/11-1, AR 335/8-1). We thank Prof. Dr. Patrick Meister, University of Vienna, for his support during the field work and his feedback. Anja Poehlein and Melanie Heinemann are hereby gratefully acknowledged for performing the amplicon sequencing and initial sequence processing after the MiSeq run. We acknowledge support by the Open Access Publication Funds of the University of Göttingen.

\section{Author contributions}

R.D., G.A., A.H. conceived the study. Experimental design and implementation of the bacterial community analysis was performed by A.H. supported by D.S. A.H., A.R., G.A., D.S. and D.F. participated in the sampling. Porewater chemistry was measured and analysed by D.F. and A.R., A.H. drafted the manuscript, which was revised by D.S. and R.D. All authors interpreted the results and contributed to the final version of the manuscript.

\section{Additional Information \\ Competing Interests: The authors declare no competing interests.}

Publisher's note: Springer Nature remains neutral with regard to jurisdictional claims in published maps and institutional affiliations.

(c) (i) Open Access This article is licensed under a Creative Commons Attribution 4.0 International License, which permits use, sharing, adaptation, distribution and reproduction in any medium or format, as long as you give appropriate credit to the original author(s) and the source, provide a link to the Creative Commons license, and indicate if changes were made. The images or other third party material in this article are included in the article's Creative Commons license, unless indicated otherwise in a credit line to the material. If material is not included in the article's Creative Commons license and your intended use is not permitted by statutory regulation or exceeds the permitted use, you will need to obtain permission directly from the copyright holder. To view a copy of this license, visit http://creativecommons.org/licenses/by/4.0/.

The Creative Commons Public Domain Dedication waiver http://creativecommons.org/publicdomain/zero/1.0/ applies to the metadata files associated with this article.

(C) The Author(s) 2019 


\section{Authigenic fORMAtion OF CA-Mg CaRbonates IN the Shallow alkaline Lake Neusiedl, Austria}

Dario Fussmann ${ }^{1}$, Avril Jean Elisabeth von Hoyningen-Huene ${ }^{2}$, Andreas Reimer ${ }^{1}$, Dominik Schneider ${ }^{2}$, Hana Babková ${ }^{3}$, Robert Peticzka $^{4}$, Andreas Maier ${ }^{4}$, Gernot Arp ${ }^{1}$, Rolf Daniel $^{2}$, and Patrick Meister ${ }^{3}$

Biogeosciences (16. April 2020), 17, 2085-2106

https://doi.org/10.5194/bg-17-2085-2020

\section{Affiliations}

1 Geobiology, Geoscience Centre, Georg-August-Universität Göttingen, Goldschmidtstraße 3, 37077 Göttingen, Germany

${ }^{2}$ Genomic and Applied Microbiology and Göttingen Genomics Laboratory, Institute of Microbiology and Genetics, Georg-August-Universität Göttingen, Grisebachstraße 8, 37077 Göttingen, Germany

${ }^{3}$ Department of Geodynamics and Sedimentology, University of Vienna, Althanstraße 14, 1090 Vienna, Austria

4 Department of Geography and Regional Research, University of Vienna, Althanstraße 14, 1090 Vienna, Austria

Supplement available at https://doi.org/10.5194/bg-17-2085-2020-supplement and on the enclosed CD/.zip file: Supplement|Chapter_C2।

\section{Author contributions:}

Conceived and designed the study: GA, RD, PM

Performed the experiments: DF, AH, AR, HB, AM, RP

Analysed the data: DF, AH, AR, DS, HB, AM, RP

Wrote the paper: DF, AH, AR, DS, RD, GA, PM 


\title{
Authigenic formation of $\mathrm{Ca}-\mathrm{Mg}$ carbonates in the shallow alkaline Lake Neusiedl, Austria
}

\author{
Dario Fussmann ${ }^{1}$, Avril Jean Elisabeth von Hoyningen-Huene ${ }^{2}$, Andreas Reimer ${ }^{1}$, Dominik Schneider ${ }^{2}$, \\ Hana Babková ${ }^{3}$, Robert Peticzka ${ }^{4}$, Andreas Maier ${ }^{4}$, Gernot Arp $^{1}$, Rolf Daniel ${ }^{2}$, and Patrick Meister ${ }^{3}$ \\ ${ }^{1}$ Geobiology, Geoscience Centre, Georg-August-Universität Göttingen, Goldschmidtstraße 3, 37077 Göttingen, Germany \\ ${ }^{2}$ Genomic and Applied Microbiology and Göttingen Genomics Laboratory, Institute of Microbiology and Genetics, \\ Georg-August-Universität Göttingen, Grisebachstraße 8, 37077 Göttingen, Germany \\ ${ }^{3}$ Department of Geodynamics and Sedimentology, University of Vienna, Althanstraße 14, 1090 Vienna, Austria \\ ${ }^{4}$ Department of Geography and Regional Research, University of Vienna, Althanstraße 14, 1090 Vienna, Austria
}

Correspondence: Dario Fussmann (dario.fussmann@uni-goettingen.de)

Received: 15 November 2019 - Discussion started: 5 December 2019

Revised: 18 February 2020 - Accepted: 11 March 2020 - Published: 16 April 2020

\begin{abstract}
Despite advances regarding the microbial and organic-molecular impact on nucleation, the formation of dolomite in sedimentary environments is still incompletely understood. Since 1960, apparent dolomite formation has been reported from mud sediments of the shallow, oligohaline and alkaline Lake Neusiedl, Austria. To trace potential dolomite formation or diagenetic alteration processes in its deposits, lake water samples and sediment cores were analyzed with respect to sediment composition, hydrochemistry and bacterial community composition. Sediments comprise $20 \mathrm{~cm}$ of homogenous mud with $60 \mathrm{wt} \%$ carbonate, which overlies dark-laminated consolidated mud containing 50 wt \% carbonate and plant debris. Hydrochemical measurements reveal a shift from oxic lake water with $\mathrm{pH} 9.0$ to anoxic sediment pore water with $\mathrm{pH} 7.5$. A decrease in $\mathrm{SO}_{4}^{2-}$ with a concomitant increase in $\Sigma \mathrm{H}_{2} \mathrm{~S}$ and $\mathrm{NH}_{4}^{+}$from 0 to $15 \mathrm{~cm}$ core depth indicates anaerobic heterotrophic decomposition, including sulfate reduction. The bacterial community composition reflects the zonation indicated by the pore water chemistry, with a distinct increase in fermentative taxa below $15 \mathrm{~cm}$ core depth.

The water column is highly supersaturated with respect to (disordered) dolomite and calcite, whereas saturation indices of both minerals rapidly approach zero in the sediment. Notably, the relative proportions of different authigenic carbonate phases and their stoichiometric compositions remain constant with increasing core depth. Hence, evidence for $\mathrm{Ca}-\mathrm{Mg}$ carbonate formation or ripening to dolomite is lacking within
\end{abstract}

the sediment of Lake Neusiedl. As a consequence, precipitation of high-magnesium calcite (HMC) and protodolomite does not occur in association with anoxic sediment and sulfate-reducing conditions. Instead, analytical data for Lake Neusiedl suggest that authigenic HMC and protodolomite precipitate from the supersaturated, well-mixed aerobic water column. This observation supports an alternative concept to dolomite formation in anoxic sediments, comprising $\mathrm{Ca}-$ $\mathrm{Mg}$ carbonate precipitation in the water column under aerobic and alkaline conditions.

\section{Introduction}

Dolomite $\left(\mathrm{CaMg}\left(\mathrm{CO}_{3}\right)_{2}\right)$ is the most abundant carbonate mineral in Earth's sedimentary record. It has rarely been observed forming in recent environments. Instead, most occurrences of large dolomite deposits in the geological record are the result of pervasive dolomitization of precursor carbonates by fluids with high $\mathrm{Mg}$ : Ca ratios and temperatures during burial (e.g., Machel, 2004). In contrast, the formation of dolomite near the sediment surface, so-called penecontemporaneous dolomite (Machel, 2004, and references therein), or even primary precipitation in shallow aquatic environments is often difficult to trace in the rock record and capture in modern environments. The difficulty in capturing ongoing dolomite formation is due to its peculiar kinetics, which are still incompletely understood despite intense laboratory and 
field experiments. Dolomite does not form in sites where sufficient $\mathrm{Ca}, \mathrm{Mg}$ and carbonate ions are provided, which is generally explained by the high kinetic barrier of dolomite nucleation and growth (e.g., Lippmann, 1973).

Based on the presence of sulfate-reducing bacteria (SRB), Vasconcelos et al. (1995) proposed a microbial model, in which sulfate-reducing bacteria mediate carbonate precipitation, while Brady et al. (1996) consider sulfate ions to be inhibitors for dolomite growth. Further experiments were performed with various different organisms, such as denitrifiers (Rivadeneyra et al., 2000), methanogenic archaea (Roberts et al., 2004) and aerobic halophilic bacteria (Sánchez-Román et al., 2009). All of these studies showed aggregate formation of carbonate minerals with the characteristic $d_{104}$ peak of dolomite under X-ray diffraction, hence supporting a microbial factor in dolomite formation. It has been hypothesized that dolomite nucleation is mediated by microbial extracellular polymeric substances (EPSs; Bontognali et al., 2014). However, Gregg et al. (2015) re-analyzed the X-ray diffraction data of many of the aforementioned microbial experiments, demonstrating that microbial dolomite products lack typical ordering reflections in XRD spectra and are in fact very high magnesium calcite (VHMC or "protodolomite"). In further studies sulfide (F. Zhang et al., 2013), dissolved organic matter (Frisia et al., 2018) or clay minerals (Liu et al., 2019) were suggested to favor protodolomite nucleation in pore fluids. Nevertheless, it is not entirely clear which of these factors play a fundamental role in natural environments and how the specific reaction mechanisms work.

While the concept that dolomite forms within sediments mediated by anaerobic microbial processes and their extracellular polymeric substances is widely acknowledged, another aspect should be taken into account: the site of dolomite formation may not always coincide with the location where the mineral is found due to relocation after precipitation. Several studies describe unlithified dolomite precipitation in warm, arid and hypersaline marine environments, like coastal sabkhas (Illing et al., 1965; Bontognali et al., 2010; Court et al., 2017), coastal lakes, such as Lagoa Vermelha in Brazil (Vasconcelos and McKenzie, 1997; van Lith et al., 2002; Sánchez-Román et al., 2009), and ephemeral lakes along the Coorong lagoon in southern Australia (von der Borch, 1976; Rosen et al., 1989; Warren, 1990; Wright and Wacey, 2005). Dolomite precipitation is further reported in endorheic hypersaline lakes, e.g., Qinghai Lake in Tibet (Deng et al., 2010), Lake Acıgöl (Turkey; Balci et al., 2016) and alkaline playa lakes such as Deep Springs Lake in California (Meister et al., 2011).

Another location where $\mathrm{Ca}-\mathrm{Mg}$ carbonate is formed can be found in Turkey, where McCormack et al. (2018) describe dolomite in Quaternary sediments from Lake Van, which is suggested to have formed at the sediment-water interface characterized by varying salinities and low temperatures. These dolomite-bearing deposits have been related to the onset of a falling paleo-lake level, hence changing hydrochem- ical conditions. Importantly, McCormack et al. (2018) locate the formation of dolomite near the sediment-water interface, where it is presumably related to microbial EPS. However, this area is also exposed to significant fluctuations in $\mathrm{pH}$, temperature and supersaturation. Precipitation experiments conducted by Deelman (1999) have shown that dolomite can form due to such fluctuations in $\mathrm{pH}$ and temperature. Hence, they agree with Ostwald's step rule because dolomite formation happens via undersaturation of other metastable carbonate phases.

Lake Neusiedl is a water body that precipitates $\mathrm{Ca}-\mathrm{Mg}$ carbonate at exceptionally low salinity $\left(1-2 \mathrm{~g} \mathrm{~L}^{-1}\right)$. It is a shallow and seasonally evaporative lake in the proximity of Vienna, Austria. Schroll and Wieden (1960) first reported the occurrence of poorly crystallized dolomite (notable by its broad XRD reflections) at this locality, and Müller et al. (1972) related its formation to diagenetic alteration of high-magnesium calcite (HMC). The $\mathrm{Mg}$ : Ca ratios in Lake Neusiedl are unusually high $(>7)$ compared to freshwater lakes, which favor the precipitation of HMC (Müller et al., 1972). Little is known about the crystallization paths of the $\mathrm{Ca}-\mathrm{Mg}$ carbonate phases in this lake, in particular whether they form in the anoxic sediment or oxic water column and if early diagenetic alteration to dolomite ("ripening") takes place.

We revisit the formation of dolomite in Lake Neusiedl by comparing the sediment geochemical and in situ pore water data and critically evaluating the location of precipitation. This approach has been used to study dolomite formation in Lagoa Vermelha (van Lith et al. 2002; Moreira et al., 2004) or in Deep Springs Lake (Meister et al., 2011). Since 2005, in situ pore water extraction via rhizon samplers has been applied for geoscientific research questions (SeebergElverfeldt et al., 2005), and several in situ pore water studies were conducted using this technique (e.g., Bontognali et al., 2010; Birgel et al., 2015; Steiner et al., 2018). Comparable in situ pore water data from an oligohaline seasonally evaporative lake, which address the question of authigenic $\mathrm{Ca}-\mathrm{Mg}$ carbonate precipitation, are absent so far. We further provide bacterial community analyses to address the potential role of microbes and their metabolisms in a carbonate mineral precipitation or alteration pathway. Hence, our study has three goals: (i) finding indications for the origin of $\mathrm{Ca}-\mathrm{Mg}$ carbonate formation, (ii) evaluating the microbiological and geochemical conditions and their influence on carbonate saturation, and (iii) discussing which factors drive the formation of $\mathrm{Ca}-\mathrm{Mg}$ carbonates in Lake Neusiedl.

\section{Study area}

Lake Neusiedl, situated at the Austrian-Hungarian border, is the largest endorheic lake in western Europe. It is located in the Little Hungarian Plain, a transition zone between the Eastern Alps and the Pannonian Basin in central 
Hungary. The region has been tectonically active since the early Miocene (Horváth, 1993) and is affected by NE-SWtrending normal faults. This early Miocene tectonic activity included the closing of the Central Paratethys Sea and the formation of Lake Pannon about 11.6 million years ago. This ancient water body was characterized by highly fluctuating water levels that caused the deposition of local evaporite layers, which influence the salinity of today's deeper aquifers in the area (Piller et al., 2007; Krachler et al., 2018). The present topography of the Little Hungarian Plain is the result of ongoing local uplift and subsidence, which commenced in the latest Pliocene (Zámolyi et al., 2017). Elevated regions are represented by the Rust and Leitha hills, which are horst-like structures located west of Lake Neusiedl. Northward, the water body is separated from the Vienna Basin by the raised Parndorf plateau, which has a $25-45 \mathrm{~m}$ higher surface elevation than the lake area. South- and eastward, Lake Neusiedl is surrounded by flats, namely the Hanság and Seewinkel plain. Despite its proximity to the Alps, the region surrounding Lake Neusiedl did not have an ice cover during the last glacial maximum. Hence, its morphology is shaped by periglacial erosion and sedimentation (van Husen, 2004). Throughout the Seewinkel plain, Pannonian marine to brackish sediments are largely covered by fluvioglacial gravels. The gravels thin out westwards and are thus missing beneath parts of Lake Neusiedl, where fine-grained, unlithified lacustrine mud directly overlies compacted Pannonian strata (Loisl et al., 2018). The absence of a gravel layer has made the former lake area vulnerable to aeolian erosion, favoring the formation of the present-day flat trough over tectonic subsidence (Zámolyi et al., 2017).

The surface area of the water body spreads over $315 \mathrm{~km}^{2}$, with a maximum depth of $1.8 \mathrm{~m}$. With a salinity of 1$2 \mathrm{~g} \mathrm{~L}^{-1}$ and elevated $\mathrm{pH}$ values (> 8.5), the water chemistry differs significantly from that of freshwater lakes (salinity: $<0.5 \mathrm{~g} \mathrm{~L}^{-1} ; \mathrm{pH}$ : 6.5-7.5). Increased amounts of sodium and bicarbonate ions mainly contribute to the lake's soda-like character (Herzig, 2014). Furthermore, the $\mathrm{Mg}$ : Ca ratio is unusually high in comparison to freshwater lakes (Krachler et al., 2012). Permanent surface water inflow is mainly provided by the Rákos and the Wulka streams, which drain a catchment area that is approximately 2.6 times the size of Lake Neusiedl $\left(1120 \mathrm{~km}^{2}\right)$. Thus, their contribution to the lake's water balance is negligible compared to the significantly higher input from precipitation, providing $80 \%-90 \%$ of the lake water (Herzig and Dokulil, 2001). As a result of its shallowness and the endorheic drainage system, the lake is very vulnerable to climatic changes, which highly influence the water level, water volume and, hence, the surface area of the lake throughout the year and over the centuries. In the past, Lake Neusiedl was characterized by highly fluctuating water levels and desiccation events (Moser, 1866), the last of which dates back between 1865 and 1870. Since 1910, the lake's water outflow can be regulated by the artificial Hanság or Einser canal in case of severe flooding events. The canal is located at the lake's southeastern shore (Fig. 1).

More than half $\left(178 \mathrm{~km}^{2}\right)$ of Lake Neusiedl's surface area is covered with reed. Due to its wind exposure and shallowness, the water column of the open water area is well mixed and contains high amounts of suspended particles. The wind sheltering effect of Phragmite spears, in contrast, leads to clearer water in the reed belt. Clastic input into the water body is minor and reflects the mineralogical composition of the western neighboring Rust and Leitha hills, which are characterized by crystalline rocks of the Eastern Alpine basement and Miocene marine carbonates ("Leithakalk"; Fig. 1). The deposits forming the present bed of Lake Neusiedl consist of fine-grained mud, which mainly contains typical authigenic carbonate phases such as $\mathrm{Mg}$ calcite and protodolomite (Löffler, 1979). Those phases can clearly be distinguished from pure calcite, which is considered to be allochthonous in the sedimentary environment of Lake Neusiedl (Müller et al., 1972). It is noteworthy that the mud volume doubled in the time from 1963 to 1988, leading to an increase in the volumetric mud / water ratio from $36: 64$ in 1963 to $49: 51$ in 1988. This mud layer covers the whole lake area and would yield an average thickness of $64 \mathrm{~cm}$, assuming an equal distribution across the lake basin (Bácsatyai, 1997). The thickness of soft sediment can increase up to $1 \mathrm{~m}$ at the border of the reed belt and open water, where Phragmite spears act as sediment traps for current driven, suspended particles (Löffler, 1979).

\section{Material and methods}

\subsection{Sampling and field measurements}

The sampling campaign at Lake Neusiedl was performed in August 2017 in the bay of Rust $\left(47^{\circ} 48^{\prime} 12.929^{\prime \prime} \mathrm{N}\right.$, $16^{\circ} 42^{\prime} 33.635^{\prime \prime} \mathrm{E}$ ), situated at the lake's central western shore. A pedalo boat was utilized to enable sampling approximately $500 \mathrm{~m}$ offshore. Physicochemical parameters of the lake water were measured directly in the field using a WTW Multi 3430 device equipped with a WTW Tetracon 925 conductivity probe, a WTW FDO 925 probe for dissolved $\mathrm{O}_{2}$, and a WTW Sentix 940 electrode for temperature and $\mathrm{pH}$ (Xylem, Rye Brook, NY, USA), calibrated against standard pH buffers 7.010 and 10.010 (HI6007 and HI6010, Hanna Instruments, Woonsocket, RI, USA; standard deviation $\leq 2 \%$ ). Lake water was retrieved from a depth of $10 \mathrm{~cm}$ with a $500 \mathrm{~mL}$ SCHOTT-DURAN glass bottle without headspace from which subsamples for anion, nutrient and total alkalinity determination were distributed into $100 \mathrm{~mL}$ polyethylene (PE) and $250 \mathrm{~mL}$ SCHOTT-DURAN glass bottles (SCHOTT, Mainz, Germany). For cation analysis, a $50 \mathrm{~mL}$ aliquot was filtered through membrane filters with a pore size of $0.7 \mu \mathrm{m}$ (Merck, Darmstadt, Germany) into a PE bottle and acidified with $100 \mu \mathrm{L} \mathrm{HNO}_{3}$ (sub-boiled). 


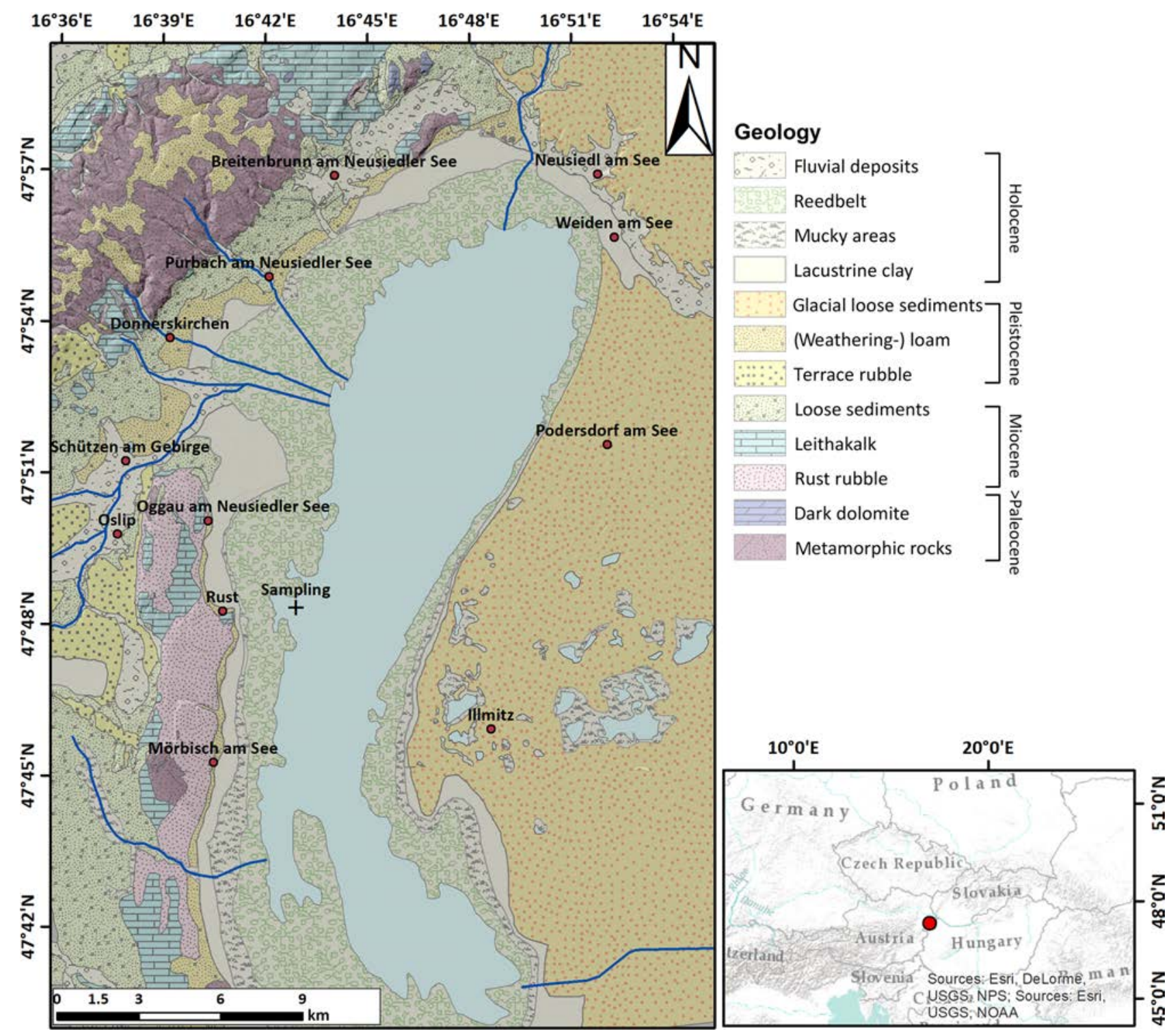

Figure 1. Lake Neusiedl and its surrounding geology, redrawn and simplified after Herrman et al. (1993).

Total alkalinity was determined via titration within $3 \mathrm{~h}$ after sampling using a handheld titration device and $1.6 \mathrm{~N} \mathrm{H}_{2} \mathrm{SO}_{4}$ cartridges (Hach Lange, Düsseldorf, Germany; standard deviation $\leq 1.5 \%$ ).

Five sediment cores, with the sample codes LN-K01, LN$\mathrm{K} 02$, LN-K03, LN-K04 and LN-K05, were retrieved using PVC tubes $(6.3 \mathrm{~cm}$ diameter; Uwitec, Mondsee, Austria) in approximately $30 \mathrm{~cm}$ lateral distance. All cores were 30 to $40 \mathrm{~cm}$ in length and were used for sediment, pore water and bacterial community profiling. Cores LN-K01 and LN-K02 were subsampled and treated for bacterial community profiling as described in von Hoyningen-Huene et al. (2019) directly after recovery. Cores LN-K03, LN-K04 and LN-K05 were hermetically sealed after recovery and stored upright at temperatures close to their natural environment $\left(22 \pm 2^{\circ} \mathrm{C}\right)$.
Effects of pressure differences are neglectable in the present case because the cores were sampled just below the lake floor.

\subsection{Petrographic, mineralogical and geochemical analyses}

Two cores, labeled LN-K04 and LN-K05, were used for sediment geochemical and petrographic analyses. Sediment dry density and porosity were calculated from the corresponding sediment weights and volumes. For bulk organic and inorganic carbon content detection, sediment increments of $2.5 \mathrm{~cm}$ were subsampled from core LN-K04. They were freeze-dried and powdered with a ball mill before they were measured by a LECO RC612 (Leco, St. Joseph, MI, USA) 
multi-phase carbon and water determination device. For calibration, Leco synthetic carbon (1 and 4.98 carbon \%) and Leco calcium carbonate (12 carbon \%) standards were used. The same increments were utilized for CNS elemental detection, which was operated with a Euro EA 3000 Elemental Analyser (HEKAtech, Wegberg, Germany); 2,5-bis(5tert-benzoxazol-2-yl)thiophene BBOT and atropine sulfate monohydrate (IVA Analysetechnik, Meerbusch, Germany) were provided as reference material. Analytical accuracy of all analyses was better than $3.3 \%$.

XRD analyses were conducted with identical increments at the Department of Geodynamics and Sedimentology in Vienna by a PANanalytical (Almelo, Netherlands) X'pert Pro device $\left(\mathrm{CuK} \alpha\right.$ radiation, $2 \theta$ refraction range of $2-70^{\circ}$ and a step size of $0.01^{\circ}$ ). Semi-quantitative phase composition analysis was performed with Rietveld refinement of peak intensities by using MAUD (version 2.8; Lutterotti et al., 2007). To ensure a better reproducibility of the semiquantitative XRD analysis, Rietveld-refined results were compared and correlated with carbon data retrieved from the aforementioned LECO RC612 device.

In core $\mathrm{LN}-\mathrm{K} 05$, sediment increments of $5 \mathrm{~cm}$ were subsampled for thin sectioning and light microscopic observations. To ensure a continuous section, rectangular steel meshes, $5 \mathrm{~cm}$ in length, were placed along the sediment column. These steel meshes, filled with soft sediment, were then embedded in LR White resin (London Resin Company, Reading, United Kingdom) after a dehydration procedure with ethanol. During dehydration, the sediments were treated with SYTOX Green nucleic acid stain (Invitrogen, Carlsbad, CA, USA) to stain eukaryotic cell nuclei and prokaryotic cells for fluorescence microscopy. Samples were cured for $24 \mathrm{~h}$ at $60^{\circ} \mathrm{C}$ before thin-section preparation. The thin sections were ground down to a thickness of 40 to $50 \mu \mathrm{m}$ and then capped with a glass cover. Petrographic observations were conducted with a petrographic and a laser-scanning microscope (ZEISS, Oberkochen, Germany; 1sm excitation: 543, 488, 633 nm; laser unit: Argon/2, HeNe543, HeNe633).

For scanning electron microscopy, non-capped unpolished thin-section fragments and freeze-dried loose sediment from cores LN-K05 and LN-K04 were placed on $12.5 \mathrm{~mm}$ plano carriers and sputtered with a platinum-palladium mixture. Field emission scanning electron microscopy was conducted with a Gemini Leo 1530 device (ZEISS, Oberkochen, Germany) with a coupled INCA x-act (Oxford Instruments, Abingdon, UK) EDX detector.

\subsection{Pore water analysis}

Redox potential and $\mathrm{pH}$ gradients were directly measured in the sediment of core $\mathrm{LN}-\mathrm{K} 03$ one week after sampling with a portable WTW 340i pH meter, equipped with an InLab Solids Pro pH electrode (Mettler Toledo, Columbus, OH, USA) and a Pt-5900 A redox electrode (SI Analytics, Mainz, Germany) through boreholes (standard deviation $\leq 2 \%$ ). Pore water was extracted from the core, using $5 \mathrm{~cm}$ CSS Rhizon samplers (Rhizosphere, Wageningen, Netherlands). Immediately after extraction, aliquots were fixed with $\mathrm{Zn}$ acetate for determination of total sulfide $\left(\Sigma \mathrm{H}_{2} \mathrm{~S}\right)$. Pore water alkalinity was determined using a modified Hach titration method with self-prepared $0.01 \mathrm{~N} \mathrm{HCl}$ cartridges as titrant. Major cation $\left(\mathrm{Ca}^{2+}, \mathrm{Mg}^{2+}, \mathrm{Na}^{+}, \mathrm{K}^{+}\right.$and $\left.\mathrm{Li}^{+}\right)$ and anion $\left(\mathrm{Cl}^{-}, \mathrm{F}^{-}, \mathrm{Br}^{-}, \mathrm{SO}_{4}^{2-}\right.$ and $\left.\mathrm{NO}_{3}^{-}\right)$concentrations of lake and pore water samples (including supernatants in the cores) were analyzed by ion chromatography with nonsuppressed and suppressed conductivity detection, respectively (Metrohm 820 IC/Metrosep C3 - 250 analytical column, Metrohm 883 Basic IC/Metrohm A Supp 5 - 250 analytical column; Metrohm, Herisau, Switzerland; standard deviation $\leq 2 \%$ ). Inductively coupled plasma mass spectrometry (ICP-MS; iCAP-Q, Thermo Fisher, Waltham, MA, USA) was used to determine $\mathrm{Sr}, \mathrm{Ba}, \mathrm{Fe}, \mathrm{Mn}, \mathrm{Rb}$ and $\mathrm{B}$ as control for the cation determination by ion chromatography (standard deviation $\leq 3 \%$ ).

Concentrations of $\mathrm{NH}_{4}^{+}, \mathrm{NO}_{2}^{-}, \mathrm{PO}_{4}^{3-}, \Sigma \mathrm{H}_{2} \mathrm{~S}$ and dissolved silica $\left(\mathrm{SiO}_{2(\mathrm{aq})}\right)$ were measured by photometric methods according to Grasshoff et al. (2009), using a SI Analytics UviLine 9400 spectrophotometer. In addition, methane and dissolved inorganic carbon (DIC) amounts were retrieved from a different core, sampled at the same locality in $\mathrm{Au}-$ gust 2017. Methane concentrations were determined from $5 \mathrm{~cm}^{3}$ sediment samples stored upside down in gas-tight glass bottles containing $5 \mathrm{~mL} \mathrm{NaOH}(5 \% \mathrm{w} / \mathrm{v})$. Aliquots of $5 \mathrm{~mL}$ headspace methane were transferred to evacuated $10 \mathrm{~mL}$ vials. The aliquots were analyzed with an automated headspace gas chromatograph (GC Agilent 7697A coupled to an Agilent 7890B auto sampler) at the University of Vienna. Methane concentrations were quantified at a runtime of $1.798 \mathrm{~min}$ by a flame ionization detector and a methanizer. For linear calibration, a standard series with the concentrations 1001, 3013 and 10003 ppb was used. DIC concentrations were retrieved by using a Shimadzu TOC-LCPH (Shimadzu, Kyoto, Japan) analyzer with an ASI-L autosampler and a reaction vessel containing a reaction solution of phosphoric acid $\left(\mathrm{H}_{3} \mathrm{PO}_{4}, 25 \%\right)$. The DIC was measured by conversion to carbon dioxide, which was detected by a NDIR detector.

All measured values were processed with the PHREEQC software package (version 3; Parkhurst and Appelo, 2013). The implemented phreeqc.dat and wateqf4.dat databases were used in order to calculate ion activities and $p \mathrm{CO}_{2}$ (partial pressure of $\mathrm{CO}_{2}$ ) of the water samples and mineral saturation states. The saturation indices of mineral phases are given as $\mathrm{SI}=\log \left(\mathrm{IAP} / \mathrm{K}_{\mathrm{SO}}\right)$.

\subsection{Bacterial 16S rRNA gene community profiling}

Two sediment cores labeled LN-K01 and LN-K02 were sampled for bacterial 16S rRNA gene-based community profiling. Each core was sampled in triplicate at every $2.5-5 \mathrm{~cm}$ 
of depth and the surface water filtered through a 2.7 (Merck, Darmstadt, Germany) and $0.2 \mu \mathrm{m}$ (Sartorius, Göttingen, Germany) filter sandwich. RNAprotect Bacteria Reagent (QIAGEN, Hilden, Germany) was immediately added to all samples in order to preserve the nucleic acids. Before storage at $-80^{\circ} \mathrm{C}$, the samples were centrifuged for $15 \mathrm{~min}$ at $3.220 \times \mathrm{g}$ and the RNAprotect Bacteria Reagent was decanted.

DNA was extracted and 16S rRNA genes were amplified and sequenced as described in detail by von HoyningenHuene et al. (2019). Briefly, DNA was extracted from $250 \mathrm{mg}$ of each homogenized sediment sample or one-third of each filter with the MoBio PowerSoil DNA isolation kit (MoBio, Carlsbad, CA, USA) according to manufacturer's instructions with an adjusted cell disruption step. Bacterial 16S rRNA genes were amplified in triplicate by PCR, with the forward primer D-Bact-0341-b-S-17 and the reverse primer S-D-Bact-0785-a-A-21 (Klindworth et al., 2013) targeting the V3-V4 hypervariable regions. Primers included adapters for sequencing on an Illumina MiSeq platform. PCR triplicates were pooled equimolar and purified with MagSi$\mathrm{NGS}^{\text {PREP }}$ magnetic beads (Steinbrenner, Wiesenbach, Germany) as recommended by the manufacturer and eluted in $30 \mu \mathrm{L}$ elution buffer (EB; Qiagen, Hilden, Germany).

PCR products were sequenced with the v3 Reagent kit on an Illumina MiSeq platform (San Diego, CA, USA) as described by Schneider et al. (2017). Sequencing yielded a total of 6044032 paired-end reads, which were quality-filtered (fastp, version 0.19.4; Chen et al., 2018), merged (PEAR, version 0.9.11; J. Zhang et al., 2013) and processed. This comprised primer-clipping (cutadapt, version 1.18; Martin, 2011), size-filtering, dereplication, denoising and chimera removal (VSEARCH, v2.9.1; Rognes et al., 2016). Taxonomy was assigned to the resulting amplicon sequence variants (ASVs; Callahan et al., 2017) via BLAST 2.7.1+ against the SILVA SSU 132 NR (Quast et al., 2012). After taxonomic assignment, 2263813 merged reads remained in the dataset. The resulting ASV abundance table was used for the visualization of community gradients along the cores (von Hoyningen-Huene et al., 2019). Data were analyzed using $\mathrm{R}$ (version 3.5.2; R Core Team, 2019) and RStudio (version 1.1.463; RStudio; R Core Team, 2016) using the base packages. Extrinsic domains, archaea and eukaryotes were removed from the ASV table for analysis. All ASVs with lower identity than $95 \%$ to database entries were assigned as unclassified. Replicates for each depth were merged and transformed into relative abundances, and all ASVs with an abundance $>0.5 \%$ were summarized by their phylogenetic orders. Putative functions of all orders were assigned according to literature on cultured bacterial taxa and the closest cultured relatives of the ASVs present in our samples. For uncultured taxa, functions were inferred from literature on genomic and metagenomic sequencing data (Table S6). The resulting table with relative abundances and functional assignments was used to generate bar charts in SigmaPlot (version 11; Systat Software, 2008).

\section{Results}

\subsection{Sediment petrography and mineralogy}

The cored sediment can be divided into three different lithological units. Unit I, in the first $15 \mathrm{~cm}$ below surface (b.s.), is characterized by homogenous, light to medium grey mud with very high water content and porosity $(>65 \mathrm{wt} \%, 0.67)$. The mud consists of very fine grained carbonate and siliciclastics, largely in the clay and silt size fraction. In the thin sections of embedded mud samples, carbonates make up most of the fine-grained matrix (Fig. 2a and b). Remnants of diatoms and ostracods occur with random orientation. Detrital grains up to fine sand fraction, consisting of quartz, feldspar, mica, chlorite and carbonates, make up as much as $20 \%$ of the sediment. The detrital carbonates are distinguishable from authigenic carbonate phases by their bigger (up to mm measuring) size and fractured shape. The $\mathrm{C}_{\text {org }}$ : $\mathrm{N}_{\text {tot }}$ ratio scatters around 10 (Fig. 3), and plant detritus is evident in thin sections as particles that are opaque, up to several hundred micrometers in size, often elongated and randomly orientated (Fig. 2a and b). These can be identified in the laser scan images due to their chlorophyll-related bright fluorescence (Fig. 4a and b).

Unit II is located between 15 and $22 \mathrm{~cm}$ b.s. and appears as slightly darker, grey-colored mud without macrostructures. The microcrystalline matrix appearance is similar to Unit I; however, phytoclasts and detrital mineral grains are more abundant and up to millimeters in size, whereas the number of bioclasts remains the same. Noticeably, detrital carbonate minerals and quartz grains occur layer-like or in defined lenses (Fig. 2c and d). The component-to-matrix ratio slightly increases up to $25: 75$, and cubic, small (up to $10 \mu \mathrm{m}$ ), opaque minerals often occur intercalated with plant detritus. The $\mathrm{C}_{\text {org }}: \mathrm{N}_{\text {tot }}$ ratio also changes from 10 at $15 \mathrm{~cm}$ to 12 at $22 \mathrm{~cm}$ b.s.

Unit III occurs from 22 to $40 \mathrm{~cm}$ b.s. It is distinctly darker than the units above and shows a significant decrease in water content and porosity to $<50 \mathrm{wt} \%$ and $<0.6$, respectively. This decrease in porosity is also recognizable by a more cohesive sediment texture. Lamination is visible at the core's outer surface but not in the cut section, in which plant detritus noticeably increases. Thin sections of this unit illustrate a rather compacted matrix, a horizontal orientation of elongated phytoclasts and a layered structure with detrital mineral grains (Fig. 2e and f), further supported by the laser scan image (Fig. 4c). Ostracod or diatom fragments still occur but are less abundant than in the units above. The particle-to-matrix ratio increases up to $35: 65$, and the $\mathrm{C}_{\text {org }}: \mathrm{N}_{\text {tot }}$ ratio steadily increases from 12 to 14 through Unit III.

In scanning electron microscope (SEM) images, the matrix appears as microcrystalline aggregate of several nanometer-sized clotted crumbs (Fig. 5). Locally, rhombohedral crystals that are small, up to $1 \mu \mathrm{m}$ in scale and irregularly 

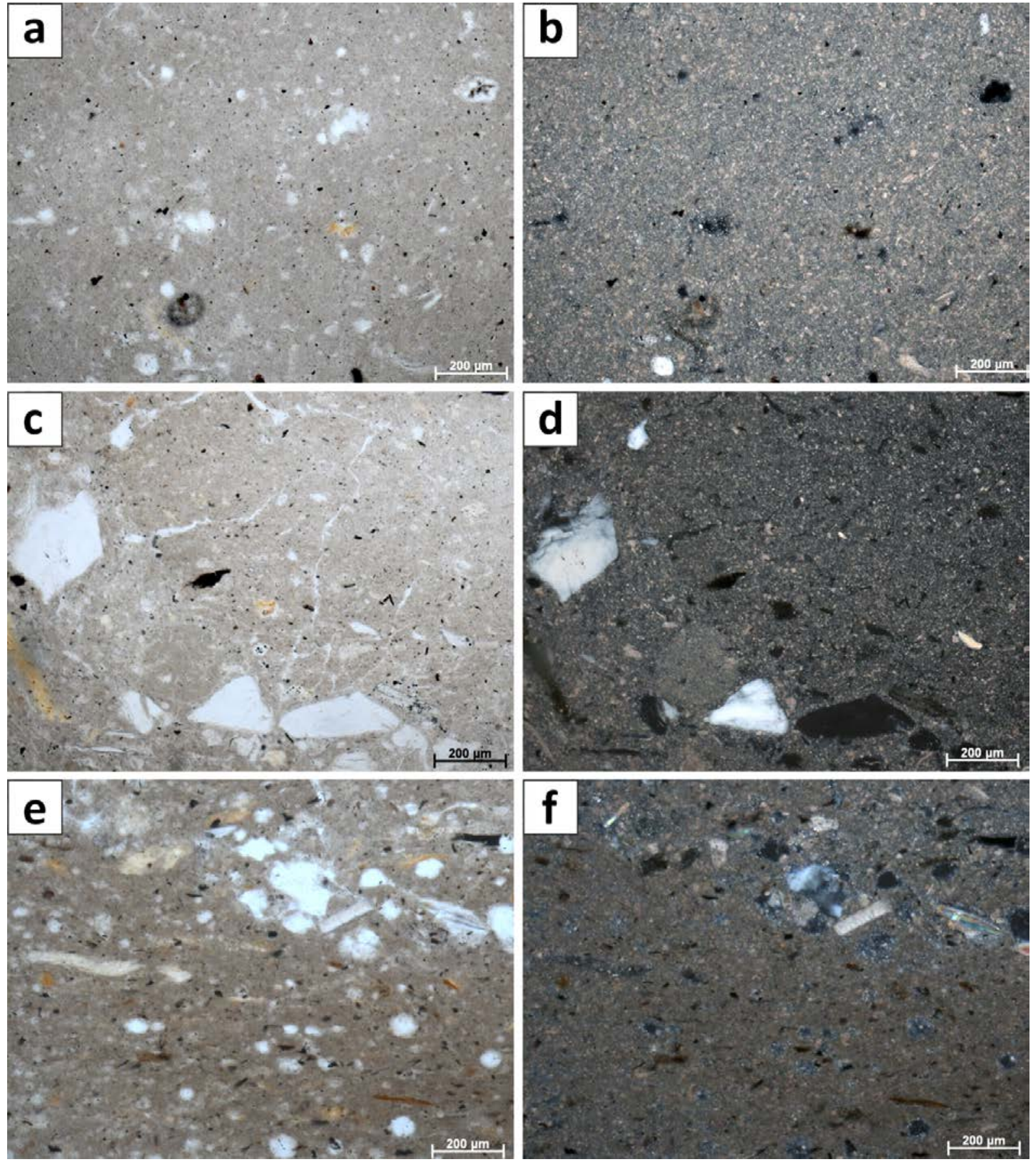

Figure 2. (a) Microfabric of Unit I at $5 \mathrm{~cm}$ depth in transmitted light. Note the randomly oriented, opaque and brownish plant particles. The microcrystalline matrix is more apparent under crossed polars (b). (c) Microfabric overview of Unit II at $17 \mathrm{~cm}$ depth. Large, up-to-fine-sandscale detrital feldspar grains occur in layers. (d) Same image section under crossed polars. (e) Microfabric of Unit III at $28 \mathrm{~cm}$, illustrating the rather compacted shape of the matrix and the elongated appearance of plant detritus. The layering is evident by the occurrence of larger detrital grains in the upper image part. (f) Same section under crossed polars.

shaped are observable. With EDX measurements, these tiny crystals were identified as $\mathrm{Ca}-\mathrm{Mg}$ carbonate phases.

According to the XRD spectra, the bulk sediment mainly consists of carbonates and quartz, with minor contributions of feldspar, clay and mica (Fig. 6). The $d_{104}$ peak shift provides a suitable approach to estimate the $\mathrm{Mg}: \mathrm{Ca}$ ratio in magnesium calcite and dolomite (Lumsden, 1979). Based on the $d_{104}$ peak positions, three carbonate phases 


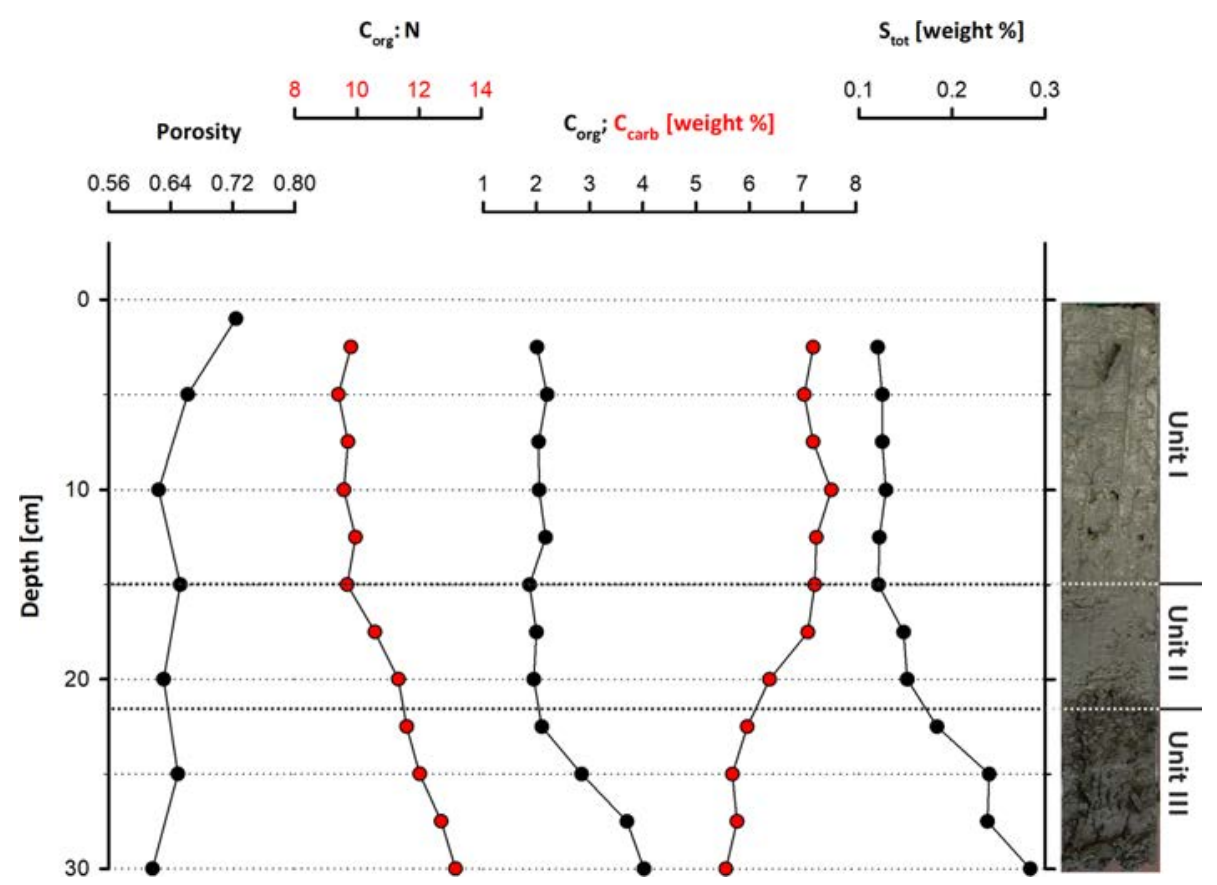

Figure 3. Geochemical parameters through Core LN-K04, showing an increasing amount of organic carbon and total sulfur and a decreasing porosity with depth.

with different $\mathrm{MgCO}_{3}$ content are present: a calcite phase with minor amounts of $\mathrm{MgCO}_{3}$, a high-magnesium-calcite phase (HMC) with circa $18 \mathrm{~mol} \% \mathrm{MgCO}_{3}$ and a very high magnesium-calcium carbonate phase (protodolomite, Fig. 6). The latter shows a 104 peak, shifted from $31^{\circ} 2 \theta$ in ordered dolomite to ca. $30.8^{\circ} 2 \theta$, indicating a $\mathrm{MgCO}_{3}$ content of approx. $45 \mathrm{~mol} \%$. Due to the fact that typical dolomite ordering peaks (i.e., 01.5 and 10.1) could not be identified in the XRD spectra, we informally define the phase as "protodolomite", i.e., a carbonate phase with a nearly $1: 1$ stoichiometry of $\mathrm{Ca}$ and $\mathrm{Mg}$, in which an incipient dolomite structure may or may not be present. Estimated relative mineral abundances vary between the three units (Fig. 7): in Unit I the amount of authigenic carbonate minerals remains relatively constant at $55 \mathrm{wt} \%$, whereas in Unit II a steep and large increase in detrital mineral phases (feldspar, quartz, calcite, mica) can be found. In Unit III the amount of $\mathrm{Ca}-\mathrm{Mg}$ carbonate minerals decreases and scatters around $40 \mathrm{wt} \%$. Mica slightly increases with depth below $23 \mathrm{~cm}$. Nevertheless, the authigenic HMC-to-protodolomite ratio does not change significantly throughout the section. Notably, neither authigenic $\mathrm{Ca}-\mathrm{Mg}$ carbonate phase shows any down-core trend in stoichiometry. $\mathrm{The} \mathrm{Mg} /(\mathrm{Ca}+\mathrm{Mg})$ ratios of distinct solid phases remain largely constant with depth (Fig. 8).

\subsection{Pore water chemistry}

The water chemistry of Lake Neusiedl is characterized by high $\mathrm{pH}$ values (9.02) and moderate salinity $(1.8 \%$ ). Sodium $\left(\mathrm{Na}^{+}\right)$and magnesium $\left(\mathrm{Mg}^{2+}\right)$ are the major cations, with concentrations of 14.3 and $5.1 \mathrm{mmol} \mathrm{L}^{-1}$, respectively. Calcium $\left(\mathrm{Ca}^{2+}\right)$ concentration is considerably lower, at $0.3 \mathrm{mmol} \mathrm{L}^{-1}$. Total alkalinity (TA) measures $11.2 \mathrm{meq}^{-1}$, whereas other major anions like chloride $\left(\mathrm{Cl}^{-}\right)$and sulfate $\left(\mathrm{SO}_{4}^{2-}\right)$ hold a concentration of 7 and $4 \mathrm{mmol} \mathrm{L}^{-1}$, respectively. Nutrient $\left(\mathrm{NH}_{4}^{+}, \mathrm{NO}_{2}^{-}, \mathrm{PO}_{4}^{3-}, \Sigma \mathrm{H}_{2} \mathrm{~S}, \mathrm{SiO}_{2(\mathrm{aq})}\right)$ concentrations lie below $0.004 \mathrm{mmol} \mathrm{L}^{-1}$.

The pore water chemistry strongly differs between the sediment and the water column. The $\mathrm{pH}$ drops significantly at the water-sediment interface to a value around 7.5, which stays constant throughout the sediment core (Fig. 9a). The entire section is anoxic, with a redox potential of $-234 \mathrm{mV}$ at the top, which increases to $-121 \mathrm{mV}$ at the bottom (Fig. 9b). $\mathrm{Na}^{+}$and $\mathrm{Cl}^{-}$contents continuously increase with depth, from 14 to 20 and from 7 to $8.8 \mathrm{mmol} \mathrm{L}^{-1}$, respectively (Fig. 9a). $\mathrm{Mg}^{2+}$ and $\mathrm{Ca}^{2+}$ show a different pattern: from 5 to $10 \mathrm{~cm}$ depth, the $\mathrm{Mg}^{2+}$ content decreases from 5 to $4 \mathrm{mmol} \mathrm{L}^{-1}$, whereas the $\mathrm{Ca}^{2+}$ content increases from 0.5 to $0.6 \mathrm{mmol} \mathrm{L}^{-1}$ in the same increment. From $10 \mathrm{~cm}$ downwards, the $\mathrm{Mg}^{2+}$ content scatters around $4 \mathrm{mmolL}^{-1}$ and the $\mathrm{Ca}^{2+}$ content decreases from 0.6 to below $0.5 \mathrm{mmol} \mathrm{L}^{-1}$ (Fig. 9a). Dissolved $\mathrm{SO}_{4}^{2-}$ and hydrogen sulfide $\left(\Sigma \mathrm{H}_{2} \mathrm{~S}\right)$ also show a noticeable trend: the $\Sigma \mathrm{H}_{2} \mathrm{~S}$ content is close to zero in the top $5 \mathrm{~cm}$ of the sediment column, rapidly increases to $1 \mathrm{mmol} \mathrm{L}^{-1}$ between 5 and $10 \mathrm{~cm}$ b.s., and remains constant to the bottom of the section. $\mathrm{SO}_{4}^{2-}$ follows an opposite trend. Its concentration decreases from 4 to $1 \mathrm{mmol} \mathrm{L}^{-1}$ in the upper $10 \mathrm{~cm}$ b.s. and remains constant at $1 \mathrm{mmol} \mathrm{L}^{-1}$ towards the section bottom. Total alkalinity also increases towards the 

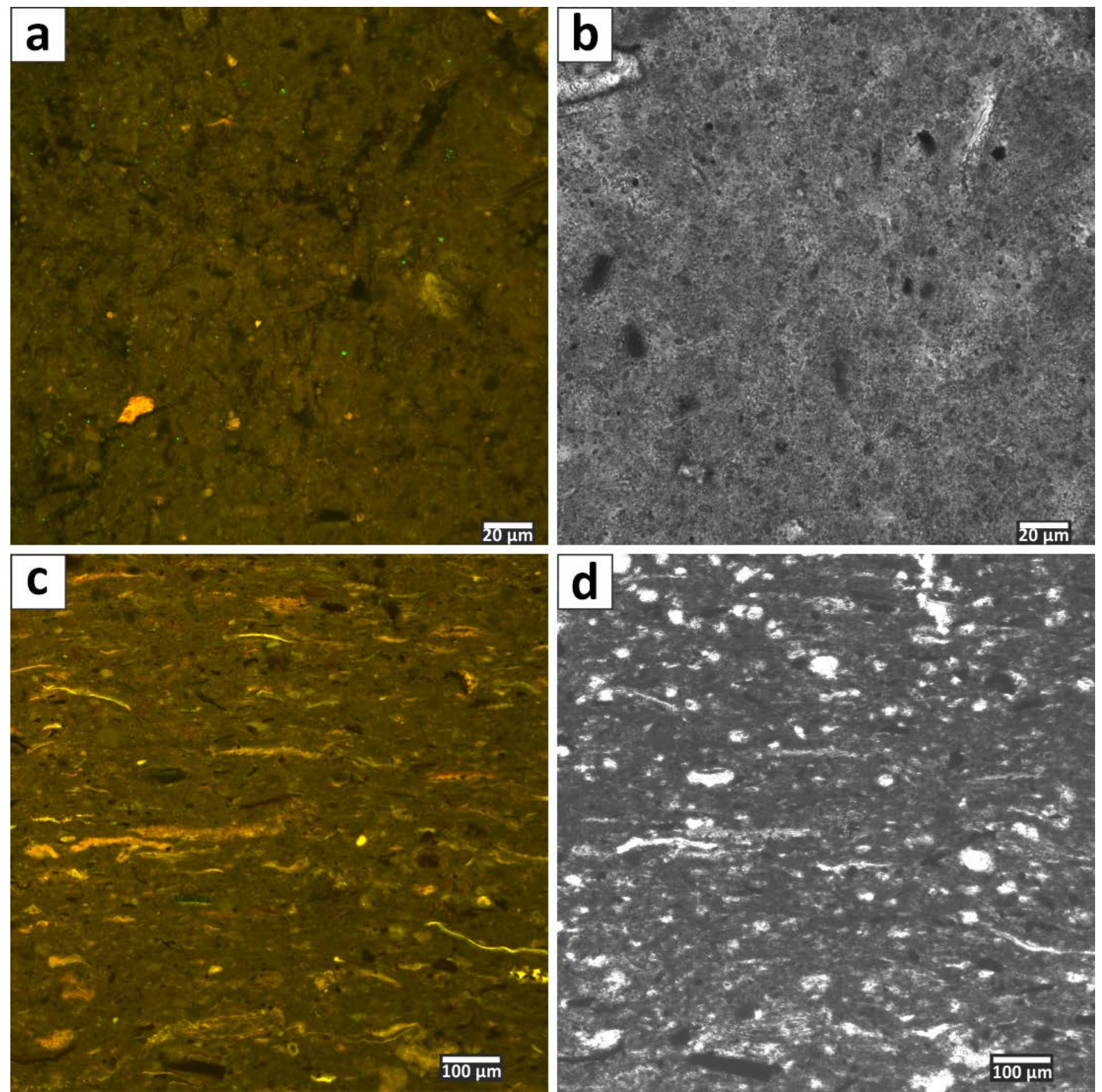

Figure 4. (a) Laser scanning micrograph (excitation $365 \mathrm{~nm}$; emission 397-700 nm) of Unit I microfabric at $2 \mathrm{~cm}$ depth. The small and randomly orientated plant particles show bright fluorescence due to their chlorophyll content. (b) Same section in transmitted light. (c) Fluorescent texture of Unit III (at $28 \mathrm{~cm}$ depth) is visible. The higher amount of plant detritus, particle layering and a compacted matrix are notable. Voids are resin-embedding artifacts. (d) Same section as in (c) but under transmitted light.

lower part of the section, from 11.2 to $16.8 \mathrm{meq} \mathrm{L}^{-1}$, with an increase between 5 and $15 \mathrm{~cm}$ depth.

$\mathrm{NO}_{2}^{-}$is present in the upper $10 \mathrm{~cm}$ of the core and reaches its highest value $\left(0.9 \mu \mathrm{mol} \mathrm{L}{ }^{-1}\right)$ at $2 \mathrm{~cm}$ b.s., while its concentration decreases to zero below $10 \mathrm{~cm}$ b.s. Dissolved iron $\left(\mathrm{Fe}^{2+}\right)$ has a similar trend in the upper $10 \mathrm{~cm}$ b.s., reaching its highest concentration at a depth of $2 \mathrm{~cm}$ $\left(1.4 \mu \mathrm{mol} \mathrm{L}^{-1}\right)$. Below $10 \mathrm{~cm}$ core depth, iron concentrations lie below $0.3 \mu \mathrm{mol} \mathrm{L}-1$, with the exception of an outlier value of $0.5 \mu \mathrm{mol} \mathrm{L}^{-1}$ at $13 \mathrm{cmb}$.s. Concentrations of ammonia
$\left(\mathrm{NH}_{4}^{+}\right)$and phosphate $\left(\mathrm{PO}_{4}^{2-}\right)$ increase with depth. In the uppermost part of the sediment column, they are close to zero and increase to 0.37 and $0.02 \mathrm{mmol} \mathrm{L}^{-1}$ at $13 \mathrm{~cm}$. These values remain constant to the bottom of the core. Dissolved silica shows a curved profile with $0.3 \mathrm{mmol} \mathrm{L}^{-1}$ at the top, reaching a maximum at $15 \mathrm{~cm}$ depth with $0.8 \mathrm{mmol} \mathrm{L}^{-1}$, and declines to concentrations around $0.5 \mathrm{mmol} \mathrm{L}^{-1}$. Methane $\left(\mathrm{CH}_{4}\right)$ concentration also shows a curved trend, reaching its highest value of $227 \mu \mathrm{mol} \mathrm{L}^{-1}$ at a depth of $20 \mathrm{~cm}$ and concentrations between 14 and $64 \mu \mathrm{mol} \mathrm{L}{ }^{-1}$ close to the sedi- 

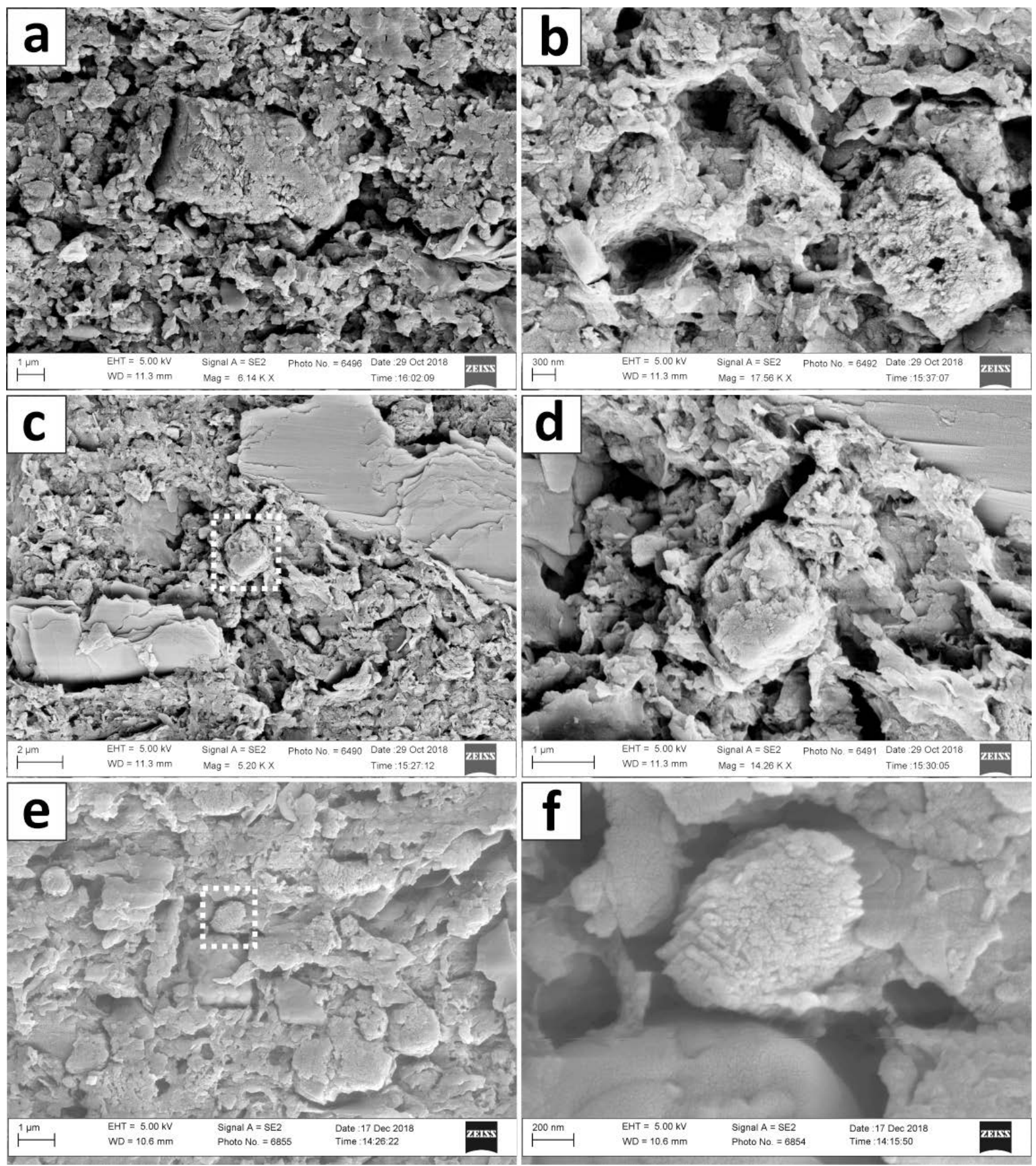

Figure 5. SEM images of Core LN-K 05, showing the crystal morphology of Ca-Mg phases with increasing depth. (a) HMC or protodolomite crystal at $9 \mathrm{~cm}$ depth. (b) Aggregate of $3 \mathrm{HMC}$ or protodolomite crystals at $17 \mathrm{~cm}$ depth. (c) Matrix overview containing microcrystalline crumbs, layered mica crystals and a HMC or protodolomite rhombohedron (indicated by dashed rectangle) at $17 \mathrm{~cm}$ depth. (d) Detail of rhombohedron visible in (c). (e) Matrix overview in $27 \mathrm{~cm}$ depth. HMC and protodolomite carbonate crystals appear rather xenomorphic (indicated by dashed rectangle). (f) Close-up of HMC and protodolomite crystal accentuated in (e). Images produced with a ZEISS Gemini Leo 1530. 

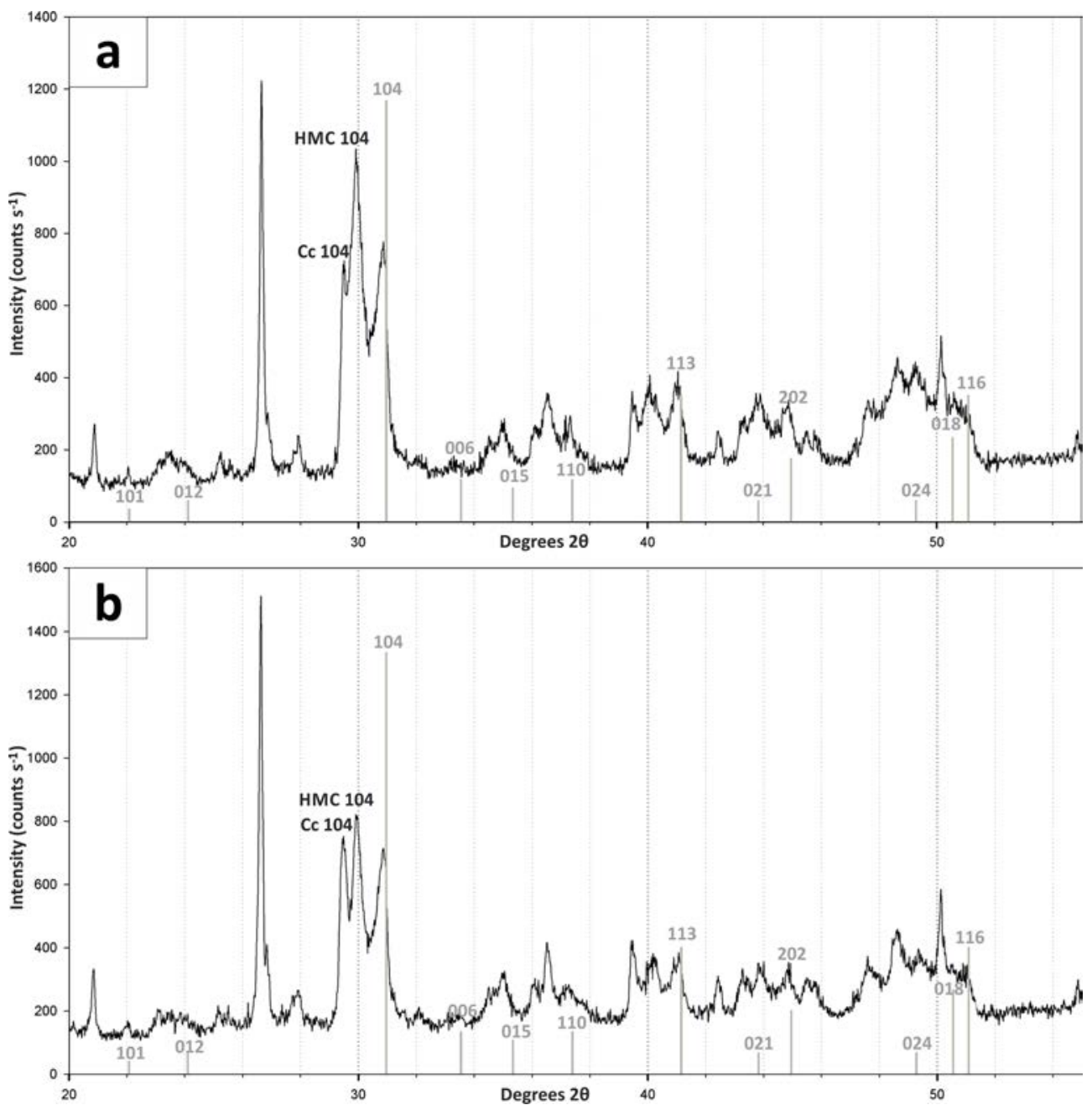

Figure 6. X-ray diffractograms of bulk Lake Neusiedl sediment (a) from $2 \mathrm{~cm}$ and (b) from $27.5 \mathrm{~cm}$ depth. Positions of dolomite peaks are marked in grey. Position of major calcite (Cc 104) and high-magnesium-calcite (HMC 104) peaks are also indicated. Note that typical dolomite ordering peaks could not be identified in the XRD spectra. Furthermore, a figure and a list containing major peaks of identified mineral phases is provided in the Supplement.

ment surface ( 5 and $1 \mathrm{~cm}$, respectively). Dissolved inorganic carbon (DIC) increases from $11.71 \mathrm{mmol} \mathrm{L}^{-1}$ at the top to $18.01 \mathrm{mmol} \mathrm{L}^{-1}$ at $30 \mathrm{~cm}$ depth. Only in the 15 to $20 \mathrm{~cm}$ increment does the amount of DIC slightly decrease, from 15.37 to $14.94 \mathrm{mmol} \mathrm{L}^{-1}$.

According to PHREEQC calculations, the water column at the sampling site (bay of Rust) is supersaturated with respect to aragonite $(\mathrm{SI}=0.92)$, calcite $(\mathrm{SI}=1.07)$, protodolomite $(\mathrm{SI}=2.92)$ and dolomite $(\mathrm{SI}=3.46$; Fig. 10$)$. Sediment pore water is close to equilibrium throughout the whole section with respect to aragonite, whereas calcite is in equilibrium to slightly supersaturated between 10 and $27.5 \mathrm{~cm}$ depth. Protodolomite reaches equilibrium between 2.5 and $5 \mathrm{~cm}$, while dolomite is supersaturated in the entire section. It should be noted that all saturation graphs reveal parallel trends, with their highest saturation at $17.5 \mathrm{~cm}$ and their lowest at $2.5 \mathrm{~cm}$ depth.

\subsection{Bacterial community composition}

Bacterial 16S rRNA gene analysis revealed the presence of a diverse bacterial community, with 1226 amplicon sequence variants (ASVs) clustered at $100 \%$ sequence identity within the water column, 2085 to $2467 \mathrm{ASVs}$ in the top $20 \mathrm{~cm}$ of the sediment core and 1417 to 1581 ASVs in the deeper sediment $(20-35 \mathrm{~cm}$ core depth). The different bacterial taxa were grouped by known metabolic properties of characterized relatives, listed in Whitman (2015) and additional literature (see Supplement). The distribution of the most abundant bacterial taxa differs between the water column and the sediment (Fig. 11a and b).

The water column is dominated by aerobic heterotrophs, mainly Alphaproteobacteria and Actinobacteria, which are only of minor abundance in the sediment. Among the Alphaproteobacteria, the SAR11 clade capable of oxidizing C1 


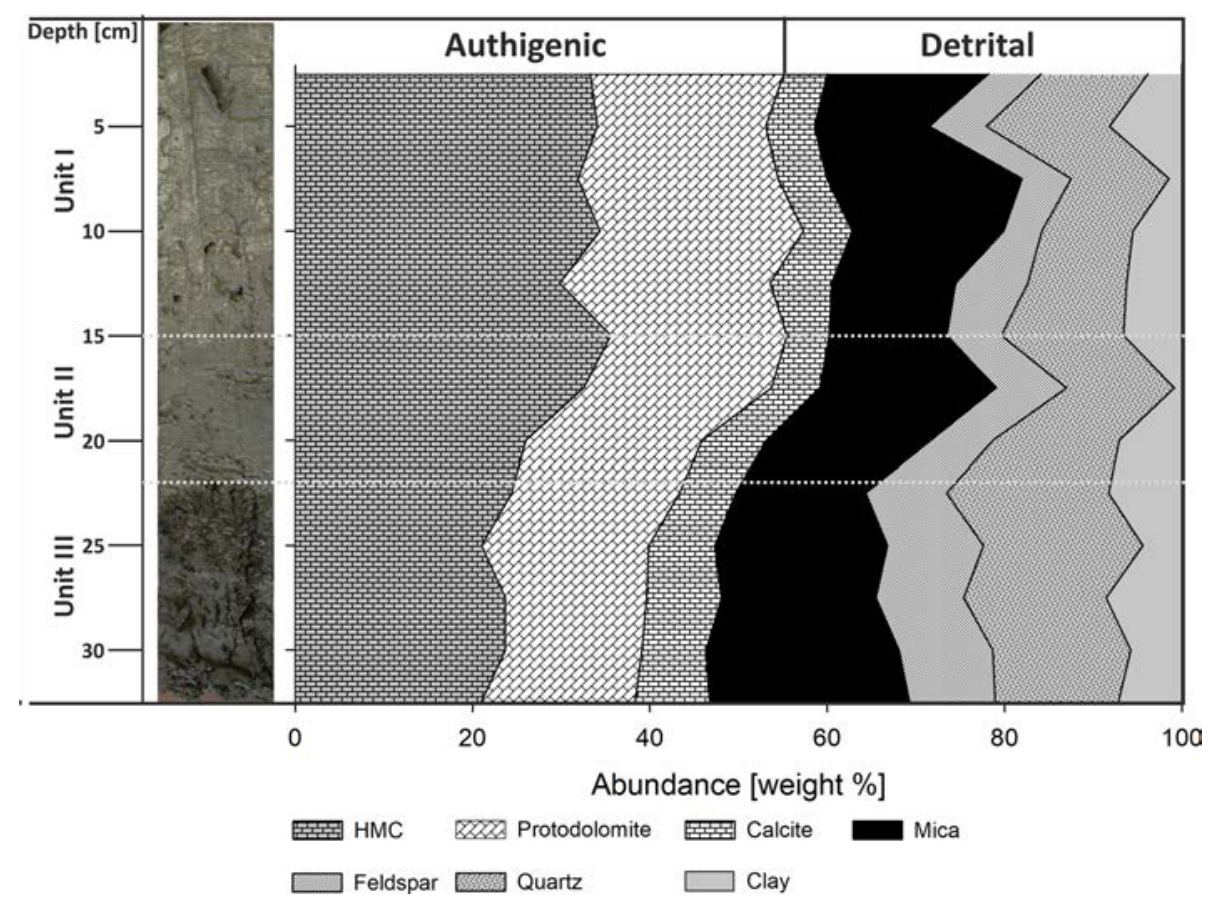

Figure 7. Core LN-K04 with the defined units I-III (left) and mineral quantities estimated from main peak heights (right; HMC: highmagnesium calcite). The changes of mineral abundances coincide with unit boundaries.

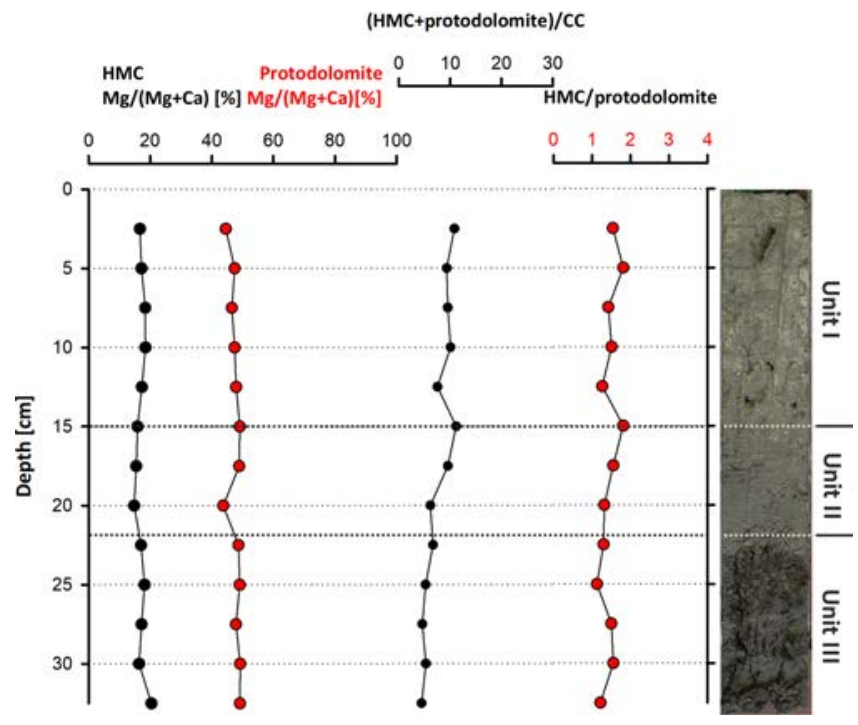

Figure 8. Stoichiometric compositions of authigenic carbonate phases (HMC and protodolomite), their abundance ratio and their relation to detrital calcite.

compounds (Sun et al., 2011) is predominant. The nitrogenfixing Frankiales are the most abundant representatives of the Actinobacteria. Furthermore, coccoid cyanobacteria (Synechococcales) and Bacteroidetes are present in high relative abundances in the water column.
Within sediment Unit I (0-15 cm b.s.), the bacterial community composition changes to mainly anaerobic and facultatively anaerobic taxa. Only the uppermost $5 \mathrm{~cm}$ shows increased relative abundances of cyanobacteria (Synechococcales) and Bacteroidetes (aerobes and facultative anaerobes; Alderkamp et al., 2006; Flombaum et al., 2013) as well as Verrucomicrobia (mostly aerobic and facultative anaerobic heterotrophs; He et al., 2017), which include nitrogen-fixing members (Chiang et al., 2018). Besides these groups, Gammaproteobacteria, Acidobacteria, Chloroflexi and sulfate-reducing Deltaproteobacteria are abundant. Deltaproteobacteria mainly consist of Desulfobacteraceae and Desulfarculales (Fig. 11c and d).

In sediment Unit II $(15-22 \mathrm{~cm}$ b.s. $)$, the relative proportions of these groups show a transition between sediment unit I and III. While Gammaproteobacteria, Acidobacteria and Deltaproteobacteria are still abundant, the relative abundance of Chloroflexi increases strongly from $24.29 \%$ to $35.43 \%$. Within the SRB, Desulfobacteraceae and Desulfarculales are successively replaced by Deltaproteobacteria of the Sva0485 clade. The Syntrophobacterales show their maximum relative abundance within sediment Unit II.

In sediment Unit III $(22-40 \mathrm{~cm}$ b.s. $)$, the abundance of Chloroflexi further increases to form the dominant bacterial phylum. The phylum consists of Dehalococcoidia and Anaerolineae. Other abundant groups in this unit are Acidobacteria, Gammaproteobacteria and Deltaproteobacteria of the Sva0485 clade. Further details of the microbial com- 

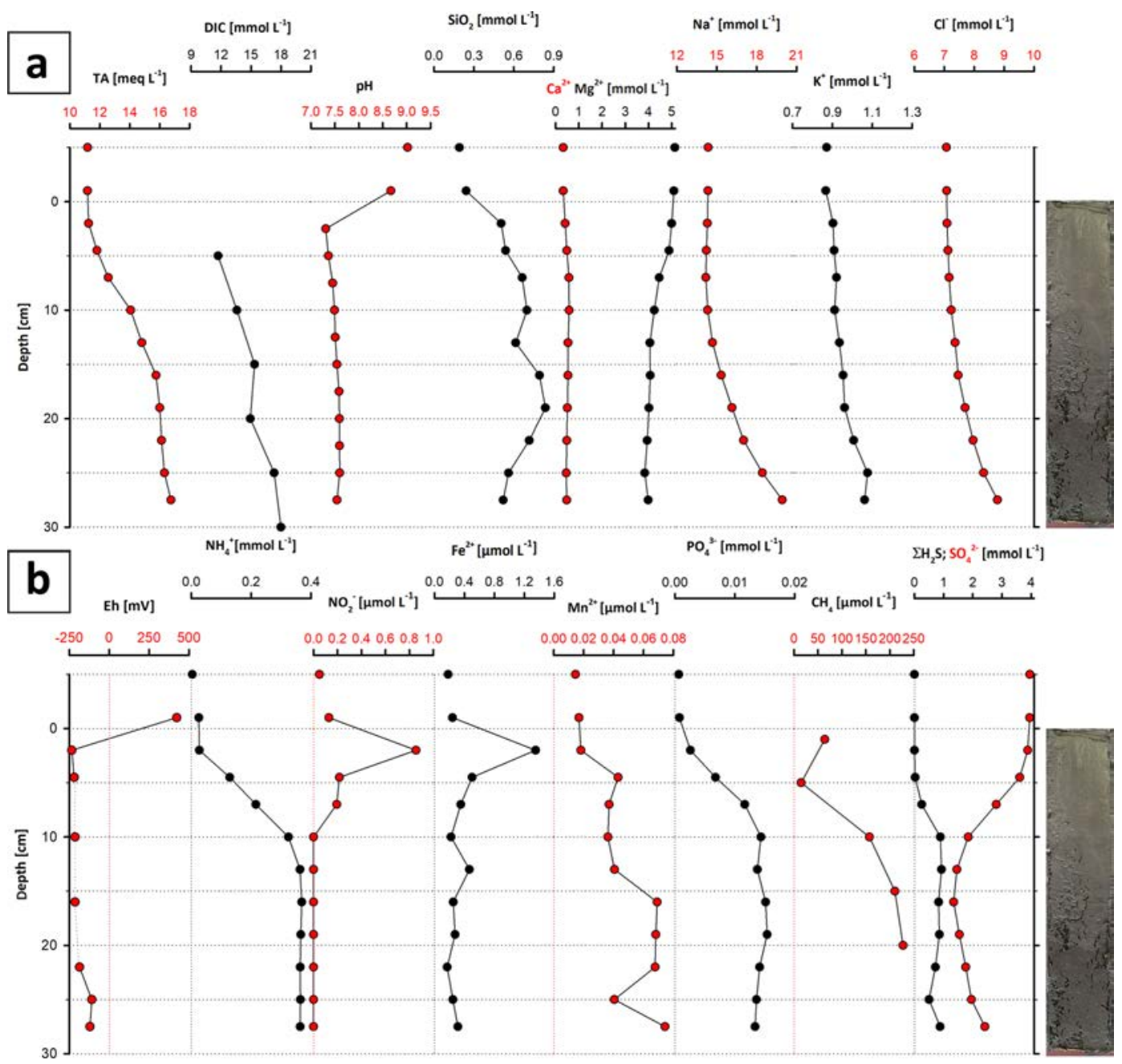

Figure 9. Major ion (a) and metabolite concentrations (b) in the pore water of core LN-K03. Note that the sample slightly above $0 \mathrm{~cm}$ depth represents the supernatant water, and the top data points represent the water column (see text for explanations).

munity composition are given in von Hoyningen-Huene et al. (2019).

\section{Discussion}

\subsection{Pore water gradients and their effect on $\mathrm{Ca}-\mathrm{Mg}$ carbonate supersaturation}

Concentrations of the conservative trending ions $\mathrm{Na}^{+}, \mathrm{K}^{+}$ and $\mathrm{Cl}^{-}$steadily increase towards the bottom of the core section, reaching 19,1 and $9 \mathrm{mmol} \mathrm{L}^{-1}$, respectively. These concentrations are considerably higher than in the water column, where these ions measure 14, 0.9 and $7 \mathrm{mmol} \mathrm{L}^{-1}$. Moreover, $\mathrm{SO}_{4}^{2-}$ shows an increase near the bottom of the core and is reported to further increase to values of $6.5 \mathrm{mmol} \mathrm{L}^{-1}$ in a longer section from a different locality in the bay of Rust (not shown in this study), which is higher than the overlying lake water $\left(3.9 \mathrm{mmol} \mathrm{L}^{-1}\right)$. This rise in ion concentration indicates an ion source below the sampled interval. While saline deep ground waters are known to be present in deep aquifers (Neuhuber, 1971; Blohm, 1974; Wolfram, 2006), it is also possible that more highly concentrated brine exists in deeper mud layers due to more recent evaporation events (Fig. 12). Lake Neusiedl dried out entirely between 1865 and 1875 (Moser, 1866), and high ion concentrations may relate to thin evaporite layers and brine that formed during this event.

The cause of the exceptionally high $\mathrm{Mg}$ : Ca ratio, which reaches values around 15 in the water column, is not yet entirely understood. The low $\mathrm{Ca}^{2+}$ concentrations in Lake Neusiedl can be linked to calcium carbonate formation (e.g., Wolfram and Herzig, 2013), but the high amounts of $\mathrm{Mg}^{2+}$ ions and their source remain elusive. Boros et al. (2014) describe similar phenomena in small alkaline lakes of the western Carpathian plain and relate the high magnesium levels to 


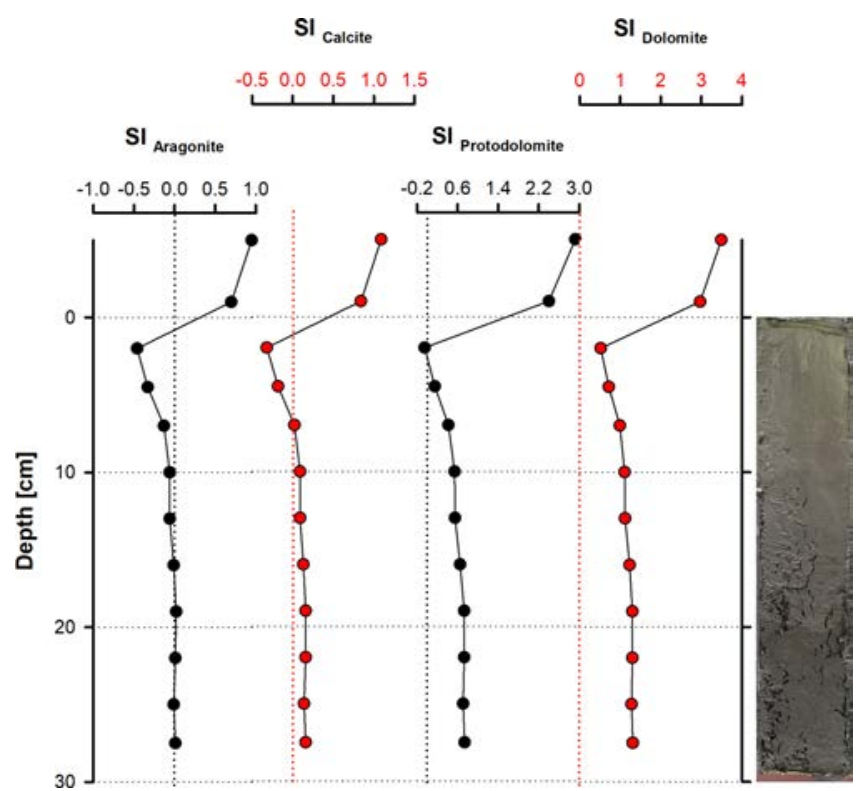

Figure 10. Saturation indices (SIs) of selected carbonate mineral phases. It can be noted that all phases are clearly supersaturated in the water column but close to saturation throughout most of the sediment column (except for the uppermost $10 \mathrm{~cm}$ ).

local hydrogeological conditions and the geological substrate of the lakes.

It should be noted that the $\mathrm{Mg}$ : Ca ratio reaches values around 7 in the $5-10 \mathrm{~cm}$ increment of the pore water section. This is caused by a considerable decrease in the $\mathrm{Mg}^{2+}$ ions in this increment (from 5 to $4 \mathrm{mmol} \mathrm{L}^{-1}$ ) and an increase in $\mathrm{Ca}^{2+}$ concentration (from 0.3 to $0.5 \mathrm{mmol} \mathrm{L}^{-1}$ ). This effect can be partly explained by a transition zone between lake and pore water in this section, in which the concentration gradient is balanced. Other factors contributing to this concentration shift may include ion exchange, e.g., with $\mathrm{NH}_{4}^{+}$generated in the pore water at clay minerals (von Breymann et al., 1990; Celik et al., 2001). However, in the case of Lake Neusiedl, the $\mathrm{NH}_{4}^{+}$concentration is not sufficient to explain this change within the $\mathrm{Mg}$ : Ca ratio. Another factor causing the decrease in $\mathrm{Mg}^{2+}$ concentrations may be the supply of dissolved silica for the precipitation of clay mineral precursor phases (Birsoy, 2002). Increasing $\mathrm{SiO}_{2}$ concentration with depth indicates the dissolution of diatom frustules, which have been observed in thin sections of the present study. It is not entirely clear if this $\mathrm{SiO}_{2}$ release into the pore water is related to hydrochemical or biogenic parameters. As the $\mathrm{SiO}_{2}$ increase in the upper $20 \mathrm{~cm}$ of the pore water neither clearly correlates with alkalinity nor with the salinity gradients (concentrations of conservative ions), and $\mathrm{pH}$ is not predictive (Ryves et al., 2006), diatom dissolution by an evident chemical undersaturation (saturation indices of amorphous $\mathrm{SiO}_{2}$ lie between -1.35 and -0.65 ) may be not the only driver for the $\mathrm{SiO}_{2}$ release. It is also conceivable that the enhanced silica release in the pore water is caused by bacteria, which attack the organic matrix of diatom frustules and, thus, expose the silica-bearing skeletons to chemical undersaturation (Bidle and Azam, 1999). Bidle et al. (2003) have linked enhanced dissolution potential to uncultured Gammaproteobacteria. This phylum showed increased abundances in the upper sediment column, supporting the hypothesis of a biogenic contribution to diatom dissolution and, hence, the provision of $\mathrm{SiO}_{2}$ to sequester $\mathrm{Mg}^{2+}$ (Fig. 12; Eq. 5) in Lake Neusiedl's pore waters.

\subsection{Microbial activity and carbonate saturation}

Microbial metabolic reactions strongly affect pore water chemistry, particularly $\mathrm{pH}$, alkalinity and hence carbonate mineral saturation state. In the present approach, the assessment of bacterial community composition is based on the metagenomic DNA within the sediment. This contains the active bacterial communities at their current depth as well as deposited, dormant or dead cells that originated in the water column or at shallower sediment depth (More et al., 2019). In the present study, a background of dormant or dead cells is evident through ASVs belonging to strict aerobes (e.g., Rhizobiales, Gaiellales) that were detected within deeper parts of the anaerobic mud core (Figs. 11, 12 and 13; Supplement Table S5).

The water column is characterized by aerobic heterotrophs, including $\mathrm{C} 1$ oxidizers (SAR11 clade of the Alphaproteobacteria) and highly abundant freshwater Actinobacteria. These are common in most freshwater environments. An impact on carbonate mineral saturation or nucleation, however, is unknown, as their role in the biogeochemical cycles remains largely undescribed (Neuenschwander, et al., 2018). A high abundance of cyanobacteria of the Synechococcales is present in the water column. Synechococcales are known to create favorable conditions for carbonate nucleation in alkaline environments by raising the $\mathrm{pH}$, photosynthetic metabolism and the complexation of cations at their cell envelopes (Thompson and Ferris, 1990). Further research is required to verify their potential role in HMC or protodolomite formation in Lake Neusiedl.

In sediment Unit I ( $0-15 \mathrm{~cm}$ b.s.) Synechococcales as well as aerobic Bacteroidetes are still abundant in the top $5 \mathrm{~cm}$, likely due to the sedimentation of their cells from the water column. The uppermost measurement at $2.5 \mathrm{~cm}$ depth revealed reducing conditions and a low, close-to-neutral $\mathrm{pH}$. This supports heterotrophic metabolisms and fermentation by Gammaproteobacteria, Acidobacteria, Chloroflexi and Deltaproteobacteria, which are the major taxa at this depth. At the very top of the sediment, a peak in $\mathrm{NO}_{2}^{-}$and $\mathrm{Fe}^{2+}$ points to nitrate reduction and $\mathrm{Fe}^{3+}$ reduction (Kotlar et al., 1996; Jørgensen and Kasten, 2006). Farther below, the successive increase in $\mathrm{NH}_{4}^{+}$and $\mathrm{PO}_{4}^{3-}$ reflects anaerobic bacterial decomposition of organics, consistent, for example, with 


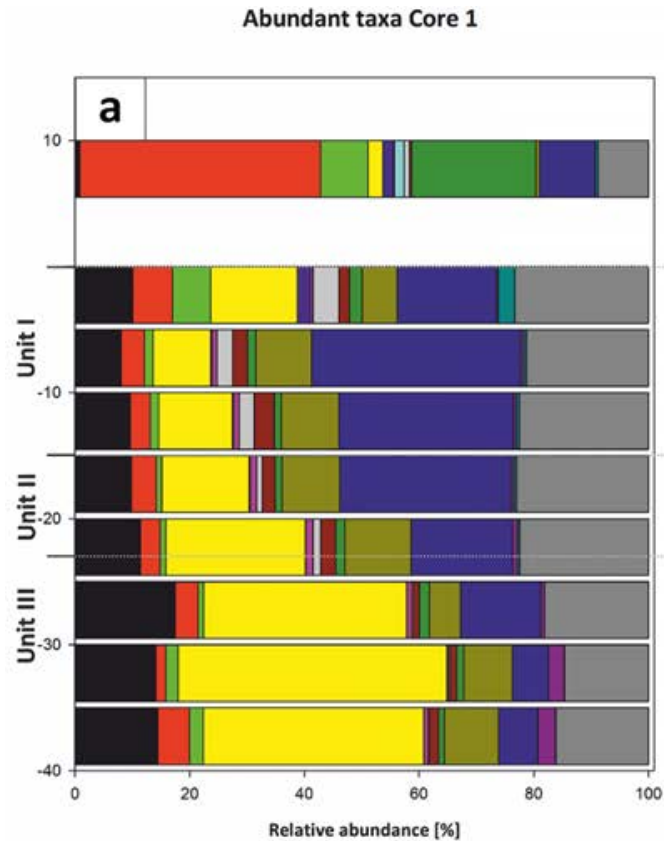

Sulfate-reducing bacteria Core 1

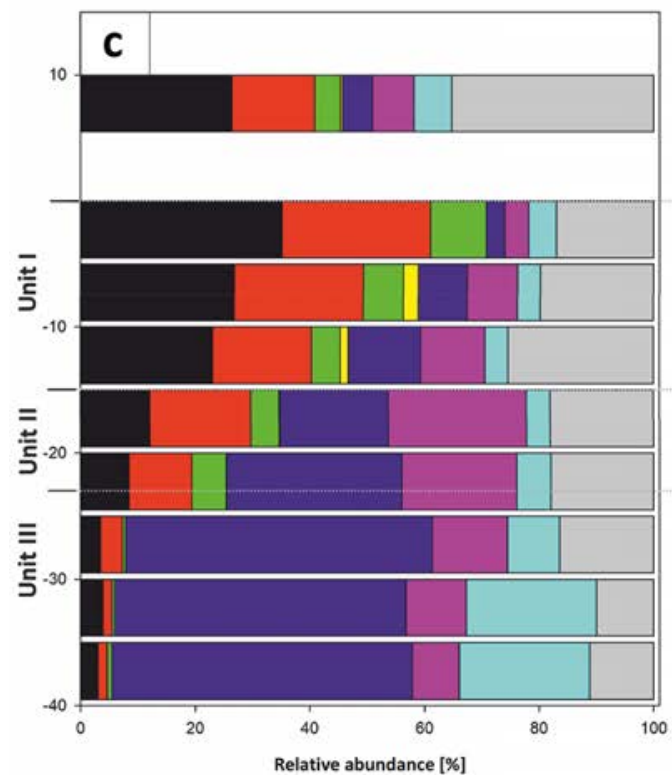

Abundant taxa Core 2

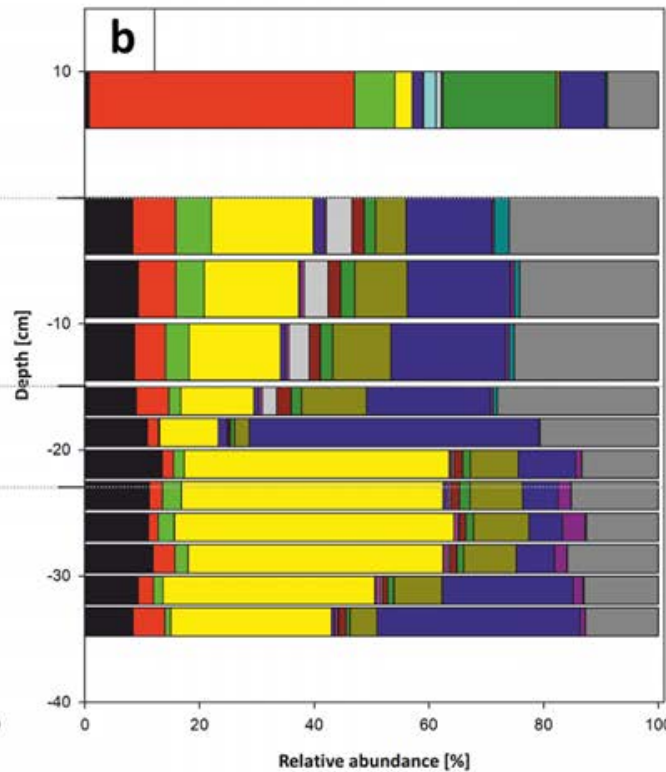

Sulfate-reducing bacteria Core 2

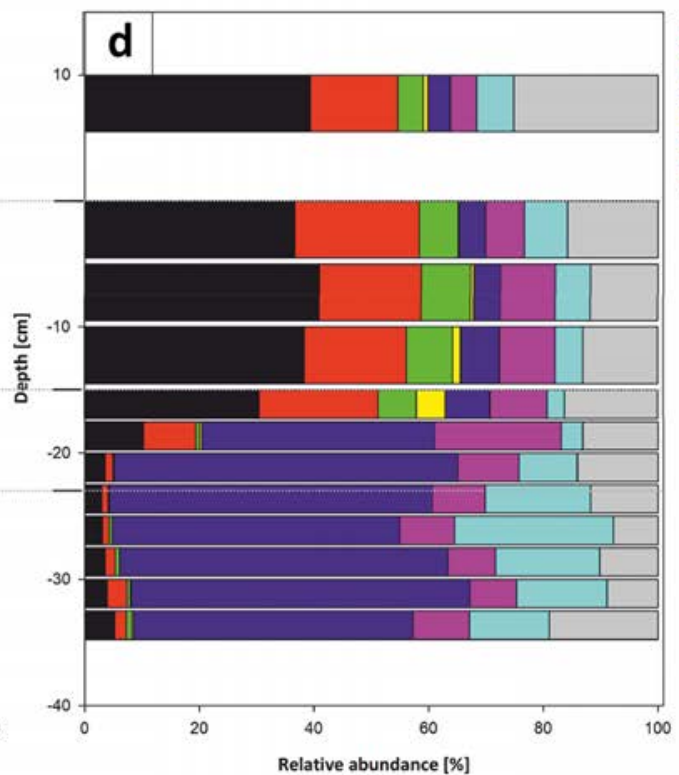

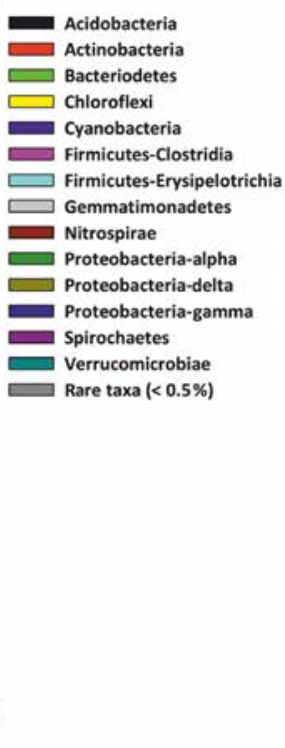

Actinobacteria

Firmicutes-Clostrid

micutes-Erysipelotrichia

Gemmatimonadetes

Proteobacteria-delta

Proteobacteria-gamm

Spirochaetes

Verrucomicrobiae

Rare taxa $(<0.5 \%)$

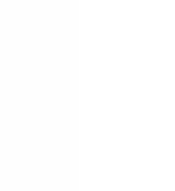

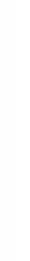

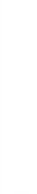




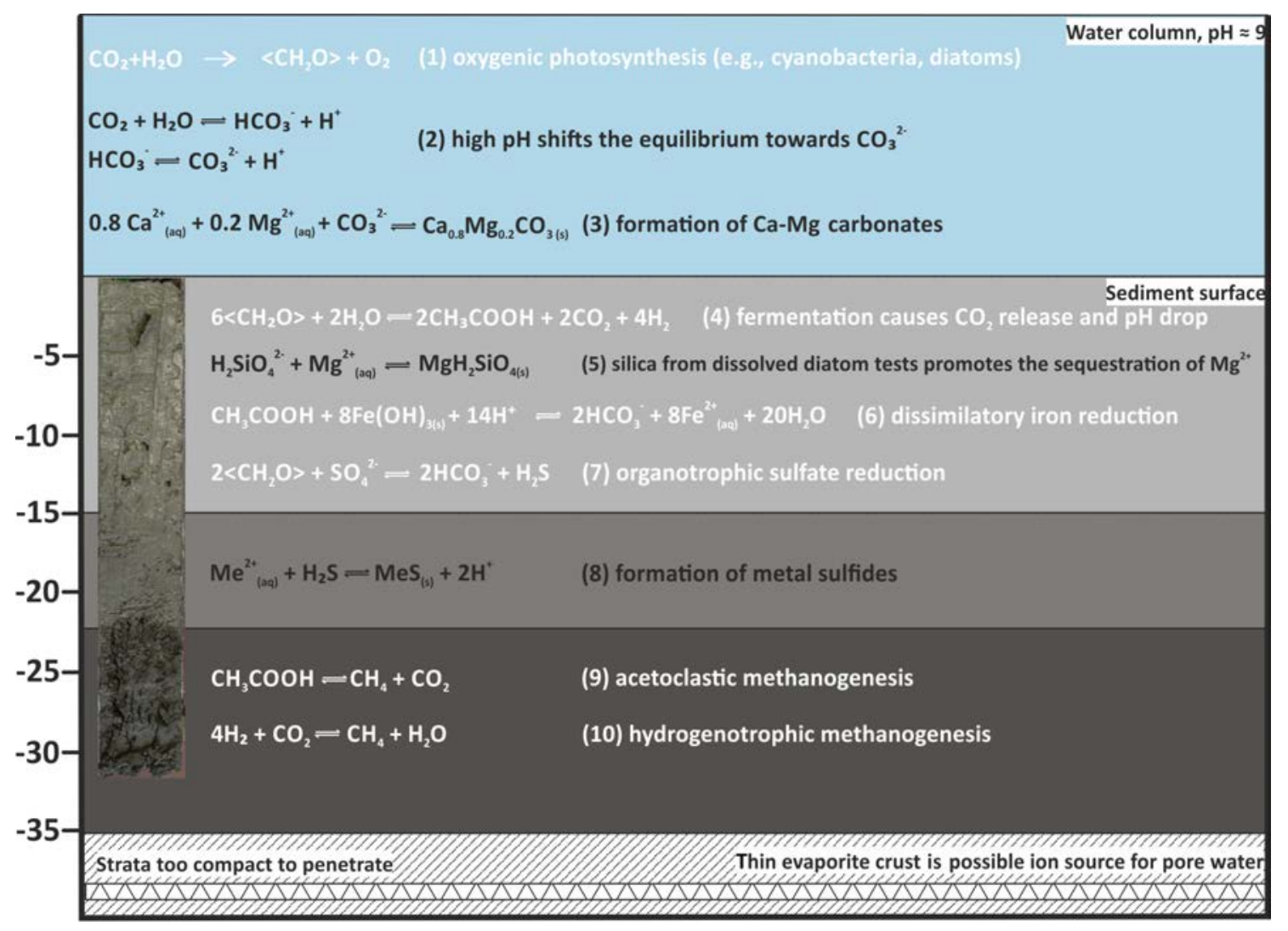

Figure 12. Suggested major microbial (simplified, indicated in white) and geochemical processes in water and sediment column of Lake Neusiedl.

at values between 6 and 7. As a consequence, the saturation index for carbonate minerals concomitantly drops. If a sufficient amount of sulfate is reduced $\left(>10 \mathrm{mmol} \mathrm{L}^{-1}\right)$, the saturation level recovers and may slightly surpass initial conditions (Meister, 2013). Only when sulfate reduction is coupled to anaerobic oxidation of methane (AOM) would the effect of both raise the $\mathrm{pH}$ to higher values. However, as methane occurs below $10 \mathrm{~cm}$ (Fig. 10), where $\mathrm{SO}_{4}^{2-}$ is still present, $\mathrm{AOM}$ is incomplete or absent.

In sediment Unit II (15-22 cmb.s.) and Unit III (22$40 \mathrm{~cm}$ b.s.), the bacterial community composition shifts towards a high abundance of Chloroflexi (Dehalococcoidia and Anaerolineae), known for their involvement in carbon cycling as organohalide respirers and hydrocarbon degraders (Hug et al., 2013). This change may reflect an increase in poorly degradable organic electron donors and hence plant debris in the laminated core Unit III. The change in the relative composition of different orders within the SRB (i.e., change from Desulfobacterales and Desulfarculales to Sva0485 and Spirochaetales) may also be related to a change in available organic substrates. In total, sulfate reduction remains high, also recognizable by the occurrence of opaque (sulfide) mineral spots and the increase in $\mathrm{S}_{\text {tot }}$ in the lower part of the section (Figs. 2e, 3). Fermentation and sulfate re- duction remain high with increasing depth, indicated by the near-neutral $\mathrm{pH}$ and raised alkalinity at low carbonate mineral saturation.

\subsection{Time and depth of carbonate formation}

A significant difference in saturation state between the water column and the sediment is evident. Whilst the water column is supersaturated with respect to aragonite, HMC, protodolomite and dolomite, they are close to equilibrium in the pore water. The downward shift of saturation from the water column to the pore water is to be expected due to the onset of anaerobic, heterotrophic metabolic activity (Fig. 12; Eq. 4).

The absence of aragonite at Lake Neusiedl is not entirely clear, as its formation is commonly linked to an interplay between high temperature, mineral supersaturation and $\mathrm{Mg}: \mathrm{Ca}$ ratios (Fernández-Díaz et al., 1996; Given and Wilkinson, 1985). Based on precipitation experiments by De ChoudensSanchez and Gonzalez (2009), which include temperatures of $19.98{ }^{\circ} \mathrm{C}$ and $\mathrm{Mg}$ : Ca ratios up to 5, aragonite would be the favored phase in Lake Neusiedl, as the lake's $\mathrm{Mg}$ : Ca ratio of 15 is too high and the concomitant calcite saturation not sufficient to provide calcite growth. However, the mentioned experiments were performed in a precipitation chamber with 
degassing conditions and hence reduced $\rho \mathrm{CO}_{2}$, which makes them incomparable to the present study. In contrast, Niedermayr et al. (2013) observed the preferential formation of calcite at high $\mathrm{Mg}$ : Ca ratios when an amino acid (polyaspartic acid) is present. As the water column bears numerous bacterial species (Fig. 11) and potentially comparable organic compounds, this is a likely scenario for Lake Neusiedl. Nevertheless, the precise evaluation of why aragonite is not present is impossible, as no related analytical data from the water column are available.

According to Löffler (1979), magnesium calcite forms first, which is then altered into protodolomite. The alteration takes place from the inside, hence resulting in a protodolomite core and a HMC rim. However, the observation that ratios of $\mathrm{HMC}$ to protodolomite remain constant around $40 \%$ to $50 \%$ indicates no significant diagenetic alteration in the uppermost $30 \mathrm{~cm}$ of the sediment. Abrupt changes in these ratios, along with changing contributions of detrital mineral phases, such as mica and quartz, rather suggest changing sedimentation. Likewise, (low-Mg) calcite essentially depends on the input of ostracod shells and transport of detrital carbonates delivered from the catchment area. Furthermore, no significant diagenetic overprint in the form of recrystallization and/or cementation is apparent from the applied light- and electron-optical methods as well as the geochemical gradients. Most importantly, the stoichiometric ratio of each carbonate phase remains constant, confirming that no large-scale recrystallization of these phases occurs.

Considering that no signs of carbonate precipitation or diagenetic alteration were observed in the sediment column from the bay of Rust, it can be concluded that carbonate minerals are unlikely to form in the pore water. Instead $\mathrm{Ca}-$ $\mathrm{Mg}$ carbonate crystals may precipitate in the water column and are deposited at the bottom of the lake (Fig. 12; Eq. 3). Age estimations for the mud sediments range from 150 years (Löffler, 1979) to 850-2300 years before present (radiocarbon ages from Neuhuber et al., 2015). Our dataset indicates that authigenic $\mathrm{Ca}-\mathrm{Mg}$ carbonate does not necessarily form in its present location, which is consistent with the large discrepancy between sediment and authigenic carbonate age.

The observed detrital mineral spectrum reflects the mineral composition of the adjacent Leitha (mica, feldspar, quartz, calcite) and Rust hills (calcite), and minerals are either windblown or transported by small, eastbound tributaries (Löffler, 1979). The layering in the lower part of the section (Unit III) reflects the lack of homogenization by wind-driven wave action and indicates a higher water level. As this unit also contains higher amounts of plant particles and siliciclastics, possibly due to a higher water influx from vegetated surroundings, it is conceivable that the deposition of Unit III reflects environmental conditions before the installation of the water level regulating the Einser canal in 1909. The increase in $\mathrm{C}_{\text {org }}$ with depth further reflects this depositional change. This fits the increasing number of plant particles with depth. The lignin-bearing plant particles are difficult to degrade for heterotrophic organisms under the prevailing anoxic conditions (Benner et al., 1984). The higher amounts of plant material may reflect a lower salinity and thus higher primary production at their time of deposition, which can also be related to the stronger water level oscillations before regulations, including a larger lake surface and a catchment area that is almost a magnitude higher (refer to a map in the Supplement, provided by Hegedüs, 1783). Based on this consideration one might concur with the sediment age estimation of circa 150 years, as proposed by Löffler (1979). Nevertheless, it is important to distinguish between actual mineral formation and sediment deposition, including relocation: an unpublished sediment thickness map (GeNeSee project; unpublished) suggests a current-driven relocation of mud deposits in the southwestern lake area, where the bay of Rust is located. Thus, the radiocarbon data from Neuhuber et al. (2015) possibly reflect the date of precipitation, whereas Löffler's age estimation may refer to the date of local mud deposition.

\subsection{Potential pathways of authigenic Ca-Mg carbonate formation}

The precise formation pathway of authigenic $\mathrm{Ca}-\mathrm{Mg}$ carbonate mineral precipitation in Lake Neusiedl has been controversially discussed. Some authors suggest a precipitation of HMC in the water column and subsequent alteration to protodolomite or dolomite within the anoxic pore water of the sediment (Müller et al., 1972). Others suggest the direct formation of protodolomite in the water column (Schiemer and Weisser, 1972). Our XRD and geochemical data support the latter hypothesis, as no diagenetic alteration is retraceable throughout the sediment section. While low saturation or even undersaturation in the sediment precludes a microbially induced precipitation in the pore water, high supersaturation in the surface water body would support precipitation in the water column. Given the high alkalinity, $\mathrm{CO}_{2}$ uptake by primary producers may have contributed to the high $\mathrm{pH}$ and high supersaturation in the surface water.

An alternative explanation to the controversially discussed microbial dolomite formation would be the ripening under fluctuating $\mathrm{pH}$ conditions in the water column. Deelman (1999) has demonstrated in his precipitation experiments that dolomite forms if the $\mathrm{pH}$ varies. At times of strong supersaturation, metastable carbonates (protodolomite) are formed, which ripen to ordered dolomite during subsequent phases of undersaturation of the metastable carbonate (while the stable phase remains supersaturated). This observation reflects Ostwald's step rule, according to which the metastable phase always forms first. Ostwald's step rule can also be demonstrated in the pore water, which is buffered by the metastable phase. Thereby the formation of the stable phase (dolomite) is inhibited despite its supersaturation. This observation is comparable with Land's (1998) "failure" 
Oxygen requirements of bacteria Core 1

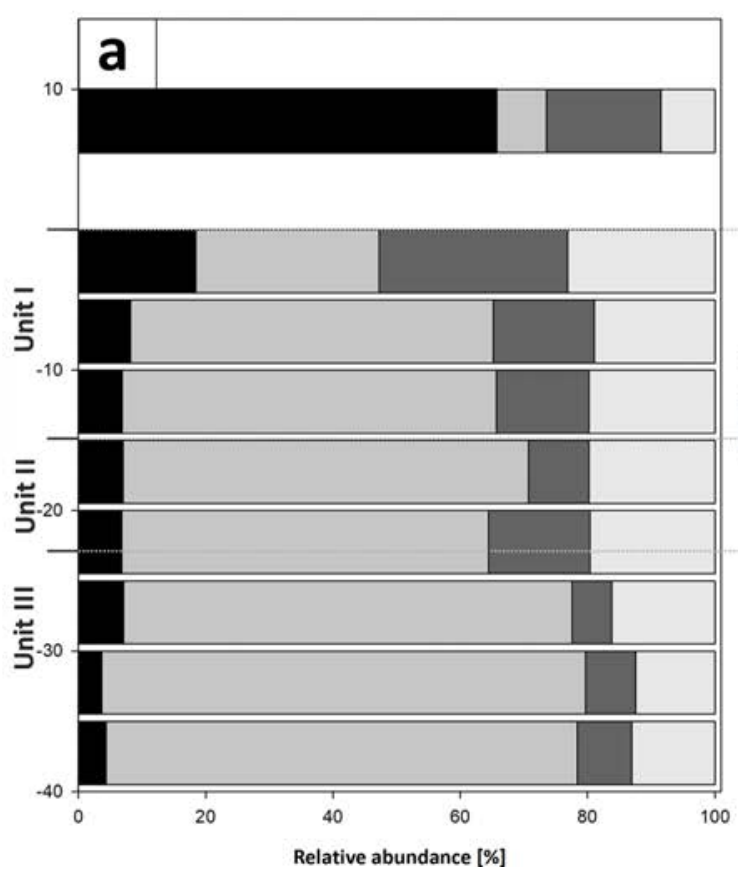

Oxygen requirements of bacteria Core 2

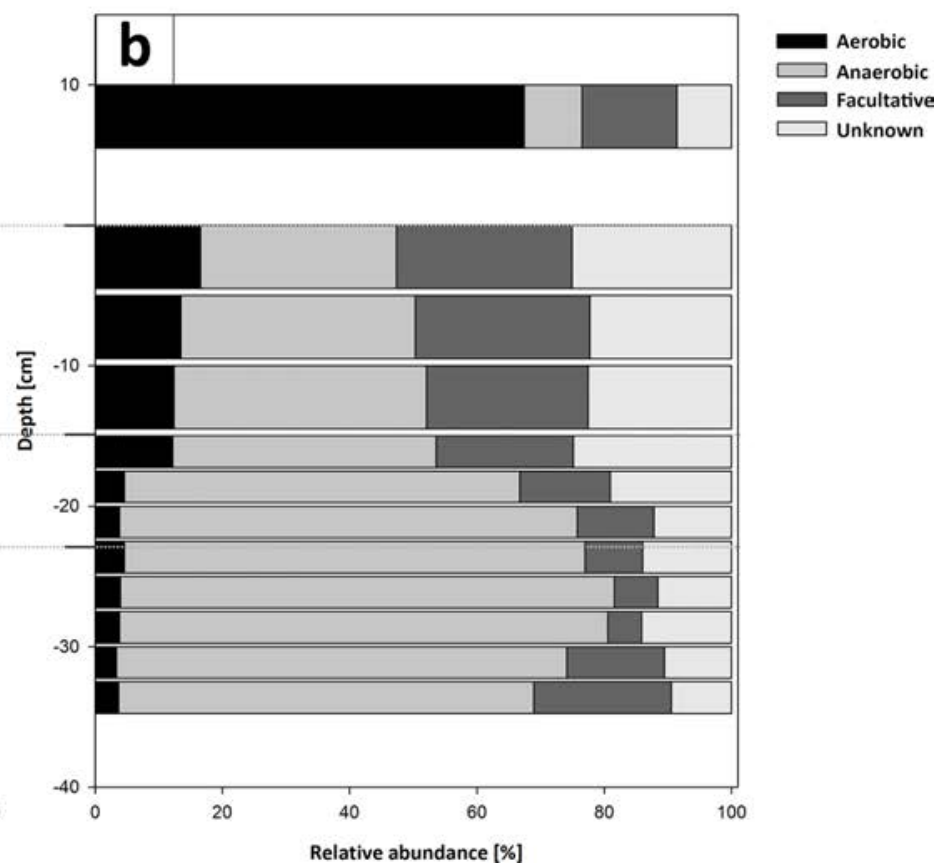

Figure 13. Oxygen utilization within the most abundant members of the bacterial community (a) and the potential energy metabolisms (b) plotted versus depth in Cores 1 and 2. The community in the water column indicates a predominantly aerobic regime. Rare taxa $(<0.5 \%$ relative abundance) were removed from the analysis, and abundances were normalized to $100 \%$. Bacteria with an unknown metabolism were grouped as unknowns. The community inhabiting the sediment shows an early onset of sulfate reduction in the upper sediment layers and a shift to fermentation at the transition from Unit II to III.

to form dolomite for 30 years despite 1000-fold supersaturation.

In Lake Neusiedl, fluctuation of the $\mathrm{pH}$ in the overlying water column is likely to occur due to variations in meteoric water input and temperature, which may cause episodes of undersaturation. This is a fact which is supported by Wolfram and Herzig (2013), who report an increase in $\mathrm{Ca}^{2+}$ concentration, depending on a dissolution of $\mathrm{Ca}$ carbonates in Lake Neusiedl's open water during the winter months, when water levels rise and temperatures decrease. Such a seasonally dependent formation mechanism has recently been suggested to explain dolomite formation in a Triassic evaporative tidal flat setting (Meister and Frisia, 2019). Alternatively, Moreira et al. (2004) proposed that undersaturation of metastable phases occurs as a result of sulfide oxidation near the sediment surface. While we traced only small abundances of sulfate-oxidizing bacteria near the sediment-water interface (1\%), fluctuating hydrochemical conditions are likely to occur in the diffusive boundary layer, where a $\mathrm{pH}$ drop is observed as a result of the biogeochemical processes discussed above. Dolomite formation in the diffusive boundary layer has been observed in Lake Van (McCormack et al., 2018) and was interpreted as a result of abundant microbial EPS, linked to a changing water level and hence chemistry. In Lake Neusiedl, the amount of EPS in the diffusive boundary layer is difficult to estimate, but the potential $\mathrm{Ca}-\mathrm{Mg}$ carbonate favoring change in hydrochemistry is granted.

\section{Conclusions}

Two phases of $\mathrm{Ca}-\mathrm{Mg}$ carbonates (HMC, protodolomite) as well as calcite occur in the form of fine-grained mud in Lake Neusiedl. Bacterial metabolic activity, including sulfate reduction and fermentation, leads to a decrease in $\mathrm{pH}$ within the sediment, leaving the $\mathrm{Ca}-\mathrm{Mg}$ carbonate phases at low or minor saturation in the pore water. In contrast, $\mathrm{Ca}-$ $\mathrm{Mg}$ carbonate phases are highly supersaturated in the alkaline water column. There, the carbonate formation mechanism may involve fluctuating hydrochemical conditions, leading to periods of undersaturation and ripening of HMC to protodolomite. Further, carbonate precipitation may be supported by phototrophic uptake of $\mathrm{CO}_{2}$ by cyanobacteria, e.g., by Synechococcus. Precipitation of $\mathrm{Ca}-\mathrm{Mg}$ carbonate, thus, most likely occurs in the open water. Based on the presented dataset, precipitation or diagenetic alteration within the sediment is not indicated. The precise $\mathrm{Ca}-\mathrm{Mg}$ carbonate reaction pathway needs further evaluation. 
Data availability. All data required for the presented plots and Supplement and analytical data were submitted to PANGEA (Data Publisher for Earth and Environmental Science) and are accessible via https://doi.org/10.1594/PANGAEA.909663 (Fussmann et al., 2019). Paired-end raw reads of the $16 \mathrm{~S}$ rRNA gene dataset are described in and accessible via von Hoyningen-Huene et al. (2019).

Supplement. The supplement related to this article is available online at: https://doi.org/10.5194/bg-17-2085-2020-supplement.

Author contributions. DF, HB, AM, RP and AR investigated, formally analyzed and curated the hydro- and geochemical data. AJEvHH investigated the bacterial communities and formally analyzed and curated the data together with DS and DF. DF wrote the original draft, which was reviewed and edited by PM, AJEvHH, AR, DS, GA and RD. GA, RD and PM conceptualized the study, acquired the funding, and administered and supervised the project.

Competing interests. The authors declare that they have no conflict of interest.

Acknowledgements. We thank Wolfgang Dröse, Birgit Röring and Axel Hackmann for their support during lab work. Furthermore, we thank Susanne Gier for support during XRD measurements and Beatrix Bethke, Caroline Haberhauer and Barbara Hofbauer for help during sampling. We also thank Erich Draganits, Regina and Rudolf Krachler, and Stephanie Neuhuber for insightful discussions. Anja Poehlein and Melanie Heinemann are acknowledged for performing the sequencing and initial sequence processing.

Financial support. This research has been supported by the German Research Foundation (DFG), research unit FOR-1644 "CHARON" (subproject TP7: grant nos. AR 335/8-1 and DA 374/11-1), by the European Commission (Marie Skłodowska-Curie IEF Project TRIADOL; grant no. 626025), and by the Department of Geodynamics and Sedimentology at the University of Vienna.

Review statement. This paper was edited by Aninda Mazumdar and reviewed by two anonymous referees.

\section{References}

Alderkamp, A.-C., Nejstgaard, J. C., Verity, P. G., Zirbel, M. J., Sazhin, A. F., and van Rijssel, M.: Dynamics in carbohydrate composition of Phaeocystis pouchetii colonies during spring blooms in mesocosms, J. Sea Res., 55, 169-181, https://doi.org/10.1016/j.seares.2005.10.005, 2006.

Bácsatyai, L., Csaplovics, E., Márkus, I., and Sindhuber, A.: Digitale Geländemodelle des Neusiedler See-Beckens, Wissenschaftliche Arbeiten aus dem Burgenland, 97, 1-53, 1997.
Balci, N., Menekşe, M., Karagüler, N. G., Şeref Sönmez, M., and Meister, P.: Reproducing authigenic carbonate precipitation in the hypersaline Lake Ac1göl (Turkey) with microbial cultures, Geomicrobiol. J., 33, 758-773, https://doi.org/10.1080/01490451.2015.1099763, 2016.

Benner, R., Maccubbin, A., and Hodson, R. E.: Anaerobic biodegradation of the lignin and polysaccharide components of lignocellulose and synthetic lignin by sediment microflora, Appl. Environ. Microbiol., 47, 998-1004, 1984.

Bidle, K. D. and Azam, F.: Accelerated dissolution of diatom silica by marine bacterial assemblages, Nature, 397, 508-512, https://doi.org/10.1038/17351, 1999.

Bidle, K. D., Brzezinski, M. A., Long, R. A., Jones, J. L., and Azam, F.: Diminished efficiency in the oceanic silica pump caused by bacteria-mediated silica dissolution, Limnol. Oceanogr., 48 , 1855-1868, https://doi.org/10.4319/lo.2003.48.5.1855, 2003.

Birgel, D., Meister, P., Lundberg, R., Horath, T. D., Bontognali, T. R., Bahniuk, A. M., de Rezende, C. E., Vásconcelos, C., and McKenzie, J. A.: Methanogenesis produces strong ${ }^{13} \mathrm{C}$ enrichment in stromatolites of Lagoa Salgada, Brazil: a modern analogue for Palaeo-/Neoproterozoic stromatolites?, Geobiology, 13, 245-266, https://doi.org/10.1111/gbi.12130, 2015.

Birsoy, R.: Formation of sepiolite-palygorskite and related minerals from solution, Clay. Clay Miner., 50, 736-745, https://doi.org/10.1346/000986002762090263, 2002.

Blohm, M.: Sedimentpetrographische Untersuchungen am Neusiedler See, Österreich, Dissertation, Ruprecht-KarlUniversität Heidelberg, 1-85, 1974.

Bontognali, T. R., Vasconcelos, C., Warthmann, R. J., Bernasconi, S. M., Dupraz, C., Strohmenger, C. J., and McKenzie, J. A.: Dolomite formation within microbial mats in the coastal sabkha of Abu Dhabi (United Arab Emirates), Sedimentology, 57, 824844, https://doi.org/10.1111/j.1365-3091.2009.01121.x, 2010.

Bontognali, T. R., McKenzie, J. A., Warthmann, R. J., and Vasconcelos, C.: Microbially influenced formation of Mg-calcite and Ca-dolomite in the presence of exopolymeric substances produced by sulphate-reducing bacteria, Terra Nova, 26, 72-77, https://doi.org/10.1111/ter.12072, 2014.

Boros, E., Horváth, Z., Wolfram, G., and Vörös, L.: Salinity and ionic composition of the shallow astatic soda pans in the Carpathian Basin, Int. J. Limnol., 50, 59-69, https://doi.org/10.1051/limn/2013068, 2014.

Brady, P.V., Krumhansl, J. L., and Papenguth, H. W.: Surface complexation clues to dolomite growth, Geochem. Cosmochem. Ac., 60, 727-731, https://doi.org/10.1016/0016-7037(95)00436$\mathrm{x}, 1996$.

Callahan, B. J., McMurdie, P. J., and Holmes, S. P.: Exact sequence variants should replace operational taxonomic units in marker-gene data analysis, ISME J., 11, 2639-2643, https://doi.org/10.1038/ismej.2017.119, 2017.

Celik, M., Özdemir, B., Turan, M., Koyuncu, I., Atesok, G., and Sarikaya, H.: Removal of ammonia by natural clay minerals using fixed and fluidised bed column reactors, Water Sci. Technol., 1, 81-88, https://doi.org/10.2166/ws.2001.0010, 2001.

Chen, S., Zhou, Y., Chen, Y., and Gu, J.: fastp: an ultra-fast all-in-one FASTQ preprocessor, Bioinformatics, 34, i884-i890, https://doi.org/10.1093/bioinformatics/bty560, 2018.

Chiang, E., Schmidt, M. L., Berry, M. A., Biddanda, B. A., Burtner, A., Johengen, T. H., Palladino, D., and Denef, V. J.: Verrucomi- 
crobia are prevalent in north-temperate freshwater lakes and display class-level preferences between lake habitats, PLoS One, 13, e0195112, https://doi.org/10.1371/journal.pone.0195112, 2018.

Court, W. M., Paul, A., and Lokier, S. W.: The preservation potential of environmentally diagnostic sedimentary structures from a coastal sabkha, Mar. Geol., 386, 1-18, https://doi.org/10.1016/j.margeo.2017.02.003, 2017.

De Choudens-Sanchez, V. and Gonzalez, L. A.: Calcite and aragonite precipitation under controlled instantaneous supersaturation: elucidating the role of $\mathrm{CaCO}_{3}$ saturation state and $\mathrm{Mg} / \mathrm{Ca}$ ration on calcium carbonate polymorphism, J. Sediment. Res., 79, 363376, https://doi.org/10.2110/jsr.2009.043, 2009.

Deelman, J.: Low-temperature nucleation of magnesite and dolomite, Neues Jb. Miner. Monat., 7, 289-302, 1999.

Deng, S., Dong, H., Lv, G., Jiang, H., Yu, B., and Bishop, M. E.: Microbial dolomite precipitation using sulfate reducing and halophilic bacteria: Results from Qinghai Lake, Tibetan Plateau, NW China, Chem. Geol., 278, 151-159, https://doi.org/10.1016/j.chemgeo.2010.09.008, 2010.

Fernandez-Diaz, L., Putnis, A., Prieto, M., and Putnis, C. $\mathrm{V}$.: The role of magnesium in the crystallization of calcite and aragonite in a porous medium, J. Sed. Res., 66, 482-491, https://doi.org/10.1306/d4268388-2b26-11d7$8648000102 \mathrm{c} 1865 \mathrm{~d}, 1996$.

Flombaum, P., Gallegos, J. L., Gordillo, R. A., Rincón, J., Zabala, L. L., Jiao, N., Karl, D. M., Li, W. K., Lomas, M. W., and Veneziano, D.: Present and future global distributions of the marine Cyanobacteria Prochlorococcus and Synechococcus, P. Natl. Acad. Sci. USA, 110, 9824-9829, https://doi.org/10.1073/pnas.1307701110, 2013.

Frisia, S., Borsato, A., and Hellstrom, J.: High spatial resolution investigation of nucleation, growth and early diagenesis in speleothems as exemplar for sedimentary carbonates, Earth-Sci. Rev., 178, 68-91, https://doi.org/10.1016/j.earscirev.2018.01.014, 2018.

Fussmann, D., von Hoyningen-Huene, A., Reimer, A., Schneider, D., Maier, A., Peticzka, R., Babkova, H., Arp, G., Rolf, D., and Meister, P.: Analytical Data Lake Neusiedl, PANGAEA, https://doi.org/10.1594/PANGAEA.909663, 2019.

Given, R. K. and Wilkinson, B. H.: Kinetic control of morphology, composition, and mineralogy of abiotic sedimentary carbonates, J. Sed. Res., 55, 109-119, https://doi.org/10.1306/212f862a2b24-11d7-8648000102c1865d, 1985.

Grasshoff, K., Kremling, K., and Ehrhardt, M.: Methods of seawater analysis, John Wiley \& Sons, 91-251, https://doi.org/10.1002/9783527613984, 2009.

Gregg, J. M., Bish, D. L., Kaczmarek, S. E., and Machel, H. G.: Mineralogy, nucleation and growth of dolomite in the laboratory and sedimentary environment: a review, Sedimentology, 62, 1749-1769, https://doi.org/10.1111/sed.12202, 2015.

He, S., Stevens, S. L., Chan, L.-K., Bertilsson, S., del Rio, T. G., Tringe, S. G., Malmstrom, R. R., and McMahon, K. D.: Ecophysiology of freshwater Verrucomicrobia inferred from metagenome-assembled genomes, mSphere, 2, e00277-17, https://doi.org/10.1128/msphere.00277-17, 2017.

Hegedüs, J. N.: Lake Neusiedl and Hansag: Universal map of the County of Sopron, State archive of Sopron, 1783.
Herrmann, P., Pascher, G., and Pistonik, J.: Geologische Karte der Republik Österreich. Geologische Bundesanstalt, Wien, 1993.

Herzig, A.: Der Neusiedler See - Limnologie eines Steppensees, Denisia 33, zugleich Kataloge des oberösterreichischen Landesmuseums, 163, 101-114, 2014.

Herzig, A. and Dokulil, M.: Neusiedler See - ein Steppensee in Europa, in: Ökologie und Schutz von Seen, edited by: Dokulil, M., Hamm, A., and Kohl, J.-G., Facultas-Universitäts-Verlag, Wien, 401-415, 2001.

Horváth, F.: Towards a mechanical model for the formation of the Pannonian basin, Tectonophysics, 226, 333-357, https://doi.org/10.1016/0040-1951(93)90126-5, 1993.

Hug, L. A., Castelle, C. J., Wrighton, K. C., Thomas, B. C., Sharon, I., Frischkorn, K. R., Williams, K. H., Tringe, S. G., and Banfield, J. F.: Community genomic analyses constrain the distribution of metabolic traits across the Chloroflexi phylum and indicate roles in sediment carbon cycling, Microbiome, 1, 22, https://doi.org/10.1186/2049-2618-1-22, 2013.

Illing, L., Wells, A., and Taylor, J.: Penecontemporary dolomite in the Persian Gulp, SEPM Special Publication, 13, 89-111, 1965.

Jørgensen, B. B. and Kasten, S.: Sulfur cycling and methane oxidation, in: Marine Geochemistry, edited by: Schulz, H. D. and Zabel, M., Springer, Berlin, 271-309, https://doi.org/10.1007/3540-32144-6_8, 2006.

Klindworth, A., Pruesse, E., Schweer, T., Peplies, J., Quast, C., Horn, M., and Glöckner, F. O.: Evaluation of general 16S ribosomal RNA gene PCR primers for classical and next-generation sequencing-based diversity studies, Nucl. Acid. Res., 41, e1, https://doi.org/10.1093/nar/gks808, 2013.

Kotlar, E., Tartakovsky, B., Argaman, Y., and Sheintuch, M.: The nature of interaction between immobilized nitrification and denitrification bacteria, J. Biotechnol., 51, 251-258, https://doi.org/10.1016/s0168-1656(96)01603-3, 1996.

Krachler, R., Korner, I., Dvorak, M., Milazowszky, N., Rabitsch, W., Werba, F., Zulka, P., and Kirschner, A.: Die Salzlacken des Seewinkels: Erhebung des aktuellen ökologischen Zustandes sowie Entwicklung individueller Lackenerhaltungskonzepte für die Salzlacken des Seewinkels (2008-2011), Österreichischer Naturschutzbund, Eisenstadt, Österreich, 2012.

Krachler, R., Krachler, R., Gülce, F., Keppler, B. K., and Wallner, G.: Uranium concentrations in sediment pore waters of Lake Neusiedl, Austria, Sci. Total Environ., 633, 981-988, https://doi.org/10.1016/j.scitotenv.2018.03.259, 2018.

Land, L. S.: Failure to Precipitate Dolomite at ${ }^{25} \mathrm{C}$ from dilute solution despite 1000-fold oversaturation after 32 years, Aquat. Geochem., 4, 361-368, 1998.

Lippmann, F.: The System $\mathrm{CaCO}_{3}-\mathrm{MgCO}_{3}$, in: Sedimentary Carbonate Minerals, edited by: Lippmann, F., Springer, Berlin, 148190, https://doi.org/10.1007/978-3-642-65474-9_4, 1973.

Liu, D., Xu, Y., Papineau, D., Yu, N., Fan, Q., Qiu, X., and Wang, H.: Experimental evidence for abiotic formation of low-temperature proto-dolomite facilitated by clay minerals, Geochim. Cosmochim. Ac., 247, 83-95, https://doi.org/10.1016/j.gca.2018.12.036, 2019.

Löffler, H.: Neusiedlersee: The limnology of a shallow lake in central europe, in: Monographiae Biologicae, 37, edited by: Junk, W., bv Publishers, The Hague, 543 pp., https://doi.org/10.1007/978-94-009-9168-2, 1979. 
Loisl, J., Tari, G., Draganits, E., Zámolyi, A., and Gjerazi, I.: Highresolution seismic reflection data acquisition and interpretation, Lake Neusiedl, Austria, northwest Pannonian Basin, Interpretation, 6, SB77-SB974, https://doi.org/10.1190/int-2017-0086.1, 2018.

Lutterotti, L., Bortolotti, M., Ischia, G., Lonardelli, I., and Wenk, H.: Rietveld texture analysis from diffraction images, Z. Kristallogr., Supplements, 26, 125-130, https://doi.org/10.1524/zksu.2007.2007.suppl_26.125, 2007.

Machel, H. G.: Concepts and models of dolomitization: a critical reappraisal, Geol. Soc. Lond. Spec. Publ. 235, 7-63, https://doi.org/10.1144/gsl.sp.2004.235.01.02, 2004.

Martin, M.: Cutadapt removes adapter sequences from highthroughput sequencing reads, EMBnet J., 17, 10-12, https://doi.org/10.14806/ej.17.1.200, 2011.

McCormack, J., Bontognali, T. R., Immenhauser, A., and Kwiecien, O.: Controls on cyclic formation of Quaternary early diagenetic dolomite, Geophys. Res. Lett., 45, 3625-3634, https://doi.org/10.1002/2018g1077344, 2018.

Meister, P.: Two opposing effects of sulfate reduction on carbonate precipitation in normal marine, hypersaline, and alkaline environments, Geology, 41, 499-502, https://doi.org/10.1130/g34185.1, 2013.

Meister, P. and Frisia, S.: Dolomite formation by nano-crystal aggregation in the Dolomia Principale of the Brenta Dolomites (Northern Italy), Riv. Ital. Paleontol. S., 125, 183-196, 2019.

Meister, P., Reyes, C., Beaumont, W., Rincon, M., Collins, L., Berelson, W., Stott, L., Corsetti, F., and Nealson, K. H.: Calcium- and magnesium-limited dolomite precipitation at Deep Springs Lake, California, Sedimentology, 58, 1810-1830, https://doi.org/10.1111/j.1365-3091.2011.01240.x, 2011.

More, K. D., Giosan, L., Grice, K., and Coolen, M. J.: Holocene paleodepositional changes reflected in the sedimentary microbiome of the Black Sea, Geobiology, 17, 436-448, https://doi.org/10.1111/gbi.12338, 2019.

Moreira, N., Walter, L. M., Vasconcelos, C., McKenzie, J. A., and McCall, P.: Role of sulfide oxidation in dolomitization: Sediments and pore-water geochemistry of a modern hypersaline lagoon system, Geology, 32, 701-704, https://doi.org/10.1130/g20353.1, 2004.

Moser, I.: Der abgetrocknete Boden des Neusiedler See's, Jahrbuch der Kaiserlich-Königlichen Geologischen Reichsanstalt Wien, $16,338-344,1866$.

Müller, G., Irion, G., and Förstner, U.: Formation and diagenesis of inorganic $\mathrm{Ca}-\mathrm{Mg}$ carbonates in the lacustrine environment, Naturwissenschaften, 59, 158-164, https://doi.org/10.1007/bf00637354, 1972.

Neuenschwander, S. M., Ghai, R., Pernthaler, J., and Salcher, M. M.: Microdiversification in genome streamlined ubiquitous freshwater Actinobacteria, ISME J., 12, 185-198, https://doi.org/10.1038/ismej.2017.156, 2018.

Neuhuber, F.: Ein Beitrag zum Chemismus des Neusiedler Sees, Sitzungsberichte der Akademie der Wissenschaften in Wien, mathematisch-naturwissenschaftliche Klasse, Abteilung 1, 179, 225-231, 1971.

Neuhuber, S., Steier, P., Gier, S., Draganits, E., and Kogelbauer, I.: Radiogenic Carbon Isotopes in Authigenic Carbonate from Lake Neusiedl, Austria, EGU General Assembly Conference Abstracts, 2015.
Niedermayr, A., Köhler, S. J., and Dietzel, M.: Impacts of aqueous carbonate accumulation rate, magnesium and polyaspartic acid on calcium carbonate formation $\left(6-40^{\circ} \mathrm{C}\right)$, Chem. Geol., 340, 105-120, https://doi.org/10.1016/j.chemgeo.2012.12.014, 2013.

Parkhurst, D. L. and Appelo, C.: Description of input and examples for PHREEQC version 3: a computer program for speciation, batch-reaction, one-dimensional transport, and inverse geochemical calculations, US Geological Survey, 2328-7055, https://doi.org/10.3133/tm6a43, 2013.

Piller, W. E., Harzhauser, M., and Mandic, O.: Miocene Central Paratethys stratigraphy-current status and future directions, Stratigraphy, 4, 151-168, 2007.

Quast, C., Pruesse, E., Yilmaz, P., Gerken, J., Schweer, T., Yarza, P., Peplies, J., and Glöckner, F. O.: The SILVA ribosomal RNA gene database project: improved data processing and web-based tools, Nucl. Acid. Res., 41, D590, https://doi.org/10.1093/nar/gks1219, 2012.

R Core Team: RStudio: integrated development for R (RStudio, Inc., Boston, MA, USA), 2016.

R Core Team: R: A language and environment for statistical computing, R Foundation for Statistical Computing, available at: https://www.r-project.org (last access: 10 April 2020), 2019.

Rivadeneyra, M. a. A., Delgado, G., Soriano, M., RamosCormenzana, A., and Delgado, R.: Precipitation of carbonates by Nesterenkonia halobia in liquid media, Chemosphere, 41, 617624, https://doi.org/10.1016/s0045-6535(99)00496-8, 2000.

Roberts, J. A., Bennett, P. C., González, L. A., Macpherson, G., and Milliken, K. L.: Microbial precipitation of dolomite in methanogenic groundwater, Geology, 32, 277-280, https://doi.org/10.1130/g20246.2, 2004.

Rognes, T., Flouri, T., Nichols, B., Quince, C., and Mahé, F.: VSEARCH: a versatile open source tool for metagenomics, Peer J., 4, e2584, https://doi.org/10.7717/peerj.2584, 2016.

Rosen, M. R., Miser, D. E., Starcher, M. A., and Warren, J. K.: Formation of dolomite in the Coorong region, South Australia, Geochim. Cosmochim. Ac., 53, 661-669, https://doi.org/10.1016/0016-7037(89)90009-4, 1989.

Ryves, D. B., Battarbee, R. W., Juggins, S., Fritz, S. C., and Anderson, N. J.: Physical and chemical predictors of diatom dissolution in freshwater and saline lake sediments in North America and West Greenland, Limnol. Oceanogr., 51, 1355-1368, https://doi.org/10.4319/lo.2006.51.3.1355, 2006.

Sánchez-Román, M., Vasconcelos, C., Warthmann, R., Rivadeneyra, M., McKenzie, J. A., and Swart, P.: Microbial dolomite precipitation under aerobic conditions: results from Brejo do Espinho Lagoon (Brazil) and culture experiments, in: Perspectives in Carbonate Geology: A Tribute to the Career of Robert Nathan Ginsburg, edited by: Swart, P. K., Eberli, G. P., McKenzie, J. A., Jarvis, I., and Stevens, T., IAS Special Publication, 41, 167-178, https://doi.org/10.1002/9781444312065, 2009.

Schiemer, F. and Weisser, P.: Zur Verteilung der submersen Makrophyten in der schilffreien Zone des Neusiedler Sees, Sitzungsberichte der Akademie der Wissenschaften in Wien, mathematische-naturwissenschaftliche Klasse, Abteilung 1., 180, 87-97, 1972.

Schneider, D., Wemheuer, F., Pfeiffer, B., and Wemheuer, B.: Extraction of total DNA and RNA from marine filter samples and generation of a cDNA as universal template for marker gene 
studies, in: Metagenomics, edited by: Streit, W. and Daniel, R., Springer, Berlin, 13-22, https://doi.org/10.1007/978-1-49396691-2_2, 2017.

Schroll, E. and Wieden, P.: Eine rezente Bildung von Dolomit im Schlamm des Neusiedler Sees, Tscher. Miner. Petrog., 7, 286289, https://doi.org/10.1007/bf01127917, 1960.

Seeberg-Elverfeldt, J., Schlüter, M., Feseker, T., and Kölling, M.: Rhizon sampling of porewaters near the sediment-water interface of aquatic systems, Limnol. Oceanogr.-Method., 3, 361371, https://doi.org/10.4319/lom.2005.3.361, 2005

Soetaert, K., Hofmann, A. F., Middelburg, J. J., Meysman, F. J., and Greenwood, J.: The effect of biogeochemical processes on $\mathrm{pH}$, Mar. Chem., 105, 30-51, https://doi.org/10.1016/j.marchem.2007.06.008, 2007.

Steiner, Z., Lazar, B., Erez, J., and Turchyn, A. V.: Comparing Rhizon samplers and centrifugation for pore- water separation in studies of the marine carbonate system in sediments, Limnol. Oceanogr.-Method., 16, 828-839, https://doi.org/10.1002/lom3.10286, 2018.

Sun, J., Steindler, L., Thrash, J. C., Halsey, K. H., Smith, D. P., Carter, A. E., Landry, Z. C., and Giovannoni, S. J.: One carbon metabolism in SAR11 pelagic bacteria, PloS one, 6, e23973, https://doi.org/10.1371/journal.pone.0023973, 2011.

Systat Software: SigmaPlot for Windows, version 11.0, 2008.

Thompson, J. and Ferris, F.: Cyanobacterial precipitation of gypsum, calcite, and magnesite from natural alkaline lake water, Geology, 18, 995-998, 1990.

van Husen, D.: Quaternary glaciations in Austria, in: Quaternary Glaciations - Extent and Chronology, Part I, Europe, Developments in Quaternary Science, 2, Elsevier, Amsterdam, 1-13, https://doi.org/10.1016/s1571-0866(04)80051-4, 2004.

van Lith, Y., Vasconcelos, C., Warthmann, R., Martins, J .C. F., and McKenzie, J. A.: Bacterial sulfate reduction and salinity: two controls on dolomite precipitation in Lagoa Vermelha and Brejo do Espinho (Brazil), Hydrobiologia, 485, 35-49, https://doi.org/10.1007/s00792-005-0441-8, 2002.

Vasconcelos, C., McKenzie, J. A., Bernasconi, S., Grujic, D., and Tiens, A. J.: Microbial mediation as a possible mechanism for natural dolomite formation at low temperatures, Nature, 377, 220-222, https://doi.org/10.1038/377220a0, 1995.

Vasconcelos, C. and McKenzie, J. A.: Microbial mediation of modern dolomite precipitation and diagenesis under anoxic conditions (Lagoa Vermelha, Rio de Janeiro, Brazil), J. Sediment. Res., 67, 378-390, https://doi.org/10.1306/d42685772b26-11d7-8648000102c1865d, 1997. von Breymann, M. T., Collier, R., and Suess, E.: Magnesium adsorption and ion exchange in marine sediments: A multicomponent model, Geochim. Cosmochim. Ac., 54, 3295-3313, https://doi.org/10.1016/0016-7037(90)90286-t, 1990.

von der Borch, C. C., Lock, D. E., and Schwebel, D.: Groundwater formation of dolomite in the Coorong region of South Australia, Geology, 3, 283-285, https://doi.org/10.1130/00917613(1975)3<283:gfodit>2.0.co;2, 1975.

von Hoyningen-Huene, A. J. E., Schneider, D., Fussmann, D., Reimer, A., Arp, G., and Daniel, R.: Bacterial succession along a sediment porewater gradient at Lake Neusiedl in Austria, Sci Data, 6, 163, https://doi.org/10.1038/s41597-019-0172-9, 2019.

Warren, J. K.: Sedimentology and mineralogy of dolomitic Coorong lakes, South Australia, J. Sediment. Res., 60, 843-858, https://doi.org/10.1306/212f929b-2b24-11d7$8648000102 \mathrm{c} 1865 \mathrm{~d}, 1990$.

Whitman, W. B.: Bergey's manual of systematics of Archaea and Bacteria, Wiley Online Library, 19-1314, 2015.

Wolfram, G.: Bedeutung und Vorkommen von Salzlebensräumen, in: Salzlebensräume in Österreich, edited by: Wolfram, G., Zulka, K. P., Albert, R., Danihelka, J., Eder, E., Fröhlich, W., Holzer, T., Holzinger, W. E., Huber, H.-J., Korner, I., Lang, A., Mazzucco, K., Milasowszky, N., Oberleitner, I., Rabitsch, W., Sauberer, N., Schagerl, M., Schlick-Steiner, B. C., Steiner, F. M. and Steiner, K.-H., Umweltbundesamt, Wien, 13-26, 2006.

Wolfram, G. and Herzig, A.: Nährstoffbilanz Neusiedler See, Wiener Mitteilungen, 228, 317-338, 2013.

Wright, D. T. and Wacey, D.: Precipitation of dolomite using sulphate-reducing bacteria from the Coorong Region, South Australia: significance and implications, Sedimentology, 52, 9871008, https://doi.org/10.1111/j.1365-3091.2005.00732.x, 2005.

Zámolyi, A., Salcher, B., Draganits, E., Exner, U., Wagreich, M., Gier, S., Fiebig, M., Lomax, J., Surányi, G., and Diel, M.: Latest Pannonian and Quaternary evolution at the transition between Eastern Alps and Pannonian Basin: new insights from geophysical, sedimentological and geochronological data, Int. J. Earth Sci., 106, 1695-1721, https://doi.org/10.1007/s00531-016-13833, 2017.

Zhang, F., Yan, C., Teng, H. H., Roden, E. E., and Xu, H.: In situ AFM observations of $\mathrm{Ca}-\mathrm{Mg}$ carbonate crystallization catalyzed by dissolved sulfide: Implications for sedimentary dolomite formation, Geochem. Cosmochem. Ac., 105, 44-55, https://doi.org/10.1016/j.gca.2012.11.010, 2013.

Zhang, J., Kobert, K., Flouri, T., and Stamatakis, A.: PEAR: a fast and accurate Illumina Paired-End reAd mergeR, Bioinformatics, 30, 614-620, https://doi.org/10.1093/bioinformatics/btt593, 2013. 


\title{
3. TOTAL AND ACTIVE BACTERIAL COMMUNITIES, POREWATER DYNAMICS AND TIME: A CROSS-SECTIONAL STUDY OF ALDABRA ATOLL SEDIMENTS
}

Avril Jean Elisabeth von Hoyningen-Huene ${ }^{1}$, Dominik Schneider ${ }^{1}$, Dario Fussmann ${ }^{2}$, Andreas Reimer ${ }^{2}$, Gernot $\operatorname{Arp}^{2}$, Rolf Daniel ${ }^{1 *}$

Submitted to Scientific Reports

\begin{abstract}
Affiliations:
${ }^{1}$ Genomic and Applied Microbiology \& Göttingen Genomics Laboratory, Institute of Microbiology and Genetics, Georg-August University of Göttingen, Göttingen, Germany

${ }^{2}$ Geobiology, Geoscience Centre, Georg-August University of Göttingen, Göttingen, Germany
\end{abstract}

\section{Author contributions:}

Conceived and designed the study: RD, GA, AH

Performed the experiments: AH, DF, AR

Analysed the data: AH, DS, DF, AR, GA

Wrote the paper: AH, DS, DF, AR, GA, RD 


\begin{abstract}
The remote Aldabra Atoll in the Indian Ocean provides the ideal opportunity to study bacterial communities in pristine sediments across an entire biome. This is the first study using bacterial 16S rRNA gene and transcript analysis to distinguish between past and present inhabitants in these carbonate sediments. This allowed us to trace the bacteria across different porewater and temporal gradients. We aimed to determine whether the bacterial community composition follows typical geochemical zonation patterns of electron transfer gradients in different sediment types. The four sampled sites at the Aldabra Atoll cover sand with high porewater exchange, bioturbated silt and mud with intermediate exchange, as well as a seasonally and episodically desiccated landlocked pool. Accordingly, the community changed from aerobic Pseudomonas in the sand to diverse surface and sulphate reduction zones in the anaerobic mud. Total sulphide peaked alongside high relative abundances of sulphate reducing (Halo-) Desulfovibrio, sulphur oxidizing Arcobacteraceae, photo(hetero)troph Cyanobacteria and Alphaproteobacteria, and fermentative Propionigenium. Deeper mud and pool sediments harboured high abundances of Halomonas or Alphaproteobacteria alongside high $\mathrm{C} / \mathrm{N}$ ratios instead of obligately anaerobic fermenters. We believe that this atypical community shift may be driven by a change in the complexity of available organic matter and sediment age.
\end{abstract}

\title{
Introduction
}

Microbial communities are major drivers of the global biogeochemical cycles. These cycles are based on a limited set of elements, which are used in the energy transduction pathways, depending on their abundance and the availability of oxygen [1]. In sediments, this results in a succession of redox zones. Once oxygen is depleted, the electron acceptors change to nitrate, followed by manganese, iron and sulphate. In the deepest sediments, $\mathrm{CO}_{2}$ is ultimately reduced to methane [2,3]. Changes in microbial community composition are favoured according to this standard biogeochemical zonation. Due to fluctuations and advection of porewaters and corresponding changes in ion concentrations, as well as bioturbation and bioirrigation, they may not necessarily appear as clearly separated zones [4,5]. This leads to a highly dynamic sediment environment with diverse bacterial communities in micro-niches characterized for instance by different levels of oxygenation [5]. Based 
on total extractable DNA, the most applied approach to studying bacterial community assemblies is the use of the 16S rRNA gene as taxonomic marker. The approach has been shown to yield overlapping signals of past and present microbial communities, depending on organic matter degradation rates in the sediment. This means that in addition to DNA of present microbes, signals from extracellular DNA, dormant or dead microbes may be detected [6]. In sediments these may accumulate from the water column or derive from former sedimentary conditions. Thus, sediments with a varying history of short term tidal, as well as episodic or long-term changes, such as flooding or climate change, are included in the DNA-based record of the microbial communities to varying extents. In order to disentangle the past and present signatures in sediments, we utilize amplicons of both 16S rRNA genes derived from total DNA and transcripts derived from total RNA.

The Aldabra Atoll is the second largest raised limestone atoll in the world. It is part of the Seychelles, situated approximately $420 \mathrm{~km}$ north of Madagascar. Aldabra covers an area of $365 \mathrm{~km}^{2}$ of which $155 \mathrm{~km}^{2}$ are attributed to the island rim [7]. Since gaining UNESCO protection status in 1982, the Aldabra lagoon has remained largely unaffected by anthropogenic impacts. In 2012, the lagoons' sediment types and benthic cover were determined using remote sensing and ground reference points for spatial models [8]. The Pleistocene limestone basement was described in detail by Braithwaite [9] and the biota, including the giant tortoises [10] and (macro-)biota of the soft sediments [11], have received some attention. The most recent studies on microbial communities were performed 30-40 years ago. They focused on microbial mats covering the limestone within the lagoon or the landlocked pools and the rates at which they fix nitrogen in the intertidal zone $[12,13]$. For the identification of dominant bluegreen algae, such as Hyella balani, Lyngbya sp., and Schizothrix, the authors relied on phenotypic description [14].

We sampled sediment depth profiles at four sites with different tidal and depositional histories during an expedition to the Aldabra Atoll in 2017. Three sites were located within the lagoon and one within the Cinq Cases pool system on the eastern island rim. Our first aim was to establish which bacterial communities thrive in the different sediment facies and how they correlate with local porewater geochemical gradients. To this extent the sampled sites included settings with strong short-term tidal exchange, but overall long-term stability, as well as long-term seasonal porewater 
change with a history of strong episodic changes in the sediment. Based on these results, we aimed to determine the bacterial involvement in the precipitation of any fresh carbonates or diagenetic alterations of the sediments. Our expectations for the geochemical and bacterial community profiles were based on the following hypotheses. Firstly, the porewater profiles and associated bacterial communities follow the standard geochemical zonation described by Jørgensen and Kasten [2 and references therein]. Secondly, the bacterial diversity decreases with increasing sediment depth [15]. Thirdly, comparison of both total (DNA-based) and potentially active (RNA-based) bacterial communities highlights present and past key players within the sediment, allowing us to understand their response to short and long-term environmental changes. This is the first study using next-generation sequencing to identify the bacterial communities of the Aldabra Atoll.

\section{Results}

Sediment cores, porewater and bulk sediment geochemistry

Sediment push cores were taken at four sampling sites across the lagoon and the main island Grand Terre (Fig. 1). All cores were limited in depth by the underlying karstic limestone. Porewater geochemistry and bulk sediment geochemistry were measured in 2.5-5 cm intervals at each sampling site (Fig. 2, Supplementary Table S1) and correlated against depth using Spearman-Rank correlations (Supplementary Table S2). 


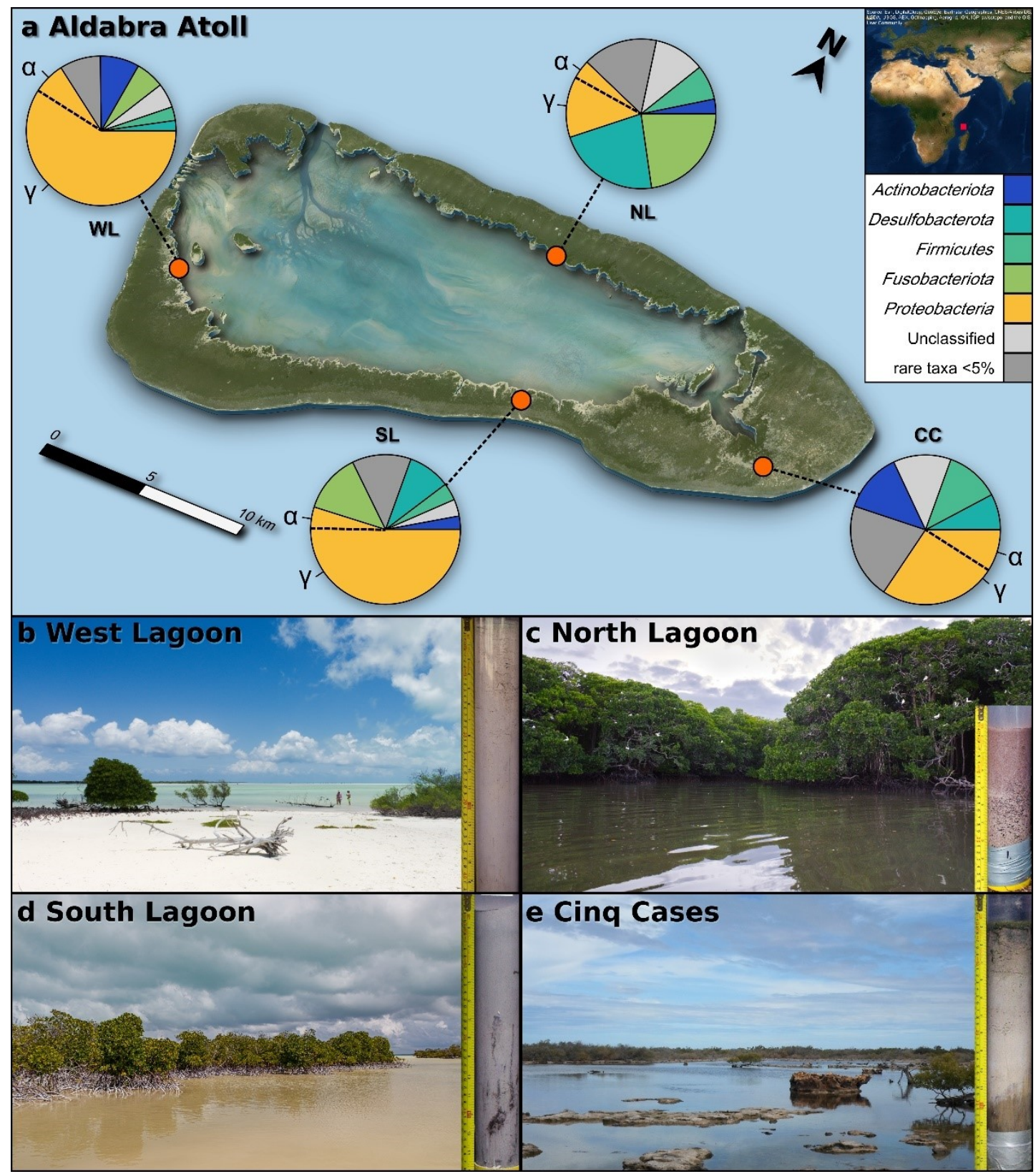

Figure 1. Aldabra Atoll, sampling sites and most abundant bacterial phyla ( $>5 \%$ ) at each site. a: Map of the Aldabra Atoll showing the four sampling sites. The global location is indicated in the top right corner, on a map generated using ArcGIS Desktop and Esri World Imagery (July 17, 2020). Most abundant bacterial phyla across all samples are shown in pie charts by sampling site: All taxa below $5 \%$ relative abundance were summarized as rare taxa. b-e: Sampling sites and a representative core for each location. 


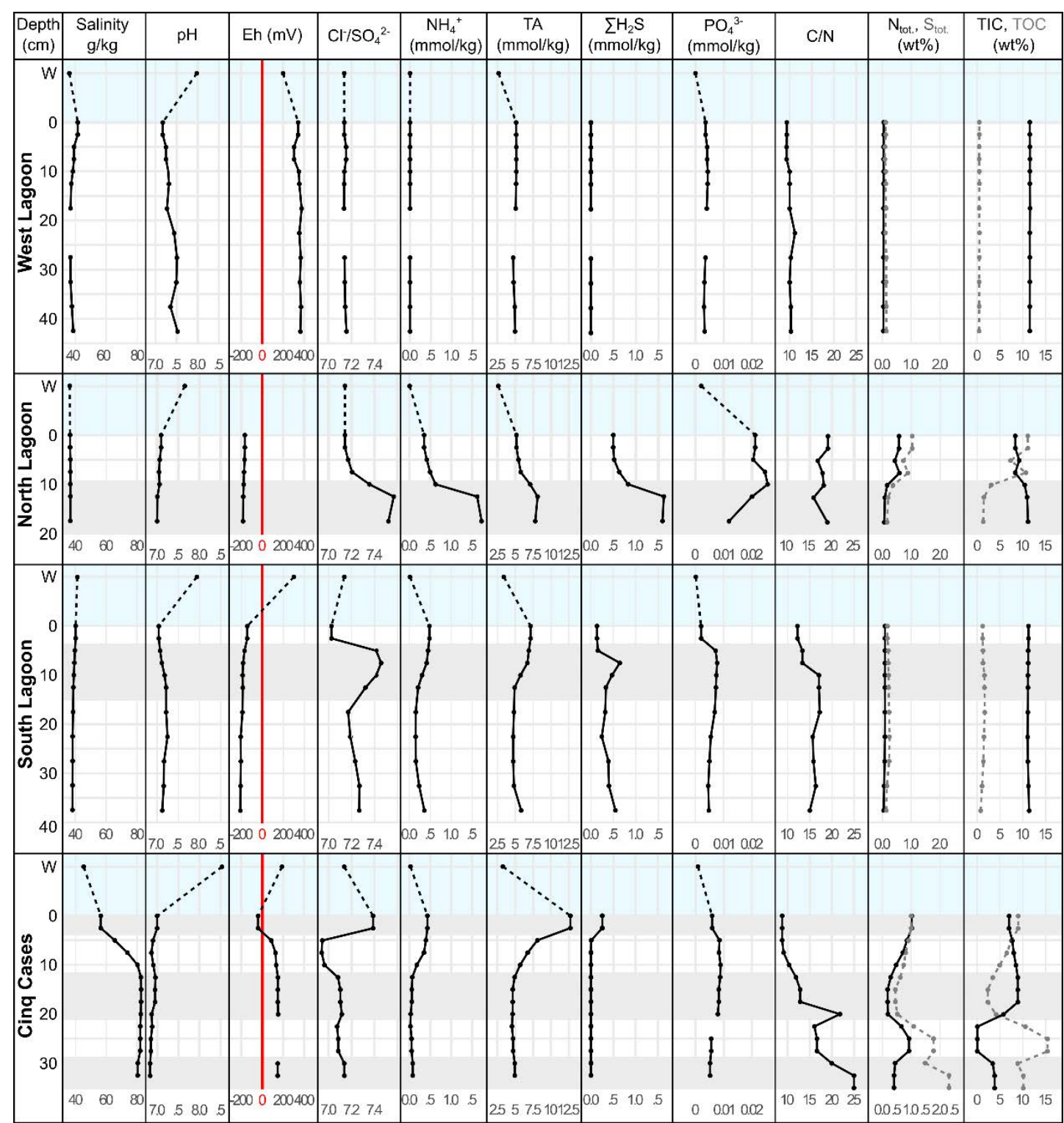

Figure 2. Selected porewater and bulk sediment geochemical profiles of the West Lagoon (WL), North (NL) and South (SL) Lagoon, and Cinq Cases (CC). Porewater profiles and sediment geochemistry were measured in two separate cores, except at Cinq Cases, where the same core was used. The water column (W) is set apart from the sediments by dashed lines and blue colour. Grey and white backgrounds indicate the geochemical zonation of the cores. The red line indicates the transition from reducing to oxidizing redox (Eh) conditions. Measurement accuracy deviated by less than $3 \%$.

In the lagoon-derived cores, pore water salinity ranged from $36-41 \mathrm{~g} / \mathrm{kg}$ at low tide, while Cinq Cases ranged between $42-82 \mathrm{~g} / \mathrm{kg}$. To account for changes in salinity, sulphate concentrations are shown as $\mathrm{Cl}^{-} / \mathrm{SO}_{4}{ }^{2-}$ ratios. The West Lagoon site was characterized by fine carbonate sand (Fig. 1b, Table 1) covered by a pink and green, slightly lithified top layer of $2-3 \mathrm{~cm}$ below the surface ( $\mathrm{cm} \mathrm{bsf}$ ). 
Table 1. Sediment characteristics (a) and sequencing features (b) of all sampling sites. a) The main environmental characteristics for each sampling site, including sediment type and depth, redox conditions, and mode of porewater exchange. b) total sample number and ASV counts, mean percentage of unclassified taxa and average diversity indices between the sampling sites and community fractions. Data were rarefied at 19,906 reads per sample for calculation of diversity indices. The phylogenetic diversity is based on a midpoint-rooted phylogenetic tree.

a) Sediment cores and features

\begin{tabular}{|c|c|c|c|c|}
\hline Location & West Lagoon & North Lagoon & South Lagoon & Cinq Cases \\
\hline Depth (cm) & 40.8 & 15.8 & 34.2 & 27.5 \\
\hline Latitude & -9.44733 & -9.38396 & -9.44298 & -9.42979 \\
\hline Longitude & 46.23641 & 46.36124 & 46.39179 & 46.49524 \\
\hline Sediments & Carbonate sand & $\begin{array}{l}\text { Coarse carbonate } \\
\text { sand and silt }\end{array}$ & $\begin{array}{l}\text { Fine-grained } \\
\text { carbonate mud }\end{array}$ & $\begin{array}{l}\text { Fine-grained } \\
\text { carbonate silt to } \\
\text { mud }\end{array}$ \\
\hline $\begin{array}{l}\text { Redox } \\
\text { conditions }\end{array}$ & Oxidizing & Reducing & Reducing & $\begin{array}{l}\text { Reducing to } \\
\text { oxidizing }\end{array}$ \\
\hline $\begin{array}{l}\text { Porewater } \\
\text { exchange }\end{array}$ & $\begin{array}{l}\text { Tidal porewater } \\
\text { exchange }\end{array}$ & $\begin{array}{l}\text { Advection, } \\
\text { bioturbation }\end{array}$ & $\begin{array}{l}\text { Advection, } \\
\text { bioturbation }\end{array}$ & $\begin{array}{l}\text { Evaporation, } \\
\text { diffusion }\end{array}$ \\
\hline $\begin{array}{l}\text { Additional } \\
\text { features }\end{array}$ & $\begin{array}{l}\text { Lithified surface } \\
\text { layer with biofilm }\end{array}$ & $\begin{array}{l}\text { Rich in organic } \\
\text { matter and faeces } \\
\text { from bird colony }\end{array}$ & $\begin{array}{l}0-15 \mathrm{~cm} \text { highly } \\
\text { bioturbated; } 15- \\
\text { bottom high plant } \\
\text { detrital input }\end{array}$ & $\begin{array}{l}\text { Surface covered } \\
\text { by microbial } \\
\text { mat, strong } \\
\text { salinity and } \mathrm{C} / \mathrm{N} \\
\text { gradient }\end{array}$ \\
\hline
\end{tabular}

b) Sequencing features (Mean)

\begin{tabular}{|c|c|c|c|c|c|c|c|c|}
\hline Location & \multicolumn{2}{|c|}{ West Lagoon } & \multicolumn{2}{|c|}{ North Lagoon } & \multicolumn{2}{|c|}{ South Lagoon } & \multicolumn{2}{|c|}{ Cinq Cases } \\
\hline Material & DNA & RNA & DNA & RNA & DNA & RNA & DNA & RNA \\
\hline Samples (N) & 35 & 46 & 23 & 25 & 35 & 36 & 69 & 73 \\
\hline Raw reads & 62,468 & 66,243 & 54,961 & 104,909 & 59,381 & 90,070 & 68,990 & 61,756 \\
\hline $\begin{array}{l}\text { Processed } \\
\text { reads }\end{array}$ & 50,923 & 55,880 & 43,171 & 71,206 & 48,033 & 63,605 & 56,897 & 45,000 \\
\hline Total ASVS & 11,731 & 8,555 & 13,989 & 12,831 & 13,335 & 11,441 & 16,393 & 14,561 \\
\hline $\begin{array}{l}\text { Unclassified } \\
\operatorname{taxa}(\%)\end{array}$ & 9.5 & 2 & 13.4 & 10 & 4.1 & 3.5 & 17.1 & 8.7 \\
\hline $\begin{array}{l}\text { Shannon } \\
\left(H^{\prime}\right)\end{array}$ & 3.99 & 2.17 & 4.86 & 4.23 & 3.97 & 3.05 & 4.82 & 4.12 \\
\hline Faith's PD & 230.9 & 94.6 & 350.1 & 236.5 & 254.7 & 144.5 & 322.8 & 207.1 \\
\hline Chaol & 2147.4 & 659.8 & 4026.5 & 2770.7 & 2420.3 & 1451.1 & 2230.3 & 1451.2 \\
\hline
\end{tabular}


The tides drain and flush the porewater space with fresh seawater leading to oxic conditions with a mean Eh of $+340 \mathrm{mV}$. All other geochemical measurements remained stable throughout the West Lagoon sediment and water column (Fig. 2). The North Lagoon cores were sampled near a red-footed booby (Sula sula) colony (Fig. 1c, Table 1), leading to increased $\mathrm{PO}_{4}{ }^{3-}$ concentrations due to their droppings (Supplementary Table S1). The sediment was fine to coarse carbonate mud, silt, and shell debris with fully reducing conditions. Below a surface zone $(0-7.5 \mathrm{~cm}$ bsf $)$, total alkalinity (TA), $\mathrm{NH}_{4}{ }^{+}, \mathrm{Cl}^{-} / \mathrm{SO}_{4}{ }^{2-}$ ratio and $\mathrm{\Sigma}_{2} \mathrm{~S}$ significantly increased in a sulphate reduction zone (10-17.5 cm bsf; Fig. 2, Supplementary Table S2). The South Lagoon sediment was sampled near the highly bioturbated mangrove edge on a large tidal flat. The sediment consisted of up to $40^{\circ} \mathrm{cm}$ deep fine-grained, grey carbonate mud (Fig. 1d, Table 1) with a negative porewater Eh. Following a surface zone with low $\mathrm{Cl}^{-} / \mathrm{SO}_{4}{ }^{2-}$ from 0-2.5 $\mathrm{cm}$ bsf, an enhanced sulphate reduction zone with high $\mathrm{Cl}^{-} / \mathrm{SO}_{4}{ }^{2-}$ and a peak in $\Sigma \mathrm{H}_{2} \mathrm{~S}$ was observed between $5-15 \mathrm{~cm}$. The bottom $15-40 \mathrm{~cm}$ bsf were traversed by mangrove roots and debris, which explain the increase in $\mathrm{C} / \mathrm{N}$ from marine values around 10 to more terrestrial values above 15 [16] (Fig. 2, Supplementary Table S1). Sulphate reduction and ammonification were diminished in this zone, as $\mathrm{Cl}^{-} / \mathrm{SO}_{4}{ }^{2-}$, $\Sigma \mathrm{H}_{2} \mathrm{~S}$, total alkalinity (TA) and $\mathrm{NH}_{4}{ }^{+}$dropped in concentration. The Cinq Cases pool system on the island of Grand Terre (Fig. 1e, Table 1) is dependent on meteoric water during the rainy season (November-April) and occasional flooding from the lagoon during spring tides. Some areas experience minor tidal water level fluctuations, suggesting low connectivity to marine waters through the karstic limestone [12]. The sediment was covered by a $1-2 \mathrm{~cm}$ thick microbial mat with peak concentrations of $\mathrm{Cl}^{-}$ $/ \mathrm{SO}_{4}{ }^{2-}, \Sigma \mathrm{H}_{2} \mathrm{~S}$, TA and $\mathrm{NH}_{4}{ }^{+}$. The underlying sediment consisted of light grey silt and showed a considerable decrease in concentration of the same porewater components. The drop occurred alongside a significant increase in salinity from $56 \mathrm{~g} / \mathrm{kg}$ in the mat to $82 \mathrm{~g} / \mathrm{kg}$ at $10 \mathrm{~cm}$ bsf (Fig. 2, Supplementary Table S2). The Eh increased from reducing conditions $(-41 \mathrm{mV}$ at $0 \mathrm{~cm}$ bsf) to increasingly oxidizing conditions, stabilizing at $+150 \mathrm{mV}$ around $10 \mathrm{~cm}$ bsf. Below $10 \mathrm{~cm}$ of depth $\mathrm{Cl}^{-} / \mathrm{SO}_{4}{ }^{2-}$ recovered to values around 7.1 and the other porewater components remained stable. A further change in sediment stratification was observed as a high TOC layer between 22.5-27.5 cm bsf. TIC was almost completely absent in this layer, which had an ochre colour. Total $\mathrm{N}$ and $\mathrm{S}$ in the sediment matched the peak in TOC (Fig. 2). The deepest sediment 
layer at Cinq Cases (30-35 cm bsf) was dark brown in colour (Fig. 1e) and rich in plant-based organic matter as the $\mathrm{C} / \mathrm{N}$ ratio reached its maximum (Fig. 2).

Bacterial community composition and diversity in sediments of Aldabra

Sequencing of the V3-V4 region of 16S rRNA genes (total or DNA-based community) and transcripts (active or RNA-based community) yielded a total of 8,473,178 (DNA) and 9,941,279 (RNA) high-quality reads. On average $79 \%$ of the reads passed bioinformatic processing and taxonomic assignment (Table 1, Supplementary Table S3). The final amplicon sequence variant (ASV) count was 32,331 in the total and 28,212 in the active community. Bacterial diversity and richness were significantly higher in the total than in the active community, which is also reflected in the proportion of unclassified taxa (Table 1). The average amount of unclassified taxa was highest at Cinq Cases for DNA-based (17.1\%) and in the North Lagoon for RNAbased communities (10 \%) (Table 1). Faith's phylogenetic diversity (PD) ranged from 230.9 in the total and 94.6 in the active community of the West Lagoon to 350.1 (DNA) and 236.5 (RNA) in the North Lagoon (Table 1, Fig. 3). 

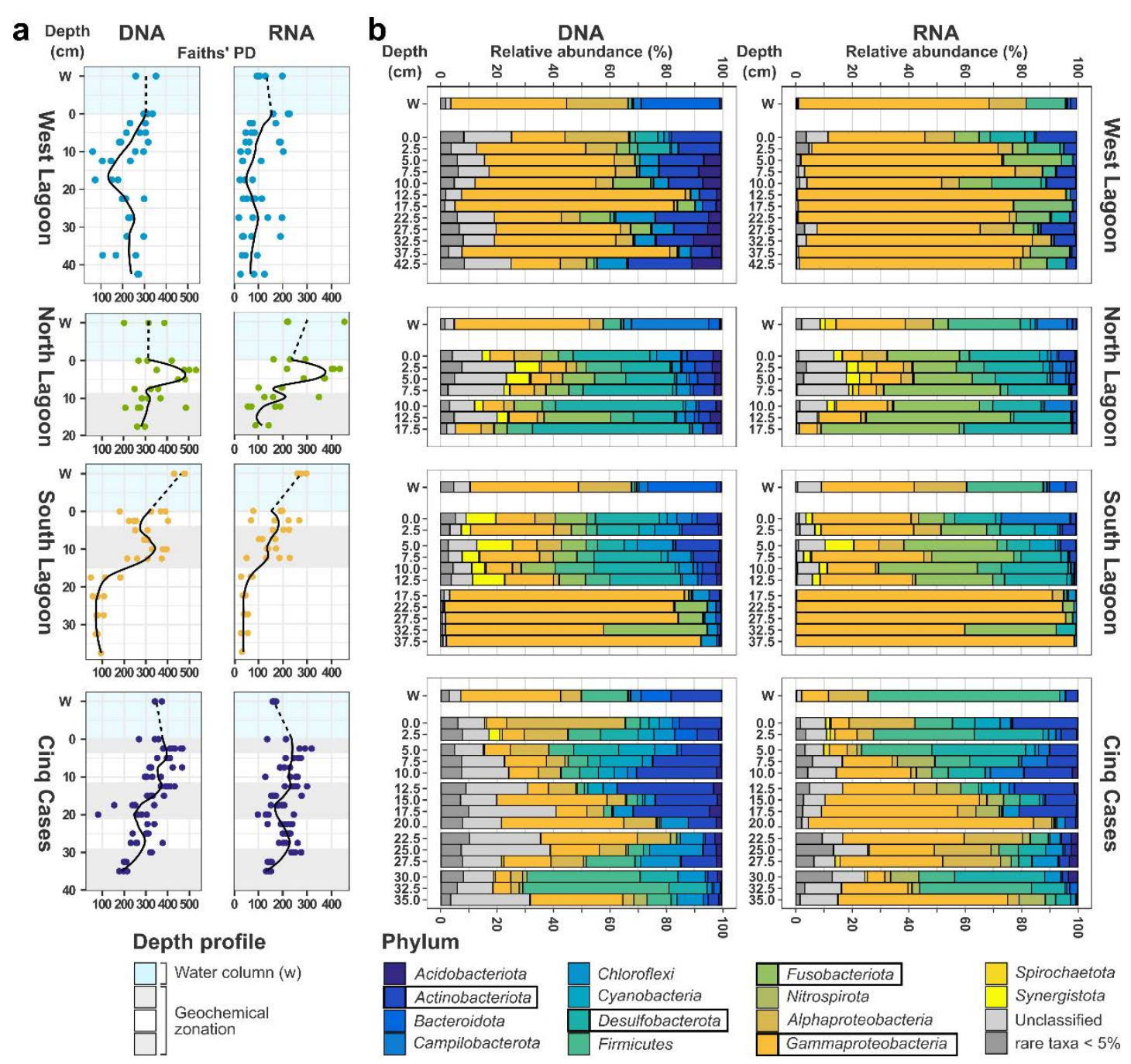

Figure 3. Overview of phylogenetic diversity gradients (a) and bacterial community composition (b) along sediment cores of the Aldabra Atoll. a: Faiths' phylogenetic diversity (PD) of the DNA and RNA-based community in relation to depth at each sampling site. b: Most abundant bacterial phyla ( $>5 \%$ relative abundance in at least one sample) in the total (DNA) and potentially active (RNA) community of the sediment and water column (W). Phyla below the threshold are summarized as rare taxa. Replicate samples from each core were averaged by depth. The most abundant phyla are highlighted by black boxes in the legend. Shading (a) and gaps (b) highlight the geochemical zonation.

The richness indicator Chao1 followed the same pattern (Table 1). In the West Lagoon, only bacterial richness in the active community decreased significantly with depth (Supplementary Table S2). The high diversity in the North Lagoon (0-7.5 cm bsf) occurred alongside increased phosphate and TOC concentrations and decreased in the sulphate reduction zone (10-17.5 cm bsf). In the South Lagoon, diversity and richness decreased significantly from the enhanced sulphate reduction zone to the underlying sediment. At Cinq Cases the sulphate reduction zone and highest diversity coincided with the microbial mat (0-2.5 cm bsf). Below this zone diversity fluctuated alongside changes in $\mathrm{Cl}^{-} / \mathrm{SO}_{4}{ }^{2-}$ ratio, salinity, and TOC (Fig. 2, Fig. 3). Both DNA-based 
phylogenetic diversity and richness decreased significantly with sediment depth alongside extracted DNA concentrations (Supplementary Table S2).

Total and active bacterial community structure along sediment cores

The compositions of the total and active bacterial community did not differ significantly from each other (Procrustes: correlation $=0.816, \mathrm{p}$-value $=0.001, \mathrm{n}=$ 130; Fig. 4). The Cinq Cases community clustered in accordance with the geochemical zones determined by the porewater profiles (Fig. 2), while the surface and sulphate reduction zones of the North and South Lagoon overlapped. The sediment crust in the West Lagoon (0-2.5 cm bsf) was treated as individual zone and clustered separately in the total, but not in the active community (Fig. 4).
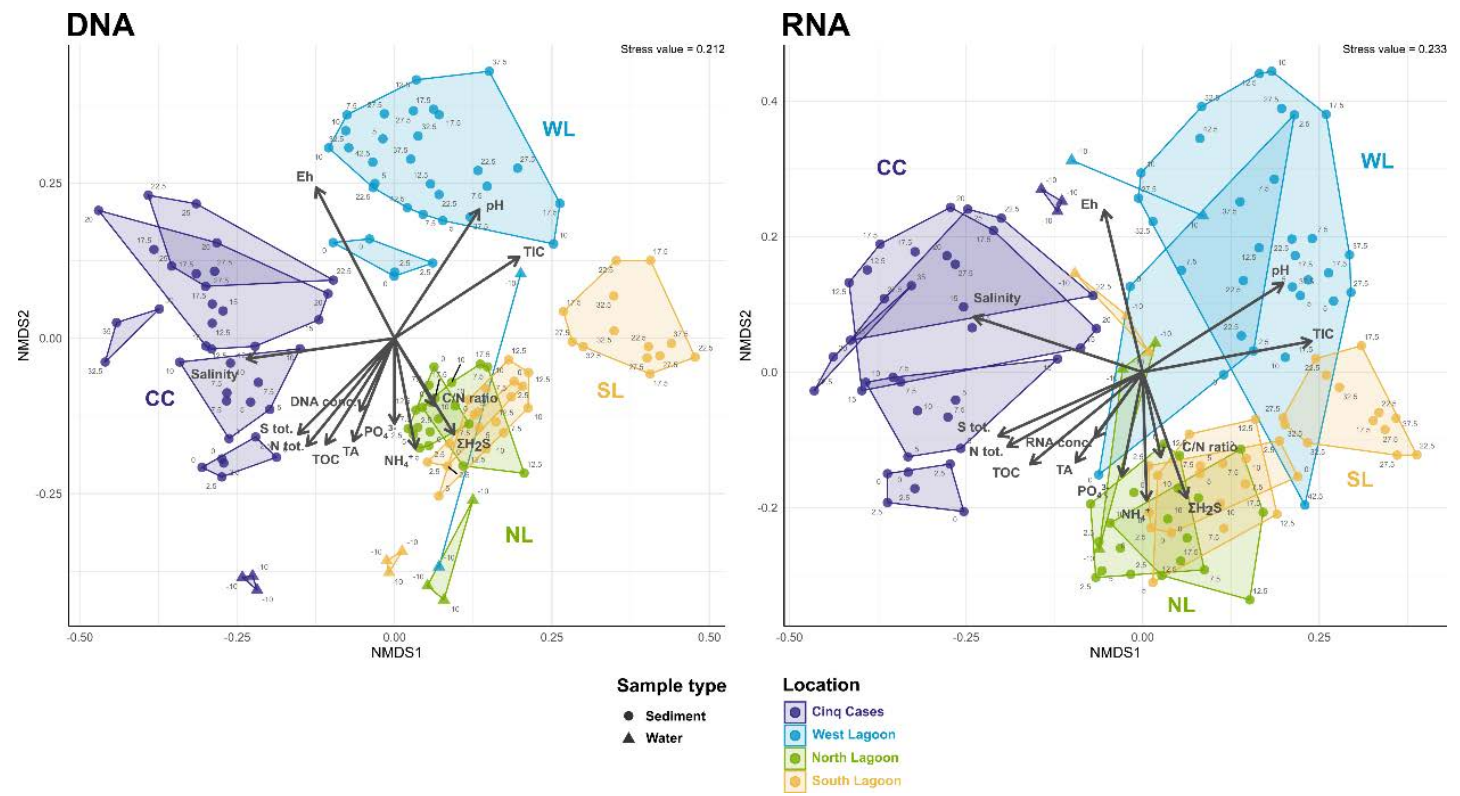

Figure 4. Non-metric multidimensional scaling of total and active bacterial community composition, geochemical zonation and significantly correlated environmental factors. NMDS based on a Bray-Curtis distance matrix of all DNA- and RNA-based sediment and water samples. The ASV table was normalized using GMPR [75], and technical and biological replicates were averaged. Outlines indicate the geochemical zonation. Environmental fit was plotted if $\mathrm{p} \leq 0.05$ (Supplementary Table $\mathrm{S} 2$ ) using $\mathrm{R}^{2}$ as arrow length.

The most abundant bacterial phyla (Fig. 3) and genera (Supplementary Fig. 1) highlight broad shifts in community composition along the sediment cores. Association networks were calculated to identify key genera which preferentially occur within the total or active community and each geochemical zone (Fig. 5, Supplementary Fig. 2). 


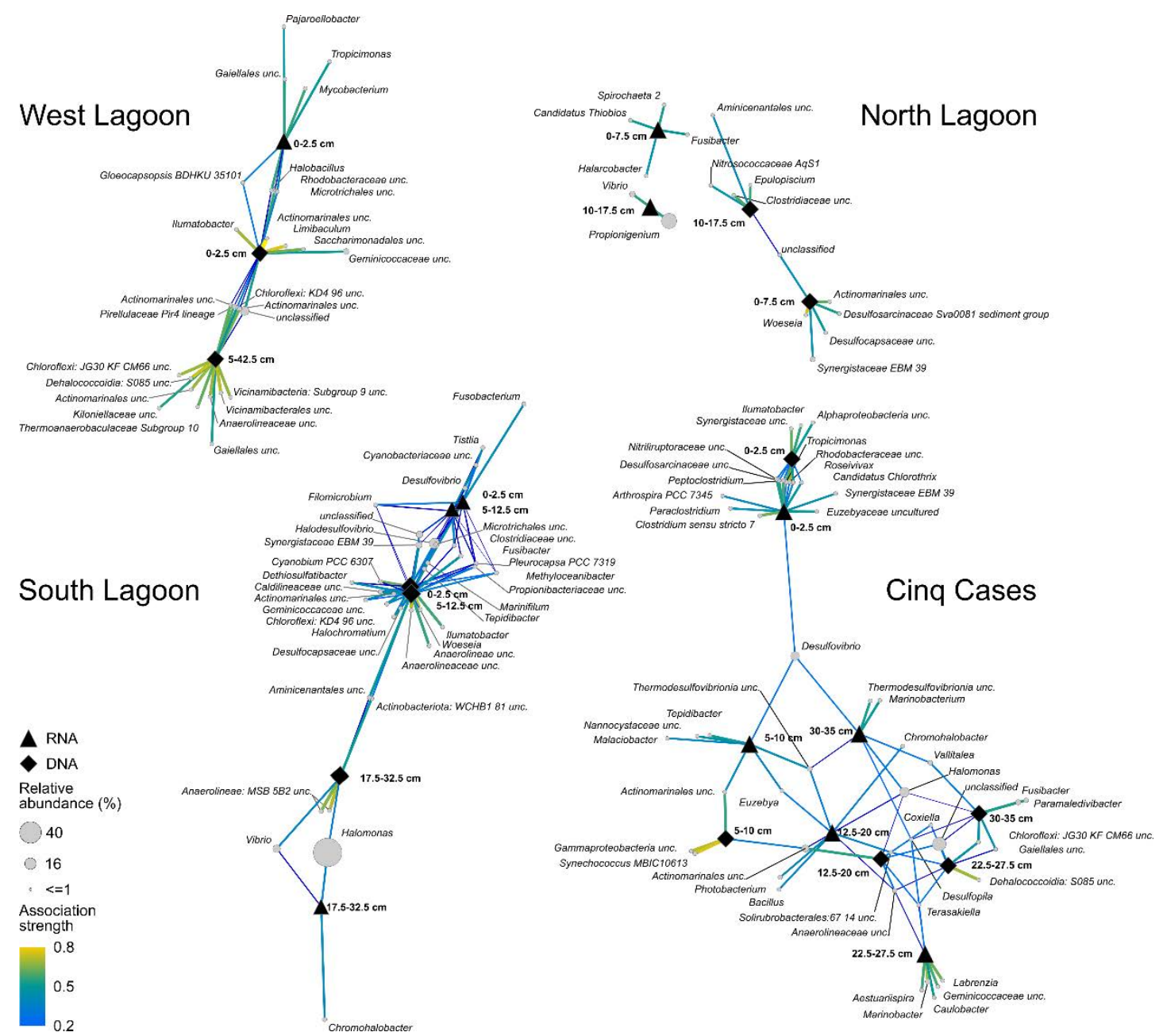

Figure 5. Genera associated with the total or active community fraction at each sampling site based on the geochemical zonation. The network was calculated using the multipatt analysis from the indicspecies package [81]. Circle sizes indicate the mean relative abundance between all samples. Edges are coloured according to their association strength to each target zone. Unclassified signifies ASVs which could not be taxonomically classified at genus level.

The West Lagoon sediment was dominated by Gammaproteobacteria (Pseudomonas), which were also detected in some samples within the water column (Fig. 3, Supplementary Fig. S1). As they were present at all depths Pseudomonas members were not significantly associated with a particular sediment zone (Fig. 5). The top 0$2.5 \mathrm{~cm}$ bsf consisted of a lithified crust, with high relative abundances of Alphaproteobacteria and Halodesulfovibrio (Fig. 3, Fig. 5), and was considered as a separate layer in the subsequent analysis. The crust was associated with cyanobacterial Gloeocapsopsis and Rhodobacteraceae, as well as uncultured Actinomarinales at the total and Tropicimonas at active community level. The total community of the crust had the highest amount of rare associated genera at the West Lagoon (Supplementary Fig. 2). The association index did not identify any abundant or rare genera associated 
with the active community at $5-42.5 \mathrm{~cm}$ bsf. The total community in these sediments was associated with Chloroflexi and Thermoanaerobaculaceae (Fig. 5).

The North Lagoon cores exhibited the highest bacterial diversity and richness (Table 1), its community shifting gradually with depth. Desulfobacterota, particularly Halodesulfovibrio, occurred up to $52 \%$ relative abundance at DNA level and Fusobacteriota up to $49 \%$ of at RNA level (Fig. 3, Supplementary Fig. S1), both increasing with sediment depth. At RNA level, the genus Propionigenium was strongly associated with the sulphate reduction zone at $10-17.5 \mathrm{~cm}$ bsf (Fig. 5) in which it was the most abundant genus. Campylobacterota (Fig. 3) were present within the water column (uncultured Arcobacteraceae) and throughout the sediments (Halarcobacter, Sulfurimonas) (Fig. 5, Supplementary Fig. S1). Halarcobacter was also associated with RNA-based community at 0-7.5 cm bsf (Fig. 5).

There was no clear community shift from surface to sulphate reduction zone in the South Lagoon. The phylum and genus level community composition mirrored that of the North lagoon (Fig. 3, Supplementary Fig. S1) and clustered closely together (Fig. 4). The fusobacterial Propionigenium was present throughout the sediment, particularly in the active community (Supplementary Fig. S1). Most associated taxa were shared between surface and sulphate reduction zone. Cyanobacteria were more strongly associated with the total than the active community. A strong shift in bacterial community composition occurred at $17.5 \mathrm{~cm}$ bsf accompanied by a drop in phylogenetic diversity (Fig. 3). From $17.5 \mathrm{~cm}$ bsf, Halomonas contributed up to $87 \%$ of the total and $66 \%$ of the active community (Supplementary Fig. S1). The number of associated bacterial genera decreased to three in the RNA-based and four in the DNA-based community, namely Chromohalobacter (RNA), two uncultured Anaerolineae (DNA), Halomonas and Vibrio (shared) (Fig. 5). The same trend was observed for the fraction with relative abundances $<2 \%$ (Supplementary Fig. S2).

The sediment at Cinq Cases showed the strongest changes in community along the sediment column. Starting in the microbial mat and underlying sediment (0-2.5 $\mathrm{cm}$ ), the community shifted from abundant Alphaproteobacteria (Tropicimonas) to Cyanobacteria (Synechococcus), Desulfobacterota (Desulfovibrio) and increasing proportions of Actinobacteriota (Actinomarinales) at 5-10 cm bsf (Fig. 3, Fig. 5). Cyanobacteria peaked in the DNA-based community at 5-10 cm bsf, while the RNAbased community harboured increased proportions of Campylobacterota (Fig. 3b). 
Actinobacteriota and Gammaproteobacteria (Halomonas) were most abundant in the 12-20 cm bsf zone (Fig. 3) where some of the lowest values for diversity were recorded (Fig. 3a). Higher relative abundances of Chloroflexi (DNA) and Alphaproteobacteria (RNA) were observed from 22.5-27.5 cm bsf alongside a peak in TOC and increasing phylogenetic diversity (Fig. 3a). The bottom sediment zone (30-35 cm bsf) was characterized by a high proportion of Firmicutes and Desulfobacterota (Fig. 3b). The association network for Cinq Cases showed that the total and active community at 0 $2.5 \mathrm{~cm}$ bsf shared most of their associated genera (>5\%) (Fig. 5). A larger number of rare genera $(<5 \%)$ was connected with the total (152) than with the active (54) community (Supplementary Fig. S2). At $5-10 \mathrm{~cm}$ bsf the campylobacterial Malaciobacter was associated with the total, while Synechococcus MBIC10613 was strongly associated with the active community. Alongside the low diversity, low TOC, total S and N (Fig. 2), a low number of genera were detected in association with the rare community from 12-20 cm bsf (Supplementary Fig. S2). The active community at $22.5-27.5 \mathrm{~cm}$ bsf was the most distinct from other sediment layers at Cinq Cases. It was associated with Alphaproteobacteria (e.g., Aestuariispira, Labrenzia, Caulobacter) and Marinobacter (Gammaproteobacteria; Fig. 5). The total community at this depth showed a preference of S085 Dehalococcoidia. The sediments from 30$35 \mathrm{~cm}$ bsf were associated with Fusibacter in the total, and Desulfovibrio and uncultured Thermodesulfovibrionia in the active community (Fig. 5, Supplementary Fig. S1). The association network of rare genera (Supplementary Fig. S2) generally shows much less interconnectivity between the deeper sediments, than the network of most abundant genera (Fig. 5).

Despite their spatial proximity, the bacterial community observed in the water samples differs strongly from the sediment communities. The amount of unknown and rare bacterial taxa within the water samples was low with $<9 \%$ relative abundance in the total and $<7 \%$ of the active community (Fig. 3b). Of the overall 30 most abundant genera, only few appeared in the water column with low relative abundances (Supplementary Fig. S1). In addition to the ubiquitous Gammaproteobacteria (Litoricola), the water column harboured high abundances of Alphaproteobacteria (HIMB11) and Bacteroidota (uncultured Cryomorphaceae) at total community level (Fig. 3, Supplementary Fig. S1). Bacteroidetes reached only low relative abundances in the active community, while Firmicutes were more abundant. 


\section{Discussion}

The Aldabra Atoll provides an ideal opportunity to study bacterial succession and geochemical zonation under changing porewater dynamics. Due to strong tidal currents, sediments poorly accumulate in the lagoon and are limited in depth depending on the karst structure of the limestone below. Nevertheless, we expected to find bacterial communities and porewater gradients reflecting the standard geochemical zonation. This would follow an energetically favourable progression from oxygen to nitrate to sulphate as main electron acceptor [2 and references therein]. Our results, however, show overlapping signatures of porewater dynamics, location and time which diverge from this pattern.

A gradient of decreasing porewater dynamics can be observed from the West Lagoon, over the North and South Lagoon, to Cinq Cases (Fig. 6).

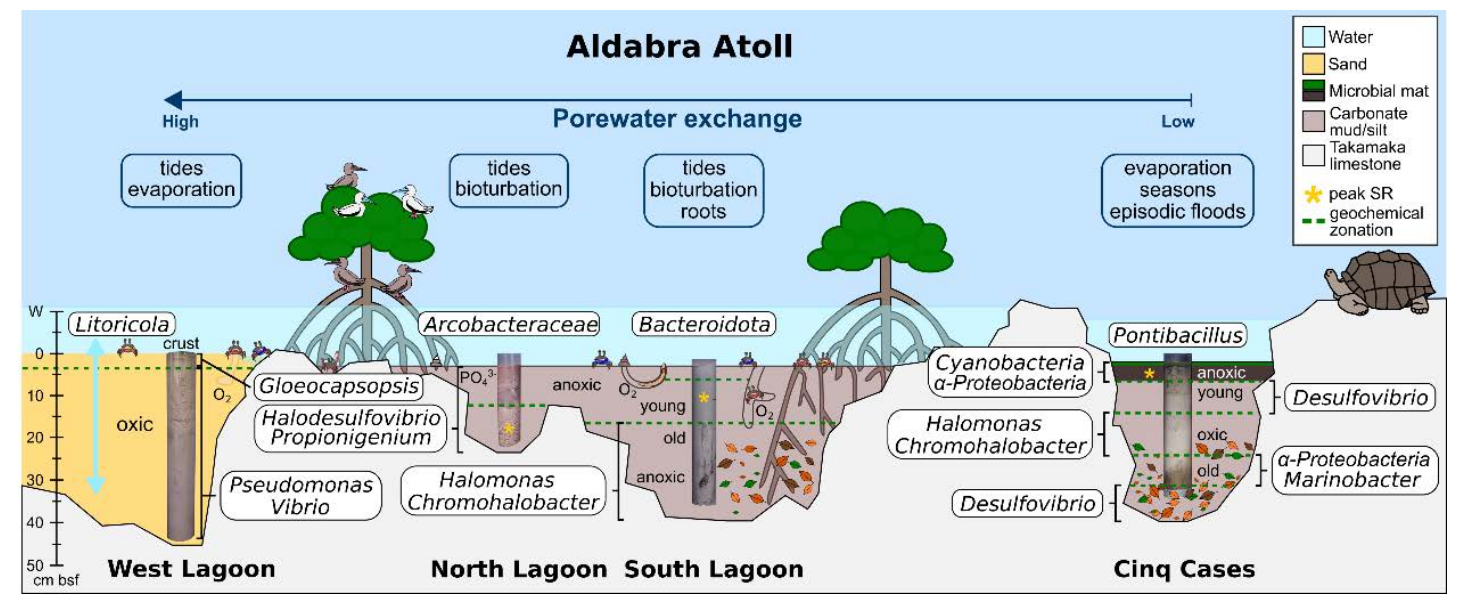

Figure 6. Model of Aldabra's sediment environments, detected bacterial key taxa and geochemical zones. The sampling sites are ordered by sediment dynamic from left to right, starting with the highest. Most abundant bacterial taxa at each site are indicated close to the respective sediment core. Pictograms indicate further factors, such as macrofaunal input, bioturbation and mangrove roots and detritus.

In the West Lagoon the fluctuation is high as sediments fall dry at low tide leading to a complete exchange of porewaters. This also results in a tidal exchange of the bacterial community, visible as overlap of water and sediment communities of the West Lagoon (Fig. 4). Planktonic taxa which are associated with the water column, i.e. Litoricola and alphaproteobacterial HIMB11 [17,18], do not accumulate in the sediment. Like the ooid sediments of the Bahamas [19], the Kiritimati lagoon [20], and Wadden Sea sands [21], the sand community of the West Lagoon is dominated by Gammaproteobacteria, primarily Pseudomonas and Vibrio (Fig. 3b, Supplementary 
Fig. S1). Pseudomonas may persist by attaching to sand particles thereby resisting the strong advection caused by the tides [19]. No strong geochemical changes or microbial gradients can be observed along the West Lagoon sediment cores, however, a lithified crust at the surface beckons further investigation. The total community of the crust ( 0 $2.5 \mathrm{~cm}$ bsf) is inhabited by Desulfobacterota (Fig. 3b) and diverse rare taxa (Supplementary Fig. S2), which may represent remnant members of a microbial mat. As the mat dried out and calcified, their DNA may have been protected by exopolymeric substances in the surrounding mat [6 and references therein]. In comparison only the uppermost sample of the active community reflects the current biofilm where phototroph Gloeocapsopsis are potentially involved in the lithification process of the crust [22]. The total community of the remaining sediment $(5-42.5 \mathrm{~cm}$ bsf) shows traces of anaerobic digesters, such as Anaerolinea or Thermoanaerobaculales (Fig. 5). They may have accumulated through tidal porewater drag from the mangrove hinterland and are either inactive under the oxic conditions or persist in oxygen-poor micro-niches [19,23 and references therein].

The North and South Lagoon represent environments with intermediate porewater exchange (Fig. 6). The sediments do not fall completely dry at low tide and are affected by mixing through the currents and bioturbation. Similar to the West Lagoon, Bacteroidota are most abundant in the total community of the lagoon water (Fig. 3b). As globally abundant primary degraders of phytoplankton blooms [24,25], their activity may be linked to phytoplankton abundance on Aldabra. Blooms may occur in eddies around the atoll [26] or more stagnant areas in the lagoon. Site specific differences in the lagoon water were most obvious in the North Lagoon where the presence of a bird colony lead to increased phosphate concentrations and an enrichment of Campylobacterota (Fig. 3b) including uncultured Arcobacteraceae and Arcobacter, which are typical for faecal contamination [27]. The porewater profiles of the North and South Lagoon mud and silt sediments follow the standard geochemical zonation [2] with a surface zone of up to 7.5 and $2.5 \mathrm{~cm}$ in the North and South Lagoon respectively, and an enhanced sulphate reduction zone below. The transition can be identified through a significant increase in $\mathrm{Cl}^{-} / \mathrm{SO}_{4}{ }^{2-}$ ratio, $\Sigma \mathrm{H}_{2} \mathrm{~S}$ and TA (Fig. 2). The bacterial community reflects these transitions gradually at best resulting in a mixed surface and sulphate reduction zone. We detected typical photo(hetero-)troph Cyanobacteria (Pleurocapsa, Cyanobium) and Alphaproteobacteria (Tropicimonas, 
Roseivivax) indicative of a surface zone with oxygen and light exposure, alongside bacteria known for their anaerobic metabolism (Propionigenium, Synergistaceae) and sulphate reduction ((Halo-)Desulfovibrio) (Fig. 3, Fig. 5, Supplementary Fig. 1). Benefiting from the sulphate reduction, Halarcobacter [28] and Candidatus Thiobios [29] oxidize sulphur compounds in the sediment directly above the highest measured $\Sigma \mathrm{H}_{2} \mathrm{~S}$ concentrations (Fig. 5). Proteolytic Synergistia (EBM 39), which were frequently observed alongside Desulfobacterota, provide additional sulphate and short-chained fatty acids [30]. Notably, Synergistales have been linked to methane production, as they grow syntrophically with methanogenic archaea [31]. Increased abundance of Synergistales may, therefore, be regarded as an indicator for methanogenesis particularly under the strongly reducing Eh of the North and South Lagoon sediments. Bacterial ammonia oxidizers were rarely detected, yet, ammoniaoxidizing archaea may be prevalent near the sediment surface [32]. The high phylogenetic diversity and variety of metabolic groups in these sediments, can be linked to both the porewater exchange with the water column [4] and strong bioturbation by i.e. fiddler crabs [5], which introduce nutrients and oxygen. The mixing also creates a multitude of microinches in the mainly anoxic sediments, leading to an enrichment of rare bacterial genera (Supplementary Fig. S2). This results in the observed mixed surface and sulphate reduction zone of the bacterial community, which cannot be distinguished as clearly as the porewaters imply.

While the North Lagoon sediments end with the sulphate reduction zone, the South Lagoon shows an additional atypical zone below. The porewater measurements and bacterial diversity drop substantially below $17.5 \mathrm{~cm}$ bsf (Fig. 2, Fig. 3). Although the presence of methanogenic archaea cannot be excluded, the abundant aerobic and facultatively anaerobic Halomonas, Vibrio and Chromohalobacter [33-35] do not match our expectations for anoxic sediments. We hypothesize that the change in bacterial community may rather be linked to a change in sediment age and abundant mangrove detritus. The change occurs below $17.5 \mathrm{~cm}$ where low quantities of extractable DNA and RNA, lower bacterial diversity and richness (Supplementary Table S1) indicate low microbial biomass. At this stage, the majority of remnant DNA from previous inhabitants may already be degraded, removing most rare and sedimented taxa. Deeper sediment layers have previously been found to record generalist communities, which can persist on less labile substrates through their 
efficient energy metabolism [15,36]. Even though the age difference is short on a geological time scale, this would explain the high relative abundances of a few versatile and specialised genera. For instance, Gammaproteobacteria have been linked with the ability to degrade organic matter in sediments with low levels of oxygen [37]. The available mangrove detritus may be in various states of decomposition visible through the increase in $\mathrm{C} / \mathrm{N}$ ratio (Fig. 2) [38]. As both Halomonas and Chromohalobacter have been observed to break down even aromatic hydrocarbons [39], they may thrive on the complex mangrove detritus. Other taxa, such as uncultured Anaerolineae may follow a different strategy and persist in this sediment through a reduced metabolism and specialisation for starvation [40]. This would also explain their reduced abundance at active community level. Deeply burrowing marine fauna or plant-degrading fungi may also impact the older sediment $[38,41]$.

At the first glance, Cinq Cases is the most settled of the four settings regarding the exchange of porewaters. It is barely affected by tidal fluctuations, therefore time and season become dominant factors. The water level at Cinq Cases is mainly determined by the rainy season and high spring tides, as well as strong evaporation during the dry season [12]. This has allowed the accretion of sediments over time, creating five distinct sediment layers including a microbial mat on the surface (Fig. 6). We expected to see clear porewater zones and corresponding community shifts in the cores, together with fully reducing redox conditions. On the contrary, we encountered mainly oxidizing sediments with strongly overlapping signatures. Starting at the sediment surface, the microbial mat drives the porewater geochemistry of the first few centimetres. It harbours the main sulphate reduction and ammonification zone of the sediment, indicated by peaks in $\Sigma \mathrm{H}_{2} \mathrm{~S}$ and ammonia (Fig. 2). The bacterial community composition resembles previous studies of microbial hypersaline mats and further subsectioning would likely yield a finer zonation [42]. Below the mat, a strong diffusion gradient to moderately hypersaline conditions drives the porewater geochemistry up to $10 \mathrm{~cm}$ bsf. The diffusion gradient and the change to oxidizing Eh suggests a complete desiccation event in the past resulting in older evaporated sediment below $10 \mathrm{~cm}$ bsf. The presence of Synechococcus in the total but not in the active community at $0-5 \mathrm{~cm}$ bsf, indicates remnants of former cyanobacterial blooms or mat. As a pile up of mats is often observed [43] this sediment may represent the old sediment surface. Like the community at $17.5-35 \mathrm{~cm}$ bsf in the South Lagoon, we find a decrease in 
diversity, as well as Halomonas and Chromohalobacter associated with the active community below $12.5 \mathrm{~cm}$ bsf (Fig. 5). As mentioned above, these taxa may be adapted to a change to less labile organic matter and, in this case, salinity. As the $\mathrm{C} / \mathrm{N}$ ratio increases and the metabolic products of the fast-lived surface community become scarce, the ability to degrade complex organic matter may become an increasingly important driver for the Cinq Cases community. This culminates in a high TOC layer (22.5-27.5 cm bsf) where the typical carbonate particles (e.g., mollusc and green algal fragments, foraminifera) of Aldabra are absent. The layer harbours high abundances of aerobic Alphaproteobacteria (Caulobacter, Aestuarispiira) and Marinobacter (Fig. 5), which have been found in putrid [44] and hydrocarbon-producing systems [45], suggesting that they can degrade the organic matter responsible for the high TOC. Caulobacter have been reported to flourish in organic soils and survive desiccation [46]. As the Eh and salinity suggest the occurrence of a desiccation event (Fig. 2), this would explain their presence at this depth, as well as the overall low phylogenetic diversity (Fig. 3a). Slow growing Desulfopila [47] and Fusibacter (Firmicutes), which have been found to occur in saline sediment with low sulphate reduction rates [48], may survive through slower fermentation of a wide range of carbohydrates [49]. The bacterial community of the deepest sediment (30-35 cm bsf) shows similarities to the uppermost 5-10 cm bsf, as the same sulphate reducing taxa are associated with the active community (Fig. 5). The higher abundance of Fusibacter in the total than in the active community, suggests they only tolerate the suboptimal oxidizing conditions and persist in the sediment through a maintenance metabolism [36]. The change to more plant-bound organic matter (higher $\mathrm{C} / \mathrm{N}$ and leaf litter) at this depth may again explain the change in community composition [38], as well as the switch in dominant sulphate reducers throughout the cores (Fig. 5).

To conclude the results of all sampling sites, we find that the bacterial communities of the Aldabra's sediments are dominated by Gammaproteobacteria and Desulfobacterota at both the total and active community level (Fig. 3). These bacterial taxa are commonly found in marine or saline sediments and water samples ranging from the Arctic [50] to the tropics [51] and the deep sea [52]. Desulfobacterota are the main sulphate reducers on Aldabra, albeit the dominant genera differ between sampling sites. While the lagoon sediments harbour mainly Halodesulfovibrio, their environmental niche is filled by Desulfovibrio at Cinq Cases. The latter have been 
found in extreme hypersaline sediment and may be better adapted to saline conditions [53]. Anaerobic Propionigenium occur exclusively in the lagoon sediments, where they have been associated with bioturbation [54]. The higher diversity and amount of associated genera in the total community, particularly in the surface sediments (Fig. 5, Supplementary Fig. S2), are in line with observations, that sequencing of sediment DNA shows an overlap between current community members and free environmental DNA, former, dormant, and sedimented taxa [6].

The changes in bacterial community composition are related to short-term porewater fluxes as well as long-term seasonal and episodic changes. The West Lagoon, characterized by the strong porewater exchange, harbours an established community of aerobic heterotrophs. As the tidal water exchange occurs regularly, this allows only few anaerobic taxa to remain in anaerobic micro-niches. The North and South Lagoon are less affected by the tides, allowing them to maintain a highly diverse surface sediment community similar to other tropical locations [55]. A switch in sediment age at $17.5 \mathrm{~cm}$ depth is signified by a substantial decrease in diversity, including a shift in dominant metabolic type from sulphur cyclers and methylotrophs to denitrifying and complex organic matter degrading Gammaproteobacteria. The latter can cope with the concomitant shift from readily available organic matter to mangrove detritus. Similar community shifts related to organic matter have been observed for instance in older Baltic Sea sediments [56]. Cinq Cases shows the least porewater exchange at first glance, depending on the seasons rather than the tides. However, on a long-term scale the small water body in comparison to the lagoon experiences episodic exchanges of porewaters due to desiccation events. This results in formation of oxidizing hypersaline sediments at the bottom, covered by less saline Holocene sediment and a microbial mat. As drought conditions on Aldabra have tripled in the past fifty years [10], desiccation events driving the bacterial community may become increasingly frequent. With the ongoing climate change, this may ultimately lead to the disappearance of long-term stable pools including the previously described stromatolites [12]. 


\section{Methods}

\section{Sample collection and storage}

Samples were taken during an expedition to the Aldabra Atoll in November 2017. Sediments were sampled using push cores made from PVC tubes (Ø $63 \mathrm{~mm}$, Thyssenkrupp Plastics, Essen, Germany) at three sites on the tidal flats of the lagoon (North, South and West Lagoon), and one site at the Cinq Cases pools on Grand Terre island (Fig. 1). At each sampling site, three sediment cores were taken for microbial analysis and one each for porewater and sediment analyses (Supplementary Fig. S3). The cores were subsampled at intervals of $2.5-5 \mathrm{~cm}$ bsf with the exclusion of $1 \mathrm{~cm}$ of the outer rim, to avoid cross contamination from the coring tube. Three $200 \mathrm{ml}$ water samples were taken $10 \mathrm{~cm}$ above each sediment and filtered through a $0.2 \mu \mathrm{m}$ polyethersulfone (Sartorius, Göttingen, Germany) and $3.0 \mu \mathrm{m}$ polycarbonate (Merck, Darmstadt, Germany) filter sandwich with a diameter of $47 \mathrm{~mm}$. Filter sandwiches were placed on NALGENETM reusable filter holders with receivers and water samples filtered using vacuum from a NALGENE ${ }^{\mathrm{TM}}$ manually operated PVC Vacuum Pump (both Thermo Fisher Scientific, Waltham, MA, USA). All samples were immediately stored in RNAprotect ${ }^{\mathrm{TM}}$ Bacteria Reagent (Qiagen, Hilden, Germany). After transport, RNAprotect ${ }^{\mathrm{TM}}$ Bacteria Reagent was removed from all samples by centrifugation at $3,150 \times \mathrm{g}$ for 1 hour. The supernatant was decanted, and samples were placed at $-80{ }^{\circ} \mathrm{C}$ for long-term storage.

\section{Coextraction of DNA and RNA}

Sediment samples were thawed on ice and homogenized before weighing into the extraction tubes. DNA and RNA were extracted simultaneously using the RNeasy ${ }^{\mathrm{TM}}$ PowerSoil Total RNA Extraction kit and the RNeasy ${ }^{\mathrm{TM}}$ PowerSoil DNA Elution kit and $1 \mathrm{~g}$ of sediment or half of a filter (water samples) per extraction as recommended by the manufacturer (Qiagen, Hilden, Germany). Final elution was performed with $50 \mu 1$ nuclease-free water $(50 \mu 1)$. In addition, RNA samples were supplemented with $1 \mu 1$ of RiboLock RNase Inhibitor (Thermo Fisher Scientific, Waltham, MA, USA) before storage at $-80^{\circ} \mathrm{C}$. DNA and RNA concentrations were measured using a NanoDrop 1000 (Thermo Fisher Scientific, Waltham, MA, USA).

$R N A$ purification and reverse transcription

Potential DNA contaminations were removed from RNA samples according to Schneider et al., [57]. RNA was purified using the RNeasy ${ }^{\mathrm{TM}}$ MinElute kit according 
to manufacturers' instructions (Qiagen). Purified RNA was reverse transcribed using SuperScriptIV (Thermo Fisher Scientific) and the manufacturers' instructions for gene-specific primers with the reverse primer S-D-Bact-0785-a-A-21 [58]. To inhibit RNases $1 \mu \mathrm{l}$ of RiboLock (Thermo Fisher Scientific) was added to the reverse transcription reaction. cDNA was treated with $0.5 \mu \mathrm{l}$ of RNase $\mathrm{H}$ (Thermo Fisher Scientific) for $20 \mathrm{~min}$ at $37^{\circ} \mathrm{C}$.

\section{Amplification and sequencing of bacterial 16S rRNA genes and transcripts}

Bacterial 16S rRNA genes and transcripts were amplified by PCR using V3-V4 primers (SD-Bact-0341-b-S-17 and S-D-Bact-0785-a-A-21 [58], purified and sequenced as described by Berkelmann et al. [59].

Raw read and amplicon sequence processing

Raw reads were quality filtered and processed as described in detail by von Hoyningen-Huene et al. [60]. Where possible, processes were parallelized with GNU parallel 20190322 [61] and comprised the following steps and bioinformatic tools. Raw reads were quality-filtered with fastp 0.20.0 [62] and merged using PEAR v0.9.11 [63]. Any remaining primer sequences were clipped using cutadapt 2.5 [64]. After merging, sequences were processed into ASVs with VSEARCH v.2.14.1 [65]. This included size-sorting, dereplication and denoising using the UNOISE3 algorithm [66] and default parameters. Chimeras were removed using a de novo and reference-based search against the SILVA SSU 138 Ref NR 99 database [67]. Quality filtered reads were mapped back to the ASVs using usearch_global in VSEARCH. ASVs were taxonomically assigned using BLAST 2.9.0+ [68] against the SILVA SSU 138 Ref NR 99 database with an identity cutoff at $\geq 90 \%$. Uncertain blast hits were removed as described previously [59]. ASV tables were generated and formatted using biom tools v1.0 [69]. ASVs were aligned using MAFFT v7.407 [70] and a phylogenetic tree was calculated using FastTreeMP 2.1.10 [71]. The tree was midpoint-rooted using FigTree v1.4.4 [72]. The fasta file including all ASVs can be found in Supplementary File S1 and the ASV table in Supplementary Table S4.

\section{Data analysis and visualisation}

All data were analysed using R Version 4.0.0 [73] and RStudio Version 1.3.959 [74]. Extrinsic domains (chloroplasts, mitochondria, archaea, eukaryota) were removed from the dataset. ASVs with a blastn identity below $95 \%$ were labelled "unclassified". ASV tables were normalized using two different methods depending on the analysis. 
GMPR was used as normalization for comparative analysis of the microbial community [75] whereas diversity and richness indices were calculated from rarefied count data as recommended by Pereira et al. [76]. The former included the bar charts, heatmaps, NMDS and association networks. Data were analysed and visualized using ampvis2 [77], vegan [78] and ggplot2 [79]. The ASV count table was rarefied at 19,906 reads. The phylogenetic diversity (Faith's PD) was calculated using picante [80], a midpoint-rooted phylogenetic tree and the rarefied ASV table. Sediment zones were determined from the geochemical profiles (Fig. 2). Association networks for abundant and rare genera were calculated using the GMPR-normalized table of taxa above or below $2 \%$ (West, North, South Lagoon) or $5 \%$ (Cinq Cases) relative abundance. The geochemical sediment zones combined with total or active community were used as grouping variable for the multipatt analysis [81]. The resulting network table was visualized using an edge-weighted spring-embedded layout in Cytoscape version 3.8.2 [82].

The Map of Aldabra was kindly supplied by the Seychelles Island Foundation (SIF). The global map indicating the location of Aldabra was generated using ArcGis Desktop 10.7.1. [83] and Esri World imagery (Sources: Esri, DigitalGlobe, GeoEye, Earthstar Geographics, CNES/Airbus DS, USDA, USGS, AEX, Getmapping, Aerogrid, IGN, IGP, swisstopo, and the GIS User Community). Maps, photographs, and plots were combined using Inkscape 1.0 [84].

\section{Porewater and bulk sediment geochemistry}

At each sampling site except Cinq Cases, one core was taken for bulk geochemistry and one for pore water chemistry in close lateral distance. The core at Cinq Cases was used for both porewater and bulk geochemical analysis. Each core was subsampled at intervals of 2.5-5 cm of depth. Redox potential (Eh) and $\mathrm{pH}$ were measured directly through boreholes in the cored sediments within 24 hours after sampling with a portable WTW 340i pH meter, equipped with an Inlab Solids Pro pH-electrode (Mettler Toledo, Columbus, OH, USA) and a Pt 5900 A redox electrode (SI Analytics, Mainz, Germany; standard deviation $\leq 2 \%$ ). Porewater was extracted from the cores with $5 \mathrm{~cm}$ CSS Rhizon samplers (Rhizosphere, Wageningen, Netherlands). Porewater alkalinity (TA), cation $\left(\mathrm{Ca}^{2+}\right.$ and $\left.\mathrm{Na}^{+}\right)$and anion $\left(\mathrm{Cl}^{-}\right.$and $\left.\mathrm{SO}_{4}{ }^{2-}\right)$, as well as $\mathrm{NH}_{4}^{+}$, $\mathrm{PO}_{4}{ }^{3-}, \Sigma \mathrm{H}_{2} \mathrm{~S}$, and bulk organic (TOC), inorganic carbon (TIC), C, N, and S, were measured as described by Fussmann et al. [85]. Measured data were converted from 
molarity ( $\mathrm{mmol} / \mathrm{l})$ to molality $(\mathrm{mmol} / \mathrm{kg})$ by density calculations with the PHREEQC software package version 3 [86].

\section{Data availability}

All raw sequences were deposited at the NCBI Sequence Read Archive as part of the BioProject PRJNA611521 with the accessions SRR11295008- SRR1129550. An overview can be found in Supplementary Table S3.

\section{References}

1. Falkowski, P. G., Fenchel, T. \& Delong, E. F. The microbial engines that drive Earth's biogeochemical cycles. Science (New York, N.Y.) 320, 1034-1039 (2008).

2. Jørgensen, B. B. \& Kasten, S. in Marine Geochemistry, edited by H. D. Schulz \& M. Zabel (Springer-Verlag, 2006), pp. 271-309.

3. Broman, E., Sjöstedt, J., Pinhassi, J. \& Dopson, M. Shifts in coastal sediment oxygenation cause pronounced changes in microbial community composition and associated metabolism. Microbiome 5, 96 (2017).

4. Billerbeck, M. et al. Surficial and deep pore water circulation governs spatial and temporal scales of nutrient recycling in intertidal sand flat sediment. Mar. Ecol. Prog. Ser. 326, 61-76 (2006).

5. Booth, J. M., Fusi, M., Marasco, R., Mbobo, T. \& Daffonchio, D. Fiddler crab bioturbation determines consistent changes in bacterial communities across contrasting environmental conditions. Scientific reports 9, 3749 (2019).

6. Torti, A., Lever, M. A. \& Jørgensen, B. B. Origin, dynamics, and implications of extracellular DNA pools in marine sediments. Marine genomics 24 Pt 3, 185-196 (2015).

7. Stoddart, D. R. The conservation of Aldabra. The Geographical Journal 134, 471 (1968).

8. Hamylton, S., Spencer, T. \& Hagan, A. B. Spatial modelling of benthic cover using remote sensing data in the Aldabra lagoon, western Indian Ocean. Mar. Ecol. Prog. Ser. 460, 35-47 (2012).

9. Braithwaite, C. J. R. Last interglacial changes in sea level on Aldabra, western Indian Ocean. Sedimentology 67, 3236-3258 (2020).

10. Haverkamp, P. J. et al. Giant tortoise habitats under increasing drought conditions on Aldabra Atoll-Ecological indicators to monitor rainfall anomalies and related vegetation activity. Ecological Indicators 80, 354-362 (2017).

11. Hughes, R. N. \& Gamble, J. C. A quantitative survey of the biota of intertidal soft substrata on Aldabra Atoll, Indian Ocean. Phil. Trans. R. Soc. Lond. B 279, 327-355 (1977).

12. Braithwaite, C., Casanova, J., Frevert, T. \& Whitton, B. A. Recent stromatolites in landlocked pools on Aldabra, Western Indian Ocean. Palaeogeography, Palaeoclimatology, Palaeoecology 69, 145-165 (1989).

13. Potts, M. \& Whitton, B. A. Nitrogen fixation by blue-green algal communities in the intertidal zone of the lagoon of Aldabra Atoll. Oecologia 27, 275-283 (1977).

14. Potts, M. \& Whitton, B. A. Vegetation of the intertidal zone of the lagoon of Aldabra, with particular reference to the photosynthetic prokaryotic communities. Proc. R. Soc. Lond. B. 208, 13-55 (1980). 
15. Walsh, E. A. et al. Relationship of bacterial richness to organic degradation rate and sediment age in subseafloor sediment. Applied and environmental microbiology 82, 4994-4999 (2016).

16. Meyers, P. A. Preservation of elemental and isotopic source identification of sedimentary organic matter. Chemical Geology 114, 289-302 (1994).

17. Choi, A., Lee, K., Oh, H.-M., Feng, J. \& Cho, J.-C. Litoricola marina sp. nov. International journal of systematic and evolutionary microbiology 60, 1303-1306 (2010).

18. Durham, B. P. et al. Draft genome sequence of marine alphaproteobacterial strain HIMB11, the first cultivated representative of a unique lineage within the Roseobacter clade possessing an unusually small genome. Standards in genomic sciences 9, 632-645 (2014).

19. Diaz, M. R., Piggot, A. M., Eberli, G. P. \& Klaus, J. S. Bacterial community of oolitic carbonate sediments of the Bahamas Archipelago. Mar. Ecol. Prog. Ser. 485, 9-24 (2013).

20. Schmitt, S. et al. Salinity, microbe and carbonate mineral relationships in brackish and hypersaline lake sediments: A case study from the tropical Pacific coral atoll of Kiritimati. Depositional Rec 5, 212-229 (2019).

21. Dyksma, S. et al. Ubiquitous Gammaproteobacteria dominate dark carbon fixation in coastal sediments. The ISME journal 10, 1939-1953 (2016).

22. Dupraz, C., Visscher, P. T., Baumgartner, L. K. \& Reid, R. P. Microbe-mineral interactions: early carbonate precipitation in a hypersaline lake (Eleuthera Island, Bahamas). Sedimentology 51, 745-765 (2004).

23. Petriglieri, F., Nierychlo, M., Nielsen, P. H. \& McIlroy, S. J. In situ visualisation of the abundant Chloroflexi populations in full-scale anaerobic digesters and the fate of immigrating species. PloS ONE 13, e0206255 (2018).

24. Wietz, M., Gram, L., Jørgensen, B. \& Schramm, A. Latitudinal patterns in the abundance of major marine bacterioplankton groups. Aquat. Microb. Ecol. 61, 179-189 (2010).

25. Wemheuer, B. et al. Impact of a phytoplankton bloom on the diversity of the active bacterial community in the southern North Sea as revealed by metatranscriptomic approaches. FEMS microbiology ecology 87, 378-389 (2014).

26. Heywood, K. J., Stevens, D. P. \& Bigg, G. R. Eddy formation behind the tropical island of Aldabra. Deep Sea Research Part I: Oceanographic Research Papers 43, 555-578 (1996).

27. Pérez-Cataluña, A. et al. Revisiting the taxonomy of the genus Arcobacter: Getting order from the chaos. Frontiers in microbiology 9, 2077 (2018).

28. Sasi Jyothsna, T. S., Rahul, K., Ramaprasad, E. V. V., Sasikala, C. \& Ramana, C. V. Arcobacter anaerophilus sp. nov., isolated from an estuarine sediment and emended description of the genus Arcobacter. International journal of systematic and evolutionary microbiology 63, 4619-4625 (2013).

29. Rinke, C. et al. High genetic similarity between two geographically distinct strains of the sulfur-oxidizing symbiont 'Candidatus Thiobios zoothamnicoli'. FEMS microbiology ecology 67, 229-241 (2009).

30. Vartoukian, S. R., Palmer, R. M. \& Wade, W. G. The division "Synergistes". Anaerobe 13, 99-106 (2007).

31. Nakasaki, K., Koyama, M., Maekawa, T. \& Fujita, J. Changes in the microbial community during the acclimation process of anaerobic digestion for treatment of synthetic lipid-rich wastewater. Journal of biotechnology 306, 32-37 (2019).

32. Shiozaki, T. et al. Nitrification and its influence on biogeochemical cycles from the equatorial Pacific to the Arctic Ocean. The ISME journal 10, 2184-2197 (2016). 
33. González-Domenech, C. M., Martínez-Checa, F., Béjar, V. \& Quesada, E. Denitrification as an important taxonomic marker within the genus Halomonas. Systematic and applied microbiology 33, 85-93 (2010).

34. Farmer, J. J., Michael Janda, J., Brenner, F. W., Cameron, D. N. \& Birkhead, K. M. in Bergey's Manual of Systematics of Archaea and Bacteria, edited by W. B. Whitman, et al. (Wiley, 2015), pp. 1-79.

35. Ventosa, A. \& Haba, R. R. in Bergey's Manual of Systematics of Archaea and Bacteria, edited by W. B. Whitman, et al. (Wiley, 2015), pp. 1-16.

36. Lloyd, K. G. Time as a microbial resource. Environmental microbiology reports 13, 18 21 (2021).

37. Mahmoudi, N. et al. Microbial community composition and diversity in Caspian Sea sediments. FEMS microbiology ecology 91, 1-11 (2015).

38. Holguin, G., Vazquez, P. \& Bashan, Y. The role of sediment microorganisms in the productivity, conservation, and rehabilitation of mangrove ecosystems: an overview. Biology and Fertility of Soils 33, 265-278 (2001).

39. Nanca, C. L., Neri, K. D., Ngo, A. C. R., Bennett, R. M. \& Dedeles, G. R. Degradation of polycyclic aromatic hydrocarbons by moderately halophilic bacteria from Luzon salt beds. Journal of health \& pollution 8, 180915 (2018).

40. Bird, J. T. et al. Uncultured microbial phyla suggest mechanisms for multi-thousand-year subsistence in Baltic Sea sediments. mBio 10 (2019).

41. Moulton, O. M. et al. Microbial associations with macrobiota in coastal ecosystems: patterns and implications for nitrogen cycling. Front Ecol Environ 14, 200-208 (2016).

42. Schneider, D., Arp, G., Reimer, A., Reitner, J. \& Daniel, R. Phylogenetic analysis of a microbialite-forming microbial mat from a hypersaline lake of the Kiritimati atoll, Central Pacific. PloS ONE 8, e66662 (2013).

43. Harris, J. K. et al. Phylogenetic stratigraphy in the Guerrero Negro hypersaline microbial mat. The ISME journal 7, 50-60 (2013).

44. Park, S., Park, J.-M., Kang, C.-H. \& Yoon, J.-H. Aestuariispira insulae gen. nov., sp. nov., a lipolytic bacterium isolated from a tidal flat. International journal of systematic and evolutionary microbiology 64, 1841-1846 (2014).

45. Evans, M. V. et al. Members of Marinobacter and Arcobacter influence system biogeochemistry during early production of hydraulically fractured natural gas wells in the Appalachian Basin. Frontiers in microbiology 9, 2646 (2018).

46. Wilhelm, R. C. Following the terrestrial tracks of Caulobacter - redefining the ecology of a reputed aquatic oligotroph. The ISME journal 12, 3025-3037 (2018).

47. Suzuki, D., Ueki, A., Amaishi, A. \& Ueki, K. Desulfopila aestuarii gen. nov., sp. nov., a Gram-negative, rod-like, sulfate-reducing bacterium isolated from an estuarine sediment in Japan. International journal of systematic and evolutionary microbiology 57, 520-526 (2007).

48. Dawson, K. S., Scheller, S., Dillon, J. G. \& Orphan, V. J. Stable isotope phenotyping via cluster analysis of nanoSIMS data as a method for characterizing distinct microbial ecophysiologies and sulfur-cycling in the environment. Frontiers in microbiology 7, 774 (2016).

49. Fadhlaoui, K. et al. Fusibacter fontis sp. nov., a sulfur-reducing, anaerobic bacterium isolated from a mesothermic Tunisian spring. International journal of systematic and evolutionary microbiology 65, 3501-3506 (2015).

50. Trivedi, C. B. et al. Microbial metabolic redundancy is a key mechanism in a sulfur-rich glacial ecosystem. mSystems 5 (2020). 
51. Yun, J., Deng, Y. \& Zhang, H. Anthropogenic protection alters the microbiome in intertidal mangrove wetlands in Hainan Island. Applied microbiology and biotechnology 101, 6241-6252 (2017).

52. Suzuki, Y. et al. Deep microbial proliferation at the basalt interface in 33.5-104 millionyear-old oceanic crust. Communications biology 3, 136 (2020).

53. Kjeldsen, K. U. et al. Diversity of sulfate-reducing bacteria from an extreme hypersaline sediment, Great Salt Lake (Utah). FEMS microbiology ecology 60, 287-298 (2007).

54. Watson, J. et al. Reductively debrominating strains of Propionigenium maris from burrows of bromophenol-producing marine infauna. International journal of systematic and evolutionary microbiology 50 Pt 3, 1035-1042 (2000).

55. Andreote, F. D. et al. The microbiome of Brazilian mangrove sediments as revealed by metagenomics. PloS ONE 7, e38600 (2012).

56. More, K. D., Giosan, L., Grice, K. \& Coolen, M. J. L. Holocene paleodepositional changes reflected in the sedimentary microbiome of the Black Sea. Geobiology 17, 436-448 (2019).

57. Schneider, D., Wemheuer, F., Pfeiffer, B. \& Wemheuer, B. Extraction of total DNA and RNA from marine filter samples and generation of a cDNA as universal template for marker gene studies. Methods in molecular biology (Clifton, N.J.) 1539, 13-22 (2017).

58. Klindworth, A. et al. Evaluation of general 16S ribosomal RNA gene PCR primers for classical and next-generation sequencing-based diversity studies. Nucleic acids research 41, e1 (2013).

59. Berkelmann, D., Schneider, D., Hennings, N., Meryandini, A. \& Daniel, R. Soil bacterial community structures in relation to different oil palm management practices. Scientific data 7, 421 (2020).

60. Hoyningen-Huene, A. J. E. von et al. Bacterial succession along a sediment porewater gradient at Lake Neusiedl in Austria. Scientific data 6, 163 (2019).

61. Tange, O. Gnu parallel-the command-line power tool. login: The USENIX Magazine 36, 42-47 (2011).

62. Chen, S., Zhou, Y., Chen, Y. \& Gu, J. fastp: an ultra-fast all-in-one FASTQ preprocessor. Bioinformatics (Oxford, England) 34, i884-i890 (2018).

63. Zhang, J., Kobert, K., Flouri, T. \& Stamatakis, A. PEAR: a fast and accurate Illumina paired-end read merger. Bioinformatics (Oxford, England) 30, 614-620 (2014).

64. Martin, M. Cutadapt removes adapter sequences from high-throughput sequencing reads. EMBnet j. 17, 10 (2011).

65. Rognes, T., Flouri, T., Nichols, B., Quince, C. \& Mahé, F. VSEARCH: a versatile open source tool for metagenomics. PeerJ 4, e2584 (2016).

66. Edgar, R. C. UNOISE2: improved error-correction for Illumina 16S and ITS amplicon sequencing (2016).

67. Quast, C. et al. The SILVA ribosomal RNA gene database project: improved data processing and web-based tools. Nucleic acids research 41, D590-6 (2013).

68. Altschul, S. F., Gish, W., Miller, W., Myers, E. W. \& Lipman, D. J. Basic local alignment search tool. Journal of Molecular Biology 215, 403-410 (1990).

69. McDonald, D. et al. The Biological Observation Matrix (BIOM) format or: how I learned to stop worrying and love the ome-ome. GigaScience 1, 7 (2012).

70. Katoh, K. \& Standley, D. M. MAFFT multiple sequence alignment software version 7: improvements in performance and usability. Molecular biology and evolution 30, 772780 (2013).

71. Price, M. N., Dehal, P. S. \& Arkin, A. P. FastTree 2--approximately maximum-likelihood trees for large alignments. PloS ONE 5, e9490 (2010).

72. Rambaut, A. FigTree - tree figure drawing tool (2018). 
73. R Core Team. $R$ : A language and environment for statistical computing. (R Foundation for Statistical Computing, 2020).

74. RStudio Team. RStudio: integrated development for $R$ (RStudio Inc., 2021).

75. Chen, L. et al. GMPR: A robust normalization method for zero-inflated count data with application to microbiome sequencing data. PeerJ 6, e4600 (2018).

76. Pereira, M. B., Wallroth, M., Jonsson, V. \& Kristiansson, E. Comparison of normalization methods for the analysis of metagenomic gene abundance data. BMC genomics 19, 274 (2018).

77. Andersen, K. S., Kirkegaard, R. H., Karst, S. M. \& Albertsen, M. ampvis2: an R package to analyse and visualise $16 S \mathrm{rRNA}$ amplicon data (2018).

78. Oksanen, J. et al. vegan: community ecology package (2018).

79. Wickham, H. ggplot2: elegant graphics for data analysis (Springer-Verlag, 2016).

80. Kembel, S. W. et al. Picante: R tools for integrating phylogenies and ecology. Bioinformatics (Oxford, England) 26, 1463-1464 (2010).

81. Cáceres, M. de \& Legendre, P. Associations between species and groups of sites: indices and statistical inference. Ecology 90, 3566-3574 (2009).

82. Shannon, P. et al. Cytoscape: a software environment for integrated models of biomolecular interaction networks. Genome research 13, 2498-2504 (2003).

83. Esri Inc. ArcGIS Desktop (Esri Inc., 2019).

84. Inkscape Developers. Inkscape (2020).

85. Fussmann, D. et al. Authigenic formation of $\mathrm{Ca}-\mathrm{Mg}$ carbonates in the shallow alkaline Lake Neusiedl, Austria. Biogeosciences 17, 2085-2106 (2020).

86. Parkhurst, D. L. \& Appelo, C. A. in U.S. Geological Survey Techniques and Methods (2013), Vol. 6, pp. 2328-7055.

\section{Acknowledgements}

We thank the Seychelles Islands Foundation (SIF) for the permission to carry out field work and sampling on Aldabra. The Seychelles Ministry of Environment, Energy, and Climate Change is kindly acknowledged for the permission to export and scientifically analyse the samples. We thank all staff of the Seychelles Island Foundation who supported our work wholeheartedly. Particularly Sheryl Sanchez and Ronny Marie for their field planning and continuous assistance during sampling. Further, we thank Marc Jean-Baptiste as island manager and the project coordinators of the SIF Nancy Bunbury, April Burt and Frauke Fleischer-Dogley for their ongoing support. We thank Anja Poehlein for amplicon sequencing and the initial sequence processing, and Melanie Heinemann and Sarah Schüßler for library and sequencing preparation. We thank Mechthild Bömecke for her ongoing support in the lab. Adrian Immenhauser and Chelsea Pederson are gratefully acknowledged for the coordination of the "CHARON" central project. This study was funded by the German research foundation (DFG) in the framework of the research unit "CHARON" (subproject TP7: DA 374/11-1, AR 335/8-1). 


\section{Supplement:}

\section{Contents:}

Supplementary Figure S1. Heatmap of the 30 most abundant genera in the total (DNA) and active (RNA) bacterial community. Replicates were normalized, transformed into relative abundances, and averaged by depth. Gaps indicate the geochemical zonation. The figure can also be found on the enclosed CD and .zip folder:

Supplement|Chapter_C3|Supplementary_Figure_S1.docx.

Supplementary Figure S2. Association networks of the rare taxa in the total and active bacterial community of each geochemical zone. The abundance cut-off was set to < $2 \%$ for all sites except Cinq Cases where $<5 \%$ was used. Named genera with an association strength above 0.7 are indicated. Edge colour and width are scaled according to the association strength of each node to the target sediment zone.

The figure can also be found on the enclosed CD and .zip folder:

supplement|Chapter_C3|Supplementary_Figure_S2.docx.

Supplementary Figure S3. Original photographs of all sediment cores from the different sampling sites. Cores $\mathrm{KO1-03}$ of each site were used for bacterial community analysis. Cores $\mathrm{KO} 4$ were used for bulk chemistry measurements at all sampling sites. Core KO4 was also used for porewater chemistry measurement at Cinq Cases. For the remaining site porewaters were measured in separate cores, namely $\mathrm{KO} 4$ in the West Lagoon, K06 in the North Lagoon and K07 in the South Lagoon. All used cores are highlighted in bold.

The figure can also be found on the enclosed CD and .zip folder:

Supplement|Chapter_C3|Supplementary_Figure_S3.docx.

Supplementary Table S1. Sample metadata including location, bacterial diversity, porewater and bulk sediment geochemical data.

The table can be found on the enclosed CD and .zip folder:

Supplement|Chapter_C3|Supplementary_Dataset_Table_S1.xIsx.

Supplementary Table S2. Spearman Rank correlations of depth against geochemical and bacterial diversity data (a). Environmental fit correlations (b). a: Significant correlation with a Rho $\geq 0.5$ or $\leq-0.5$ and a significance above 0.001 are highlighted. Significant p-values are indicated as asterisks: ${ }^{* *} \leq 0.001, * * \leq 0.01, * \leq 0.05$. b: Results of the environmental fit analysis used for the NMDS arrows in Fig. 4.

The table can also be found on the enclosed CD and .zip folder:

Supplement|Chapter_C3|Supplementary_Dataset_Table_S2.xIsx. 
Supplementary Table S3. Sequencing raw read counts, accession numbers and processing statistics.

The table can be found on the enclosed $C D$ and zip folder:

Supplement|Chapter_C3|Supplementary_Dataset_Table_S3.xIsx.

Supplementary Table S4. Unnormalized ASV count table with taxonomic assignments. All hits with an identity $<95 \%$ and hit quality $<93 \%$ are indicated as "No blast hit". The table can be found on the enclosed CD and zip folder:

Supplement|Chapter_C3|Supplementary_Dataset_Table_S4.xIsx.

Supplementary Data File S1. ASV sequences of the dataset in fasta format.

The file can be found on the enclosed CD and zip folder:

Supplement|Chapter_C3|Supplementary_Dataset_Data_S1.txt. 

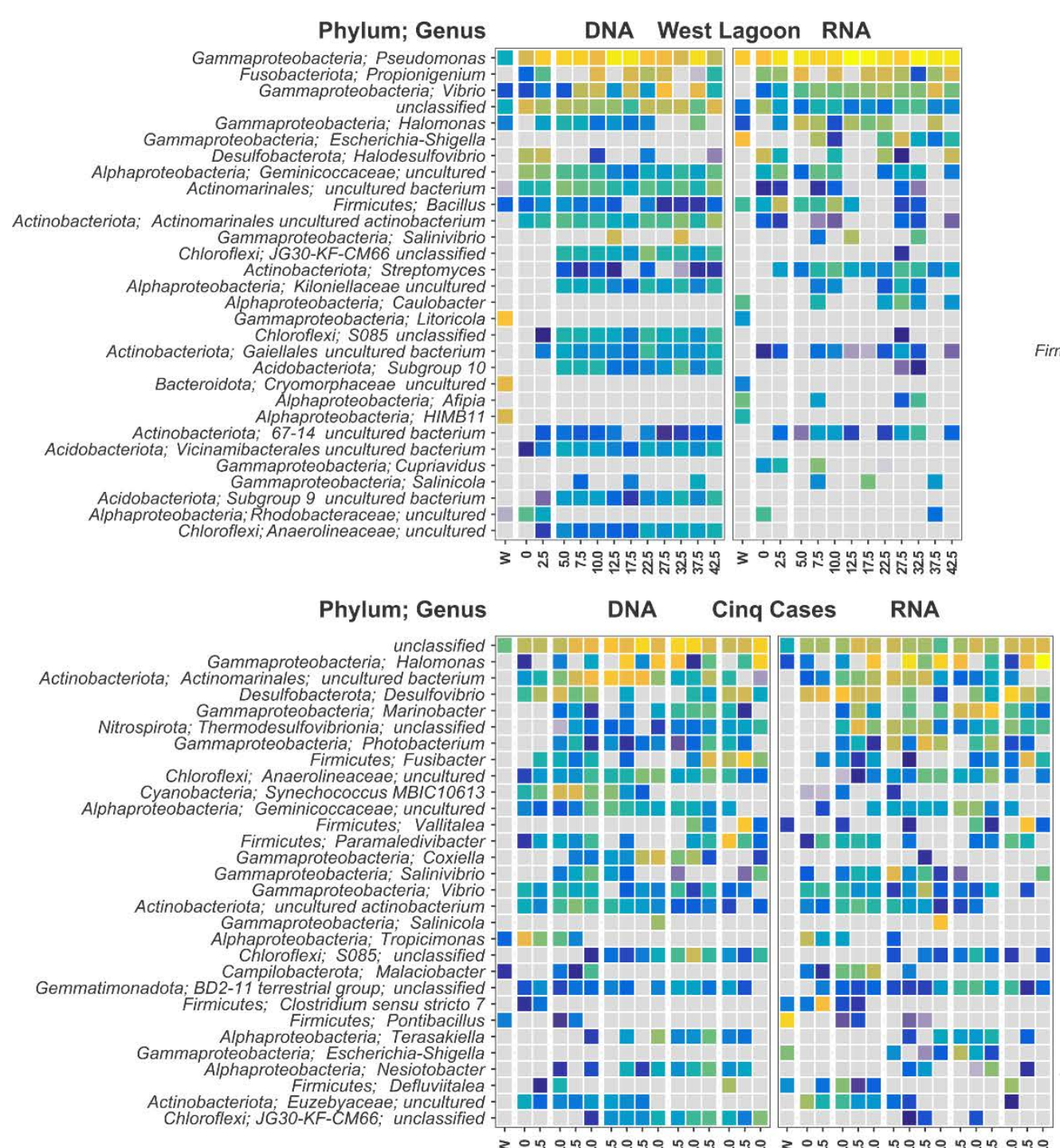

Phylum; Genus DNA North Lagoon RNA
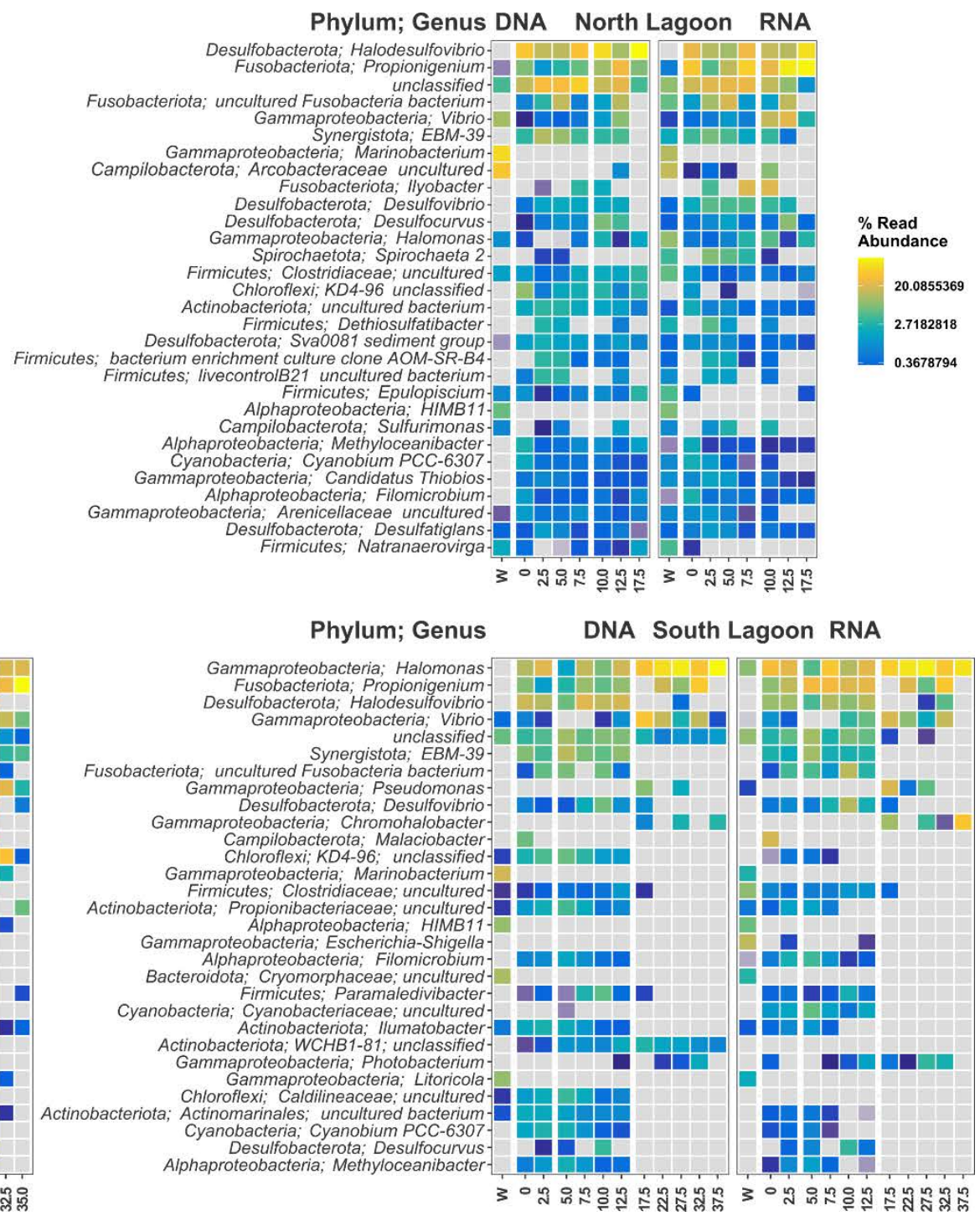

Supplementary Figure S1. Heatmap of the 30 most abundant genera in the total (DNA) and active (RNA) bacterial community. Replicates were normalized, transformed into relative abundances, and averaged by depth. Gaps indicate the geochemical zonation. 

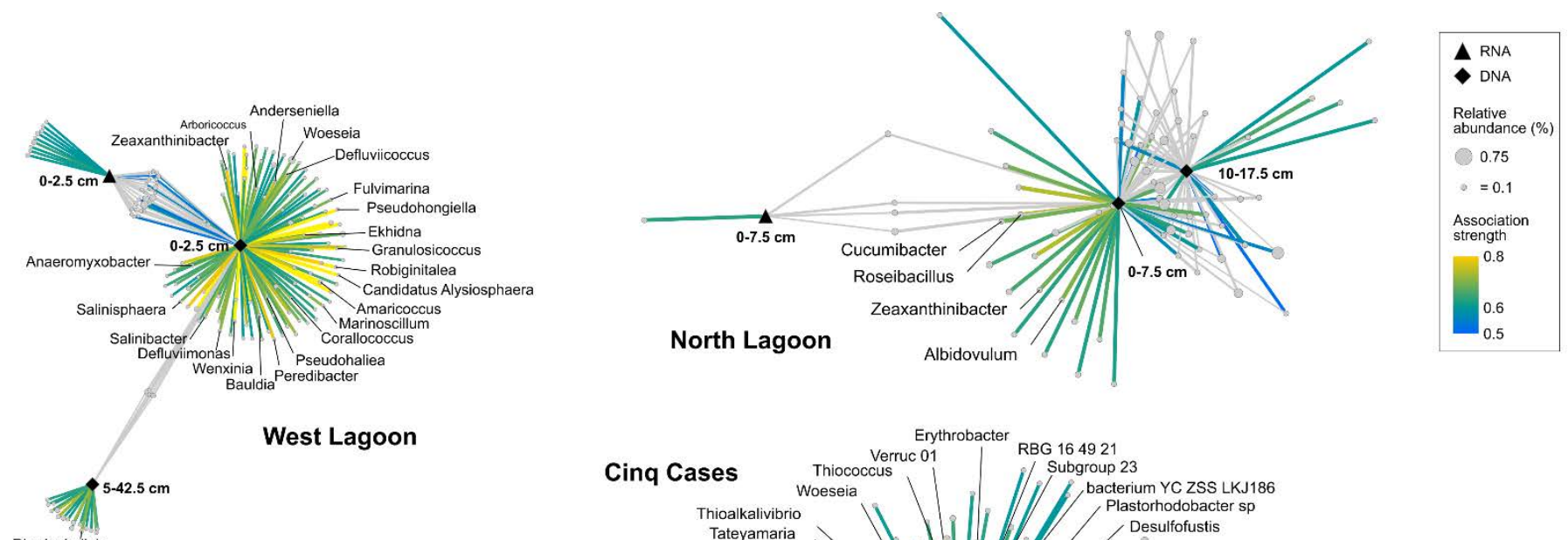

West Lagoon

$$
\text { Rhodopirellula }
$$

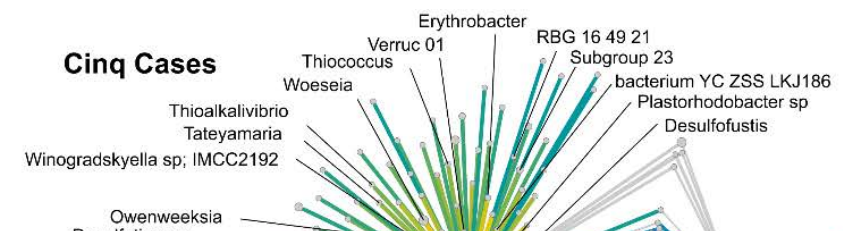

South Lagoon
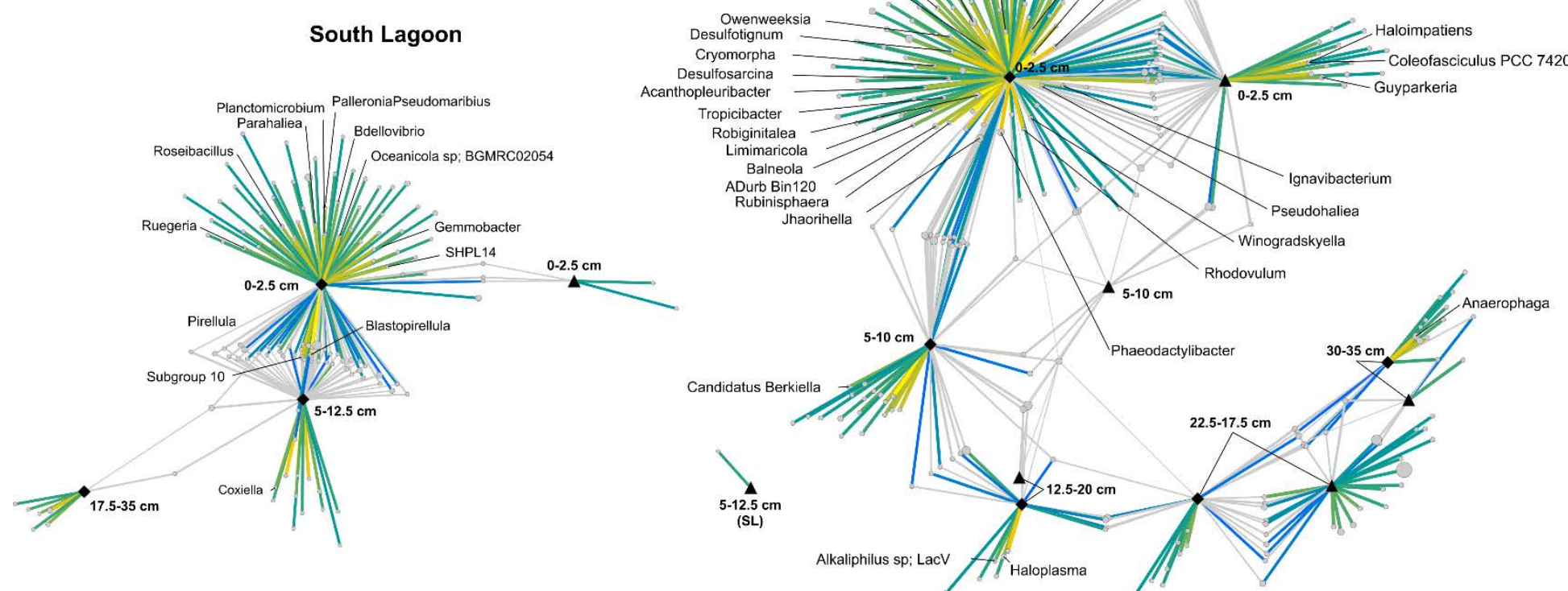

Supplementary Figure S2. Association networks of the rare taxa in the total and active bacterial community of each geochemical zone. The abundance cut-off was set to $<2 \%$ for all sites except Cinq Cases where $<5 \%$ was used. Named genera with an association strength above 0.7 are indicated. Edge colour and width are scaled according to the association strength of each node to the target sediment zone. 


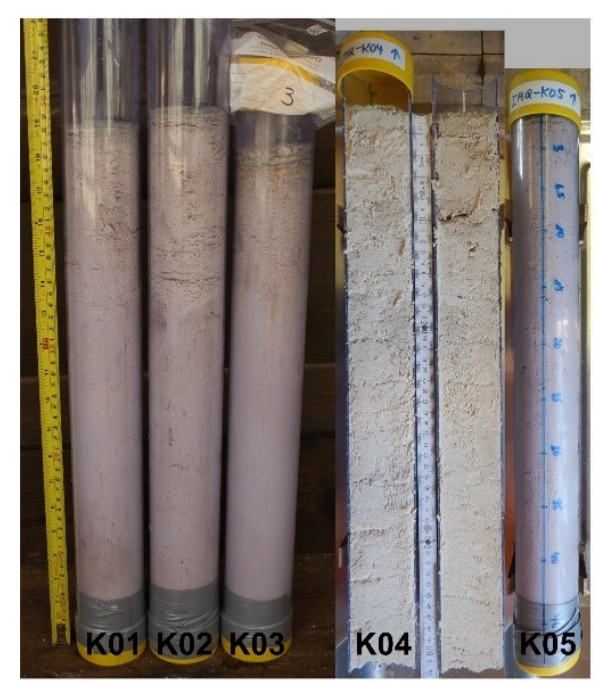

a West Lagoon

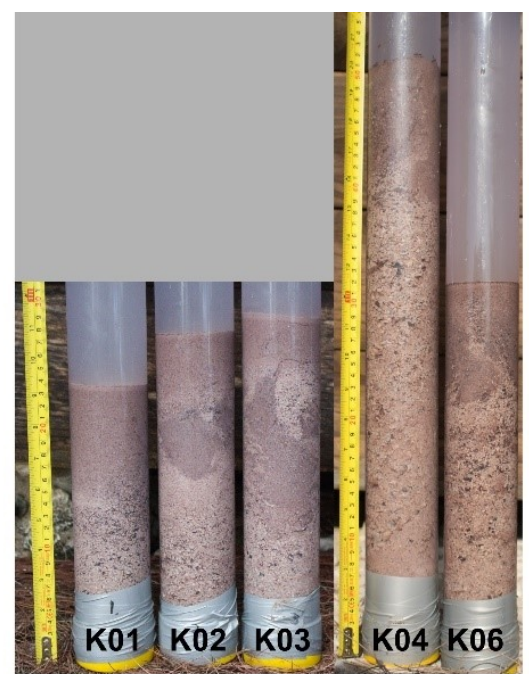

b North Lagoon

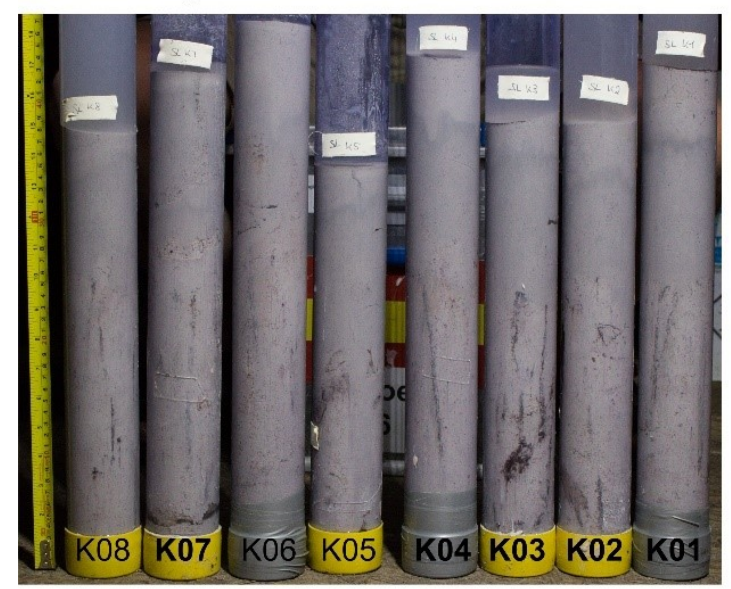

c South Lagoon

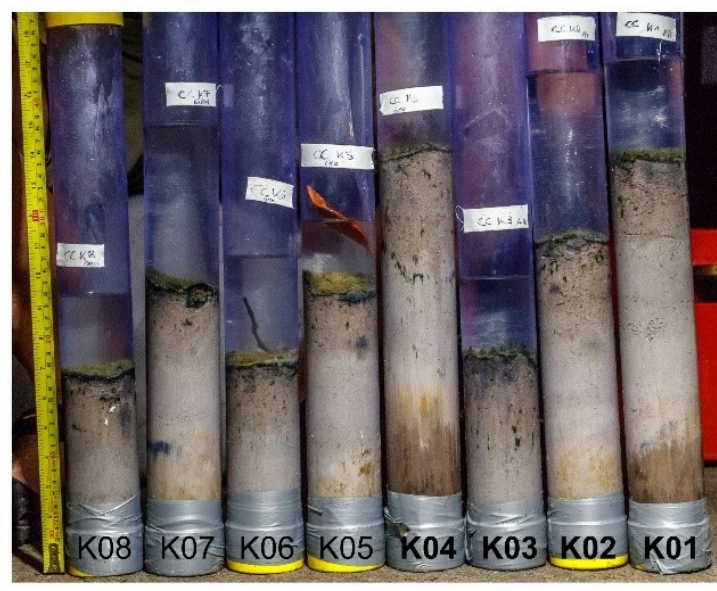

d Cinq Cases

Supplementary Figure S3. Original photographs of all sediment cores from the different sampling sites. Cores K01-03 of each site were used for bacterial community analysis. Cores K04 were used for bulk chemistry measurements at all sampling sites. Core K04 was also used for porewater chemistry measurement at Cinq Cases. For the remaining site porewaters were measured in separate cores, namely K04 in the West Lagoon, K06 in the North Lagoon and K07 in the South Lagoon. All used cores are highlighted in bold. 
Supplementary Table S2. Spearman Rank correlations of depth against geochemical and bacterial diversity data (a). Environmental fit correlations (b). a: Significant correlation with a Rho $\geq 0.5$ or $\leq-0.5$ and a significance above 0.001 are highlighted. Significant $p$-values are indicated as asterisks: *** $\leq$ $0.001, * * \leq 0.01, * \leq 0.05$. b: Results of the environmental fit analysis used for the NMDS arrows in Fig.

\begin{tabular}{|c|c|c|c|c|}
\hline a) Location & $\begin{array}{l}\text { West } \\
\text { Lagoon }\end{array}$ & $\begin{array}{l}\text { North } \\
\text { Lagoon }\end{array}$ & $\begin{array}{l}\text { South } \\
\text { Lagoon }\end{array}$ & Cinq Cases \\
\hline $\begin{array}{l}\text { Faith's } \\
(D N A)\end{array}$ & $-0.394^{*}$ & -0.204 & $-0.796 * * *$ & $-0.682 * * *$ \\
\hline $\begin{array}{l}\text { Faith's } \\
\text { (RNA) }\end{array}$ & $-0.389^{* *}$ & $-0.634 * * *$ & $-0.838 * * *$ & -0.197 \\
\hline Chaol (DNA) & -0.185 & 0.047 & $-0.743 * * *$ & $-0.618 * * *$ \\
\hline Chaol (RNA) & $-0.498 * * *$ & $-0.538 * *$ & $-0.807 * * *$ & $-0.414^{* * *}$ \\
\hline$D N A(n g / \mu l)$ & 0.136 & 0.154 & -0.169 & $-0.529 * * *$ \\
\hline$R N A(n g / \mu l)$ & 0.169 & 0.125 & 0.208 & $-0.360^{* *}$ \\
\hline$R N A: D N A$ ratio & 0.190 & 0.068 & $0.681 * * *$ & $0.538 * * *$ \\
\hline$p H$ & $0.604 * * *$ & $-0.966 * * *$ & 0.282 & $-0.784 * * *$ \\
\hline$e H(m v)$ & $0.823 * * *$ & $-0.990 * * *$ & $-0.982 * * *$ & $0.498 * * *$ \\
\hline Salinity (g/kg) & $-0.413^{*}$ & $0.918 * * *$ & $-0.989 * * *$ & $0.593 * * *$ \\
\hline $\boldsymbol{T A}$ & $-0.438^{*}$ & $0.978 * * *$ & $-0.420^{* *}$ & $-0.446 * * *$ \\
\hline $\mathrm{NH}_{4}^{+}$ & -0.127 & $0.993 * * *$ & $-0.374^{*}$ & $-0.550 * * *$ \\
\hline $\mathrm{Cl}^{-} / \mathrm{SO}_{4}{ }^{2-}$ & 0.321 & $0.978 * * *$ & $0.360^{*}$ & 0.053 \\
\hline$\sum \mathrm{H}_{2} \mathrm{~S}$ & NA & $0.966 * * *$ & 0.573 & $-0.829 * * *$ \\
\hline $\mathrm{PO}_{4}^{3-}$ & -0.277 & 0.139 & 0.318 & $-0.360^{* *}$ \\
\hline$T I C$ & $-0.369^{*}$ & $-0.925 * * *$ & 0.159 & $-0.313^{* *}$ \\
\hline TOC & -0.275 & $-0.948 * * *$ & 0.159 & $0.369^{*}$ \\
\hline Total N & $-0.883 * * *$ & $-0.739 * * *$ & $-0.872 * * *$ & $-0.301^{* *}$ \\
\hline Total S & $0.683 * * *$ & $-0.948 * * *$ & 0.301 & $0.461 * * *$ \\
\hline$C / N$ & $0.807 * * *$ & $-0.562 * *$ & $0.655 * * *$ & $0.946 * * *$ \\
\hline
\end{tabular}




\begin{tabular}{|c|c|c|c|c|c|c|c|c|c|c|}
\hline & NMDS1 & NMDS2 & $\mathrm{r} 2$ & $\operatorname{Pr}(>r)$ & significance & NMDS1 & NMDS2 & $\mathrm{r} 2$ & $\operatorname{Pr}(>r)$ & significance \\
\hline$D N A / R N A(n g / \mu l)$ & -0.42629 & -0.90459 & 0.185 & 0.001 & $* * *$ & -0.57163 & -0.82051 & 0.1537 & 0.001 & $* * *$ \\
\hline Salinity (g/kg) & -0.99028 & -0.13908 & 0.6239 & 0.001 & $* * *$ & -0.94629 & 0.32333 & 0.709 & 0.001 & $* * *$ \\
\hline$p H$ & 0.54466 & 0.83865 & 0.6787 & 0.001 & $* * *$ & 0.83496 & 0.55032 & 0.6304 & 0.001 & $* * *$ \\
\hline$e H(m v)$ & -0.45681 & 0.88956 & 0.8256 & 0.001 & $* * *$ & -0.22151 & 0.97516 & 0.667 & 0.001 & $* * *$ \\
\hline $\boldsymbol{T A}$ & -0.36731 & -0.9301 & 0.352 & 0.001 & $* * *$ & -0.58076 & -0.81407 & 0.2963 & 0.001 & $* * *$ \\
\hline $\mathrm{NH}^{+}$ & 0.18334 & -0.98305 & 0.3613 & 0.001 & $* * *$ & 0.03014 & -0.99955 & 0.3997 & 0.001 & $* * *$ \\
\hline $\mathrm{PO}_{4}^{3-}$ & -0.00052 & -1 & 0.2098 & 0.001 & $* * *$ & -0.19062 & -0.98166 & 0.2714 & 0.001 & $* * *$ \\
\hline$\sum \boldsymbol{H}_{2} \mathrm{~S}$ & 0.52313 & -0.85225 & 0.3641 & 0.001 & $* * *$ & 0.3187 & -0.94786 & 0.4261 & 0.001 & $* * *$ \\
\hline TOC & -0.53804 & -0.84292 & 0.4551 & 0.001 & $* * *$ & -0.76015 & -0.64974 & 0.4867 & 0.001 & $* * *$ \\
\hline TIC & 0.83372 & 0.55219 & 0.6273 & 0.001 & $* * *$ & 0.98222 & 0.18774 & 0.6561 & 0.001 & $* * *$ \\
\hline Total N & -0.62726 & -0.77881 & 0.5495 & 0.001 & $* * *$ & -0.86696 & -0.49838 & 0.5417 & 0.001 & $* * *$ \\
\hline Total S & -0.70375 & -0.71045 & 0.5251 & 0.001 & $* * *$ & -0.90788 & -0.41924 & 0.5613 & 0.001 & $* * *$ \\
\hline$C / N$ & 0.50512 & -0.86305 & 0.175 & 0.001 & $* * *$ & 0.20025 & -0.97975 & 0.1823 & 0.001 & $* * *$ \\
\hline
\end{tabular}

$--$

Signif. codes: 0 ‘***’ 0.001 '**’ 0.01 '*' 0.05 '? 0.1 “ ' 1

Permutation: free

Number of permutations: 999 


\section{Pontibacillus SP. Ald_Sl1 and Psychroflexus SP. ALD_RP9, TWO NOVEL MODERATELY HALOPHILIC BACTERIA ISOLATED FROM SEDIMENT AND WATER FROM the Aldabra Atoll, Seychelles}

Avril J. E. von Hoyningen-Huene ${ }^{1}$, Tabea J. Schlotthauer ${ }^{1}$, Dominik Schneider ${ }^{1}$, Anja Poehlein ${ }^{1}$, Rolf Daniel ${ }^{1 *}$

PLoS ONE (26. August 2021) 16, e0256639

https://doi.org/10.1371/journal.pone.0256639

\section{Affiliations:}

${ }^{1}$ Genomic and Applied Microbiology \& Göttingen Genomics Laboratory, Institute of Microbiology and Genetics, Georg-August University of Göttingen, Göttingen, Germany

\section{Author contributions:}

Conceived and designed the study: RD, DS, AH

Performed the experiments: AH, TS, AP

Analysed the data: AH, TS, DS, AP

Wrote the paper: AH, TS, DS, AP, RD 


\section{Abstract}

Pontibacillus sp. ALD_SL1 and Psychroflexus sp. ALD_RP9 are two novel bacterial isolates from mangrove sediment and a moderately hypersaline pool on the Aldabra Atoll, Seychelles. The isolates represent two novel species were characterised physiologically and genomically. Pontibacillus sp. ALD_SL1 is a facultatively anaerobic yellow, motile, rod-shaped Gram-positive, which grows optimally at a $\mathrm{NaCl}$ concentration of $11 \%, \mathrm{pH} 7$ and $28^{\circ} \mathrm{C}$. It is the third facultatively anaerobic member of the genus Pontibacillus. The organism gains energy through the fermentation of pyruvate to acetate and ethanol under anaerobic conditions. The genome is the first among Pontibacillus that harbours a megaplasmid. Psychroflexus sp. ALD_RP9 is an aerobic heterotroph, which can generate energy by employing bacteriorhodopsins. It forms Gram-negative, orange, non-motile rods. The strain grows optimally at $\mathrm{NaCl}$ concentrations of $10 \%, \mathrm{pH} 6.5-8$ and $20^{\circ} \mathrm{C}$. The Psychroflexus isolate tolerated $\mathrm{pH}$ conditions up to 10.5 , which is the highest $\mathrm{pH}$ tolerance currently recorded for its genus. Psychroflexus sp. ALD_RP9 taxonomically belongs to the clade with the smallest genomes. Both isolates show extensive adaptations to their saline environments yet utilise different mechanisms to ensure survival.

\section{Introduction}

We describe two novel bacterial isolates from the Aldabra Atoll, Seychelles. They represent two novel species within the Pontibacillus and Psychroflexus genera. Samples from mangrove sediment within the lagoon (Pontibacillus isolate) and water from a moderately hypersaline pool on Grand Terre island (Psychroflexus isolate) were used for enrichment and isolation of halophilic bacteria.

The genus Pontibacillus belonging to the Bacillaceae was first described by Lim et al. as bacillus pertaining to the sea [1]. It harbours seven validated species, P. chungwhensis [1], P. halophilus [2], P. litoralis [3], P. marinus [4], P. salicampi [5], P. salipaludis [6], and P. yanchengensis [7]. Members of the Pontibacillus are Gram-positive, facultatively anaerobic, moderately halophilic, endospore-forming rods and are motile through peritrichous flagella. The isolates derive from marinerelated habitats including salt farms across Asia and marine lifeforms, such as sea anemones and sea urchins [8]. They require salt for growth, which generally ranges 
from 0.5 to $25 \%(\mathrm{w} / \mathrm{v}) \mathrm{NaCl}$. Optimal growth was recorded between 2 and $10 \%(\mathrm{w} / \mathrm{v})$ $\mathrm{NaCl}$. The $\mathrm{pH}$ optimum ranges from 7 to 8 and optimal growth temperatures from 25 to $40{ }^{\circ} \mathrm{C}$. Members of Pontibacillus form white- to orange-pigmented smooth colonies with a diameter of 1 to $3 \mathrm{~mm}$.

The second isolate belongs to the genus Psychroflexus within the family Flavobacteriaceae. It was isolated from the pink, lower water layer of a saline landlocked pool (Westpool D). Psychroflexus (meaning cold bend) was first described by Bowman et al. in 1989 [9], who isolated the strain Ps. torquis from Antarctic sea ice and re-classified Flavobacterium gondwanense [10] to Ps. gondwanensis. The genus encompasses 12 validated and two non-validated published species. Psychroflexus species were isolated from hypersaline to saline lakes [11, 12] and salterns in China [13], Hawaii [14], Korea [15, 16], Antarctica [17], as well as saline soil [18], cheese [19] and coastal sediments [20, 21]. Growth occurs between 0 and $20 \%(\mathrm{w} / \mathrm{v}) \mathrm{NaCl}$, a $\mathrm{pH}$ of 6 to 10 , and -16 to $40{ }^{\circ} \mathrm{C}$, demonstrating a high diversity in temperature tolerance and global dispersal of the genus. The growth optimum is generally around 2 to $10 \% \mathrm{NaCl}, \mathrm{pH} 7$ to 8 , and 10 to $15^{\circ} \mathrm{C}$ or 25 to $30^{\circ} \mathrm{C}$, depending on arctic or tropical origin. Most isolates occur within the latter temperature range, thereby differing strongly from the type strain. All isolates of this genus are orange in colour.

In this study, we present two novel species affiliated to the Pontibacillus and the Psychroflexus genus. The isolates were characterised phenotypically (i) using standard microbiological techniques. In addition, complete genomes were generated using a hybrid approach of Illumina and Nanopore sequencing. Both genomes represent the second complete genome of the corresponding genus. The genomes were used to assess the phylogenetic affiliation (ii) and the potential metabolism (iii) of the strains.

\section{Materials and methods}

\section{Isolation and culture}

Pontibacillus sp. ALD_SL1 and Psychroflexus sp. ALD_RP9 were isolated from halophile medium using mangrove sediment from the South Lagoon of the Aldabra Atoll (ALD_SL), Seychelles (9²6'34.8"S, 46 $\left.233^{\prime} 30.5^{\prime \prime} \mathrm{E}\right)$ and water from the 
bottom water layer of Westpool D also known as Ronny's Pool (ALD_RP) (9²6'40.5"S, 46 $\left.{ }^{\circ} 27^{\prime} 6.8^{\prime \prime} \mathrm{E}\right)$. The water (salinity 9.9\%, pH 7.9, $0.10 \mathrm{mg} / \mathrm{L} \mathrm{O}_{2}, 32.5^{\circ} \mathrm{C}$ ) was sampled underneath a sharp halocline. The stratification of this pool was likely caused by the occurrence of the first rainfall, leading to a bacterial bloom in the sampled bottom layer. Prior to use, the untreated sediment was stored at $-80{ }^{\circ} \mathrm{C}$ and the water sample at $4{ }^{\circ} \mathrm{C}$. Liquid modified growth medium with $9 \%$ total salinity (MGM9) was prepared from $30 \%(\mathrm{w} / \mathrm{v})$ concentrated saltwater stock solution $(\mathrm{SW})$ as described by Dyall-Smith [22]. Briefly, the $30 \% \mathrm{SW}$ was prepared from $240 \mathrm{~g} / \mathrm{L} \mathrm{NaCl}$, $30 \mathrm{~g} / \mathrm{L} \mathrm{MgCl} 2 \cdot 6 \mathrm{H}_{2} \mathrm{O}, 35 \mathrm{~g} / \mathrm{L} \mathrm{MgSO}_{4} 7 \mathrm{H}_{2} \mathrm{O}, 7 \mathrm{~g} / \mathrm{L} \mathrm{KCl}, 0.5 \mathrm{~g} / \mathrm{L} \mathrm{CaCl}_{2} \cdot 2 \mathrm{H}_{2} \mathrm{O}$ and $0.2 \mathrm{~g} / \mathrm{L} \mathrm{NaHCO}_{3}$ in deionized water. The $\mathrm{pH}$ was adjusted to 7.5 using tris(hydroxymethyl)aminomethane (Tris) buffer. For $1 \mathrm{~L}$ of MGM9, $300 \mathrm{~mL}$ of $30 \%$ $\mathrm{SW}$ were added to $5 \mathrm{~g} / \mathrm{L}$ peptone (Oxoid) and $1 \mathrm{~g} / \mathrm{L}$ yeast extract and deionized water. The $\mathrm{pH}$ was adjusted to 7.5 using Tris buffer. For solid medium, $15 \mathrm{~g} / \mathrm{L}$ BactoAgar (BD Biosciences, Franklin Lakes, New Jersey, USA) was added before autoclaving. Untreated mangrove sediment (500 mg) was thawed, homogenized, and suspended in $1 \mathrm{ml}$ of sterile $9 \% \mathrm{SW}$. Dilution series were prepared from the sediment suspension (SL) and from $100 \mu 1$ of water sample (RP). They were plated on MGM9 and incubated at $28{ }^{\circ} \mathrm{C}$ in the light. Isolate ALD_SL1 was picked after two days from a sediment plate and ALD_RP9 was picked after five days from a plate with water sample. Both isolates were re-streaked at least three times to purify cultures. Pure isolates were stored at $-80^{\circ} \mathrm{C}$ in liquid MGM9 with $15 \%$ glycerol.

\section{Morphology}

Cells from a one-day-old culture were negatively stained with either $0.1 \%$ phosphotungstic acid ( $\mathrm{pH} 7$ ) or $0.5 \%$ uranyl acetate and applied onto a copper grid. Their morphology was determined using a Jeol 1011 electron microscope (Eching, Munich, Germany).

\section{Growth experiments}

Growth under differing $\mathrm{NaCl}, \mathrm{pH}$ and temperature conditions were determined in an adjusted liquid MGM (nMGM). For this purpose, the SW was prepared without $\mathrm{NaCl}$, which was added later in the required quantities. Salt tolerance was tested in $5 \%$ $(\mathrm{w} / \mathrm{v})$ increments of $\mathrm{NaCl}$ up to a concentration of $25 \%$ and $1 \%$ increments between 8 and $12 \%$. For the determination of $\mathrm{pH}$ and temperature optima, the isolates were 
incubated in medium with $11 \% \mathrm{NaCl}$ (Pontibacillus sp. ALD_SL1) and 9\% $\mathrm{NaCl}$ (Psychroflexus sp. ALD_RP9). Temperature was tested between 10 and $50{ }^{\circ} \mathrm{C}$ at intervals of $5^{\circ} \mathrm{C}$ between 20 and $40^{\circ} \mathrm{C}$ and $28^{\circ} \mathrm{C}$ instead of $30^{\circ} \mathrm{C}$, and $\mathrm{pH}$ values between 5.5 and 10.5 at intervals of 0.5. Pontibacillus sp. ALD_SL1 was incubated in $11 \% \mathrm{NaCl}$ to reflect its slightly higher salt optimum. The $\mathrm{pH}$ intervals were adjusted with the addition of buffers (2-morpholinoethanesulfonic acid (MES), pH 5.5 and 6.0; Tris, pH 6.5 to 9.0; 3-(cyclohexylamino)-2-hydroxypropane-1-sulfonic acid (CAPSO), $\mathrm{pH} 9.5,10.0$ and 10.5) at concentrations of $1 \mathrm{M}$. For measurement of salinity and temperature optima, $\mathrm{pH}$ was set to 7.5. The $\mathrm{pH}$ and salinity experiments were incubated at $28^{\circ} \mathrm{C}$. All cultures were incubated using an Orbitron shaker (Infors HT, Einsbach, Germany) at $180 \mathrm{rpm}$. Growth under the different conditions was determined in triplicate (S1 Table). For this purpose, the optical density $\left(\mathrm{OD}_{600}\right)$ was measured using an Ultraspec 3300 pro photometer (Amersham Pharmacia Biotec Europe GmbH, Munich, Germany) after $28 \mathrm{~h}$, when both isolates had reached the stationary growth phase. Growth under anaerobic conditions was tested by placing inoculated nMGM plates with $11 \% \mathrm{NaCl}$ (nMGM11) into an anaerobic jar with AnaeroGen 3.5 L gas packs (Thermo Fisher Scientific, Waltham, MA, USA) to generate an anaerobic atmosphere. The plates were incubated at $28{ }^{\circ} \mathrm{C}$ and monitored for colony growth for 14 days. Motility of the isolates was determined in soft nMGM11 with $3.5 \mathrm{~g} / \mathrm{L}$ agar.

\section{Physiological characterisation}

Enzyme activity and carbohydrate utilisation of both isolates was tested using the API ZYM and API 50 CHB kits (bioMérieux, Nürtingen, Germany) according to the instructions of the manufacturer with adjusted salt concentrations. ALD_SL1 and ALD_RP9 cultures were washed twice before testing and resuspended in $11 \%$ or $5 \%$ saline respectively, for application in the API ZYM kit. The CHB medium of the $50 \mathrm{CHB}$ kit was supplemented with $11 \% \mathrm{NaCl}$. Reactions in the $50 \mathrm{CHB}$ kit were recorded up to $72 \mathrm{~h}$ of incubation. Oxidase production was tested by applying a drop of Oxidase Reagent (bioMérieux, Nürtingen, Germany) to a Rotilabo-test disk ( $\varnothing$ $6 \mathrm{~mm}$ ). After adding a colony to the disk, it was monitored for a colour change. Catalase activity was tested in the same manner, but with $3 \% \mathrm{H}_{2} \mathrm{O}_{2}$ as reagent and monitoring for bubble development. Each test was replicated three times. Both isolates were examined by Gram-staining [23]. 


\section{Genome sequencing}

Genomic DNA was extracted from isolate cultures using the MasterPure Complete DNA and RNA Purification kit and the instructions of the manufacturer (Epicentre, Madison, USA) for the extraction of DNA from cell samples with the following adjustments. Cell cultures were pelleted and washed twice in PBS before DNA extraction. Cells were lysed in Cell Lysis Solution without Proteinase K and mechanically disrupted in a FastPrep (MP Biomedicals, Santa Ana, USA) for $20 \mathrm{~s}$ at $4 \mathrm{~m} / \mathrm{s}$ with $0.1 \mathrm{~mm}$ glass beads. Afterwards, $2.5 \mu 1$ of Proteinase K $(20 \mathrm{mg} / \mathrm{mL}$, Biotechrabbit, Düsseldorf, Germany) were added. Genomic DNA was eluted in $50 \mu 1$ of nucleic acid free water and sequenced using both Illumina and Nanopore technology. Illumina paired-end reads were generated on a MiSeq sequencer using v3 chemistry (Illumina, San Diego, CA, USA) and Nanopore sequences were generated with a MinIon (Oxford Nanopore Technologies, Oxford, England) as described previously [24].

\section{Bioinformatic processing and analysis}

Illumina and Nanopore reads were quality-filtered using fastp v0.20.0 [25]. Nanopore long-reads were filtered with a sequence cut-off of 1,000 bp (Psychroflexus sp. ALD_RP9) or $500 \mathrm{bp}$ (Pontibacullus sp. ALD_SL1). Porechop v0.2.4 [26] was used for adapter-trimming and read-splitting. Sequences were assembled with Unicyler v0.4.8 and the conservative hybrid assembly approach [27]. Initial assessment of genome relatedness and taxonomy was performed using the Genome Taxonomy Database Tool kit (GTDB-Tk) and database v1.0.1 [28]. Assembled genomes were annotated with the NCBI Prokaryotic Genome Annotation Pipeline (PGAP) v4.13 [29] and are accessible under the accessions CP062974, CP062975 and CP062973. The 16S rRNA gene consensus sequences of each genome were aligned against the 16S rRNA gene sequences of all other members of each genus with ClustalW in MEGA-X 10.1.8 [30]. MEGA-X was also used to calculate neighborjoining, maximum-likelihood and maximum-parsimony phylogenetic trees with the Kimura two-parameter model and 1,000 bootstraps. Genome average nucleotide identity (ANI) was compared using the ANIm method in pyANI v0.2.10 [31] and similarities visualised using the Blast Ring Image Generator (BRIG) [32]. All available genome assemblies, ranging from contig via scaffold to complete, were used for ANI 
analysis. Cellular functions of both isolate genomes were inferred using BlastKOALA against the KEGG database [33] and pathway visualisation using the KEGG Mapper [34]. Transmembrane domains and signal peptides were predicted using TMHMM v.2.0 [35] and SignalP 5.0 servers [36]. Genomic islands and prophages were identified using IslandViewer4 [37] and PHASTER [38]. Putative antibiotic resistance genes (ARGs) were identified by searching the Resfams database v1.2.2 using HMMER 3.3 $[39,40]$. ARGs detected with Resfams were additionally verified with deepARG v2.0. Further hits were added to the putative list if identified genes crossed a threshold of $50 \%$ identity, a bit score above 50 and an e-value below 1e-20 [41].

\section{Results and discussion}

\section{Cell and colony morphology}

Pontibacillus sp. ALD_SL1 is a Gram-positive, rod-shaped aerobic heterotroph, which forms yellow, opaque colonies with an entire margin. Cells are 2.5$3 \mu \mathrm{m} \times 0.8-1 \mu \mathrm{m}$, motile rods with peritrichous flagella (Fig 1A). Psychroflexus sp. ALD_RP9 is a Gram-negative, rod-shaped aerobic heterotroph. It forms orange, convex, gelatinous colonies. Cells are 1.1-1.3 $\mu \mathrm{m}$ x 0.4-0.6 $\mu \mathrm{m}$ in size, lack flagella and pili, and are surrounded by a web of exopolysaccharides (EPS), which contribute to the gelatinous texture of the colonies (Fig 1B).
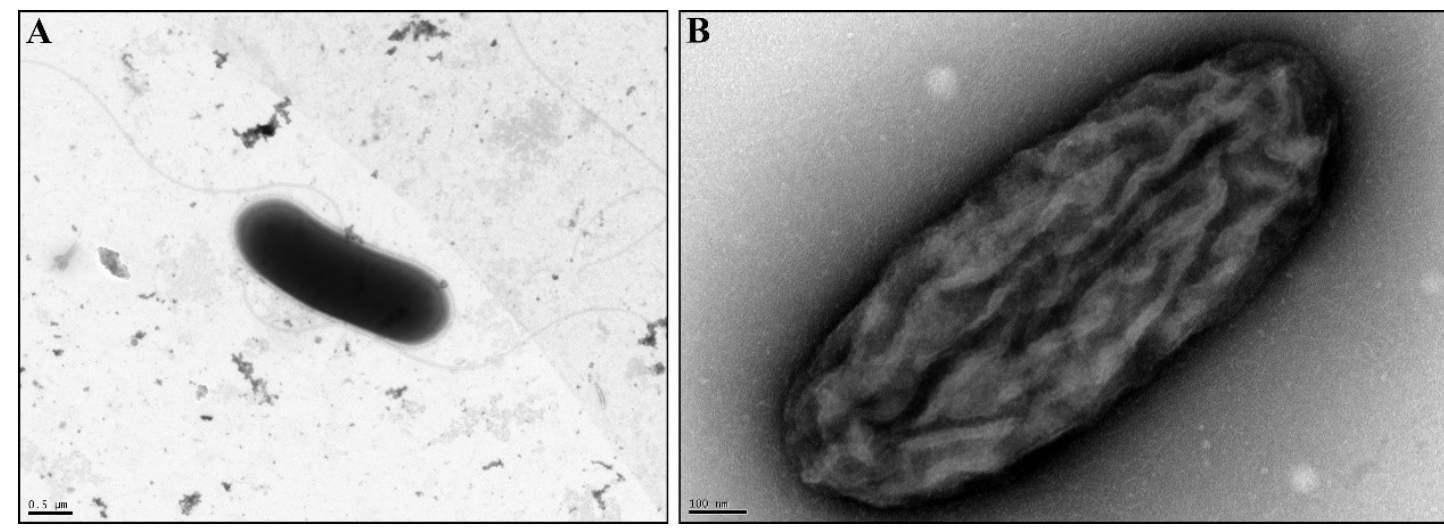

Fig 1. Transmission electron micrograph of Pontibacillus sp. ALD_SL1 (A) and Psychroflexus sp. ALD_RP9 (B). Cells from an overnight culture were stained with phosphotungstic acid $(\overline{\mathrm{A}})$ or uranyl acetate $(\mathrm{B})$. A: rod-shaped Pontibacillus sp. ALD_SL1 with two long peritrichious flagella. B: Psychroflexus sp. ALD_RP9 cells are rod-shaped and lack flagella or pili. EPS are visible as a web of thin filaments broadly surrounding the cell. The scale bars in the bottom left measure $0.5 \mu \mathrm{m}(\mathrm{A})$ and $0.1 \mu \mathrm{m}(\mathrm{B})$. 


\section{Growth kinetics and optima}

Both isolates were moderately halophilic with growth matching the reported ranges for members of the corresponding genus $[5,12]$. The $\mathrm{NaCl}$ optima were at $10 \%$

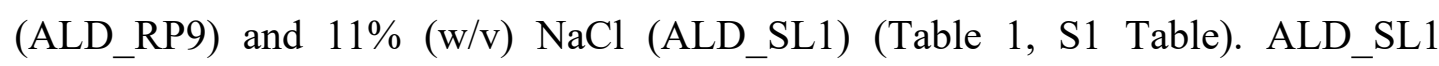
maintained growth between $\mathrm{pH}$ values of 6 and 10 with an optimum at $\mathrm{pH} 7$. ALD_RP9 showed optimal growth between pH 6.5 and 8 and diminished growth between $\mathrm{pH} 9-10.5$. Growth beyond $\mathrm{pH} 10.5$ was not tested due to strong precipitation of medium components above this value. ALD_SL1 grew optimally at $28^{\circ} \mathrm{C}$. ALD_RP9 had a narrower growth range $\left(20-40{ }^{\circ} \mathrm{C}\right)$ but same optimum as other members of the genus [19]. Incubation for 14 days under an anaerobic atmosphere showed growth of Pontibacillus sp. ALD_SL1, indicating that it is one of the facultative anaerobes of the genus [3, 6]. Psychroflexus sp. ALD_RP9 showed only punctiform colonies, which may have benefited from residual oxygen at the start of the experiment.

Table 1. Morphological, growth and enzymatic characteristics of Pontibacillus sp. ALD_SL1 and Psychroflexus sp. ALD_RP9.

\begin{tabular}{|lcc|}
\hline Characteristic & Pontibacillus sp. & Psychroflexus sp. \\
\hline Cell length $(\mu \mathrm{m})$ & ALD_SL1 & ALD_RP9 \\
Pigmentation & $2.5-3$ & $0.4-0.6$ \\
Gram-staining & yellow & orange \\
Motility & + & - \\
Microaerophilic growth & + & - \\
Temperature range $\left({ }^{\circ} \mathrm{C}\right)$ & + & + \\
NaCl range $(\%$, w/v $)$ & $20-40(28)$ & $20-40(20)$ \\
pH range & $5-20(11)$ & $5-15(10)$ \\
Enzyme activity: & $6-10(7)$ & $-10.5(6.5-8)$ \\
Oxidase & - & - \\
Catalase & + & + \\
Alkaline phosphatase & + & + \\
Esterase $(\mathrm{C} 4)$ & + & + \\
Esterase lipase $(\mathrm{C} 8)$ & + & + \\
\hline
\end{tabular}




\begin{tabular}{|c|c|c|}
\hline Leucine arylamidase & - & + \\
\hline Valine arylamidase & - & + \\
\hline Cysteine arylamidase & - & + \\
\hline Trypsin & - & + \\
\hline Acid phosphatase & - & + \\
\hline $\begin{array}{l}\text { Naphtol-AS-BI- } \\
\text { phosphohydrolase }\end{array}$ & - & + \\
\hline$\alpha$-glucosidase & + & - \\
\hline Acid production: & & - \\
\hline Glycerol & + & - \\
\hline D-Ribose & + & - \\
\hline D-Glucose & + & - \\
\hline D-Fructose & + & - \\
\hline D-Maltose & + & + \\
\hline Sucrose & + & - \\
\hline D-Trehalose & + & - \\
\hline Inulin & + & - \\
\hline Starch & + & + \\
\hline Glycogen & + & - \\
\hline $\begin{array}{l}\text { Potassium 5- } \\
\text { ketogluconate }\end{array}$ & $\mathrm{V}$ & - \\
\hline
\end{tabular}

Temperature, $\mathrm{NaCl}$ and $\mathrm{pH}$ optima are indicated in brackets. Both strains were negative for lipase (C4), $\alpha$-chymotrypsin, $\alpha / \beta$-galactosidase, $\beta$-glucuronidase, $\beta$ glucosidase, $N$-acetyl- $\beta$-glucosaminidase, $\alpha$-mannosidase and $\alpha$-fucosidase. Unless listed, tests from the API CHB kit were negative after 72 hours. Reactions are positive $(+)$, negative $(\mathrm{n})$ or variable $(\mathrm{v})$.

Both isolates were tested for activity of certain enzymes and carbohydrate metabolism using API kits ZYM and CHB. Pontibacillus sp. ALD_SL1 was catalase positive and oxidase negative and showed enzyme activity for four of the 19 tested substrates, namely alkaline phosphatase, esterase (C4), esterase lipase (C8) and $\alpha$ glucosidase activity. Acid production was observed for 10 of the 50 tested carbohydrates, including glycerol, D-ribose, D-glucose, D-fructose, D-maltose, 
sucrose, D-trehalose, inulin, starch, and glycogen (Table 1). This profile indicated that ALD_SL1 is metabolically more similar to P. chungwhensis than to P. salipaludis [6], which cluster together phylogenetically (Fig 2). Psychroflexus sp. ALD_RP9 was both catalase and oxidase negative and hydrolysed 9 of the 19 tested substrates using alkaline phosphatase, esterase (C4) and esterase lipase (C8), leucine, valine, and cysteine arylamidase, trypsin, acid phosphatase, and napthol-AS-BIphosphohydrolase. Metabolic tests with the CHB kit showed acid production from maltose and starch (Table 1). While the growth ranges of all Psychroflexus isolates are similar, results from the metabolic tests differ strongly within the genus. Interpretation of these results is hampered by inconsistencies between studies and analyses regarding preparation (with/without $\mathrm{NaCl}$ ) and incubation times (2-10 days) [12, 19]. 


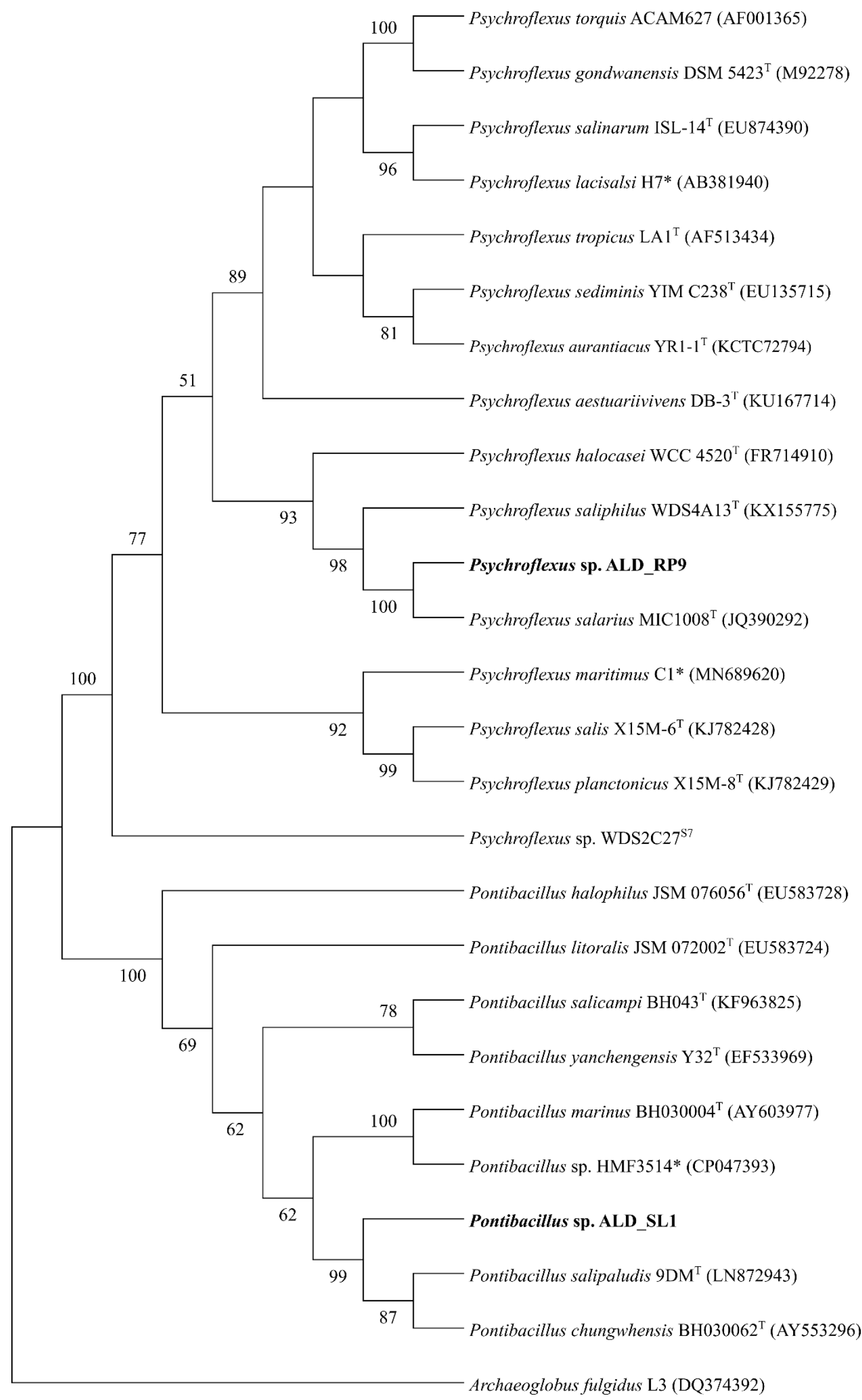


Fig 2. Neighbor-joining phylogenetic tree of the Pontibacillus and Psychroflexus genera. The tree includes 16S rRNA gene sequences from genomes $(*)$, and genome scaffolds (S and scaffold number). The optimal tree with the sum of branch length 1.05278265 is shown. The percentage of replicate trees in which the associated taxa clustered together in the bootstrap test $(1,000$ replicates) are shown next to the branches. Bootstrapping values at the branches indicate the mean result of the neighbor-joining, maximum-likelihood and maximum-parsimony method. Evolutionary distances were calculated using the Kimura 2-parameter model with Archaeoglobus fulgidus L3 as an outgroup.

\section{Genome assembly and characteristics}

Two complete genomes were assembled with a hybrid assembly using long Nanopore reads and short Illumina paired-end reads. Quality-filtering with fastp removed 59\% of the ALD_SL1 Nanopore reads, mainly due to the length constraints. Quality-filtering of ALD_SL1 Illumina reads removed $4 \%$ of the reads. The Pontibacillus sp. ALD_SL1 genome (CP062974) and plasmid (CP062975) were assembled from 233,024 quality-filtered Nanopore reads with a mean length of $1,438 \mathrm{bp}$ and 7,554,974 quality-filtered Illumina reads with a mean length of $235 \mathrm{bp}$. The genome assembly resulted in a closed circular chromosome $(3,811,075 \mathrm{bp})$ and megaplasmid $(897,839 \mathrm{bp})$ with a GC content of 40.84 and $42.38 \%$, respectively. The whole genome exhibited a mean read coverage of $443 \mathrm{x}, 4,759$ putative proteinencoding genes, 24 rRNAs, 78 tRNAs and five non-coding RNAs (Table 2). Of all sequenced Pontibacillus isolates, this is the only genome to harbour a (mega)plasmid. Of 1,236 hypothetical proteins in the whole genome, 725 are located on this plasmid. More than $50 \%$ of the megaplasmid were predicted as genomic islands, including two prophage regions. The chromosome harbours one putative prophage region (Fig 3). 
Table 2. Genome compositions

\begin{tabular}{|lcc|}
\hline Genome characteristic & $\begin{array}{c}\text { Pontibacillus sp. } \\
\text { ALD_SL1 }\end{array}$ & $\begin{array}{c}\text { Psychroflexus sp. } \\
\text { ALD_RP9 }\end{array}$ \\
\hline Genome size & $4.7 \mathrm{Mbp}$ & $2.6 \mathrm{Mbp}$ \\
Extrachromosomal features & Plasmid: 897,839 bp & - \\
Genome coverage & $443 \mathrm{x}$ & $1,056 \mathrm{x}$ \\
GC content & $41.1 \%$ & $33.1 \%$ \\
Protein coding genes (CDS) & 4,759 & 2,336 \\
RNA-encoding genes & 107 & 49 \\
\multicolumn{1}{c}{ rRNA } & 24 & 9 \\
tRNA & 78 & 36 \\
nc RNA & 5 & 4 \\
Pseudogenes & 157 & 13 \\
Hypothetical proteins & 1,263 & 431 \\
Genes with transmembrane & 1,350 & 546 \\
domains & 437 & 492 \\
Genes with signal peptides & 271 & 298 \\
SP (Sec/SPI) & 6 & 193 \\
TAT (Tat/SPI) & 160 & \\
Lipo (Sec/SPII) & & \\
\hline
\end{tabular}




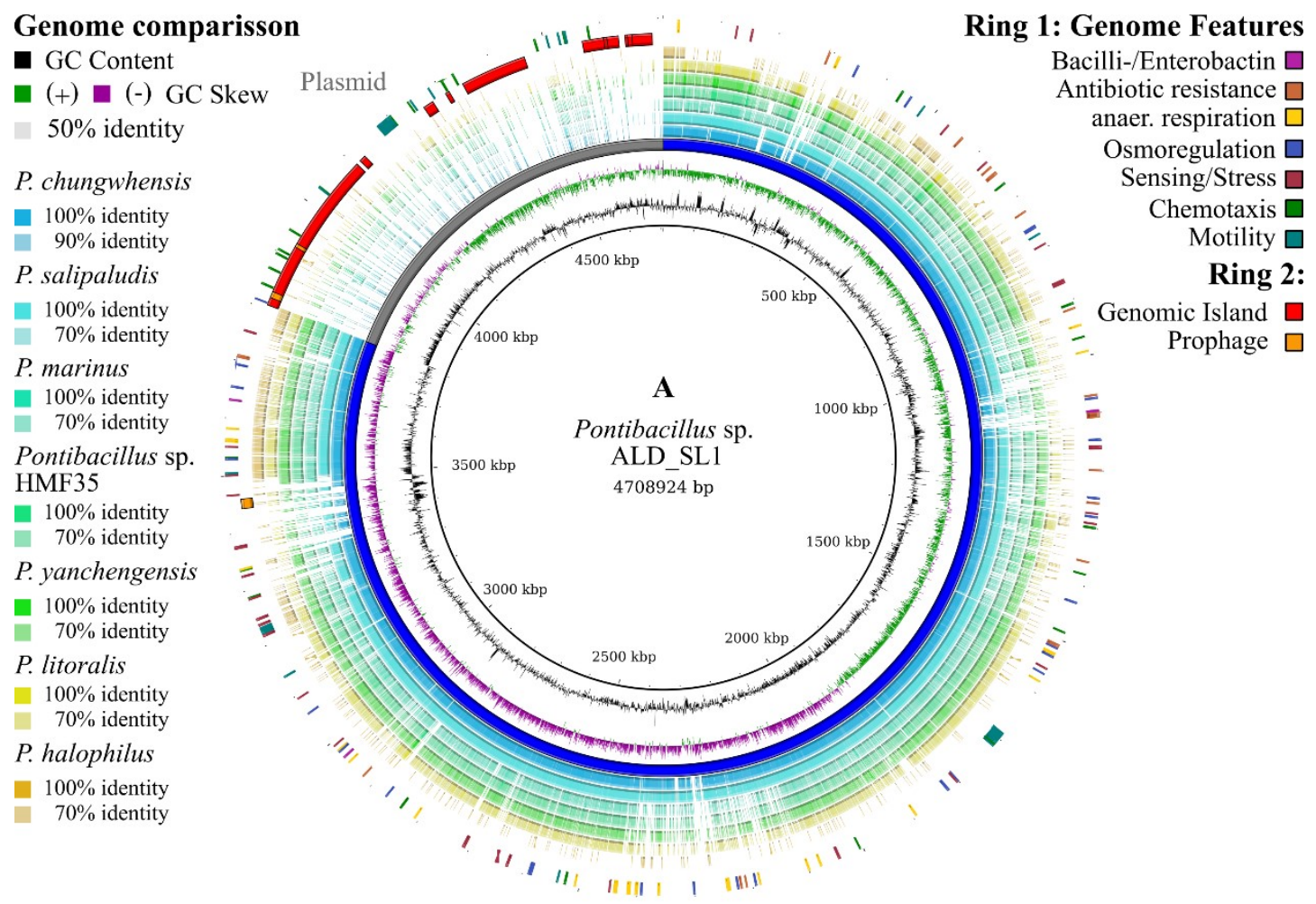

Genome comparisson

Ring 1: Genome Features

- GC Content

- (+) - (-) GC Skew

$50 \%$ identity

P. salarius

$100 \%$ identity

- $70 \%$ identity

P. halocasei

$100 \%$ identity

$70 \%$ identity

P. maritimus

$100 \%$ identity

$70 \%$ identity

P. salis

$100 \%$ identity

- $70 \%$ identity

P. planctonicus

$100 \%$ identity

$70 \%$ identity

P. aestuariivivens

$100 \%$ identity

$70 \%$ identity

P. aurantiacus

$100 \%$ identity

$70 \%$ identity

P. sediminis

$100 \%$ identity

- 70\% identity

Psychroflexus sp.

WDS2C27

$100 \%$ identity

$70 \%$ identity

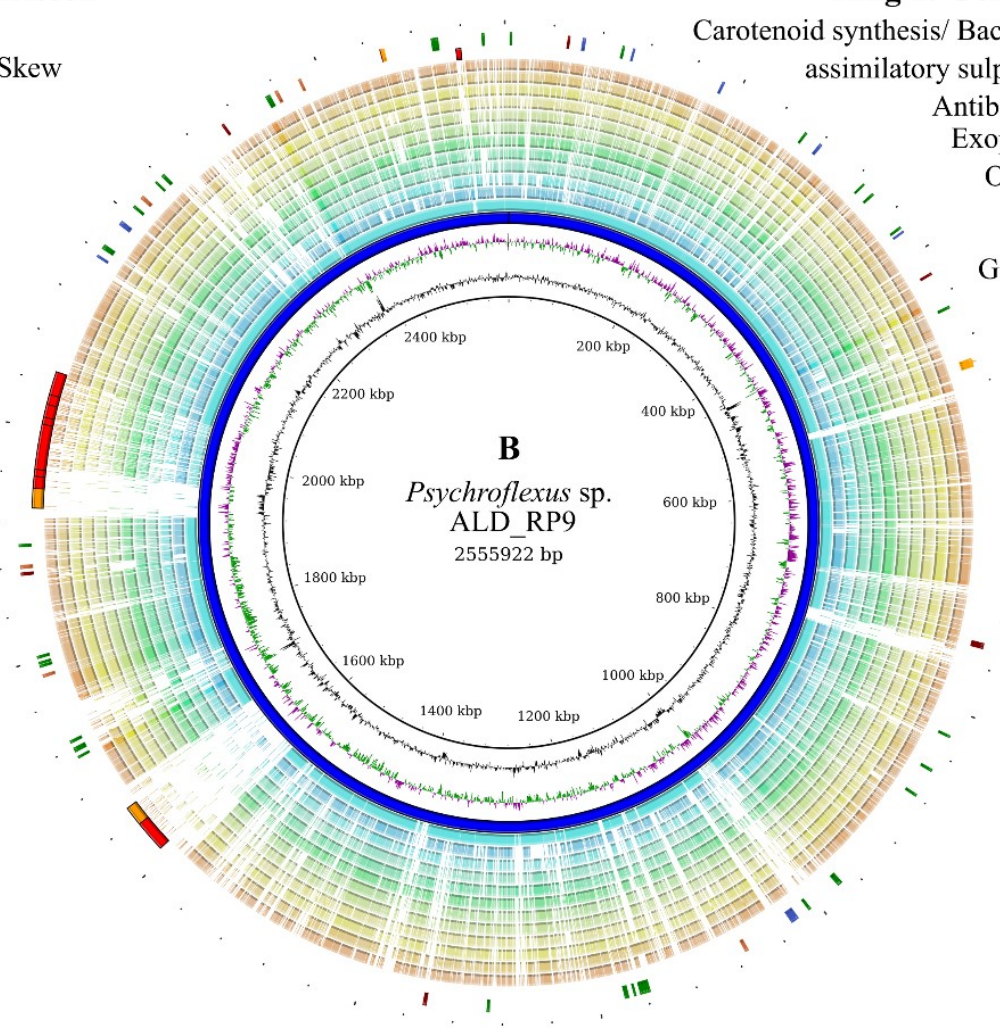

Antibiotic resistance $\square$ xopolysaccharide $\square$ Osmoregulation $\square$

Ring 2:

Genomic Island Prophage $\square$

Fig 3. Genome features and comparison of Pontibacillus sp. ALD SL1 and Psychroflexus sp. ALD_RP9 with all available scaffolds and genomes of their genus. The image was generated using BRIG [32] and a nucleotide blast for genome comparison. Ring 1: selected genome features from the functional annotation with BlastKOALA [33]. Ring 2: genomic islands (red) predicted with IslandViewer 4 [37] 
and prophages (orange) identified using PHASTER [38]. Rings 3-9 (A) and 3-11 (B): available genomes and scaffolds for each genus.

Quality filtering prior to Psychroflexus sp. ALD_RP9 assembly resulted in the removal of $16 \%$ of Nanopore and $4 \%$ of Illumina reads. The complete circular genome (CP062973) was assembled from 119,567 Nanopore reads with a mean length of $14,283 \mathrm{bp}$ and 3,909,382 Illumina reads with a mean length of $262 \mathrm{bp}$. The genome comprises a single circular chromosome $(2,555,922 \mathrm{bp})$ with a GC content of $33.1 \%$. The mean read coverage was 1,056 -fold. A total of 2,336 putative protein-encoding genes were assigned of which 431 were hypothetical. In addition, genes for nine rRNAs, 36 tRNAs and four non-coding RNAs were identified. Two genomic islands were identified, which overlap with the prophage predictions. These regions share low sequence similarity or are absent from the other Psychroflexus genomes (Fig 3).

\section{Phylogeny}

A neighbour-joining phylogenetic tree was built with the consensus 16S rRNA gene sequences from each isolate and the 16S rRNA genes of all available genomes and scaffolds (Fig 2). GTDB-Tk resolved their taxonomy to the genus level with a RED value of 0.995 (ALD_SL1) and 0.994 (ALD_RP9), indicating that both are new species. Relatedness on the genomic level was assessed through average nucleotide identity analysis (ANIm) with all available genomes and genome assemblies (Fig 4). The available Pontibacillus genomes in the NCBI database consist of seven contiglevel assemblies, two scaffolds and one complete genome (Pontibacillus sp. HMF3514). Pontibacillus sp. ALD_SL1 is most closely related to P. chungwhensis BH030062 ${ }^{\mathrm{T}}$ (ANI 93\%) and P. salipaludis CGMCC 1.15353 (ANI 91\%), which were isolated from a solar saltern in Chungwha, Korea [1] and marine sediment in Tuticorn, India [6]. All other available genome assemblies remain below 90\% ANI, however, these values may be exaggerated due to gaps in the unclosed genomes and scaffolds. Available Psychroflexus assemblies comprise seven contig-level genomes, seven scaffolds and one complete genome (Ps. torquis). Psychroflexus sp. ALD_RP9 is most closely related to Ps. salarius $\mathrm{MIC} 1008^{\mathrm{T}}$ with an ANI of $89 \%$ and forms a wellsupported cluster with Ps. saliphilus WDS4A14 ${ }^{\mathrm{T}}$ and Ps. halocasei WCC $4520^{\mathrm{T}}$. The relation of this branch to the cluster around the type species Ps. torquis ACAM627 
and Ps. tropicus $\mathrm{LA}^{\mathrm{T}}$ could not fully be resolved (bootstrap values $<60$ ) using the three tree building methods (Fig 2). Members on this branch contain the smallest genomes of the genus with an average of $2.62 \mathrm{Mbp}$. Smaller genomes and a higher percentage of coding genes (92\%) than more distant relatives i.e., Ps. torquis (4.32 Mbp, 81\%) [42], indicate genome streamlining [43]. However, it has been proposed that the reverse is true and Ps.torquis may have benefitted from extensive gene acquisition to survive in its native arctic environment, leading to an increased genome size [42].
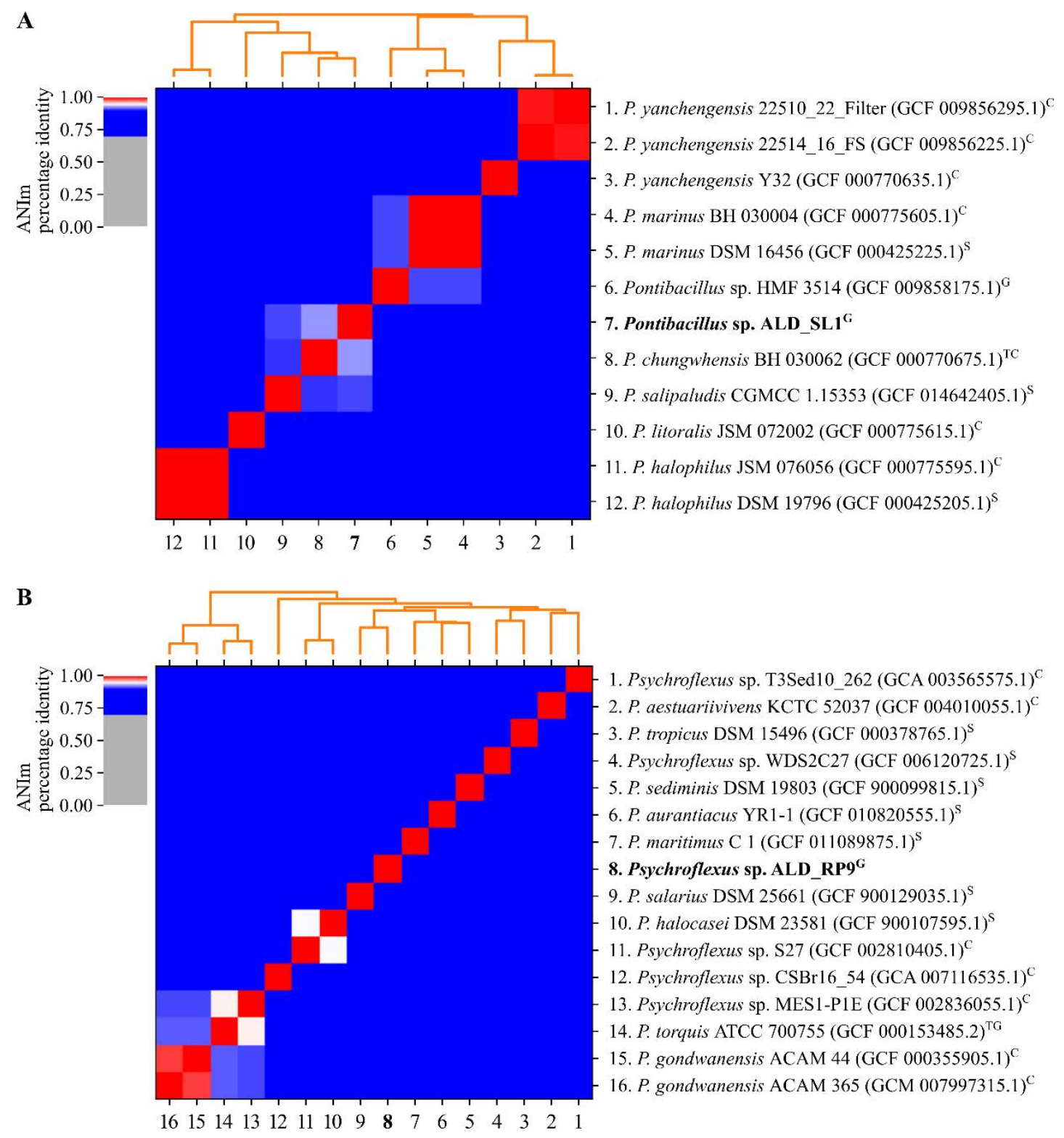

Fig 4. Relatedness of Pontibacillus (A) and Psychroflexus (B) genomes. All available genome assemblies of each genus were aligned and compared using ANIm in pyANI v0.2.10. [31]. The level of genome completeness is indicated in upper case: contig (C), scaffold (S), full genome $(G)$, genus type species $(T)$. 


\section{Genome features}

Pontibacillus sp. ALD_SL1 protein sequences were sorted into KEGG categories using BlastKoala [33] and KEGG Mapper [34], resulting in the assignment of 2,305 entries to 214 pathways (Table 3). Most genes of the Pontibacillus sp. ALD_SL1 genome were assigned to carbohydrate metabolism (266), followed by amino acid metabolism (228) and the metabolism of cofactors and vitamins (114). The most prevalent genes on the megaplasmid belong to cell motility (40) and replication and repair (32). Pontibacillus sp. ALD_SL1, like P. litoralis [3] and P. salipaludis [6], is putatively one of the facultatively anaerobic members of the genus. Under anaerobic conditions, it can generate energy potentially through oxidative phosphorylation (cox genes, F-type ATPase), and pyruvate metabolism, including fermentation to acetate (ala, pta, ackA), lactate (ldh), formate (pflD), butanol (crt, ptb, buk) and ethanol (ald, adh). Under nutrient-limiting conditions, ALD_SL1 can scavenge for iron using the siderophores bacilli- and enterobactin (entA-E). All 19 putative antibiotic resistance genes (ARGs) predicted for Pontibacillus sp. ALD_SL1 were located on the chromosome. The genes are mainly ATP-binding cassette (ABC) transporters, such as multidrug efflux pumps. In addition, putative resistance genes to fosfomycin (fosB), aminoglycosides (aacC, aadD, aadK), glycopeptides (vanY), tetracycline (tetB) and $\beta$ lactam antibiotics (penP) were detected (S2 Table). Resistance to aminoglycosides, tetracycline, phosphomycin and ampicillin has previously been shown for other isolates of the genus $[3,5,6]$. $\mathrm{ABC}$ transporters not only convey resistance to antibiotics, but also act as channels for osmotic regulation in the marine environment. Transporters include $\mathrm{Na}^{+} / \mathrm{H}^{+}$antiporters (nhaC, mrpA-G) regulating cell homeostasis [44], $\mathrm{K}^{+}$transporters (trkA, kch), as well as mechanosensitive channels (mscL) (Fig $5 \mathrm{~A}$ ). Genes for the transport of compatible solutes proline, glycine and betaine (proV$\mathrm{X}$, opuD/betL, opuA-C), which act as osmolytes [45], were detected as in other Pontibacilli [8]. Genes for ectoine synthesis, which are common in many halotolerant bacteria [45 and references therein] as well as P. marinus [4], were not detected in the ALD_SL1 genome. Further regulation of osmotic and other stressors could occur via the encoded putative quorum-sensing and subsequent phosphor-relay systems. These are involved in the regulation of membrane fluidity (desK/R), degradative enzymes ( $\operatorname{degS} / \mathrm{U})$ [46], competence (comX/K) [47], and induce sporulation (spo genes) [48] (Fig 5A). While regulators of cell competence were present in the genome, a type IV 
secretion system for plasmid conjugation was not detected. ALD_SL1 can sense its environment and adjust its position using chemotaxis genes ( $\mathrm{mcp} / \mathrm{che})$, which control flagella movement [49]. The chemotaxis receptors may be sensitive to oxygen, amongst other attractants, as the isolate showed aerotactic behaviour during motility testing. Most of its motility genes (i.e., fliG/M/N, motA/B) are situated both at the chromosome and the megaplasmid (Table 3). While encoding the same putative proteins, the genes share only low homology to each other. This indicates that they were acquired through horizontal gene transfer via the large mobile genetic elements (genomic islands/prophages) on the plasmid, rather than by interreplicon duplication [50]. As the plasmid does not harbour any essential genes, it is likely not critical for cell viability.

Table 3. Functional assignment of genes into KEGG categories

\begin{tabular}{|c|c|c|c|}
\hline \multirow[t]{2}{*}{ KEGG category } & \multicolumn{2}{|c|}{$\begin{array}{c}\text { Pontibacillus sp. } \\
\text { ALD_SL1 }\end{array}$} & \multirow{2}{*}{$\begin{array}{c}\text { Psychroflexus sp. } \\
\text { ALD_RP9 } \\
\text { Chromosome }\end{array}$} \\
\hline & Chromosome & Plasmid & \\
\hline $\begin{array}{l}\text { Total Entries/ Pathways } \\
\text { Metabolism }\end{array}$ & $2,305 / 214$ & $252 / 72$ & $1,160 / 214$ \\
\hline Carbohydrate metabolism & 266 & 8 & 157 \\
\hline Energy metabolism & 101 & 1 & 90 \\
\hline Lipid metabolism & 59 & 7 & 40 \\
\hline Nucleotide metabolism & 73 & 9 & 65 \\
\hline Amino acid metabolism & 228 & 10 & 179 \\
\hline $\begin{array}{l}\text { Metabolism of other amino acids } \\
\text { Glycan biosynthesis and }\end{array}$ & 38 & 4 & 26 \\
\hline metabolism & 34 & 9 & 49 \\
\hline $\begin{array}{l}\text { Metabolism of cofactors and } \\
\text { vitamins }\end{array}$ & 114 & 7 & 97 \\
\hline $\begin{array}{l}\text { Biosynthesis of other secondary } \\
\text { metabolites }\end{array}$ & 29 & 1 & 28 \\
\hline $\begin{array}{l}\text { Xenobiotics biodegradation and } \\
\text { metabolism }\end{array}$ & 32 & 1 & 32 \\
\hline
\end{tabular}




\begin{tabular}{|lccc|}
\hline Genetic Information Processing & 7 & 3 & 3 \\
Transcription & 82 & 0 & 79 \\
Translation & 35 & 3 & 28 \\
Folding, sorting and degradation & 72 & 32 & 64 \\
Replication and repair & & & \\
Environmental Information & & & 28 \\
Processing & 97 & 4 & 37 \\
Membrane transport & 78 & 10 & 7 \\
Signal transduction & & & 11 \\
Cellular Processes & 9 & 0 & 30 \\
Transport and Catabolism & 12 & 7 & 4 \\
Cell growth and death & & & \\
Cellular community - & 76 & 5 & \\
prokaryotes & 50 & 40 & \\
Cell motility & & 3 & \\
Human Diseases & 18 & & \\
Drug resistance: antimicrobial & & & \\
\hline
\end{tabular}




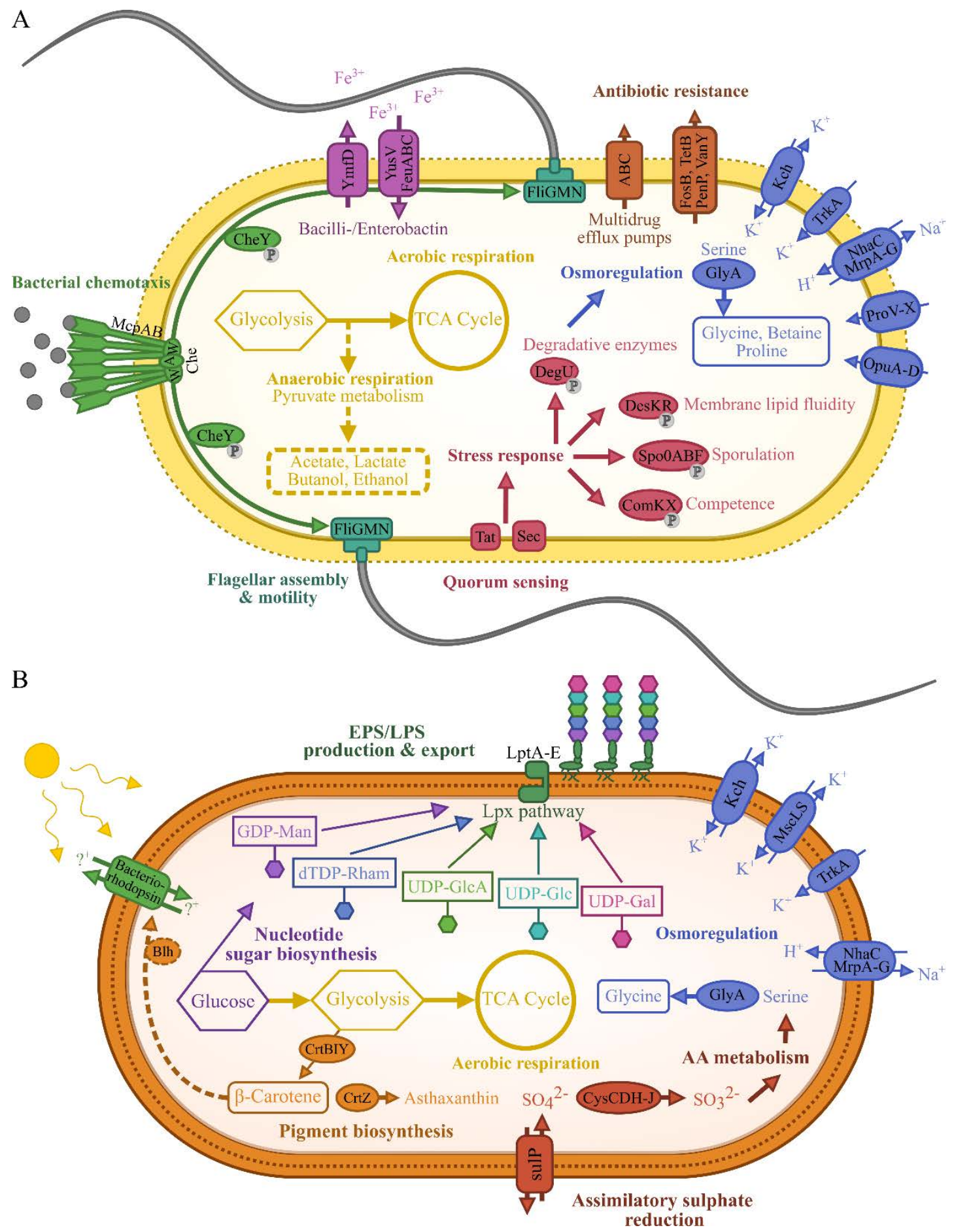

Fig 5. Key aspects of the Pontibacillus sp. ALD_SL1 (A) and Psychroflexus sp. ALD_RP9 (B) metabolism. Metabolic pathways and capabilities were reconstructed from the complete genomes against the KEGG database using BlastKoala [33] and the KEGG Mapper [34].

Psychroflexus sp. ALD_RP9 genes matched 1,160 KEGG entries which were assigned to 214 pathways. Most entries belonged to amino acid (179) and carbohydrate 
(157) metabolism, followed by the metabolism of cofactors and vitamins (97). ARG search indicated that Psychroflexus sp. ALD_RP9 harbours six potential antibiotic resistance genes. Four of these are multidrug $\mathrm{ABC}$ transporters, one a multidrug and toxic compound extrusion (MATE) family resistance protein and one a bicyclomycin multidrug efflux protein (S2 Table). It has previously been shown, that Psychroflexi are resistant to aminoglycosides, polyketide, and quinolone antibiotics [13, 20], but the identified ARGs cannot directly be linked to resistance against specific antibiotic compounds. Psychroflexus sp. ALD_RP9 employs a different strategy compared to Pontibacillus sp. ALD_SL1 to cope with the high salinity in its environment. To maintain turgor, it employs a series of $\mathrm{Na}^{+} / \mathrm{H}^{+}$antiporters (NhaC/D, MrpA) [44, 51] and (mechanosensitive) ion transport channels (MscL/S, Kch) and proteins (TrkA) [52]. These may also support its ability to cope with the high $\mathrm{pH}$ tolerated. In addition, ALD_RP9 has an extensive exopolysaccharide layer surrounding the cells (Fig 1) and colonies have an almost jelly-like consistency. The EPS layer can protect from high salinity and $\mathrm{pH}$ values, as well as provide protection against desiccation [53]. ALD_RP9 forms its EPS layer by using a variety of nucleotide sugars and the Raetz pathway (lpx/waa genes). They are translocated and connected with the outer membrane via an lipopolysaccharide (LPS) transport system (lpt genes, Fig 5B) [54]. Acquisition of EPS/LPS genes has previously been observed in Ps. torquis, for which it was hypothesised that they support growth under psychrophilic conditions [42]. Psychroflexus sp. ALD_RP9 harbours some additional EPS genes within regions which are absent from all other strains (Fig 4). This suggests that ALD_RP9 has acquired additional EPS genes to support its survival. While EPS provides some desiccation protection, ALD_RP9 uses carotenoids (crtB/I/Y/Z genes) within its cell membrane to protect from irradiation and oxidative stress. The carotenoids can also be cleaved into retinal by $\mathrm{Blh}$, which is required as co-factor for bacteriorhodopsin function [55]. In Psychroflexus members the bacteriorhodopsins most likely act as proton pumps that can drive ATP synthesis. This can be used to supplement their energy metabolism while under osmotic and other stress conditions [56, 57]. 


\section{Conclusions}

We describe two novel bacterial species within the Pontibacillus and the Psychroflexus genus. Pontibacillus sp. ALD_SL1 is the third facultative anaerobe of the genus and first Pontibacillus to harbour a (mega-)plasmid. The plasmid contains genomic islands in large proportions and likely supports chemotaxis and motility but is not essential for cell viability. Psychroflexus sp. ALD_RP9 shows an enhanced capability to grow at high $\mathrm{pH}$ values in comparison to other Psychroflexus species. It clusters phylogenetically with members harbouring smallest genomes of the genus. Further, it contains genomic regions which are not present in other Psychroflexi and encode for additional genes involved in EPS synthesis. These may provide enhanced protection towards the moderately hypersaline conditions in its habitat. Taken together, both Pontibacillus sp. ALD_SL1 and Psychroflexus sp. ALD_RP9 are highly adapted to their environment but follow different strategies to support their survival.

\section{Acknowledgments}

We thank the Seychelles Islands Foundation (SIF) for the permission to carry out the field work and sampling on Aldabra. The Seychelles Ministry of Environment, Energy, and Climate Change is kindly acknowledged for the permission to export and scientifically analyse the samples. We gratefully acknowledge the support of the entire SIF staff throughout the expedition to Aldabra. The Westpool D water data was kindly supplied by Prof. Dr. Gernot Arp, Dario Fussmann and Dr. Andreas Reimer. We thank Maximilian Greger for his assistance during isolation of the bacteria. Thank you to Mechthild Bömecke and Ines Friedrich for their ongoing support and advice. Technical assistance during sequencing by Melanie Heinemann and Sarah Schüßler and with transmission electron microscopy by PD Dr. Michael Hoppert is hereby gratefully acknowledged. 


\section{References}

1. Lim J-M, Jeon CO, Song SM, Kim C-J. Pontibacillus chungwhensis gen. nov., sp. nov., a moderately halophilic Gram-positive bacterium from a solar saltern in Korea. Int J Syst Evol Microbiol. 2005;55:165-70. doi:10.1099/ijs.0.63315-0.

2. Chen Y-G, Zhang Y-Q, Xiao H-D, Liu Z-X, Yi L-B, Shi J-X, et al. Pontibacillus halophilus sp. nov., a moderately halophilic bacterium isolated from a sea urchin. Int J Syst Evol Microbiol. 2009;59:1635-9. doi:10.1099/ijs.0.002469-0.

3. Chen Y-G, Zhang Y-Q, Yi L-B, Li Z-Y, Wang Y-X, Xiao H-D, et al. Pontibacillus litoralis sp. nov., a facultatively anaerobic bacterium isolated from a sea anemone, and emended description of the genus Pontibacillus. Int J Syst Evol Microbiol. 2010;60:560-5. doi:10.1099/ijs.0.009910-0.

4. Lim J-M, Jeon CO, Park D-J, Kim H-R, Yoon B-J, Kim C-J. Pontibacillus marinus sp. nov., a moderately halophilic bacterium from a solar saltern, and emended description of the genus Pontibacillus. Int J Syst Evol Microbiol. 2005;55:1027-31. doi:10.1099/ijs.0.63489-0.

5. Lee J-C, Kim Y-S, Yun B-S, Whang K-S. Pontibacillus salicampi sp. nov., a moderately halophilic bacterium isolated from saltern soil. Int J Syst Evol Microbiol. 2015;65:375-80. doi:10.1099/ijs.0.066423-0.

6. Sultanpuram VR, Mothe T, Mohammed F, Chintalapati S, Chintalapati VR. Pontibacillus salipaludis sp. nov., a slightly halophilic bacterium isolated from a salt pan. Int J Syst Evol Microbiol. 2016;66:3884-9. doi:10.1099/ijsem.0.001281.

7. Yang Y, Zou Z, He M, Wang G. Pontibacillus yanchengensis sp. nov., a moderately halophilic bacterium isolated from salt field soil. Int J Syst Evol Microbiol. 2011;61:1906-11. doi:10.1099/ijs.0.023911-0.

8. Huang J, Qiao ZX, Tang JW, Wang G. High quality draft genome sequence of the moderately halophilic bacterium Pontibacillus yanchengensis $\mathrm{Y} 32(\mathrm{~T})$ and comparison among Pontibacillus genomes. Stand Genomic Sci. 2015;10:93. doi:10.1186/s40793-015-0085-y.

9. Bowman JP, McCammon SA, Lewis T, Skerratt JH, Brown JL, Nichols DS, McMeekin TA. Psychroflexus torquis gen. nov., sp. nov., a psychrophilic species from Antarctic sea ice, and reclassification of Flavobacterium gondwanense (Dobson et al. 1993) as Psychroflexus gondwanense gen. nov., comb. nov. 
Microbiology (Reading). 1998;144 (Pt 6):1601-9. doi:10.1099/00221287-144-61601.

10. Dobson SJ, Colwell RR, McMeekin TA, Franzmann PD. Direct sequencing of the polymerase chain reaction-amplified $16 \mathrm{~S}$ rRNA gene of Flavobacterium gondwanense sp. nov. and Flavobacterium salegens sp. nov., two new species from a hypersaline Antarctic lake. Int J Syst Bacteriol. 1993;43:77-83. doi:10.1099/00207713-43-1-77.

11. Chen Y-G, Cui X-L, Wang Y-X, Tang S-K, Zhang Y-Q, Li W-J, et al. Psychroflexus sediminis sp. nov., a mesophilic bacterium isolated from salt lake sediment in China. Int J Syst Evol Microbiol. 2009;59:569-73. doi:10.1099/ijs.0.003269-0.

12. Zhong Z-P, Liu Y, Wang F, Zhou Y-G, Liu H-C, Liu Z-P. Psychroflexus salis sp. nov. and Psychroflexus planctonicus sp. nov., isolated from a salt lake. Int J Syst Evol Microbiol. 2016;66:125-31. doi:10.1099/ijsem.0.000687.

13. Jin S, Xia J, Dunlap CA, Rooney AP, Du Z-J. Psychroflexus saliphilus sp. nov., isolated from a marine solar saltern. Int J Syst Evol Microbiol. 2016;66:5124-8. doi:10.1099/ijsem.0.001482.

14. Donachie SP, Bowman JP, Alam M. Psychroflexus tropicus sp. nov., an obligately halophilic Cytophaga-Flavobacterium-Bacteroides group bacterium from an Hawaiian hypersaline lake. Int J Syst Evol Microbiol. 2004;54:935-40. doi:10.1099/ijs.0.02733-0.

15. Chun J, Kang JY, Jahng KY. Psychroflexus salarius sp. nov., isolated from Gomso salt pan. Int J Syst Evol Microbiol. 2014;64:3467-72. doi:10.1099/ijs.0.0652190 .

16. Yoon J-H, Kang S-J, Jung Y-T, Oh T-K. Psychroflexus salinarum sp. nov., isolated from a marine solar saltern. Int J Syst Evol Microbiol. 2009;59:2404-7. doi:10.1099/ijs.0.008359-0.

17. Zhang H, Hosoi-Tanabe S, Nagata S, Ban S, Imura S. Psychroflexus lacisalsi sp. nov., a moderate halophilic bacterium isolated from a hypersaline lake (HunazokoIke) in Antarctica. J Microbiol. 2010;48:160-4. doi:10.1007/s12275-010-0018-9.

18. Wu S-G, Wang J-J, Wang J-N, Chen Q, Sheng D-H, Li Y-Z. Psychroflexus aurantiacus sp. nov., isolated from soil in the Yellow River Delta wetlands. Int J Syst Evol Microbiol. 2020;70:6284-93. doi:10.1099/ijsem.0.004527. 
19. Seiler H, Bleicher A, Busse H-J, Hüfner J, Scherer S. Psychroflexus halocasei sp. nov., isolated from a microbial consortium on a cheese. Int J Syst Evol Microbiol. 2012;62:1850-6. doi:10.1099/ijs.0.034801-0.

20. Park S, Jung Y-T, Park J-M, Kim S-G, Yoon J-H. Psychroflexus aestuariivivens sp. nov., isolated from a tidal flat. Int J Syst Evol Microbiol. 2016;66:2146-51. doi:10.1099/ijsem.0.001000.

21. Zhong Y-L, Zhang R, Zhang X-Y, Yu L-X, Zhao M-F, Du Z-J. Psychroflexus maritimus sp. nov., isolated from coastal sediment. Arch Microbiol. 2020;202:2127-33. doi:10.1007/s00203-020-01933-9.

22. Dyall-Smith M. The Halohandbook: Protocols for haloarchaeal genetics. Version 7.2; 2009. Available from: https://haloarchaea.com/wpcontent/uploads/2018/10/Halohandbook_2009_v7.3mds.pdf.

23. Claus D. A standardized Gram staining procedure. World J Microbiol Biotechnol. 1992;8:451-2. doi:10.1007/BF01198764.

24. Friedrich I, Hollensteiner J, Schneider D, Poehlein A, Hertel R, Daniel R. First complete genome sequences of Janthinobacterium lividum EIF1 and EIF2 and their comparative genome analysis. Genome Biol Evol. 2020;12:1782-8. doi:10.1093/gbe/evaa148.

25. Chen S, Zhou Y, Chen Y, Gu J. fastp: an ultra-fast all-in-one FASTQ preprocessor. Bioinformatics. 2018;34:i884-i890. doi:10.1093/bioinformatics/bty560.

26. Wick RR. porechop; 2018. Available from: https://github.com/rrwick/Porechop.

27. Wick RR, Judd LM, Gorrie CL, Holt KE. Unicycler: Resolving bacterial genome assemblies from short and long sequencing reads. PLoS Comput Biol. 2017;13:e1005595. doi:10.1371/journal.pcbi.1005595.

28. Chaumeil P-A, Mussig AJ, Hugenholtz P, Parks DH. GTDB-Tk: a toolkit to classify genomes with the Genome Taxonomy Database. Bioinformatics 2019. doi:10.1093/bioinformatics/btz848.

29. Tatusova T, DiCuccio M, Badretdin A, Chetvernin V, Nawrocki EP, Zaslavsky L, et al. NCBI prokaryotic genome annotation pipeline. Nucleic Acids Res. 2016;44:6614-24. doi:10.1093/nar/gkw569.

30. Kumar S, Stecher G, Li M, Knyaz C, Tamura K. MEGA X: Molecular evolutionary genetics analysis across computing platforms. Mol Biol Evol. 2018;35:1547-9. doi:10.1093/molbev/msy096. 
31. Pritchard L, Glover RH, Humphris S, Elphinstone JG, Toth IK. Genomics and taxonomy in diagnostics for food security: soft-rotting enterobacterial plant pathogens. Anal. Methods. 2016;8:12-24. doi:10.1039/C5AY02550H.

32. Alikhan N-F, Petty NK, Ben Zakour NL, Beatson SA. BLAST Ring Image Generator (BRIG): simple prokaryote genome comparisons. BMC Genomics. 2011;12:402. doi:10.1186/1471-2164-12-402.

33. Kanehisa M, Sato Y, Morishima K. BlastKOALA and GhostKOALA: KEGG tools for functional characterization of genome and metagenome sequences. J Mol Biol. 2016;428:726-31. doi:10.1016/j.jmb.2015.11.006.

34. Kanehisa M, Sato Y. KEGG Mapper for inferring cellular functions from protein sequences. Protein Sci. 2020;29:28-35. doi:10.1002/pro.3711.

35. Krogh A, Larsson B, Heijne G von, Sonnhammer EL. Predicting transmembrane protein topology with a hidden Markov model: application to complete genomes. J Mol Biol. 2001;305:567-80. doi:10.1006/jmbi.2000.4315.

36. Almagro Armenteros JJ, Tsirigos KD, Sønderby CK, Petersen TN, Winther O, Brunak S, et al. SignalP 5.0 improves signal peptide predictions using deep neural networks. Nat Biotechnol. 2019;37:420-3. doi:10.1038/s41587-019-0036-z.

37. Bertelli C, Laird MR, Williams KP, Lau BY, Hoad G, Winsor GL, Brinkman FSL. IslandViewer 4: expanded prediction of genomic islands for larger-scale datasets. Nucleic Acids Res. 2017;45:W30-W35. doi:10.1093/nar/gkx343.

38. Arndt D, Grant JR, Marcu A, Sajed T, Pon A, Liang Y, Wishart DS. PHASTER: a better, faster version of the PHAST phage search tool. Nucleic Acids Res. 2016;44:W16-21. doi:10.1093/nar/gkw387.

39. Eddy SR. Accelerated profile HMM searches. PLoS Comput Biol. 2011;7:e1002195. doi:10.1371/journal.pcbi.1002195.

40. Gibson MK, Forsberg KJ, Dantas G. Improved annotation of antibiotic resistance determinants reveals microbial resistomes cluster by ecology. ISME J. 2015;9:207-16. doi:10.1038/ismej.2014.106.

41. Arango-Argoty G, Garner E, Pruden A, Heath LS, Vikesland P, Zhang L. DeepARG: a deep learning approach for predicting antibiotic resistance genes from metagenomic data. Microbiome. 2018;6:23. doi:10.1186/s40168-018-0401$\mathrm{Z}$. 
42. Feng S, Powell SM, Wilson R, Bowman JP. Extensive gene acquisition in the extremely psychrophilic bacterial species Psychroflexus torquis and the link to sea-ice ecosystem specialism. Genome Biol Evol. 2014;6:133-48. doi:10.1093/gbe/evt209.

43. Giovannoni SJ, Cameron Thrash J, Temperton B. Implications of streamlining theory for microbial ecology. ISME J. 2014;8:1553-65. doi:10.1038/ismej.2014.60.

44. Padan E, Venturi M, Gerchman Y, Dover N. Na+/H+ antiporters. Biochimica et Biophysica Acta (BBA) - Bioenergetics. 2001;1505:144-57. doi:10.1016/S00052728(00)00284-X.

45. Roberts MF. Organic compatible solutes of halotolerant and halophilic microorganisms. Saline Syst. 2005;1:5. doi:10.1186/1746-1448-1-5.

46. Dartois V, Débarbouillé M, Kunst F, Rapoport G. Characterization of a novel member of the DegS-DegU regulon affected by salt stress in Bacillus subtilis. J. Bacteriol. 1998;180:1855-61. doi:10.1128/JB.180.7.1855-1861.1998.

47. Dogsa I, Choudhary KS, Marsetic Z, Hudaiberdiev S, Vera R, Pongor S, MandicMulec I. ComQXPA quorum sensing systems may not be unique to Bacillus subtilis: a census in prokaryotic genomes. PLoS One. 2014;9:e96122. doi:10.1371/journal.pone.0096122.

48. Galperin MY, Mekhedov SL, Puigbo P, Smirnov S, Wolf YI, Rigden DJ. Genomic determinants of sporulation in Bacilli and Clostridia: towards the minimal set of sporulation-specific genes. Environ Microbiol. 2012;14:2870-90. doi:10.1111/j.1462-2920.2012.02841.x.

49. Jones CW, Armitage JP. Positioning of bacterial chemoreceptors. Trends Microbiol. 2015;23:247-56. doi:10.1016/j.tim.2015.03.004.

50. diCenzo GC, Finan TM. The divided bacterial genome: structure, function, and evolution. Microbiol Mol Biol Rev 2017. doi:10.1128/MMBR.00019-17.

51. Moparthi VK, Kumar B, Mathiesen C, Hägerhäll C. Homologous protein subunits from Escherichia coli NADH:quinone oxidoreductase can functionally replace MrpA and MrpD in Bacillus subtilis. Biochim Biophys Acta. 2011;1807:427-36. doi:10.1016/j.bbabio.2011.01.005.

52. Epstein W. The roles and regulation of potassium in bacteria. In: : Elsevier; 2003. p. 293-320. doi:10.1016/S0079-6603(03)75008-9. 
53. Decho AW, Gutierrez T. Microbial extracellular polymeric substances (EPSs) in ocean systems. Front Microbiol. 2017;8:922. doi:10.3389/fmicb.2017.00922.

54. Whitfield C, Trent MS. Biosynthesis and export of bacterial lipopolysaccharides. Annu Rev Biochem. 2014;83:99-128. doi:10.1146/annurev-biochem-060713035600 .

55. Klassen JL. Phylogenetic and evolutionary patterns in microbial carotenoid biosynthesis are revealed by comparative genomics. PLoS One. 2010;5:e11257. doi:10.1371/journal.pone.0011257.

56. Feng S, Powell SM, Wilson R, Bowman JP. Light-stimulated growth of proteorhodopsin-bearing sea-ice psychrophile Psychroflexus torquis is salinity dependent. ISME J. 2013;7:2206-13. doi:10.1038/ismej.2013.97.

57. Feng S, Powell SM, Wilson R, Bowman JP. Proteomic insight into functional changes of proteorhodopsin-containing bacterial species Psychroflexus torquis under different illumination and salinity levels. J Proteome Res. 2015;14:384858. doi:10.1021/acs.jproteome.5b00241. 


\section{Supplement:}

\section{Contents:}

S1 Table. Growth ranges of Pontibacillus sp. ALD_SL1 and Psychroflexus sp. ALD_RP9. Measurements are given in triplicate as $\mathrm{OD}_{600}$ for each isolate. The starting OD has been subtracted from the values to reflect active growth rates.

The table can also be found on the enclosed CD and .zip folder:

supplement|Chapter_C4|S1_Table.xIsx.

S2 Table. Genomic features of Pontibacillus sp. ALD_SL1 and Psychroflexus sp. ALD_RP9. The table includes selected KEGG hits, antibiotic resistance genes, genomic islands and phages, and their location on the genomes.

The table can be found on the enclosed $C D$ and zip folder:

supplement|Chapter_c4|S2_Table.xIsx. 
S1 Table. Growth ranges of Pontibacillus sp. ALD_SL1 and Psychroflexus sp. ALD_RP9. Measurements are given in triplicate as $\mathrm{OD}_{600}$ for each isolate. The starting $\mathrm{OD}$ has been subtracted from the values to reflect active growth rates.

\begin{tabular}{|c|c|c|c|c|c|c|c|c|c|}
\hline \multicolumn{5}{|c|}{ Pontibacillus sp. ALD_SL1 } & \multicolumn{5}{|c|}{ Psychroflexus sp. ALD_RP9 } \\
\hline $\mathrm{NaCl}(\%)$ & 1 & 2 & 3 & Mean & $\mathrm{NaCl}(\%)$ & 1 & 2 & 3 & Mean \\
\hline $\mathbf{0}$ & 0.33 & 0.18 & 0.21 & 0.24 & $\mathbf{0}$ & 0.08 & 0.09 & 0.04 & 0.07 \\
\hline 5 & 2.13 & 1.77 & 1.87 & 1.92 & 5 & 3.09 & 3.15 & 3.18 & 3.14 \\
\hline 8 & 3.73 & 3.74 & 3.81 & 3.76 & 8 & 3.07 & 3.00 & 3.16 & 3.08 \\
\hline 9 & 4.18 & 4.00 & 4.22 & 4.13 & 9 & 3.09 & 3.13 & 3.14 & 3.12 \\
\hline 10 & 4.05 & 3.88 & 3.92 & 3.95 & 10 & 3.82 & 3.80 & 3.72 & 3.78 \\
\hline 11 & 5.65 & 5.63 & 5.60 & 5.63 & 11 & 3.16 & 3.24 & 3.33 & 3.24 \\
\hline 12 & 4.30 & 5.01 & 5.55 & 4.95 & 12 & - & - & - & - \\
\hline 15 & 3.60 & 3.71 & 3.56 & 3.62 & 15 & 1.73 & 1.77 & 1.52 & 1.67 \\
\hline 20 & 1.11 & 1.11 & 0.84 & 1.02 & 20 & 0.29 & 0.24 & 0.26 & 0.26 \\
\hline 25 & 0.15 & 0.45 & 0.07 & 0.22 & 25 & 0.07 & 0.06 & 0.04 & 0.06 \\
\hline pH & 1 & 2 & 3 & Mean & pH & 1 & 2 & 3 & Mean \\
\hline 5.5 & 0.02 & 0.03 & 0.03 & 0.03 & 5.5 & 0.06 & 0.10 & 0.07 & 0.08 \\
\hline 6 & 4.45 & 4.35 & 4.28 & 4.36 & 6 & 2.71 & 2.70 & 2.73 & 2.71 \\
\hline 6.5 & 4.65 & 4.36 & 4.29 & 4.43 & 6.5 & 3.10 & 3.11 & 3.32 & 3.18 \\
\hline 7 & 4.71 & 4.85 & 4.98 & 4.85 & 7 & 3.08 & 3.12 & 3.11 & 3.10 \\
\hline 7.5 & 3.80 & 4.16 & 3.91 & 3.96 & 7.5 & 3.19 & 3.06 & 3.21 & 3.15 \\
\hline 8 & 3.75 & 3.73 & 3.49 & 3.66 & 8 & 3.27 & 3.12 & 3.15 & 3.18 \\
\hline 8.5 & 3.38 & 3.81 & 3.95 & 3.71 & 8.5 & 2.83 & 2.99 & 2.92 & 2.91 \\
\hline 9 & 3.50 & 3.83 & 3.45 & 3.59 & 9 & 1.45 & 1.48 & 1.53 & 1.49 \\
\hline 9.5 & 3.91 & 3.94 & 4.46 & 4.10 & 9.5 & 1.13 & 1.40 & 1.09 & 1.21 \\
\hline 10 & 2.34 & 1.72 & 2.30 & 2.12 & 10 & 1.11 & 1.13 & 1.02 & 1.09 \\
\hline 10.5 & 0.00 & 0.00 & 0.00 & 0.00 & 10.5 & 0.84 & 0.86 & 0.83 & 0.84 \\
\hline Temperature $\left({ }^{\circ} \mathrm{C}\right)$ & 1 & 2 & 3 & Mean & Temperature $\left({ }^{\circ} \mathrm{C}\right)$ & 1 & 2 & 3 & Mean \\
\hline 10 & 0.00 & 0.00 & 0.00 & 0.00 & 10 & 0.06 & 0.08 & 0.09 & 0.08 \\
\hline 20 & 2.61 & 2.69 & 2.62 & 2.64 & 20 & 3.21 & 3.12 & 3.20 & 3.18 \\
\hline 25 & 3.82 & 3.55 & 2.84 & 3.40 & 25 & - & - & - & - \\
\hline 28 & 4.77 & 4.73 & 4.62 & 4.71 & 28 & 3.15 & 3.15 & 3.11 & 3.14 \\
\hline 35 & 4.04 & 4.27 & 4.22 & 4.18 & 35 & 2.98 & 2.82 & 2.98 & 2.93 \\
\hline 40 & 3.41 & 3.60 & 3.63 & 3.55 & 40 & 2.89 & 2.81 & 2.74 & 2.81 \\
\hline 50 & 0.06 & 0.03 & 0.05 & 0.05 & 50 & 0.06 & 0.00 & 0.00 & 0.02 \\
\hline
\end{tabular}




\title{
5. Aldabras' hypersaline POOLS: METAgenOMIC INSIGHTS INTO LITHIFYING AND UNLITHIFYING ENVIRONMENTS
}

Avril J. E. von Hoyningen-Huene ${ }^{1}$, Dominik Schneider ${ }^{1}$, Anja Poehlein ${ }^{1}$, Dario Fussmann ${ }^{2}$, Andreas Reimer ${ }^{2}$, Axel Himmelbach ${ }^{3}$, Nils Stein ${ }^{3}$, Gernot Arp ${ }^{2}$, Rolf Daniel $^{1}$

Manuscript draft

\begin{abstract}
Affiliations:
${ }^{1}$ Genomic and Applied Microbiology and Göttingen Genomics Laboratory, Institute of Microbiology and Genetics, Georg-August-University Göttingen, Göttingen, Germany.

${ }^{2}$ Geobiology, Faculty of Geosciences and Geography, Georg-August-University Göttingen, Göttingen, Germany.

${ }^{3}$ Genomics of Genetic Resources, Leibniz Institute of Plant Genetics and Crop Plant Research (IPK), Gartersleben, Germany
\end{abstract}

\section{Author contributions:}

Conceived and designed the study: RD, GA, DS, AvH

Performed the experiments: AvH, AP, DF, AR, AH, NS

Analysed the data: AvH, DS

Wrote the paper: AvH 


\begin{abstract}
The remote Aldabra Atoll harbours a series of moderately hypersaline pools associated with the formation of stromatolites. We used metagenomes and metagenome assembled genomes (MAGs) to study the microbial community composition and function within the water column, microbial mats and sediments of two pools Cinq Cases and Westpool D. The two sites differed by sediment depth and the presence of stromatolites at present (Westpool D) or in the past (Cinq Cases). Cinq Cases harbours non-lithified microbial mats and derived MAGs encode genes for photosynthesis, fermentation, sulphide oxidation and sulphate reduction. Below the mat and surface sediments an older, desiccated, and redox-positive bottom sediment occurred, characterized by MAGs derived from both aerobic heterotrophs and sulphate reducers. Westpool D harbours a stromatolite-forming biofilm at the pool margin, a noncalcifying microbial mat within the pool, as well as a purple sulphur bacterial bloom in its stratified water column. The calcifying biofilm and non-lithified microbial mat hosted different Cyanobacteria, potentially leading to the two different outcomes. Overall, the two pools showed little overlap between their microbial communities. They exemplify the range of environmental conditions and microbial populations on Aldabra, leading to the precipitation or dissolution of stromatolites.
\end{abstract}

\title{
Introduction
}

In recent years it has become possible to assemble whole genomes from metagenomes derived from total environmental DNA (Ayling et al., 2020). The so-called metagenome assembled genomes (MAGs) allow detailed insight into the metabolic pathways of "microbial dark matter". This includes microbes, which have thus far not been cultured or are only available as unclassified 16S rRNA sequences (Rinke et al., 2013). MAGs and single cell assembled genomes (SAGs) can highlight the metabolic flexibility within individual prokaryotic groups. Combined with existing genomic data of sequenced isolates, they allow analysis of core genes and niche partitioning in different ecosystems (Delmont and Eren, 2018). Though MAGs are imperfect reconstructions of genomes and should be evaluated with caution (Frioux et al., 2020), they provide the possibility to better understand extreme or understudied environments until cultured and sequenced representatives are available. 
Microbial communities have been studied along depth gradients in sediment cores ranging from the coastal marine environment (Dyksma et al., 2016) to shallow and deep-sea sediment (Bird et al., 2019; Peoples et al., 2019), as well as soda (Hoyningen-Huene et al., 2019) or meromictic (Rissanen et al., 2019) lakes ranging from temperate environments to the arctic circles. Hypersaline lakes and lagoons are rarely subjected to sediment coring beyond the surface sediment, as they are often studied with a focus on the water column (Naghoni et al., 2017) or precipitation features, such as microbialites (Saghaï et al., 2016) and microbial mats (Schneider et al., 2013; Baumgartner et al., 2009). The aim of most studies is to a) identify the abundant members, and b) understand their involvement in shaping their environment through their metabolism. Together with the measurement of corresponding porewater profiles, a standard biogeochemical model for sediments has been established. This follows the availability of electron acceptors starting with oxygen in the first millimetres of sediment and transitioning via manganese, iron and nitrate to sulphate and ultimately $\mathrm{CO}_{2}$ (Falkowski et al., 2008; Jørgensen and Kasten, 2006).

In a previous study (Chapter C.3) we determined the bacterial composition of sediments and water samples from the Aldabra Atoll in the Indian Ocean using 16S rRNA genes and transcripts. The data were analysed alongside detailed sediment porewater and bulk geochemical profiles. The landlocked saline pools of Cinq Cases (CC), situated on Grand Terre Island, showed a porewater and associated bacterial community profile divergent to the standard biogeochemical model. The profiles suggested that temporal and episodic environmental factors had a large impact on the sediment. This was formed of an evaporated, highly saline, redox positive older sediment at the bottom, which was rich in plant-based organic matter. The older sediment was covered by a younger sediment layer topped with a microbial mat (data not shown). The high phylogenetic diversity in the mat and corresponding peaks in the porewater profiles indicated, that it drove the biogeochemical process in the upper part of the core. The lower, potentially oxic part harboured aerobic heterotrophs, as well as remains of sulphate reducers and fermenters (Chapter C.3).

This initial study opened a variety of questions, including the metabolic capabilities of the large proportion of uncultured Actinobacteriota in the sediments, as well as the high relative abundance of sulphate reducers in the potentially oxic sediments at the bottom of the cores. In order to better understand these bacteria and 
expand the profile to archaea, eukaryotes and viruses, we opted to profile these taxa using metagenomes and MAGs. We included an additional sampling site, Westpool D (WPD), as it harbours stromatolites and different types of biofilms. The pool resembles descriptions for CC more than thirty years ago which harboured stromatolites at the time (Braithwaite et al., 1989). As the stromatolites in CC were no longer evident during our expedition in 2017, it exemplifies the circumstances in which stromatolites may have developed on Aldabra in the past. This allows us to better understand differences between then and now. Taken together, this is the first study using metagenomes and metagenome-assembled genomes to characterise the diverse microbial community of the Aldabra Atoll.

\section{Materials \& Methods}

\section{Sampling}

Samples were taken during an expedition to the Aldabra Atoll, Seychelles at the end of the dry season in November 2017. Three sediment push cores and water samples were retrieved from the $\mathrm{CC}$ pool system in the southeast of the rim-island Grand Terre (-9.42979 S, 46.49524 E; Figure 1.A). The push cores were sampled at $2.5 \mathrm{~cm}$ depth intervals (Figure 1.C). The second sample set was taken in triplicate at WPD (-9.44458 S, 46.45188 E), which was characterized by a stratified water column and stromatolites at the rim (Figure 1.B). Samples comprise the upper green and lower pink water layer of the stratified water column, the microbial mat and underlying sediment at the base of the pond, and the stromatolite biofilm (Figure 1.D). All water samples were filtered through a $0.2 \mu \mathrm{m}$ and $3.0 \mu \mathrm{m}$ filter sandwich, as described by Hoyningen-Huene et al., (2019). All samples were stored immediately in RNAProtect Bacteria Reagent (Qiagen, Hilden, Germany). 
A Cinq Cases

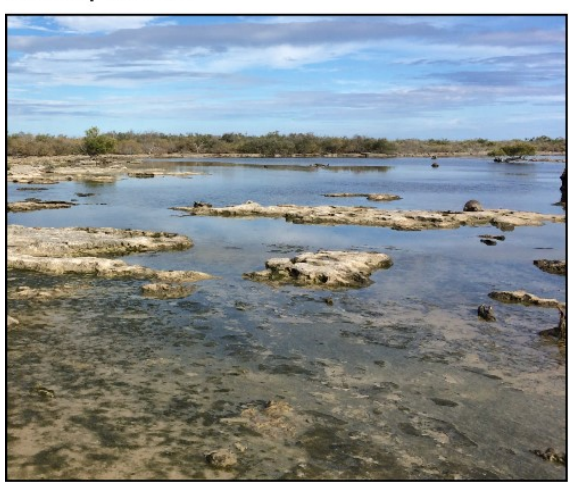

C Cinq Cases sediment cores D Westpool D samples
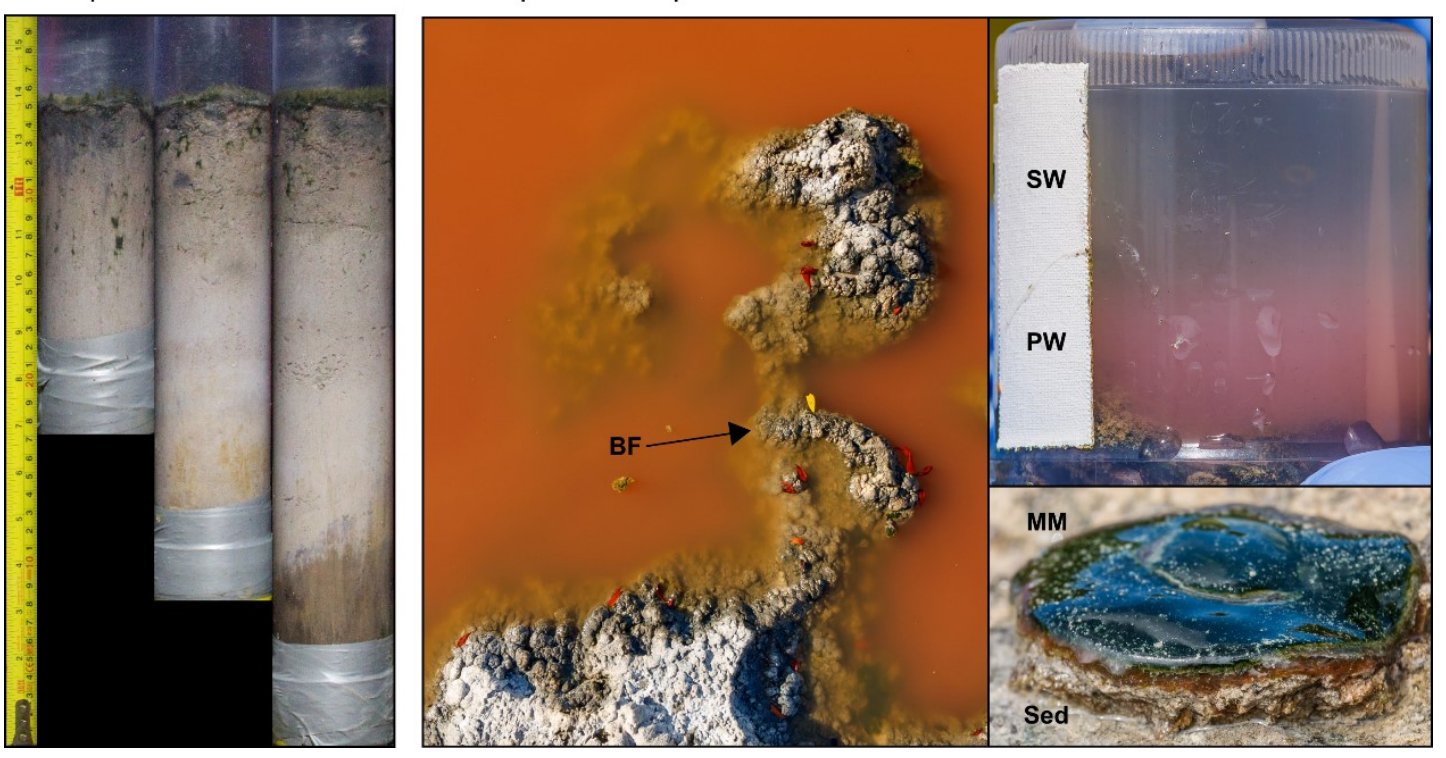

Figure 1. Sampling sites Cinq Cases (A) and Westpool D (B), sediment cores sampled at CC (C) and sampling sites at WPD (D). (C) Three sediment cores sampled at CC in $2.5 \mathrm{~cm}$ depth intervals. The image was modified from Supplementary Figure S3 in Chapter C.3 as follows: the three sediment cores used for metagenomic analysis were cropped and aligned to visualise the sediment succession (D). WPD from above including the stromatolites where the biofilm $(\mathrm{BF})$ was retrieved. The pictures on the right depict the stratified water column and underlying microbial mat. Here, the greenish surface water (SW), pink bottom water (PW), microbial mat (MM) and underlying sediment (Sed) were retrieved.

\section{Porewater and sediment geochemistry}

Pond water parameters, sediment porewater and bulk geochemistry were measured as described by (Fussmann et al., 2020) and in Chapter C.3.

\section{DNA extraction and sequencing}

DNA was extracted using the PowerSoil Total RNA and DNA accessory kit (Qiagen), as described in Chapter C.3. Bacterial 16S rRNA amplicons were generated by PCR, sequenced, and processed as described in (Chapter C.1, von Hoyningen-Huene et al. 2019). DNA extracts of the three water samples from CC were pooled for metagenome sequencing. Libraries were built using the Nextera ${ }^{\mathrm{TM}}$ DNA Flex Library Preparation 
Kit and Nextera ${ }^{\mathrm{TM}}$ DNA CD Indexes (Illumina, San Diego, CA, USA). Sample and library concentrations were measured using a Qubit and the Qubit 1x dsDNA HS Assay Kit 0.2-100 ng (Thermo Fisher Scientific, Walton, MA, USA). Library sizes were verified with the Agilent High Sensitivity DNA Kit (Agilent Technologies, Waldbronn, Germany). All samples were pooled equimolar and 2x250 bp paired-end reads were sequenced using a NovaSeq6000 instrument, the NovaSeq 6000 SP Reagent Kit v1.5 (500 cycles) and the NovaSeq XP 2-Lane Kit v1.5 as recommended by the manufacturer (Illumina).

\section{Initial sequence processing}

Short reads were quality-filtered using fastp v0.20.0 in paired-end mode with adapter removal (Chen et al., 2018b). After quality-filtering, the samples were interleaved and short reads were taxonomically assigned using Kraken v2.0.8-beta (Wood et al., 2019) and the NCBI non-redundant nucleotide database (NCBI nr/nt: downloaded 22.07.2020) and Kaiju v1.7.0 with the nr_euk subset (Menzel et al., 2016) of the NCBI BLAST nr database (downloaded 2020-07-21).

\section{Co-assembly, binning, and annotation}

The quality-filtered reads were co-assembled using megahit v1.2.9 in paired-end mode (Li et al., 2015) with a minimum kmer-size of 27, as recommended for complex metagenomes by the developers. The co-assembly quality was evaluated using MetaQUAST (Mikheenko et al., 2016). After co-assembly, contig names were simplified using anvi-script-reformat-fasta from anvi'o v7 (Eren et al., 2021) and reads were mapped to the contigs using bowtie2 (Langmead and Salzberg, 2012). Contigs were loaded into anvi'o v7 contig databases with a size cut-off of 1,000 bp. Genes were annotated using prodigal v2.6.3 (Hyatt et al., 2010) and common marker genes were identified using anvi-run-hmms with the default hmm-databases. Clusters of orthologous groups (COGs) (Tatusov et al., 2000) were annotated using anvi-run$n c b i-\operatorname{cogs}$ and DIAMOND (Buchfink et al., 2015). The contigs were binned, optimized and refined using anvi'o. Within the anvi'o framework, the binners CONCOCT v1.1.0 (Alneberg et al., 2014) and MetaBAT 2 v2.15 (Kang et al., 2019) were used with anvi'o standard settings. Maxbin2 was used with recommended settings and a sequence cut-off of 5,000 bp (Wu et al., 2016) and its bins were added to the anvi'o profile. All bins were optimised with DASTool v1.1.2 (Sieber et al., 2018) and manually refined in anvi'o up to a completion $>90 \%$ and redundancy $>10 \%$. The 
resulting metagenome assembled genomes (MAGs) were taxonomically assigned by screening ribosomal single-copy core genes against the GTDB database (v95, 17.07.2020) (anvi-run-scg-taxonomy). The most prevalent gene (ribosomal S11) was used to estimate the taxonomic composition of the samples (anvi-estimate-scgtaxonomy). Information on taxonomy, bin completeness, mean coverage and redundancy was summarized using anvi-summarize (Eren et al., 2021).

\section{Data analysis and visualization}

Hmm-hits based on 71 bacterial single copy core genes (anvi-get-sequences-for-hmmhits) were aligned using muscle v3.8.1551 (Edgar, 2004). A Newick phylogenetic tree was generated using FastTree v2.1 (Price et al., 2010) through anvi-genphylogenomic-tree and visualized with anvi-interactive (Eren et al., 2015). For heatmaps of the most abundant taxa, the 16S rRNA gene and short-read data were normalized using gmpr (Chen et al., 2018a) and MAGs using mean coverages (Eren et al., 2015). The count data were transformed into relative abundances for plotting in R. Heatmaps were generated in R-Studio (RStudio Team, 2021) using base R (R Core Team, 2020), ggplot2 (Wickham, 2016) and ampvis2 (Andersen et al., 2018). Figures were finalized in inkscape v1.0 (Inkscape Developers, 2020). Metabolic potential of the MAGs was estimated by screening the contigs using HMMs against the KOfam database (Aramaki et al., 2020). KEGG module completeness (Kanehisa et al., 2014) was estimated through anvi-estimate-metabolism. Heatmaps on selected metabolic features in the most abundant taxa were generated using both the estimated metabolism tables and the taxonomic abundance information from the anvi'o summary.

\section{Results and discussion}

\section{Characteristics of the pools and sediments}

The porewater and bulk geochemistry in the $\mathrm{CC}$ sediment have been described previously (Chapter C.3). Their biogeochemical zonation was based on the $\mathrm{Cl}^{-} / \mathrm{SO}_{4}{ }^{2-}$ and $\mathrm{C} / \mathrm{N}$ ratios along the sediment cores (Figure 2). The data suggest that the sediment column must have dried out in the past, leaving behind hypersaline and potentially oxygenated sediments (12.5-35 cm bsf), indicated by the positive Eh. The older sediment is covered by a recent sediment with cyanobacterial traces of former microbial mats from 5-10 cm bsf. It is covered by a current unlithified microbial mat (0-2.5 cm bsf). No porewater profiles are available for the biolfilm, microbial mat and 
sediment at WPD. Key data for the stratified water column are depicted in Table 1. The water in WPD is derived from marine water indicated by the matching $\mathrm{Na}^{+} / \mathrm{Cl}^{-}$ ratio with the open ocean. The water has evaporated to higher salinities during the dry season; however, recent rainfall caused a salt stratified water column. A bacterial bloom in the bottom water layer led to anoxic conditions with a lower $\mathrm{pH}$ and slightly lower $\mathrm{Cl}^{-} / \mathrm{SO}_{4}{ }^{2-}$ ratio in comparison to the seawater (Table 1).

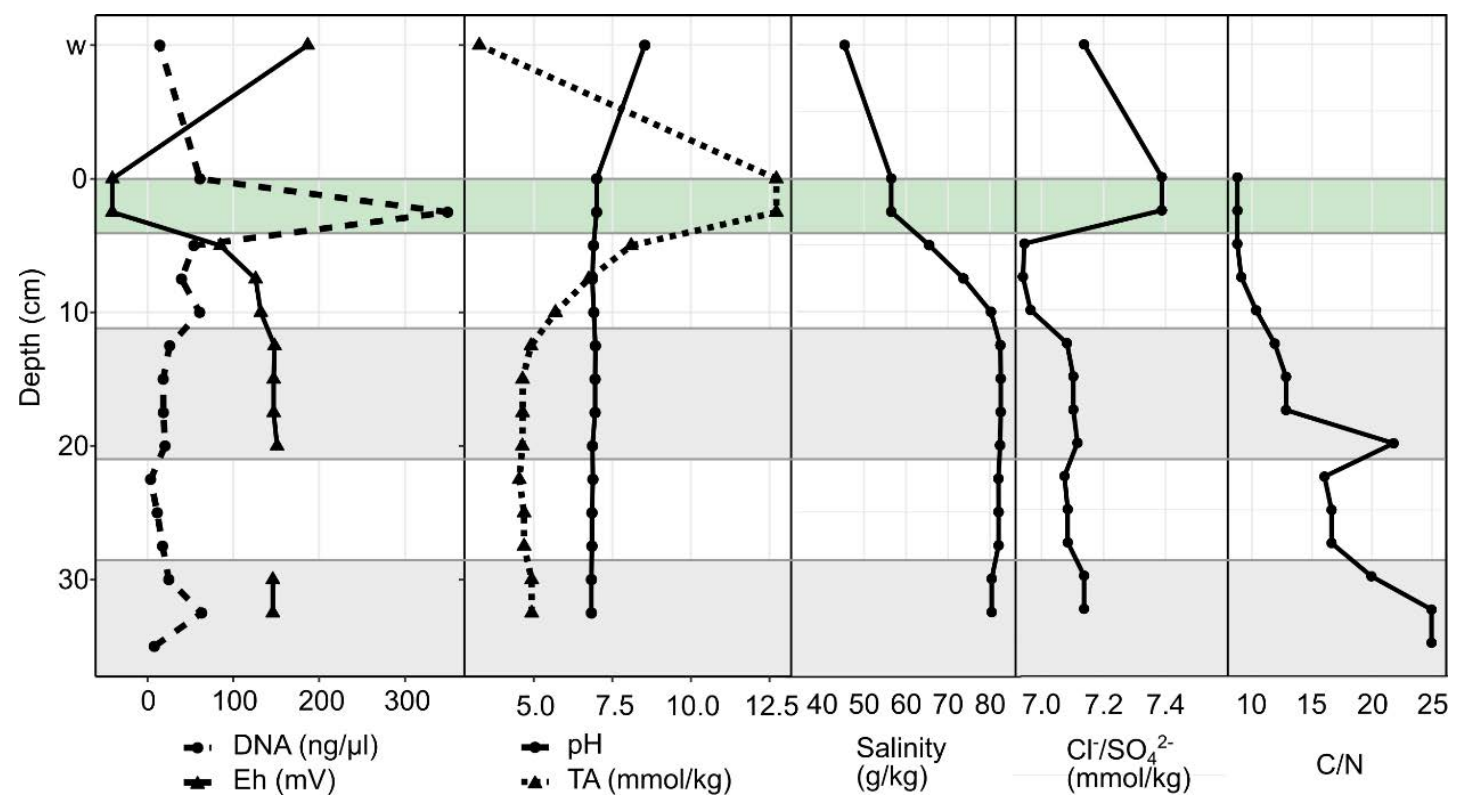

Figure 2. Selected porewater and bulk sediment geochemical profiles and extracted DNA concentrations from Cinq Cases. The current microbial mat is highlighted in green. The data were taken from Chapter C.3.

Table 1 Key water column geochemistry at WPD and open seawater off Aldabra for comparison:

\begin{tabular}{|c|c|c|c|c|c|c|c|}
\hline Sample & $\begin{array}{c}\mathrm{O}_{2} \\
(\mathrm{mmol} / \mathrm{kg})\end{array}$ & $\begin{array}{c}\text { Eh } \\
(\mathrm{mV})\end{array}$ & pH & $\mathbf{T A}$ & $\begin{array}{l}\mathrm{Cl}^{-} / \mathrm{SO}_{4}{ }^{2-} \\
(\mathrm{mol} / \mathrm{mol})\end{array}$ & $\begin{array}{c}\text { Salinity } \\
\text { (g/kg) }\end{array}$ & $\begin{array}{c}\mathrm{Na}^{+} / \mathrm{Cl}^{-} \\
(\mathrm{mol} / \mathrm{mol})\end{array}$ \\
\hline $\begin{array}{r}\text { Surface } \\
\text { Water }\end{array}$ & 0.18 & 169 & 8.2 & 5.8 & 19.5 & 63 & 0.86 \\
\hline Pink Water & 0.00 & 128 & 7.7 & 5.6 & 19.3 & 99 & 0.86 \\
\hline $\begin{array}{r}\text { Open } \\
\text { seawater }\end{array}$ & 0.24 & 201 & 8.2 & 2.35 & 19.4 & 35 & 0.86 \\
\hline
\end{tabular}

\section{General sequence data analysis and taxonomic classification}

Sequencing resulted in a total of 1,432,621,890 paired-end short reads of which $1,377,038,838$ reads remained after quality-filtering and adapter trimming (Table S1). Initial taxonomic assignment of the short-reads showed that bacteria contribute the majority of sequences ranging between $30-60 \%$, followed by eukaryote reads (10- 
$16 \%$ ), archaea (1-4\%) and viruses (0-4\%) (Figure 3.A). The majority of eukaryotic reads was assigned to animals (Chordata) and plants (Streptophyta), which are native to the atoll. This includes the bioturbating molluscs (Mollusca), polychaete worms (Platyhelminthes), crabs (Arthropoda), tortoises, birds and different fish sequences (Chordata) (Figure 3.B). The most abundant fungi belonged to the Ascomycota and Basidiomycota at abundances below 2\%. Archaea were most abundant in the $35 \mathrm{~cm}$ bsf sediment sample at CC and the stromatolite biofilm at WPD (Figure 3). Due to the first rainfall, the $\mathrm{CC}$ water column may have been subject to changes in the microbial community at the time of sampling. This was suggested by the high abundance of Pontibacillus in the active (RNA-based), but not the total (DNA-based) bacterial community (Chapter C.3) or MAGs. Changes in the microbial community composition may be caused by or lead to increased viral predation, explaining the high relative abundance of viruses in the water column (Figure 3.A).

\section{Taxonomy and metabolic features of metagenome-assembled genomes}

Co-assembly of the quality filtered sequences resulted in 5,761,716 contigs with a length $\geq 1,000 \mathrm{bp}$, a maximum contig length of $887,890 \mathrm{bp}$, and N50 of 2,889 bp (Table S2, Table S3). Binning and bin refinement resulted in a total of 1,093 MAGs across all samples covering $21 \%$ of the contigs $\geq 1,000$ bp. $37 \%$ of the MAGs had a coverage $>90 \%$ and redundancy $<10 \%$ after manual refinement. The GTDB used for taxonomic classification is currently limited to bacteria and archaea (Chaumeil et al., 2019). For this reason, only bacterial and archaeal MAGs were subsequently considered in the analysis. Taxonomic assignment placed 30 MAGs among the Archaea and 559 among the Bacteria. Phylogenetic clustering resulted in 21 main phyla present in the MAG dataset (Figure 4). Most MAGs derive from the most abundant phyla found in the 16S rRNA dataset of Aldabra. They comprise Alpha- and Gammaproteobacteria, Actinobacteriota and Desulfobacterota (Figure 5, Chapter C.3). Chloroflexota showed low relative abundances in the 16S rRNA dataset (Chapter C.3), yet a large number of MAGs (40), in comparison to other phyla, were assigned to this phylum (Figure 4). The MAGs may be derived from WPD where Chloroflexota were abundant in the sediment and microbial mat (Figure 5.B). Other Chloroflexota MAGs may reflect some of the ASVs which remained unclassified using 16S rRNA (Chapter C.3). 
A

$\%$ Read

Abundance

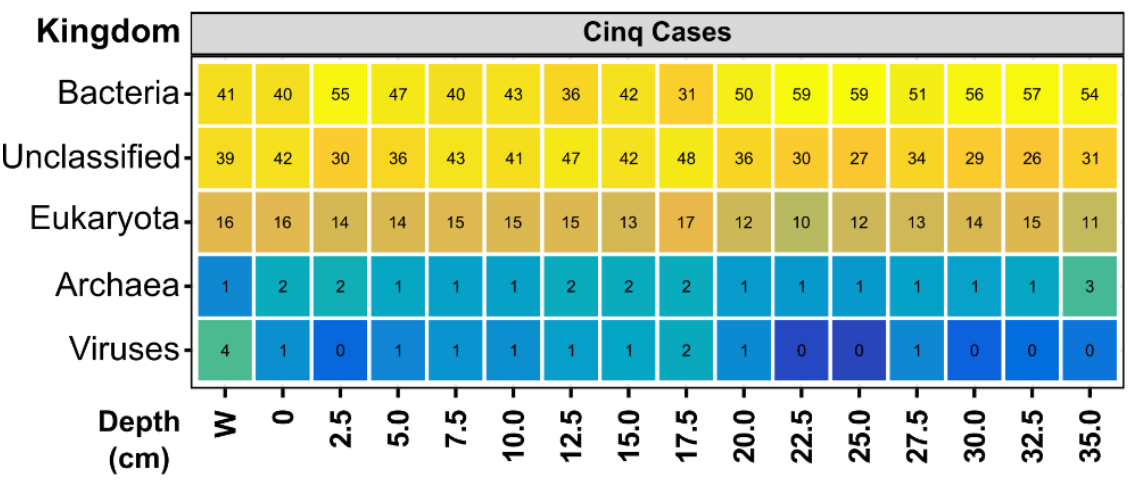

B

$\%$ Read
Abundance
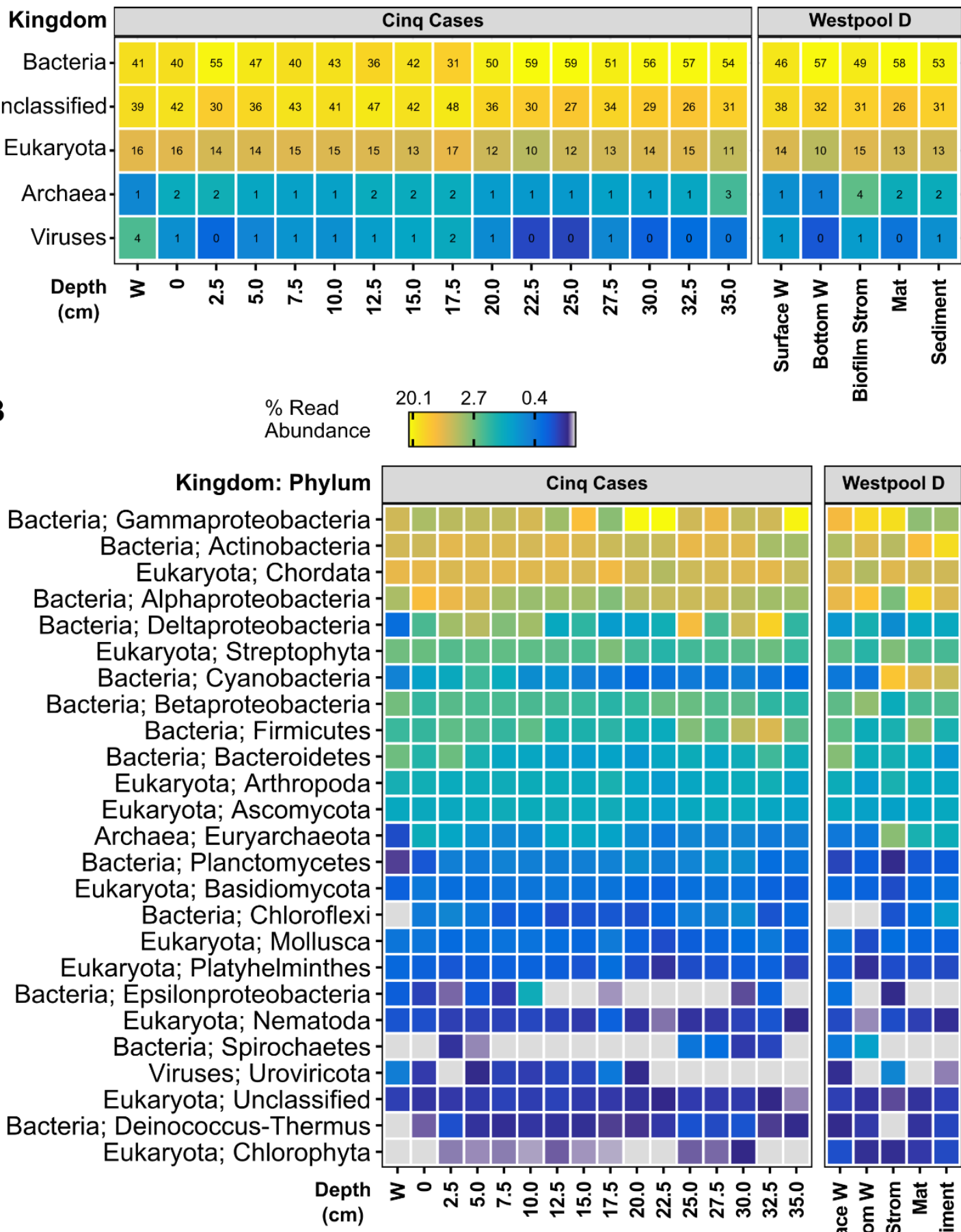

(cm)

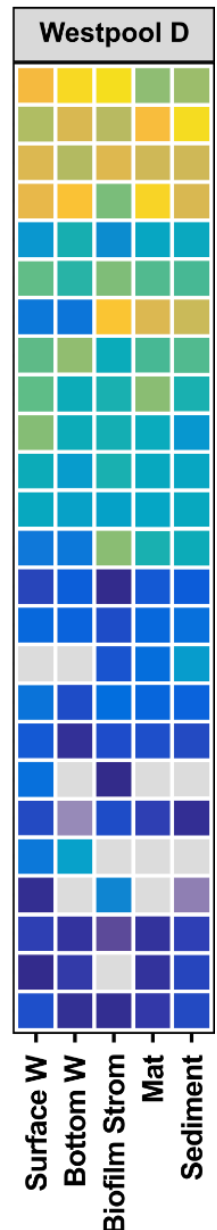

Figure 3. Distribution of kingdoms (A) and abundant phyla (B) among the qualityfiltered metagenome reads. The data were normalized using gmpr (Chen et al. 2018a). Unclassified taxa were removed for the phylum level visualisation (B). 


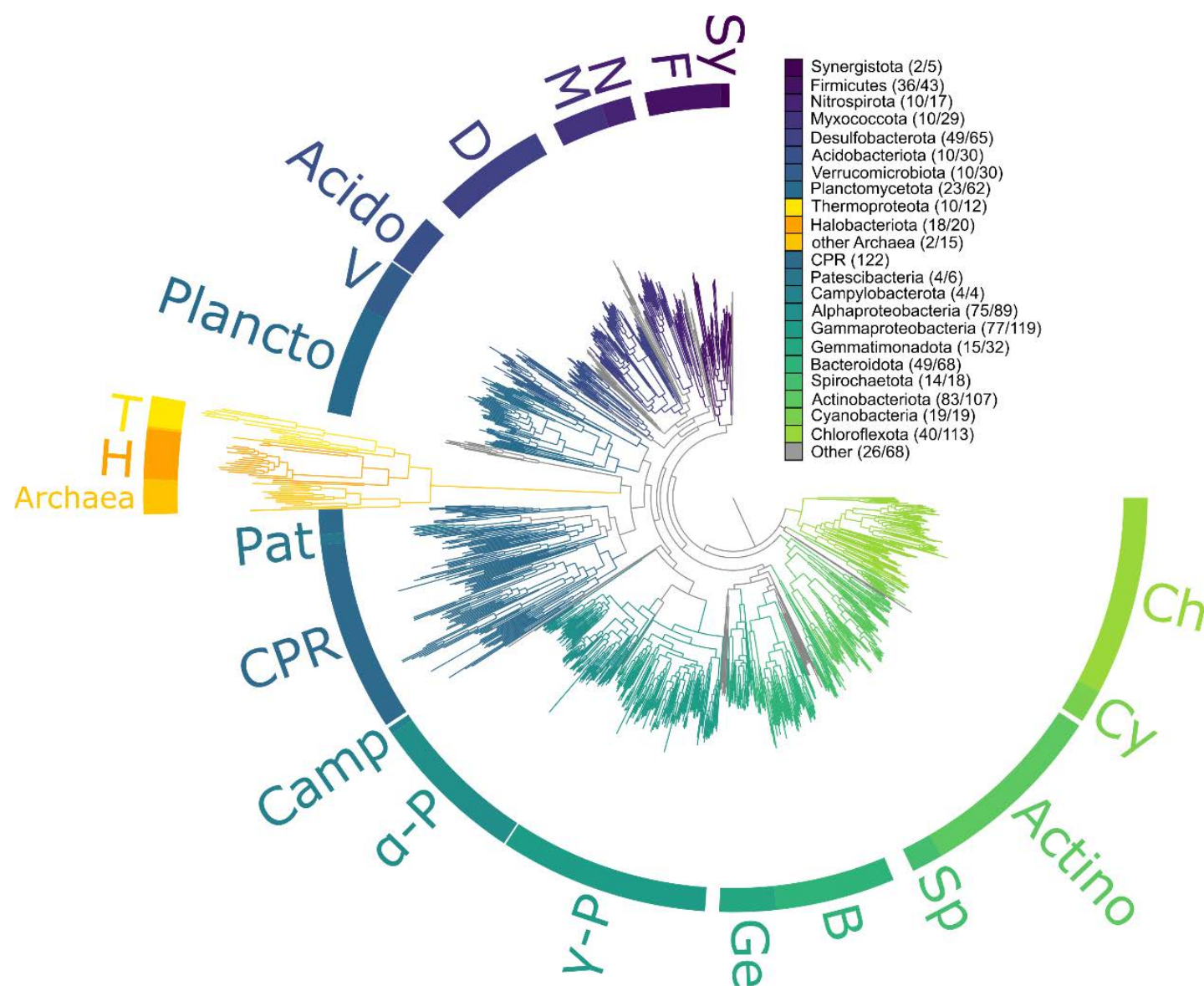

Figure 4. Newick phylogenetic tree of all MAGs $(n=1,093)$. The tree is based on a set of 71 bacterial and archaeal single copy core genes. Colour coding indicates phyla determined by classified MAGs on the tree. Numbers in brackets indicate the number of MAGs which were classified within each phylum branch.

The most abundant genera among the MAGs show a good overlap with the most abundant genera identified in the 16S rRNA gene analysis (Figure 5). At CC they include Halomonas, Desulfovibrio, Vibrio and Salinivibrio (Figure 5.A). At WPD MAGs classified as Thiohalocapsa, Salinivibrio, Cyanobium, Francisella, Alkalispirochaeta and Arthrospira could be reconstructed from the metagenomes. Differences in taxonomic assignment between the NCBI, GTDB (Chaumeil et al., 2019) and SILVA (Quast et al., 2013) database used for taxonomic assignment of short-reads, MAGs and 16S rRNA (Chapter C.3), respectively, may result in the observed differences in genus level taxonomy (Figure 5). 

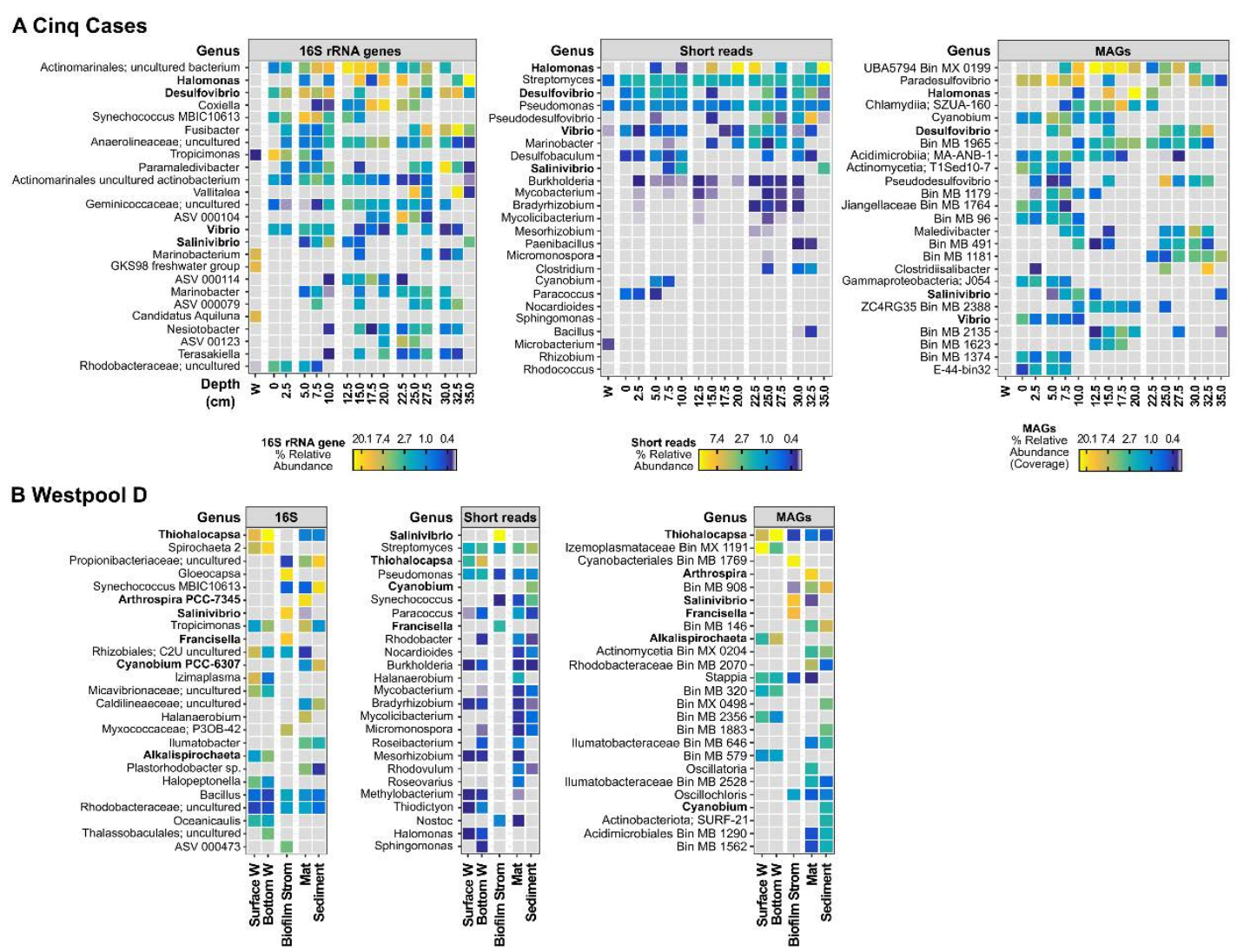

Figure 5. Most abundant 25 genera at CC (A) and WPD (B) in the bacterial 16S rRNA amplicons, short reads, and post-assembly binning (MAGs). Only bacteria and archaea were considered in the dataset. Taxa present in the 16S rRNA and MAG dataset are highlighted in bold. The amplicon and short-read data were normalized using gmpr (Chen et al., 2018a) and MAGs using read coverages (Eren et al., 2015). All genera were plotted as relative abundances with a minimum abundance of $0.25 \%$.

16S rRNA gene data provides a detailed picture of the bacterial community composition at high taxonomic resolution. Metagenomes and MAGs, on the other hand, allow us an insight into the potential metabolism of individual community members (Frioux et al., 2020). Metabolic assignment using KEGG orthologs and KEGG modules (Aramaki et al., 2020) show that MAGs encoding similar metabolic capabilities, i.e., dissimilatory sulphate reduction or photosynthesis, are sometimes limited to specific phyla (Figure 6). Differences in the number of genes within the pathway-modules may lead to different levels of completeness on the phylum level. However, they provide an approximation of the distribution of metabolic capabilities. Oxygenic photosynthesis is exclusively encoded by Cyanobacteria-derived MAGs, with exception of the Vampirovibrionia, which are obligate parasites of green algae (Soo et al., 2015). Genes for anoxygenic photosynthesis are limited to Chloroflexota and Alphaproteobacteria MAGs in this dataset. Dissimilatory sulphate reduction 
genes are mainly a feature of the Desulfobacterota and Thermodesulfovibrionia (Nitrospirota) MAGs (Figure 6). Interestingly Acidobacteriota MAGs also harbour dissimilatory sulphate reduction (DSR) genes. In the Thermoanaerobaculia the KEGG module for DSR was annotated completely. Other classes of the phylum harboured MAGs with partial annotations, indicating that these taxa may play a role in sulphur cycling on Aldabra. Thiosulphate oxidation via the SOX pathway is limited to Gamma- and Alphaproteobacteria MAGs, while assimilatory sulphate reduction (ASR) is a common feature in most phyla. Genes involved in the production of acetate are also common among the MAGs. However, only few MAGs, classified as Desulfobulbia and Desulfomonilia, harboured the Wood-Ljungdahl pathway for acetogenesis. Potential methanogens were found among the Methanosarcina, Methanomicrobia, Lokiarchaeia and potentially Bathyarchaeia. Most samples indicated a slightly oxic milieu through the positive Eh (Figure 2). Methanogenesis is, thus, likely only a minor factor in the pools of Aldabra. In agreement with this, we only detected low completeness for methanotrophic pathways, which oxidize the methane produced by Archaea (Jørgensen and Kasten 2006). As they have often been found as nitrogen cyclers in soil, we expected the Actinobacteriota MAGs to harbour genes for i.e., $\mathrm{N}_{2}$-fixation (Sellstedt and Richau 2013). However, in opposition to sulphur, we did not find a specific phylum specialized on the use of nitrogen among their annotated energy metabolisms. Gene-modules for the different nitrogen cycling pathways (assimilatory nitrate reduction to ammonia (ANRA), dissimilatory nitrate reduction to ammonia (DNRA), denitrification, nitrification, complete ammonia oxidation to nitrate (comammox), $\mathrm{N}_{2}$-fixation) are encoded to varying completeness among the classes, explaining their overall low mean completeness (Figure 6). The exception to this are the two potential acetogens, which encode a wide metabolic capability regarding energy metabolism and harbour $\mathrm{N}_{2}$-fixation genes. The two uncultured classes Bin 61 and Mor1 of the Acidobacteriota are likely able to contribute to sediment ammonification via DNRA. 


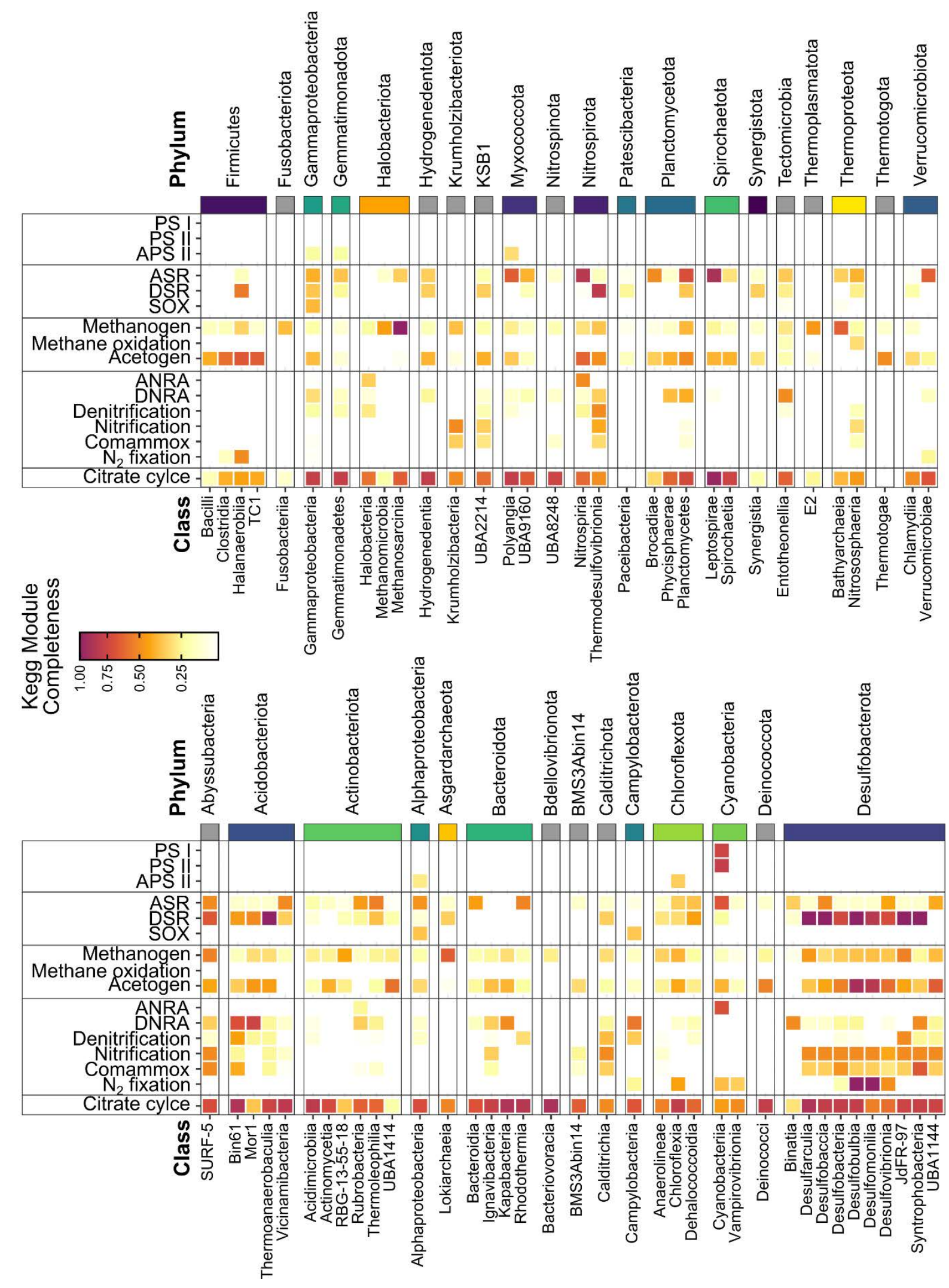


Figure 6. Mean completeness of selected energy metabolic pathways among the classes represented in the MAG dataset. The individual classes are sorted by their phylum affiliation. Colours match the phylogenetic tree in Figure 4 for reference. Abbreviations: PS/, II: photosystem I/II, APS: anoxygenic photosystem, ASR/DSR: assimilatory/dissimilatory sulphate reduction, SOX: thiosulphate oxidation to sulphate, ANRA/DNRA: assimilatory/dissimilatory nitrate reduction to ammonia, Comammox: complete oxidation of ammonia to nitrate or complete nitrification.

\section{Cinq Cases}

In lake sediments oxygen is usually rapidly metabolized leading to anoxic sediments within the first few centimetres of depth (Cai et al., 2002). The sediment Eh at CC suggests the opposite trend with negative values at the surface, which became positive by $10 \mathrm{~cm}$ bsf alongside a two-fold increase in salinity. Together with the bacterial community, which changes from sulphate reducers to facultatively anaerobic Halomonas, we concluded that the cores show a temporal progression from the current microbial mat at the surface to older, desiccated sediment below $10 \mathrm{~cm}$ (Chapter C.3). The metagenomic dataset further supports these observations and provides data on the major metabolic pathways encoded in the DNA. Starting at the surface, the water column at $\mathrm{CC}$ had a salinity of $45 \mathrm{~g} / \mathrm{kg}$ and a $\mathrm{pH}$ of 8.5 . The microbial community is dominated by bacteria, however, only few MAGs could be retrieved, as the data was limited to one sample. The MAGs include Pontimonas, which is likely an aerobic heterotroph, and Litoricola, which harbours the SOX genes for thiosulphate oxidation (Figure 7.A). The sediment surface was characterized by a microbial mat, which drove the sediment porewater geochemistry and harboured a taxonomically and metabolically diverse community (Chapter C.3; Figure 7.A). Cyanobium is the only abundant genus encoding carbon fixation through photosynthesis. While most cyanobacteria on Aldabra harbour $\mathrm{N}_{2}$-fixation genes, this is not the case for the Cyanobium MAGs. Like in other marine sediments (Garner et al., 2020; More et al., 2019; Chapter C.3) their remnant cells and DNA can accumulate in sediments even past their lifetime. At Cinq Cases Cyanobium is most abundant directly below the microbial mat (Figure 5.A: $5-10 \mathrm{~cm}$ ) where past mat layers remain as traces on the long-term, similar to Eleuthera, Bahamas (Glunk et al., 2011). Alongside cyanobacteria, the mat and underlying sediment are dominated by DSR-gene encoding Paradesulfovibrio and Desulfovibrio MAGs (Figure 5.A). In addition to the release of $\mathrm{CO}_{2}$ through anaerobic respiration of sulphate they may produce acetate from organic matter, thereby contributing to a lower $\mathrm{pH}$ around 7 in the sediment (Figure 7.A). 
Further metabolic modules in MAGs of the mat and sediment encode anoxygenic photosynthesis (J054, Gammaproteobacteria), aerobic and anaerobic heterotrophy, i.e., MA-ANB-1 and T1-Sed10-7. The latter two are currently uncultured Actinobacteriota only available as MAGs. The two Vibrio MAGs in our dataset encode the genes to produce ammonia through $\mathrm{N}_{2}$-fixation as well as DNRA. Thus, they can gain energy under the reducing conditions and contribute to the strong ammonification (highest TA) observed in the mat (Figure 2: 0-2.5 cm bsf). The currently unclassified MAGs in the top $10 \mathrm{~cm}$ bsf harbour genes for diverse metabolic capabilities, including thiosulphate oxidation (SOX), acetogenesis, aerobic and anaerobic heterotrophy (Figure 7).

Below the mat-driven sediment $(0-10 \mathrm{~cm}$ bsf $)$, the bacterial community changes to Halomonas and unclassified MAGs, including the most abundant MAG at CC, Bin MX 0199 (Acidimicrobiia). The sediment (12.5-20 cm bsf) represents the surface of the old, evaporated sediment (Chapter C.3) and has the highest percentage of unclassified reads (36-48\%) in the entire dataset (Figure 3). Due to the presence of Halomonas and their metabolic flexibility, we previously hypothesized, that a shift in available organic matter and sediment oxygenation led to the shift in community composition (Chapter C.3). Desiccation of the sediment may have selected for highly resilient taxa represented by MAGs which could not be taxonomically assigned (Figure 7). Looking at their metabolic annotation, the most abundant MAGs (Bin MX 0199, Bin MB 2388, 1623, 1965, 2135) likely do not rely on anaerobic respiration for their energy metabolism. In the case of Bin MB 1965 and Bin MB 2135 they may be able to contribute to nitrification in the sediments. Together with the positive redox values in the sediment, the large number of MAGs associated with an aerobic metabolism support the hypothesis of oxic sediment below $10 \mathrm{~cm}$. The oxygenation of the sediment may have occurred upon desiccation, suggested by the high salinity. Reducing conditions may not have had time to re-establish since desiccation and were therefore restricted to the surface sediments at the time of sampling.

In the sediment below (22.5 $\mathrm{cm}$ bsf), the phylogenetic assignments of the MAGs change again to Para-, Pseudodesulfovibrio and Desulfovibrio harbouring DSR genes. In addition, we find Clostridiisalibacter and Bin MB 1181. The former is likely a fermenter whereas the latter may depend upon sulphate and nitrate reduction for its energy metabolism (Figure 7.A). While the geochemical zones shift based on 
total organic carbon (Chapter C.3), the abundant MAGs between 22.5-35 cm bsf remain the same (Figure 5.A). The similarity of MAGs between the upper 5-10 cm bsf and the bottom $25-35 \mathrm{~cm}$ bsf, suggests that the sediment between 15-22.5 cm of depth interrupts the pre-existing sediment and microbial community. This trend was also observed in the 16S rRNA-based community profiles (Chapter C.3). The sediment sample most affected by this is characterized by a substantial peak in $\mathrm{C} / \mathrm{N}$ ratio and low phylogenetic diversity (Chapter C.3; Figure 2). The origin of this peak could not conclusively be reconstructed. We hypothesized that the change in organic material available for degradation may play a role in changing the bacterial community (Chapter C.3). Interestingly, the Eh in the deepest sediments remains positive, which suggests that oxygen is still present. This would generally have an inhibitory effect on the growth of sulphate reducers, as oxygen-based respiration yields more energy (Baumgartner et al., 2006). However, it has been shown, that sulphate reducers are able to tolerate low oxygen concentrations leading to reduced growth or are able to use oxygen and nitrate before switching to sulphate reduction (Baumgartner et al., 2006 and references therein). An example for this are the Nitrospirota-derived MAGs, which increase in abundance from $22.5-35 \mathrm{~cm}$ bsf. They harbour DNRA as well as DSR genes (Figure 7.A), indicating that they may be able to switch their energy metabolism to cope with the conditions in these sediments. 

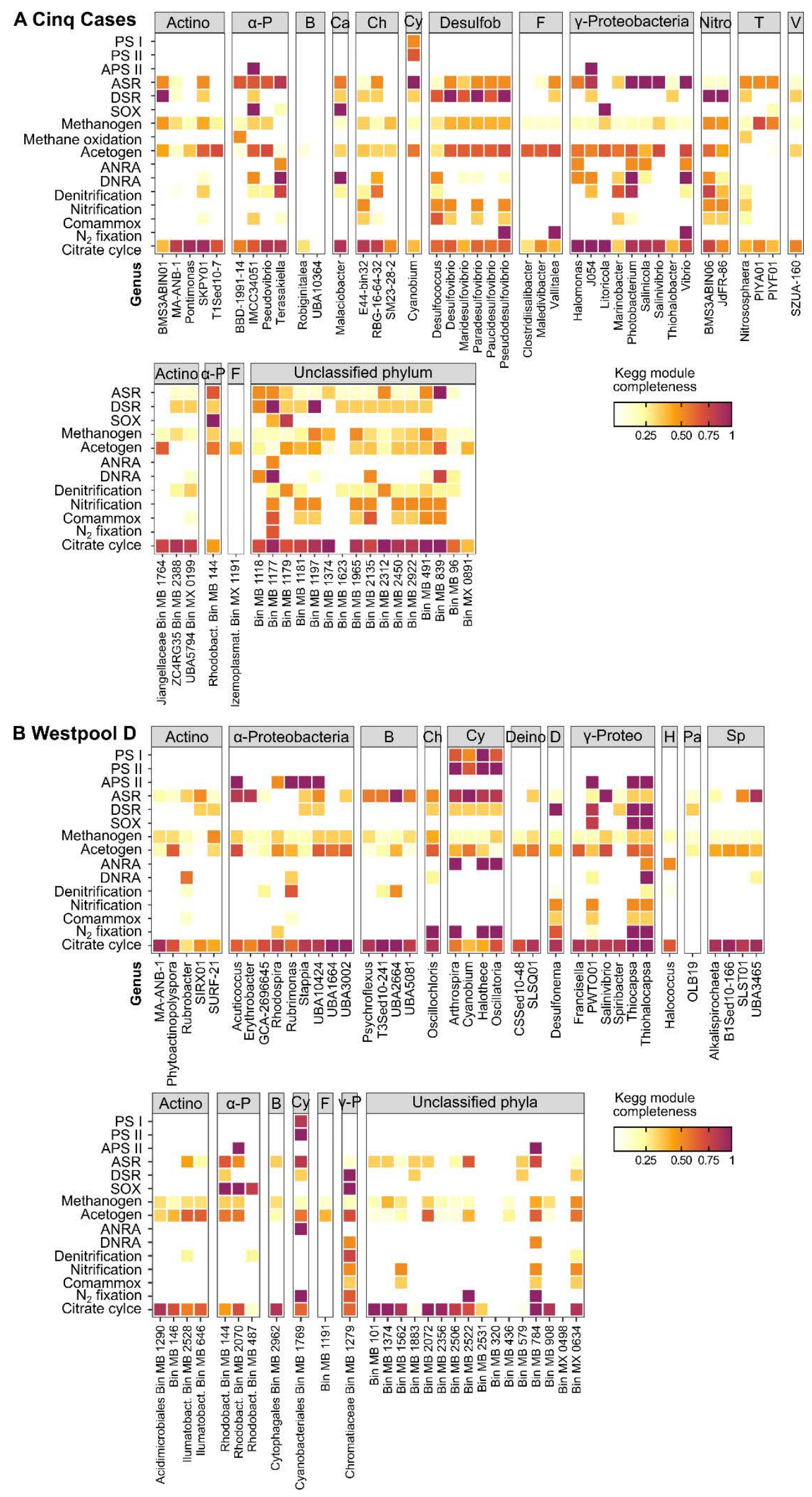
Figure 7. Most abundant MAGs at CC (A) and WPD (B) and their encoded energy metabolism. MAGs with a coverage $>3$ are grouped at the genus level using mean completeness of the encoded KEGG modules. In addition, all unclassified MAGs within the 50 most abundant genera were plotted individually. Abbreviations: PSI/II: photosystem I/II, APS II: anoxygenic photosystem II, ASR: assimilatory sulphate reduction, DSR: dissimilatory sulphate reduction, SOX: thiosulphate oxidation to sulphate by SOX complex, ANRA: assimilatory nitrate reduction to ammonia, DNRA: dissimilatory nitrate reduction to ammonia, Comammox: complete nitrification of ammonia to nitrate.

\section{Westpool D}

WPD is a small pond located southwest of CC on Grand Terre. It is characterized by a stratified water column, overlying a jelly-like microbial mat and sediment, as well as stromatolites around the rim of the pond (Figure 1.D). The upper water layer of the pool had a greenish colour and harboured Spirochaeta 2, uncultured Rhizobiales and Cand. Izimaplasma according to $16 \mathrm{~S}$ rRNA gene-based taxonomic profiling (Figure 5.B). Cand. Izimaplasma and the uncultured Rhizobiales were likely represented by Bin MX 1191 and the Stappia MAGs. Most other MAGs, however, remained unclassified (Figure 5.B). Bin MX 1191 is most likely derived from an aerobic heterotroph. The Stappia-affiliated MAGs and most other alphaproteobacterial MAGs of WPD are derived from purple non-sulphur bacteria (Figure 7.B) harbouring the genes for anoxygenic photosynthesis (Imhoff et al., 2017). The bacterial bloom is formed of Thiohalocapsa, which is the most abundant genus in both the 16S rRNA gene and metagenome dataset (Figure 5.B). The purple sulphur bacteria caused an intense pink coloration of the water (Figure 1.B: PW) and fix carbon using anoxygenic photosynthesis (Figure 7.B). As the corresponding MAG encodes the genes for both DSR and SOX, it is strongly involved in carbon, nitrogen and sulphur cycling in this water layer. Simultaneously to thiosulphate oxidation it may be capable of using nitrate as electron acceptor (Li et al., 2018), as it harbours DNRA genes. Ammonia may be produced using the detected $\mathrm{N}_{2}$-fixation genes (Figure 7.B). It is, therefore, able to flourish in the anoxic bottom water layer, as well as the oxic water above, driving the local biogeochemical cycles.

The microbial mat and sediment directly below the water column share most of their abundant genera (Figure 5.B). This includes MAGs affiliated to cyanobacteria, Arthrospira, Oscillatoria and Cyanobium, as well as unclassified MAGs. With the exception of Cyanobium, all cyanobacterial MAGs harbour $\mathrm{N}_{2}$-fixation genes alongside photosynthesis genes. Four of the unclassified MAGs belonged to the Actinobacteriota and one to the potentially phototroph Alphaproteobacteria. The 
others remained unclassified at the phylum level (Figure 7.B). The only abundant MAG in the sediment with all genes for dissimilatory sulphate reduction, belongs to the purple sulphur bacteria (Chromatiaceae Bin MB 1279) and is likely linked to the brown-pink layer underneath the green surface of the mat (Figure 1.D). Dissimilatory sulphate reduction in the pond is almost exclusively found among the MAGs assigned to Gammaproteobacteria and to one Desulfonema (Figure 7.B). Genes for alternative energy metabolism to oxygen are not prevalent among the abundant classifiable or unclassifiable taxa (Figure 7.B). The lack of MAGs from sulphate reducers belonging to the Desulfobacterota is unexpected, as they harbour the most prevalent sulphate reducers across all other sampling sites of the atoll (Chapter C.3) and are a major component of microbial mats elsewhere (Schneider et al., 2013; Warden et al., 2016; Haas et al., 2018). The same applies to the only abundant MAG of the Chloroflexota, Oscillochloris. While they are not among the most abundant genera in the 16S rRNA gene data, its MAGs are present in the microbial mat and sediment, as well as the biofilm covering the stromatolite (Figure 5.B). Interestingly, even though Chloroflexota members are not among the most abundant genera across the atoll (relative abundance $<0.4 \%$ ), a branch of 113 MAGs affiliated to this phylum was assembled from the dataset (Figure 4). This may be due to the fact that Chloroflexota are difficult to isolate in pure culture (Grouzdev et al., 2018). The result is a high proportion of incomplete genomes and MAGs from mixed cultures and environmental DNA in the databases, which may cause inaccuracies in taxonomic assignment. The main colonizers of the biofilm covering the stromatolite are represented by MAG MB 1769 and MAGs from Salinivibrio and Francisella. They have no or low coverage in the water column, the mat and sediment (Figure 5.B). Bin MB 1769 was classified as the Cyanobacteriales and encodes $\mathrm{N}_{2}$-fixation and photosynthesis genes (Figure 7.B). Its high relative abundance in the biofilm suggests that the MAG is derived from the Gloeocapsa which were dominant in the biofilm 16S rRNA gene data (Figure 5). Salinivibrio and Francisella MAGs likely both belong to the aerobic heterotrophs living within the Gloeocapsa biofilm. Its photosynthetic activity produces oxygen and organic matter for the aerobic heterotrophs. Notably, Bin MB 1769 is not present in the unlithified microbial mat of WPD. As Gloeocapsa have previously been found in calcifying microbial mats (Dupraz et al., 2004), this suggests, that they drive microbially mediated precipitation of carbonates on the stromatolite they cover. 


\section{Pool development on Aldabra}

Taking together our results for CC and WPD, they represent variable pool environments on Aldabra potentially leading to the precipitation or dissolution of carbonates. WPD is a smaller, highly evaporated pool with stromatolites in the process of precipitation. The conditions in this pool exemplify which conditions must have prevailed at Cinq Cases in the past for stromatolites to form. The detected Thiohalocapsa bloom is likely a result of recent rainfall layering freshwater on top of the hypersaline pool water. This has also been observed elsewhere on the atoll, including puddles and shallow pools at CC (Potts and Whitton, 1979; Braithwaite et al., 1989). When not exposed to a bloom event, the low prevalence of genes for anaerobic energy metabolism among the prokaryotic community suggests, that the WPD water column and shallow sediment remain oxic. This would also explain the difference in abundant community members compared to the surface sediment of CC in both the 16S rRNA gene and metagenome dataset. CC is a more extensive pool system and has undergone long-term environmental changes, including sediment accumulation, then desiccation and again lagoonal flooding. While past descriptions of WPD are not available, the microbial mats of CC were described by Braithwaite et al. (1989). At the time, the area showed a similar sediment thickness as in 2017 and extensive stromatolite and oncolite cover around the rim of the pools. While we were not able to find any of the described precipitates in 2017, their description of CC shows parallels to WPD. In addition to the stromatolites there, the authors made a distinction between mats covering the sediment and mats covering the stromatolites. They suggest that lithification at the time only occurred in mats harbouring Entophysalis and Pleurocapsa (Braithwaite et al., 1989). We cannot confirm the specific taxa, as different methods for taxonomic description were used and classifications have changed in the last decades. Nevertheless, our results for WPD also support their observation, that different members of the Cyanobacteria are involved in the lithification process. 


\section{Conclusion}

Here we present the first metagenome dataset of the water column, microbial mats and sediments of two landlocked, moderately hypersaline pools on the Aldabra Atoll. The data elaborate on our previous results on sediments with regard to biogeochemical cycling at $\mathrm{CC}$ and place them into context with another landlocked pool, WPD. We found that the sediments of CC are mainly colonized by DSR-encoding MAGs, despite oxidizing conditions. A peak in $\mathrm{C} / \mathrm{N}$ and enrichment of aerobic heterotrophs within the cores suggest a disrupting sediment layer with a high organic content. The source of this layer remains unknown but may be related to complete desiccation of the pool in the past. WPD shows similarities to CC in the 1970s as it harbours stromatolites and two types of microbial biofilm and mat covers. The MAGs reconstructed from this sampling site, show little overlap with the MAG data from CC. WPD exemplifies environmental conditions and microbial communities required for the development of stromatolites on Aldabra. CC represents an older system which has undergone substantial changes during its history, leading to both the precipitation and dissolution of carbonates. WPD therefore highlights conditions, which likely prevailed at CC in the past, when stromatolites were part of its landscape.

\section{References}

Alneberg, J. et al. (2014) 'Binning metagenomic contigs by coverage and composition', Nature Methods, 11(11), pp. 1144-1146. doi: 10.1038/nmeth.3103.

Andersen, K.S. et al. (2018) 'ampvis2: an R package to analyse and visualise 16S rRNA amplicon data', bioRxiv. doi: 10.1101/299537.

Aramaki, T. et al. (2020) 'KofamKOALA: KEGG Ortholog assignment based on profile HMM and adaptive score threshold', Bioinformatics (Oxford, England), 36(7), pp. 22512252. doi: 10.1093/bioinformatics/btz859.

Ayling, M., Clark, M.D. and Leggett, R.M. (2020) 'New approaches for metagenome assembly with short reads', Briefings in Bioinformatics, 21(2), pp. 584-594. doi: 10.1093/bib/bbz020.

Baumgartner, L.K. et al. (2006) 'Sulfate reducing bacteria in microbial mats: Changing paradigms, new discoveries', Sedimentary Geology, 185(3-4), pp.131-145. doi: 10.1016/j.sedgeo.2005.12.008.

Baumgartner, L.K. et al. (2009) 'Microbial species richness and metabolic activities in hypersaline microbial mats: insight into biosignature formation through lithification', Astrobiology, 9(9), pp. 861-874. doi: 10.1089/ast.2008.0329.

Bird, J.T. et al. (2019) 'Uncultured microbial phyla suggest mechanisms for multi-thousandyear subsistence in Baltic Sea sediments', MBio, 10(2). doi: 10.1128/mBio.02376-18. 
Braithwaite, C. et al. (1989) 'Recent stromatolites in landlocked pools on Aldabra, Western Indian Ocean', Palaeogeography, Palaeoclimatology, Palaeoecology, 69, pp. 145-165. doi: 10.1016/0031-0182(89)90162-4.

Buchfink, B., Xie, C. and Huson, D.H. (2015) 'Fast and sensitive protein alignment using DIAMOND', Nature Methods, 12(1), pp. 59-60. doi: 10.1038/nmeth.3176.

Cai, W.-J. et al. (2002) 'Porewater redox species, $\mathrm{pH}$ and $\mathrm{pCO}_{2}$ in aquatic sediments: Electrochemical sensor studies in Lake Champlain and Sapelo Island', in Taillefert, M. and Rozan, T.F. (eds.) Environmental Electrochemistry. (ACS Symposium Series). Washington, DC: American Chemical Society, pp. 188-209. doi: 10.1021/bk-2002-0811.ch010.

Chaumeil, P.-A. et al. (2019) 'GTDB-Tk: a toolkit to classify genomes with the Genome Taxonomy Database', Bioinformatics (Oxford, England), 36(6), pp. 1925-1927. doi: 10.1093/bioinformatics/btz848.

Chen, L. et al. (2018) 'GMPR: A robust normalization method for zero-inflated count data with application to microbiome sequencing data', PeerJ, 6, e4600. doi: 10.7717/peerj.4600.

Chen, S. et al. (2018) 'fastp: an ultra-fast all-in-one FASTQ preprocessor', Bioinformatics (Oxford, England), 34(17), i884-i890. doi: 10.1093/bioinformatics/bty560.

Delmont, T.O. and Eren, A.M. (2018) 'Linking pangenomes and metagenomes: the Prochlorococcus metapangenome', PeerJ, 6, e4320. doi: 10.7717/peerj.4320.

Dupraz, C. et al. (2004) 'Microbe-mineral interactions: early carbonate precipitation in a hypersaline lake (Eleuthera Island, Bahamas)', Sedimentology, 51(4), pp. 745-765. doi: 10.1111/j.1365-3091.2004.00649.x.

Dyksma, S. et al. (2016) 'Ubiquitous Gammaproteobacteria dominate dark carbon fixation in coastal sediments', The ISME Journal, 10(8), pp. 1939-1953. doi: 10.1038/ismej.2015.257.

Edgar, R.C. (2004) 'MUSCLE: multiple sequence alignment with high accuracy and high throughput', Nucleic Acids Research, 32(5), pp. 1792-1797. doi: 10.1093/nar/gkh340.

Eren, A.M. et al. (2015) 'Anvi'o: an advanced analysis and visualization platform for 'omics data', PeerJ, 3, e1319. doi: 10.7717/peerj.1319.

Eren, A.M. et al. (2021) 'Community-led, integrated, reproducible multi-omics with anvi'o', Nature Microbiology, 6(1), pp. 3-6. doi: 10.1038/s41564-020-00834-3.

Falkowski, P.G., Fenchel, T. and Delong, E.F. (2008) 'The microbial engines that drive Earth's biogeochemical cycles', Science, 320(5879), pp. 1034-1039. doi: 10.1126/science.1153213.

Frioux, C. et al. (2020) 'From bag-of-genes to bag-of-genomes: metabolic modelling of communities in the era of metagenome-assembled genomes', Computational and Structural Biotechnology Journal, 18, pp. 1722-1734. doi: 10.1016/j.csbj.2020.06.028.

Fussmann, D. et al. (2020) 'Authigenic formation of $\mathrm{Ca}-\mathrm{Mg}$ carbonates in the shallow alkaline Lake Neusiedl, Austria', Biogeosciences, 17(7), pp. 2085-2106. doi: 10.5194/bg-17-20852020 .

Garner, R.E., Gregory-Eaves, I. and Walsh, D.A. (2020) 'Sediment metagenomes as time capsules of lake microbiomes', MSphere, 5(6). doi: 10.1128/mSphere.00512-20.

Glunk, C. et al. (2011) 'Microbially mediated carbonate precipitation in a hypersaline lake, Big Pond (Eleuthera, Bahamas)', Sedimentology, 58(3), pp. 720-736. doi: 10.1111/j.13653091.2010.01180.x. 
Grouzdev, D.S. et al. (2018) 'Draft genome sequences of 'Candidatus Chloroploca asiatica' and 'Candidatus Viridilinea mediisalina', candidate representatives of the Chloroflexales order: phylogenetic and taxonomic implications', Standards in Genomic Sciences, 13(1), p. 24. doi: 10.1186/s40793-018-0329-8.

Haas, S. et al. (2018) 'Low-light anoxygenic photosynthesis and Fe-S-biogeochemistry in a microbial mat', Frontiers in Microbiology, 9, p. 858. doi: 10.3389/fmicb.2018.00858.

Hoyningen-Huene, A.J.E. von et al. (2019) 'Bacterial succession along a sediment porewater gradient at Lake Neusiedl in Austria', Scientific Data, 6(1), p. 163. doi: 10.1038/s41597-0190172-9.

Hyatt, D. et al. (2010) 'Prodigal: prokaryotic gene recognition and translation initiation site identification', BMC Bioinformatics, 11, p. 119. doi: 10.1186/1471-2105-11-119.

Imhoff, J.F. et al. (2017) 'Photosynthesis is widely distributed among Proteobacteria as demonstrated by the phylogeny of PufLM reaction center proteins', Frontiers in Microbiology, 8, p. 2679. doi: 10.3389/fmicb.2017.02679.

Inkscape Developers (2020) Inkscape (Version 1.0). Available at: https://inkscape.org.

Jørgensen, B.B. and Kasten, S. (2006) 'Sulfur cycling and methane oxidation', in Schulz, H.D. and Zabel, M. (eds.) Marine Geochemistry. Berlin/Heidelberg: Springer-Verlag, pp. 271-309. doi: 10.1007/3-540-32144-6_8.

Kanehisa, M. et al. (2014) 'Data, information, knowledge and principle: back to metabolism in KEGG', Nucleic Acids Research, 42(Database issue), D199-205. doi: 10.1093/nar/gkt1076.

Kang, D.D. et al. (2019) 'MetaBAT 2: an adaptive binning algorithm for robust and efficient genome reconstruction from metagenome assemblies', PeerJ, 7, e7359. doi: 10.7717 /peerj. 7359 .

Langmead, B. and Salzberg, S.L. (2012) 'Fast gapped-read alignment with Bowtie 2', Nature Methods, 9(4), pp. 357-359. doi: 10.1038/nmeth.1923.

Li, D. et al. (2015) 'MEGAHIT: an ultra-fast single-node solution for large and complex metagenomics assembly via succinct de Bruijn graph', Bioinformatics (Oxford, England), 31(10), pp. 1674-1676. doi: 10.1093/bioinformatics/btv033.

Li, Y. et al. (2018) 'Coupled carbon, sulfur, and nitrogen cycles mediated by microorganisms in the water column of a shallow-water hydrothermal ecosystem', Frontiers in Microbiology, 9, p. 2718. doi: 10.3389/fmicb.2018.02718.

Menzel, P., Ng, K.L. and Krogh, A. (2016) 'Fast and sensitive taxonomic classification for metagenomics with Kaiju', Nature Communications, 7, p. 11257. doi: $10.1038 /$ ncomms11257.

Mikheenko, A., Saveliev, V. and Gurevich, A. (2016) 'MetaQUAST: evaluation of metagenome assemblies', Bioinformatics (Oxford, England), 32(7), pp. 1088-1090. doi: 10.1093/bioinformatics/btv697.

More, K.D. et al. (2019) 'Holocene paleodepositional changes reflected in the sedimentary microbiome of the Black Sea', Geobiology, 17(4), pp. 436-448. doi: 10.1111/gbi.12338.

Naghoni, A. et al. (2017) 'Microbial diversity in the hypersaline Lake Meyghan, Iran', Scientific Reports, 7(1), p. 11522. doi: 10.1038/s41598-017-11585-3. 
Peoples, L.M. et al. (2019) 'Microbial community diversity within sediments from two geographically separated hadal trenches', Frontiers in Microbiology, 10, p. 347. doi: 10.3389/fmicb.2019.00347.

Potts, M. and Whitton, B.A. (1979) ' $\mathrm{pH}$ and Eh on Aldabra Atoll 2. Intertidal photosynthetic microbial communities showing zonation', Hydrobiologia, 67(2), pp.99-105. doi: 10.1007/BF00126708.

Price, M.N., Dehal, P.S. and Arkin, A.P. (2010) 'FastTree 2--approximately maximumlikelihood trees for large alignments', PloS One, 5(3), e9490. doi: 10.1371/journal.pone.0009490.

Quast, C. et al. (2013) 'The SILVA ribosomal RNA gene database project: improved data processing and web-based tools', Nucleic Acids Research, 41(Database issue), D590-6. doi: $10.1093 / \mathrm{nar} / \mathrm{gks} 1219$.

$\mathrm{R}$ Core Team (2020) R: A language and environment for statistical computing. (Version 4.0.0). Vienna, Austria: R Foundation for Statistical Computing. Available at: http://www.r-project.org.

Rinke, C. et al. (2013) 'Insights into the phylogeny and coding potential of microbial dark matter', Nature, 499(7459), pp. 431-437. doi: 10.1038/nature12352.

Rissanen, A.J. et al. (2019) 'Vertical stratification of bacteria and archaea in sediments of a small boreal humic lake', FEMS Microbiology Letters, 366(5). doi: 10.1093/femsle/fnz044.

RStudio Team (2021) RStudio: integrated development for R (Version 1.4.1106). Boston, MA: RStudio Inc. Available at: http://www.rstudio.com.

Saghaï, A. et al. (2016) 'Comparative metagenomics unveils functions and genome features of microbialite-associated communities along a depth gradient', Environmental Microbiology, 18(12), pp. 4990-5004. doi: 10.1111/1462-2920.13456.

Schneider, D. et al. (2013) 'Phylogenetic analysis of a microbialite-forming microbial mat from a hypersaline lake of the Kiritimati atoll, Central Pacific', PloS One, 8(6), e66662. doi: 10.1371/journal.pone.0066662.

Sellstedt, A. and Richau, K.H. (2013) 'Aspects of nitrogen-fixing Actinobacteria, in particular free-living and symbiotic Frankia', FEMS Microbiology Letters, 342(2), pp. 179-186. doi: 10.1111/1574-6968.12116.

Sieber, C.M.K. et al. (2018) 'Recovery of genomes from metagenomes via a dereplication, aggregation and scoring strategy', Nature Microbiology, 3(7), pp. 836-843. doi: 10.1038/s41564-018-0171-1.

Soo, R.M. et al. (2015) 'Back from the dead; the curious tale of the predatory cyanobacterium Vampirovibrio chlorellavorus', PeerJ, 3, e968. doi: 10.7717/peerj.968.

Tatusov, R.L. et al. (2000) 'The COG database: a tool for genome-scale analysis of protein functions and evolution', Nucleic Acids Research, 28(1), pp. 33-36. doi: 10.1093/nar/28.1.33.

Warden, J.G. et al. (2016) 'Characterization of microbial mat microbiomes in the modern thrombolite ecosystem of Lake Clifton, Western Australia using shotgun metagenomics', Frontiers in Microbiology, 7, p. 1064. doi: 10.3389/fmicb.2016.01064.

Wickham, H. (2016) ggplot2: elegant graphics for data analysis. New York, NY: SpringerVerlag. 
Wood, D.E., Lu, J. and Langmead, B. (2019) 'Improved metagenomic analysis with Kraken 2', Genome Biology, 20(1), p. 257. doi: 10.1186/s13059-019-1891-0.

Wu, Y.-W., Simmons, B.A. and Singer, S.W. (2016) 'MaxBin 2.0: an automated binning algorithm to recover genomes from multiple metagenomic datasets', Bioinformatics (Oxford, England), 32(4), pp. 605-607. doi: 10.1093/bioinformatics/btv638. 


\section{Supplement:}

\section{Contents:}

Table S1. Sequencing information and read processing statistics.

The table can be found on the enclosed $C D$ and zip folder:

Supplement|Chapter_C5|Table_S1.xIsx.

Table S2. Summary of bins, bin quality and taxonomic affiliation.

The table can be found on the enclosed $C D$ and zip folder:

Supplement|Chapter_C5|Table_S2.xIsx.

Table S3. Post-assembly statistics and summary derived for contigs (a) and the anvi'o profile (b). a) The contig summary and statistics were generated using metaQUAST. b) the anvi'o profile summary was generated using anvi-summarize on the refined bins.

The table can also be found on the enclosed CD and zip folder:

Supplement|Chapter_C5|Table_S3.xIsx. 
Table S3. Post-assembly statistics and summary derived for contigs (a) and the anvi'o profile (b). a) The contig summary and statistics were generated using metaQUAST. b) the anvi'o profile summary was generated using anvi-summarize on the refined bins.

\begin{tabular}{|c|c|c|c|}
\hline Co-assembly & Final contigs & Anvi'o Key & Value \\
\hline \# contigs (>= $0 \mathrm{bp}$ ) & 5761716 & Created on & 08.03.2021 09:53 \\
\hline \# contigs (>= $1000 \mathrm{bp}$ ) & 5761716 & Version & 35 \\
\hline \# contigs (>= 5000 bp) & 421247 & Number of contigs & $5,761,716$ \\
\hline \# contigs (>= 10000 bp) & 147300 & Number of splits & $5,791,598$ \\
\hline$\#$ contigs ( $>=25000 \mathrm{bp}$ ) & 33514 & Contig length cutoff min & 1,000 \\
\hline$\#$ contigs ( $>=50000$ bp) & 9025 & Contig length cutoff max & $9,223,372,036,854,770,000$ \\
\hline Total length (>= $0 \mathrm{bp}$ ) & 14475009184 & Samples in profile & 47 \\
\hline Total length $(>=1000 \mathrm{bp})$ & 14475009184 & Total nucleotides & $14.48 \mathrm{~Gb}$ \\
\hline Total length (>= $5000 \mathrm{bp}$ ) & 5146533741 & SNVs profiled & True \\
\hline Total length (>= $10000 \mathrm{bp}$ ) & 3285585622 & SCVs profiled & False \\
\hline Total length (>= $25000 \mathrm{bp}$ ) & 1603112313 & IN/DELs profiled & True \\
\hline Total length (>= $50000 \mathrm{bp}$ ) & 774380607 & Report variability full & False \\
\hline \# contigs & 5761716 & Min coverage for variability & 10 \\
\hline Largest contig & 887890 & Total nucleotides & $14.48 \mathrm{~Gb}$ \\
\hline Total length & 14475009184 & Number of contigs & $5,761,716$ \\
\hline Reference length & 3782798 & Number of splits & $5,791,598$ \\
\hline N50 & 2889 & Genes are called & True \\
\hline N75 & 1531 & External gene calls & False \\
\hline L50 & 987063 & External amino acid sequences & False \\
\hline L75 & 2778881 & K-mer size & 4 \\
\hline \# misassemblies & 28 & Split length & 20,000 \\
\hline \# misassembled contigs & 25 & Splits consider gene calls & True \\
\hline Misassembled contigs length & 537321 & SCG taxonomy was run & True \\
\hline \# local misassemblies & 136 & & KEGG_Class, \\
\hline \# scaffold gap ext. mis. & 0 & & COG20_CATEGORY, \\
\hline \# scaffold gap loc. mis. & 0 & Gene function sources & $\begin{array}{l}\text { COG20_FUNCTION, KOfam, } \\
\text { KEGG_Module, } \\
\text { COG20_PATHWAY }\end{array}$ \\
\hline
\end{tabular}




\section{Co-assembly}

\# unaligned mis. contigs

\# unaligned contigs

Unaligned length

Genome fraction (\%)

Duplication ratio

\# N's per 100 kbp

\# mismatches per 100 kbp

\# indels per 100 kbp

Largest alignment

Total aligned length

\section{Final contigs}

96

$5760658+902$ part

14472532636

63.112

1.073

0

4344.6

64.3

51108

2458572 


\section{General Discussion}

In this thesis, microbial community composition and function are studied in carbonate sediments. Porewater and bulk sediment geochemical data are used to describe the different sediment settings at Lake Neusiedl and the Aldabra Atoll. The geochemical composition provides indications for the broad metabolic processes, which occur in each sediment zone. Microbial community analysis covers the living components of each of the investigated ecosystems. Taxonomic identification using both 16S rRNA genes and transcripts allows an insight into the bacterial communities from two standpoints. On the one hand, the 16S rRNA gene-based taxonomy, amplified from total DNA from the environmental samples, gives information on all bacterial taxa in the sediments. This includes extracellular DNA which has not been degraded yet, dead cells which have been preserved in the sediment or sedimented from the water column, as well as dormant microbes, which survive using a minimal metabolism (Lloyd, 2021; Torti, Lever and Jørgensen, 2015). On the other hand, amplicons derived from 16S rRNA gene transcripts reflect the part of the community, which is actively producing ribosomes. It is therefore used as a proxy for the metabolically active community. The amplicon data provide a detailed overview on the taxonomy of the bacterial community members. In addition, whole genome sequencing, metagenomes and metagenome assembled genomes (MAGs) are used to understand what the communities' capabilities are. While the metagenome approach does not allow the identification of actively transcribed metabolic pathways, it provides an overview of the functions encoded and enriched within a microbial community. In addition, it allows the identification and characterisation of many uncultured and unclassified taxa (Frioux et al., 2020). All microbiological approaches are only as good as the databases which are used as references. For this reason, it is important to isolate and characterize novel bacterial species. Thus, the isolation and characterization of two novel bacterial species complements this study. It provides additional insights into microorganisms thriving in the studied ecosystems and enhances the public databases. 


\section{Microbiome of the Aldabra Atoll}

\subsection{Sampling sites on the Aldabra Atoll}

The sediments sampled on the Aldabra Atoll can be subdivided into three categories depending on location, sediment facies and bioturbation, in accordance with descriptions by Farrow (1971). Firstly, the carbonate sand in the West Lagoon (Figure 4) categorized as polychaete sandflats. The sand consisted of medium to very fine sand with "fair" sorting in the past (Farrow, 1971), as well as this study (Chapter C.3). It was classified as habitat with a moderate probability of lithification preserving it in the later limestone (Farrow, 1971).

Secondly, the mangrove mudflats in the South Lagoon. These are densely colonized by Uca marionis fiddler crabs, which leave behind burrows with mud chimneys and faecal pellets (Farrow, 1971). The sediment consists of grey, fine silt with "fair to poor" sorting. It was categorized as having a high potential of being preserved in lithified form (Farrow, 1971). The North Lagoon sediment resembles Farrows' description for the mangrove mud at Bras Cinq Cases, which is characterized by red-brown mud rich in organic matter (Farrow, 1971). The sediment is strongly affected by the local mangroves and is acidic enough to leave traces of corrosion on local mollusc shells (Farrow, 1971).

The third category of sediment from Aldabra was sampled at the landlocked pools. These harboured carbonate mud and silt with differing organic content (Chapter C.3) and hypersaline conditions. In the past, the pools harboured salinities from marine-influenced freshwater to hypersaline conditions (Braithwaite et al., 1989; Donaldson, 1978). The pools typically experience no bioturbation, allowing the development of microbial mats and stromatolites. This thesis includes the, to our knowledge, undescribed Westpool D which harboured stromatolites, and the Cinq Cases basin which has a history of stromatolites (Braithwaite et al., 1989). At the time of sampling in 2017, Cinq Cases no longer harboured stromatolites (Chapter C.5).

\subsection{Carbonate sand flats in the lagoon of Aldabra}

The West Lagoon carbonate sand has a high porosity and is subject to strong tidal exchange of its porewaters. Neither the bacterial community in the bulk of the sand, 
nor the porewater geochemical data showed substantial gradients with sediment depth. The bacterial community showed 20-60\% of Gammaproteobacteria and 10-20\% uncultured Actinobacteriota (Chapter C.3). These phyla have also been found to be abundant in the sands of South Carolina (Taylor and Kurtz, 2020), California (Boehm, Yamahara and Sassoubre, 2014), the North Sea (Degenhardt et al., 2020; Musat et al., 2006) and the Bahamas (O'Reilly et al., 2017), however, always at lower abundances. The sand bacterial diversity was low on Aldabra in comparison to these other sites. Common sand associated Bacteroidetes, such as Flavobacteriales (Probandt et al., 2018), were present in the water column, but virtually absent in the sediment. Pirellulaceae belonging to the Planctomycetes were associated with the total bacterial community but present only at low relative abundance (1-3\%). Many environmental drivers may affect the sand bacterial community structure. Shared drivers among sandbased community studies include the degree of disturbance through tidal mixing, porewater exchange and season (Boehm, Yamahara and Sassoubre, 2014; Böer et al., 2009; Degenhardt et al., 2020; Chapter C.3). Differences in community type may also be a result of sampling time in relation to tidal status, as the sand-particle attached community differs strongly from the free-living porewater community (Gobet et al., 2012; Chapter C.3). This may explain the low diversity in the West Lagoon (Chapter C.3), as the samples were taken from a virtually dried out core at low tide.

In addition, geographical location could be an important factor for the community composition, as most of the aforementioned studies were based around temperate beaches. Microbial communities situated closer to tropical locations, such as Californian (Boehm, Yamahara and Sassoubre, 2014) or Hawaiian (Cui et al., 2013) beaches, contain higher proportions of Pseudomonas, Vibrio and Acidobacteria, similar to the sands of Aldabra (Chapter C.3). At a functional level, the sand environment selects for bacterial taxa which have the ability to flourish under constantly changing nutrient and oxygen conditions. They can persist in the sediment by attaching to sand grains or forming conglomerates (Probandt et al., 2018). This often leads to an enrichment of nitrogen cycling taxa (Boehm, Yamahara and Sassoubre, 2014; Chapter C.3; Figure 6), such as Pseudomonas, Halomonas, Vibrio and Planctomycetes. Most of these are denitrifiers which can use nitrate as alternative electron acceptor to oxygen (González-Domenech et al., 2010; Lalucat et al., 2006; Liu et al., 2020). In permeable coastal sediments, the fluctuating oxygen availability 
has been shown to stimulate denitrification (Marchant et al., 2017), indicating that the same effect occurs in the West Lagoon sand.

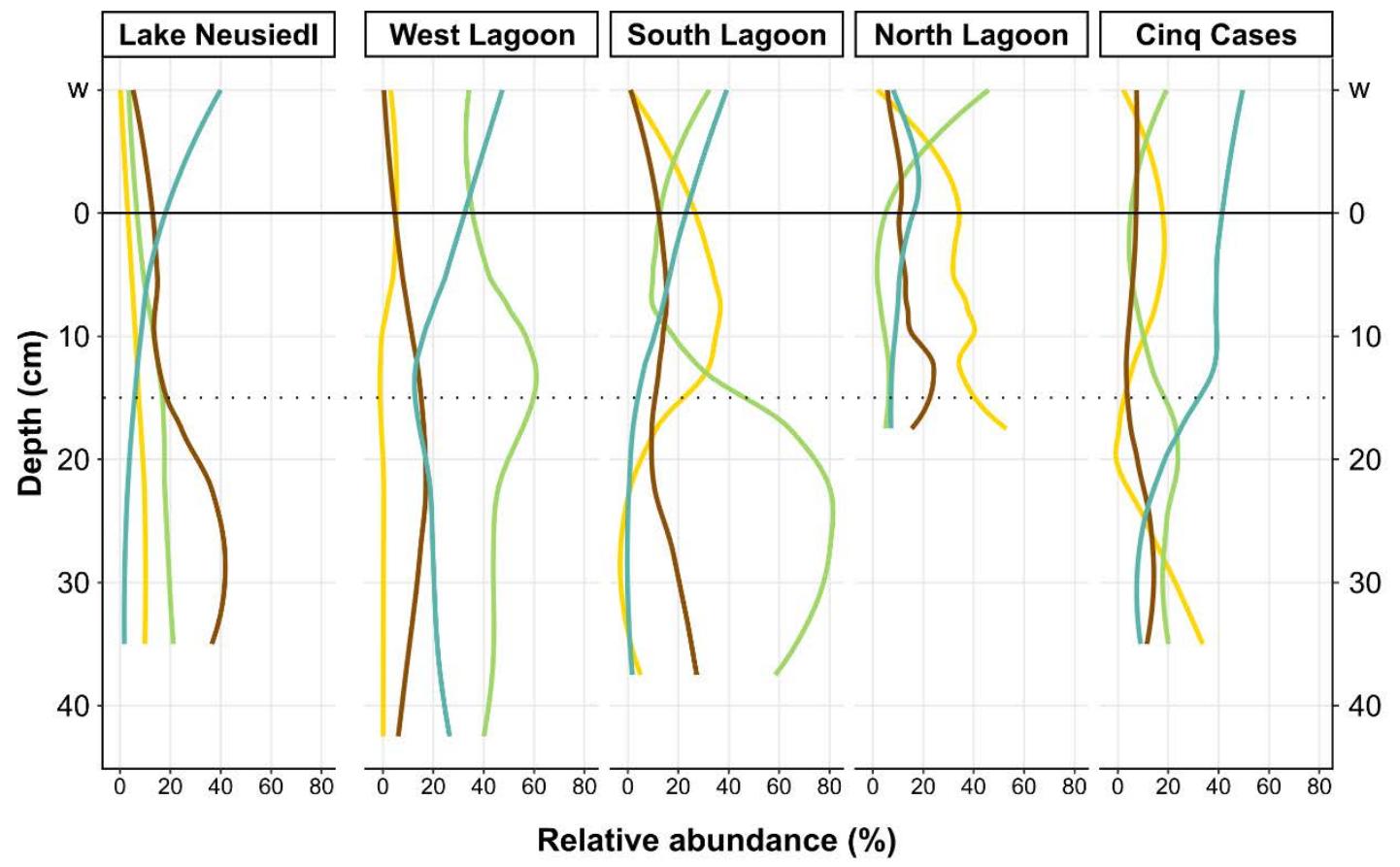

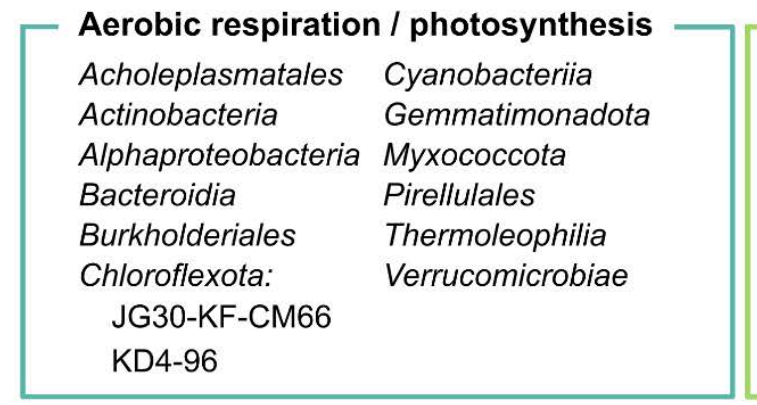

\begin{tabular}{|ll|}
\hline Anaerobic respiration / fermenter \\
Acetothermiia & Erysipelotrichia \\
Anaerolineae & Holophagae \\
Alteromonadales & Izemoplasmatales \\
Chloroflexia & Latescibacteria \\
Clostridia & Patescibacteria \\
Dehalococcoidia & Thermoanaerobaculales
\end{tabular}

Denitrification

Aeromonadales Nitrospira Alteromonadales Oceanospirillales Aminicenantales Pseudomonadales Bacillales Rhizobiales Corynebacteriales Steroidobacterales Micrococcales Vibrionales

Figure 6. Potential bacterial metabolism along the sediments of Lake Neusiedl and the four sampling sites on Aldabra. The most abundant bacterial orders (Neusiedl $>1 \%$, Aldabra $>5 \%$ relative abundance) were categorized by their potential energy metabolism according to literature on bacterial isolates within their order (Appendix 1.2). The line at $0 \mathrm{~cm}$ represents the sediment water interface. The dotted line at $15 \mathrm{~cm}$ indicates a transition depth in the bacterial profiles. 


\subsection{Biogeochemical cycling in carbonate mud and silt}

Different types of carbonate mud and silt were sampled during the course of this study. On Aldabra, this includes the mud and silt in the North and South Lagoon, the carbonate mud of Cinq Cases (Chapters C.3 and C.5), and the carbonate mud of Lake Neusiedl (Chapters C.1 and C.2). The most abundant bacterial phyla on Aldabra resemble other intertidal and mangrove sediments in the Indian Ocean (Chapter B.1, Figure 1). Lake Neusiedl harboured high relative abundances of Chloroflexota, similar to other lacustrine systems (Chapter B.1, Figure 1). All sediments initially followed the classical biogeochemical zonation pattern (Chapter B.2, Figure 2) with a sulphate reduction zone within the approximately first $15 \mathrm{~cm}$ of sediment. Sulphate reduction was clearly visible in the porewaters by a decrease in sulphate and concomitant increase in total sulphides. It was driven by members of the Desulfobacterota at all sites, which are the main sulphate reducers globally (Chapter B.1, Figure 1; Jørgensen, Findlay and Pellerin, 2019). Desulfobacterota show site-specific differences in the distribution of their families. At Neusiedl the main sulphate reducers within the sulphate reduction zone were Desulfarculales and Desulfobacterales (Chapters C.1 and C.2). In the marine sediments of Aldabra, we identified Desulfobacterales and Desulfovibrionales instead (Chapter C.3). Desulfobacterales and Desulfovibrionales can both be found in marine (Jochum et al., 2018) as well as hypersaline and alkaline environments (Foti et al., 2007). This suggests that their distribution is not dependent on the lacustrine or marine setting. Desulfarculales has been classified as a strictly anaerobic mesophilic family with a preference for freshwater and marine environments (Waite et al., 2020). The elevated salinities over ocean values in the lagoon sediments and landlocked pools, as well as oxygenation of the sediment through bioturbation, may explain their absence from the Aldabra sediments.

Following the sulphate reduction zone, Neusiedl sediments transitioned to Dehalococcoidia, Anaerolineales and Syntrophobacterales (Chapter C.1, Figure 6). Dehalococcoidia are known for their organohalide respiration and Anaerolineales are highly abundant plant-degraders in anaerobic wastewater digesters (Hug et al., 2013; Xia et al., 2016), suggesting that fully anoxic conditions prevail at Neusiedl. The higher abundance of Syntrophobacterales below $15 \mathrm{~cm}$ of depth alongside increasing methane concentrations indicates the onset of methanogenesis by archaea to which 
they are potential synthrophs (Kuever, 2014). This transition from sulphate reduction to methanogenesis at the bottom of the sediment, makes the Neusiedl sediment cores a perfect example of the classical geochemical zonation (Figure 6; Jørgensen and Kasten, 2006).

The sediments on Aldabra show a different bacterial and biogeochemical succession with depth (Figure 6). As a result of bioturbation and tidal disturbance the upper $15 \mathrm{~cm}$ of depth showed a mixed surface and sulphate reduction zone. It harboured typically fermenting taxa (Propionigenium) and synthrophs (Synergistaceae EBM-39), alongside sulphate reducers (Desulfobacterota) and sulphide oxidizers (Campilobacterota) (Figure 6; Chapter C.3). Instead of increasing relative abundances of fermenting anaerobes and methanogens like in the proof-ofconcept study (Chapter C.1), we found Gammaproteobacteria known for their metabolic flexibility to be abundant (Chapter C.3 and C.5). Their abundance increased alongside a drop in phylogenetic diversity in comparison to the sulphate reduction zone (Chapter C.3). Porewater total alkalinity and ammonia concentrations also decreased in this sediment, indicating a decrease in metabolic activity.

In the South Lagoon, the switch in dominant community type occurred upon transition from bioturbated sediment to older sediment harbouring mangrove debris below $15 \mathrm{~cm}$ of depth (Figure 6). At Cinq Cases, the change occurred alongside a peak in $\mathrm{C} / \mathrm{N}$ ratio and intermittent carbonate-free sediment. While organic matter also increases in the deeper sediments of Lake Neusiedl, explaining the increase in fermenting Chloroflexota, the sediment showed no abrupt changes in geochemistry or sediment facies (Chapter C.2). For the South Lagoon and Cinq Cases, we linked the change in community type to a change in sediment age, availability and complexity of organic matter (Chapter C.3). Comparison with Lake Neusiedl suggests that sediment history may indeed influence the bacterial community by providing more stable or frequently disturbed environments. Stable ecosystem rich in nutrients are more habitable to a diverse bacterial community. A diverse bacterial community with a large variety of specialist taxa, such as sulphate reducers (Chen et al., 2021), can establish in their specific ecological niches. Frequently disturbed sediments or sediments with inaccessible nutrients are more inhabitable. Frequent disruption requires reestablishment of the community, while environments with inaccessible nutrients or oligotroph conditions represent a kind of desert. Both environments harbour fewer, 
generalist taxa, or pioneers, which are able to quickly colonize environments using their large metabolic repertoire (Chen et al., 2021).

At Aldabra the metabolically versatile and ubiquitous Gammaproteobacteria, such as Pseudomonas, Halomonas and Vibrio, may represent bacterial generalists or pioneers. At Cinq Cases they colonize previously desiccated sediments ahead of the reducing bacterial community at the surface. In the South Lagoon, they persist in anoxic sediments of an older age (Chapter C.3). Gammaproteobacteria MAGs derived from Cinq Cases harboured genes for DNRA and denitrification. DNRA yields more energy than denitrification under nitrate limiting conditions (Strohm et al., 2007). The ability to switch between energy metabolic pathways, may therefore be an advantage during sediment colonization (Chapter C.5). Whether these taxa are selected by their ability to degrade more complex organic matter in the form of mangrove debris, survive in potentially more oligotrophic sediments, or simply endure, can however not fully be determined from the current dataset. Synergistic interactions with plant matter degrading fungi may be an additional factor, which has not been assessed in this study. Metagenomes, however, indicate that overall fungal abundance is low and decreases in the zones with low bacterial diversity (Chapter C.5).

Sulphate reducers represent the group of highly specialized taxa (Chen et al., 2021). The bioturbated surface sediments on Aldabra provide a multitude of ecological niches filled by specialized Desulfovibrio, Synergistota EBM-39 and Propionigenium. They are adapted to their individual niches by reducing sulphate for their energy metabolism (Galushko and Kuever, 2015), synergism with other specialists (He et al., 2018) or association with burrowing fauna (Watson et al., 2000). Even though frequent bioturbation may create localised extinction events for individual taxa, their fast growth and specialization may lead to quick re-establishment within their specific ecological niche (Monard et al., 2016). At Cinq Cases specialized taxa can be found in the microbial mat and underlying sediments, as well as the bottom of the cores (30$35 \mathrm{~cm}$ bsf). The mat harbours the highest bacterial diversity, including bacterial taxa with a multitude of metabolic traits (Chapter C.3). The bottommost sediment at Cinq Cases shows traces of the previous microbial community. Despite the positive redox conditions, MAGs derived from this sediment harbour sulphate reduction genes, and complete KEGG modules for methanogenesis (Chapter C.5). In this zone, archaea reach their highest abundance in the Cinq Cases metagenomes (3\%). Together with 
the nitrogen cycling Gammaproteobacteria above, this suggests that the sediment may have followed the standard biogeochemical zonation in the past (Figure 6).

\section{Carbonate precipitation and diagenesis}

The aim of this thesis was to determine the microbial taxa populating different carbonate environments and understanding their potential involvement in the precipitation and diagenesis of carbonates. First, we studied the alkaline Lake Neusiedl consisting of authigenic high magnesium calcite (HMC) and protodolomite (Chapters C.1 and C.2). The remaining carbonate sediments derive from five different areas on the limestone Aldabra Atoll (Chapters C.3 and C.5). They include fine-grained carbonate sand, coarse to fine carbonate silt, mud and shell debris, as well as a succession of sediments with varying degrees of carbonate content. Lastly, we focused on an actively precipitating, moderately hypersaline pool and its stromatolites (Chapter C.5).

\subsection{Precipitation, diagenesis, and microbes}

Carbonate precipitation is dependent upon the saturation of its chemical components in the environment, as well as $\mathrm{pH}$, alkalinity, and available nucleation sites (Dupraz et al., 2009). Carbonates can precipitate along creek surfaces (Schneider et al., 2015), in microbial mats and stromatolites (Baumgartner et al., 2009; Glunk et al., 2011), or in the water column (McCormack et al., 2018). Once formed and sedimented, carbonates undergo changes, for instance due to fluctuating $\mathrm{pH}$ conditions or microbial boring, leading to their dissolution, re-precipitation and recrystallization (Mackenzie and Andersson, 2011). These changes fall under the term diagenesis and lead to altered isotopic signatures $(\mathrm{O}, \mathrm{C})$ and exchange of ions $(\mathrm{Mg}, \mathrm{Ca}, \mathrm{Sr})$ in the carbonate crystals. By cycling carbonate compounds or accumulating carbonates intracellularly, microbes can alter the isotopic signature of carbonates and potentially skew the data (Hesse and Schacht, 2011; Pederson et al., 2019). As isotopic signatures of carbonates are commonly used to reconstruct the climatic history of sediments (Pederson et al., 2019), it is therefore important to understand microbial succession and metabolism in presentday sediments. 


\subsection{Precipitation in the water column: Lake Neusiedl}

Lake Neusiedl has been the focus of various studies targeting its dolomite and high magnesium calcite (HMC) sediments (Müller, Irion and Förstner, 1972; Schroll and Wieden, 1960, Chapter C.2). The dolomite at Neusiedl is of particular interest, as dolomite is used as a proxy to understand past climatic conditions. It is also difficult to achieve its precipitation under laboratory conditions, leading to an ongoing discussion on the exact conditions required for its precipitation (McCormack et al., 2018 and references therein). In our study of Lake Neusiedl (Chapter C.2), the sediments consisted of HMC, protodolomite and calcite, as well as almost $50 \%$ of detrital minerals including mica, feldspar, quartz, and clay (Chapter C.2). The microbial community within these sediments reflected the high amount of plant-based organic content with high abundances of Chloroflexota (Chapter C.1). Both Anaerolineales and Dehalococcoidia have been detected in anaerobic environments where they have been described as acetogenic primary fermenters and plant degraders (Hug et al., 2013; McIlroy et al., 2017), explaining their increasing abundance alongside plant detritus in the sediment. Sulphate reducing Desulfobacterota were present throughout the cores but changed from Desulfarculales and Desulfobacterales in the upper sediment (0-10 cm/Unit I) to SVA0485 and Syntrophobacterales in units II $(15-22.5 \mathrm{~cm})$ and III $(25-40 \mathrm{~cm})($ Chapter C.1). As Syntrophobacterales populations have been found to increase in conjunction with methanogenic archaea (Ziels et al., 2015), this indicates, that archaea may play an increasingly important role at the bottom of the cores (Unit II/III). While methanogenesis and anaerobic methane oxidation could potentially lead to further carbonate precipitation, acetate, and other acidic fermentation products of the Chloroflexota likely outweigh this process. At Lake Neusiedl, this means that the overall $\mathrm{pH}$ is significantly lower in the sediments than in the water column (7.6 in comparison to $>8.5)$ leading to signs of dissolution of diatoms and HMC crystals in the thin sections (Chapter C.2; Figure 7).

The water column shows a different picture regarding carbonate precipitation. It is highly saturated in calcite, aragonite, and dolomite, and has a high $\mathrm{pH}$, ideal for carbonate precipitation. The microbial community consists of aerobic heterotrophs, such as SAR11 Alphaproteobacteria, freshwater hgcI Actinobacteriota and Bacteroidota (Chapter C.1). Little is known about freshwater Actinobacteriota apart 
from the fact, that they exhibit some of the smallest cell-sizes for freshwater bacteria and belong to the photoheterotroph picoplankton (Dwulit-Smith et al., 2018; Warnecke, Amann and Pernthaler, 2004). Their small cell size may facilitate abiotic precipitation in the supersaturated water column of Lake Neusiedl by acting as small nucleation sites. In addition, we detected freshwater Synechococcus, which are the photoautotrophic members of the microbial community able to actively precipitate carbonates in the form of S-layer sheaths (Thompson et al., 1997). In the water column, it has been observed that Synechococcus can shed their sheaths, ensuring their continued growth (Thompson et al., 1997). Their shed sheaths may represent first carbonate nuclei and form the basis for further precipitation and diagenetic alteration of the original cyanobacterial carbonate (Figure 7).

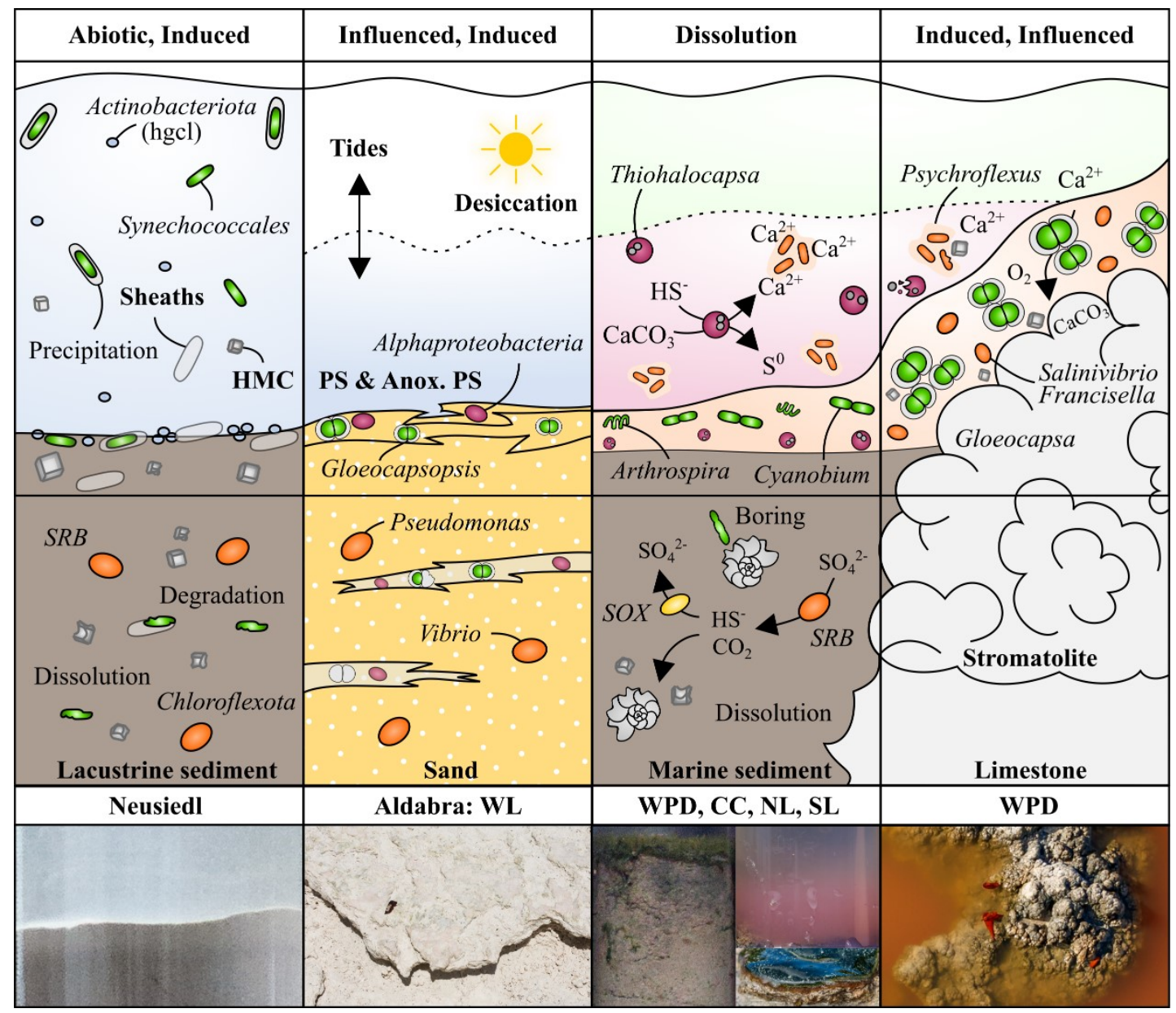

Figure 7. Modes of carbonate precipitation and dissolution across the sampling sites discussed in this thesis. Abbreviations: HMC: high magnesium calcite, SRB: sulphate reducing bacteria, SOX: sulphide oxidizing bacteria, (Anox.) PS: (anoxygenic) photosynthesis. Sampling sites: WL: West Lagoon, WPD: Westpool D, CC: Cinq Cases, NL: North Lagoon, SL: South Lagoon. 
To verify our hypothesis on the formation of carbonates at Lake Neusiedl, further studies should include the assessment of the archaeal community in the sediment, alongside sediment isotopic composition. If methanogenesis or anaerobic oxidation of methane play a significant role, this should lead to isotopically lighter carbonates (Reeburgh, 2007).

\subsection{Precipitation and dissolution in sand and sediment:}

\section{Aldabra Lagoon}

Tidal currents and protected embayments lead to the accumulation of sediments on the Aldabra Atoll (Farrow, 1971; Stoddart et al., 1971). Frequent tidal exchange, shallow water depth and evaporation lead to changes in sediment $\mathrm{pH}$, carbonate saturation and alkalinity on the sand and mudflats. In the lagoon of Aldabra, we sampled three different sediment environments including carbonate sand in the West Lagoon, grey fine-grained carbonate mud in the South Lagoon, and red-brown coarse carbonate sand and silt in the North Lagoon (Chapter C.3).

Based on the sediment facies, the North and South Lagoon have very different sediments. The bacterial community in the upper $0-15 \mathrm{~cm}$ of the two sampling sites show a highly similar community composition (Chapter C.3). The data showed that sulphate reducing Desulfobacterota, and other heterotrophs create a low $\mathrm{pH}$, which leads to local dissolution of carbonates and high total alkalinity (Chapter C.3). Previous studies suggest that long-term sulphate reduction and the resulting increase in alkalinity and release of $\mathrm{Ca}^{2+}$ from EPS degradation should lead to precipitation favouring conditions (Dupraz et al., 2004; Gallagher et al., 2012). Additional metabolic products, such as $\mathrm{CO}_{2}$ and acetate from aerobic and anaerobic heterotrophs likely negate this effect. The resulting net dissolution of carbonates was previously found in the South Lagoon sediments (Dune Jean Louis sediment in Gaillard, Bernier and Gruet, 1994). In 2017, dissolution features on shell debris alongside algal borings were also found in the North Lagoon sediments (data not shown). These are in line with the description for acidic red-brown mangrove mud by Farrow (1971) and have the lowest $\mathrm{pH}$ of the lagoon sediments. As the sediments we encountered in the lagoon were not covered by microbial mats and photoautotrophs were present only at low relative abundances, the surface sediments will likely not change towards precipitating conditions. In addition, syntrophic taxa indicating the presence of methanogenic 
archaea were only detected in the upper $15 \mathrm{~cm}$ of sediment, where heterotroph activity likely outweighs any $\mathrm{pH}$ increases by methanogens. The same applies to the deeper sediment (South Lagoon $>15 \mathrm{~cm}$ ). While we expected the deeper sediments to favour methanogens, we detected mainly Gammaproteobacteria. Halomonas, Photobacterium and Vibrio MAGs derived from Cinq Cases harbour genes for DNRA, denitrification and $\mathrm{N}_{2}$-fixation, suggesting that their ability to cycle nitrogen is advantageous in these sediments (Chapter C.5). We linked their onset to the presence of mangrove debris and plant material, which is more challenging to degrade (Chapter C.3). The associated $\mathrm{pH}$ changes favour dissolution of carbonates.

The West Lagoon carbonate sand is the only sampled environment within the lagoon with sediment conditions favourable for carbonate precipitation. This occurs in the first millimetres of sand, which are characterized by a lithified crust derived from a microbial biofilm (Chapter C.3). The biofilm is light pink and green in colour and harbours the highest bacterial diversity within the sediment column. It is inhabited by photoheterotrophic Alphaproteobacteria, sulphate reducing Desulfobacterota and cyanobacterial Gloeocapsopsis. These taxa are also found in the calcifying microbial mats of the Bahamas (Dupraz et al., 2004) and likely drive both biogenically induced and influenced precipitation. The most likely scenario for carbonate precipitation in the West Lagoon is linked to the outgoing tides. While these recede, the sediment desiccates leading to increased saturation of carbonates and their compounds around the microbial biofilm. Within the biofilm, the Gloeocapsopsis may either actively or passively precipitate carbonate in form of a sheath or removal of $\mathrm{CO}_{2}$, thereby shifting the carbonate equilibrium. At the same time, sulphate reducers and heterotrophic Alphaproteobacteria may degrade EPS and create local dissolution zones on the sand particles, leading to an increase of free $\mathrm{Ca}^{2+}$-ions in the biofilm. Together with the evaporitic conditions, precipitates are formed, ultimately leading to an initial cementation of the sand surface (Figure 7). The tidal influence on the sediment here may also be the limitation to lithification in the West Lagoon, as the porewater space will be diluted at hight tide and unbound precipitates may be washed away. An indication for the short-lived nature of lithified surfaces in the West Lagoon, are the past descriptions of these features nearby. Potts and Whitton (1980) described the crusts as lagoonal stromatolites, suggesting that they reached a larger thickness than the crusts we observed. Braithwaite et al. (1989) however, criticised this classification 
of the crusts classifying them as laminated sediments, rather than stromatolites, as they lacked precipitated carbonate at the time.

Of the three sites in the lagoon, only the West Lagoon showed recent carbonate precipitation in the form of cemented sand layers. Intermittent crusts throughout the cores suggest that parts of the lithifications may be preserved on a longer term. The North and South Lagoon mud represented environments where carbonate dissolution can currently take place. Particularly the North Lagoon sediments show signs of diagenesis through endolithic borings and traces of dissolution. While carbonates do not seem to precipitate in the water column and sediments of Aldabra's lagoon, an alternative source of carbonates may be the fish sheltered within the lagoon. These have been shown to contribute low and high $\mathrm{Mg}$-calcite and aragonite to the carbonate sediments at Great Bahama Bank (Perry et al., 2011), which is one of the closest present-day analogues to the Aldabra Atoll (Farrow, 1971).

\subsection{Precipitation in microbial mats and stromatolites:}

\section{Aldabras' landlocked pools}

Westpool D and Cinq Cases are two moderately hypersaline pools on Grand Terre Island, which have a history of stromatolites. The Cinq Cases sediment, stromatolites and microbial mats were first described by Braithwaite (1989) including the geochemistry of the pool water column. In their study, Cinq Cases was sampled in the middle of the dry season (July/August 1984). In comparison, we sampled at the end of the dry season (November 2017) (Chapter C.3). The conditions in 1984 describe a higher $\mathrm{pH}$ and salinity than in 2017 (Table 2). The description of water and sediment depth, as well as sediment texture match our observations of light brown to grey, organic rich, fine-grained sediment. The main difference between now and then is the occurrence of stromatolites and oncolites, as well as bright pink bacterial blooms at the pool margins in 1984 (Braithwaite et al., 1989). In 2017, the stromatolites were no longer present and the blooms at Cinq Cases occurred in puddles as a result of first rain showers. Both the stromatolites and blooms, however, were found at a previously undescribed sampling site, Westpool D. Westpool D is a small pond in the South of Grand Terre Island (Chapter B.3, Figure 4). It harboured a stratified water column with a pink bacterial bloom in the bottom water layer, as well as partially submerged stromatolites around the rim (Chapter C.5). The $\mathrm{pH}$ and temperature at the time of 
sampling were lower than present-day Cinq Cases, however alkalinity, $\mathrm{Ca}^{2+}, \mathrm{Mg}^{2+}$, and salinity were higher, particularly within the bacterial bloom (Table 2). The geochemical conditions at Westpool D closely resemble the conditions measured at Cinq Cases in 1984 (Table 2).

Table 2. Chemical parameters of the water column at Cinq Cases and Westpool D at past (Braithwaite et al., 1989) and present conditions. TA, $\mathrm{Ca}^{2+}, \mathrm{Mg}^{2+}\left(\mathrm{mmol} \mathrm{L}^{-1}\right)$ concentrations of 1984 were calculated from the $p \mathrm{TH}, p \mathrm{Ca}$ and $p \mathrm{TH}$ (total hardness) by reversal of the negative logarithm used for $p\left(p=-\log \left[\mathrm{mol} \mathrm{L}^{-1}\right]\right)$ and transformation into $\mathrm{mmol} \mathrm{L}^{-1}$. $\mathrm{Mg}^{2+}$ was derived by subtracting $\mathrm{Ca}^{2+}$ from TH values, as described by Braithwaite et al. (1989). The salinity was approximated from Braithwaite's specific conductivity $\left(\mathrm{mS} \mathrm{cm}^{-1}\right)$ measurements (Braithwaite et al., 1989) using the oceanlife water salinity converter (Oceanlife S.r.l, 2017). Actual salinities in 1984 may have differed slightly as the marine contributions to Cinq Cases used as calculation basis were suggested to be lower at the time (Braithwaite et al., 1989).

\begin{tabular}{|c|c|c|c|c|c|c|c|}
\hline & $\mathrm{pH}$ & $\begin{array}{c}\mathrm{TA} \\
\left(\mathrm{meq} \mathrm{L}^{-1}\right)\end{array}$ & $\begin{array}{c}\mathrm{T} \\
\left({ }^{\circ} \mathrm{C}\right)\end{array}$ & $\begin{array}{c}\mathrm{Ca}^{2+} \\
\left(\mathrm{mmol} \mathrm{L}^{-1}\right)\end{array}$ & $\begin{array}{c}\mathrm{Mg}^{2+} \\
\left(\mathrm{mmol} \mathrm{L}^{-1}\right)\end{array}$ & $\begin{array}{c}\text { Salinity } \\
\left(\mathrm{g} \mathrm{kg}^{-1}\right)\end{array}$ & DIC \\
\hline \multicolumn{8}{|l|}{ Cinq Cases } \\
\hline 1984 & $\begin{array}{c}8.88- \\
9.51\end{array}$ & $\begin{array}{c}2.08- \\
5.01\end{array}$ & $\begin{array}{r}22.5- \\
31.2\end{array}$ & $\begin{array}{c}19.4- \\
28.2\end{array}$ & $\begin{array}{l}63.0- \\
149.6\end{array}$ & $\sim 100$ & - \\
\hline 2017 & 8.5 & 3.37 & 33.2 & 13.9 & 70.5 & 45.5 & 2.4 \\
\hline \multicolumn{8}{|l|}{$\begin{array}{l}\text { Westpool D } \\
\text { (2017) }\end{array}$} \\
\hline Surface & 8.2 & 6.03 & 27.2 & 21.1 & 99.6 & 62.9 & 5.1 \\
\hline Bottom & 7.7 & 6.00 & 32.5 & 30.1 & 161.8 & 99.2 & 5.2 \\
\hline
\end{tabular}

Cinq Cases and Westpool D harboured different microbial mats covering lithified and non-lithified surfaces, both at present and in the past. The unlithified mats were either green and spongy at Cinq Cases or gelatinous in Westpool D and harboured multiple cyanobacterial genera, including Arthrospira, Cyanobium or Synechococcus (Chapter C.5). The filamentous cyanobacteria Lyngbya and Schizothrix described morphologically by Braithwaite (1989), only occurred at very low relative abundances in the dataset, although the "fluffy" nature of the microbial mat at Cinq Cases would suggest their presence (Chapter C.5). Some differences in cyanobacterial taxonomy are expected due to discrepancies between morphological identification and 16S rRNA gene analysis. In addition, 16S rRNA gene analysis and frequent phylogenetic rearrangements within the Cyanobacteria can lead to differences in taxonomic assignment (Willis and Woodhouse, 2020). 
Previously observed lithifications at Cinq Cases were linked to the presence of coccoid cyanobacteria Pleurocapsa and Entophysalis (Braithwaite et al., 1989), as well as Plectonema gloeophilum (Riding, 1977) (now Leptolyngbya gloeophila). The lithifications, observed as stromatolites and oncolites, were no longer discoverable in 2017. This may be a result of the increasing drought frequency on Aldabra leading to lower water levels at Cinq Cases throughout the year (Haverkamp et al., 2017). A climatic change to dryer conditions was previously suggested by Stoddart (1971), who observed that the pools were deeper and larger in the past. The subsequent exposure of stromatolites to wind and rain (which typically has an acidic $\mathrm{pH}$ ) may have led to their erosion within the last 30 years.

Coccoid cyanobacteria were also identified within the biofilm scraped directly off the living stromatolite at Westpool D. Using metagenomic assembly, we were able to assemble a MAG derived from the most abundant bacterial genus of the biofilm (Cyanobacteriales Bin MB 1769, completion 90.1\%, redundancy 4.2\%). The $16 \mathrm{~S}$ rRNA gene analysis and scanning electron microscopical observations (data not shown) indicate that it is a coccoid Gloeocapsa, although its precise taxonomy remains to be verified (Chapter C.5). Gloeocapsa share the biofilm environment with Salinivibrio and Francisella, which potentially benefit from the cyanobacterial carbon fixation and produce additional EPS. In addition, Salinivibrio is able to locally increase the $\mathrm{pH}$ and was previously hypothesized to mediate the precipitation of high magnesium calcite in an evaporitic Sabkha (Al Disi et al., 2017). The Gloeocapsa in the calcifying biofilm at Westpool D are virtually absent in the microbial mat at the bottom of the pond. This jelly-like mat does not contain signs of precipitation, such as carbonate granules (Chapter C.5). The most abundant cyanobacteria are Arthrospira and Cyanobium, alongside Alphaproteobacteria with the ability to fix carbon through anoxygenic photosynthesis. Desulfobacterota are virtually absent from the mat, sediment and biofilm. Genes for dissimilatory sulphate reduction are almost exclusively encoded within the Thiohalocapsa and Thiocapsa responsible for the bacterial bloom (Chapter C.5). The bloom itself has a pH-lowering effect. It is therefore unlikely that sulphate reducers play a role in alkalinity increase and concomitant biogenically induced carbonate precipitation at Westpool D.

Comparing the lithifying with non-lithifying surfaces, coccoid cyanobacteria were be associated with precipitated surfaces in 2017 (Chapter C.5), as well as in the 
past (Braithwaite et al., 1989). This matches results derived from microbial mats at Kiritimati atoll (Kiribati, Schneider et al., 2013) and Eleuthera (Bahamas, Dupraz et al., 2004), microbialites at Lake Van (Turkey, López-García et al., 2005) and Alchichica crater (Mexcico, Saghaï et al., 2016), thrombolites at Lake Clifton (Australia, Warden et al., 2016) and stromatolites at Niuafo'ou Island (Tonga, Kazmierczak and Kempe, 2006). At all sites, coccoid cyanobacteria including Gloeocapsa, Cyano- or Halothece, and Pleurocapsa were implicated with calcifications or precipitation of carbonates. This was linked to their carbonate capsules, which showed outward signs of crystallization or were observed in association with nanoprecipitates (López-García et al., 2005). Filamentous cyanobacteria, on the other hand, have been found in many unlithified microbial mats, including Niuafo'ou (Kazmierczak and Kempe, 2006), Aldabra Atoll (Braithwaite et al., 1989), and Eleuthera (Dupraz et al., 2004). An exception to this are the thrombolites at Highbourne Cay (Bahamas, Mobberley et al., 2015), karst-water tufa (Germany, Schneider et al., 2015) and Shark Bay (Australia, Wong et al., 2015). These thrombolites are formed through trapping of ooids and other existing carbonates within a network of filamentous cyanobacteria (Leptolyngbya, Microcoleus, Phormidium) covering their surface (Mobberley et al., 2015). Thereby they can provide additional precipitation surfaces within the biofilm or microbial mat, besides their calcifying sheaths.

Interestingly, the definition of stromatolites and thrombolites indicate the opposite developmental history. According to Kennard and James (1986) laminated stromatolites are formed by filamentous microbes in mat-like communities, which trap sediments and internally precipitate carbonate. Thrombolites on the other hand are characterized by individual clusters of coccoid, precipitating communities (Kennard and James, 1986). This suggests that there are differences between precipitating and preserved members of the community. A notion which is supported by the observed successions of bacterial biofilms on Highbourne Cay stromatolites (Baumgartner et al., 2009; Reid et al., 2000). Different members of the community are responsible for trapping, binding, and subsequent calcification of each stromatolite layer. Petryshyn et al. (2021) linked the different microbial taxa detected in 16S rRNA genes and metagenomes from stromatolites to different stages of stromatolite development. This follows the sequential action of builders, tenants, and squatters. According to this, the 
squatters and tenants degrade the cell and DNA remnants of the original builders, leaving behind only their own traces in the stromatolite (Petryshyn et al., 2021).

Based on this information, we propose the following model for the growing stromatolite at Westpool D. Gloeocapsa in the biofilm at the stromatolite surface represent the builders, which provide the initial localized biologically induced carbonate precipitation. The tenants are Salinivibrio and Francisella, which cause localized pH changes and influence precipitation (Al Disi et al., 2017). As the pond contains only low quantities of sediment, trapping and cementation of carbonate particles is unlikely. Sulphate reducers play no role in the precipitation process (Figure 7).

\subsection{Role of the water column in carbonate precipitation at Westpool D and Cinq Cases}

At Westpool D, the precipitation of carbonates may be supported by the moderately hypersaline water conditions and bacterial bloom within the water column. The reconstructed MAG, affiliated to Thiohalocapsa at the centre of the bloom, harbours genes for anoxygenic photosynthesis, sulphate reduction and thiosulphate oxidation (Chapter C.5). In the first instance, the bacterial bloom had a significant pH-lowering effect on the water column (Table 2). This indicates that $\mathrm{pH}$ reduction due to sulphide oxidation and/or sulphate reduction outweigh the $\mathrm{pH}$ increase of anoxygenic photosynthesis. During the bloom and its biological degradation immediately afterwards, conditions may therefore not favour carbonate precipitation. After the bloom, the situation may change, as Thiohalocapsa are able to deposit elemental sulphur in their cells (Anil Kumar et al., 2009; Hubas et al., 2017). Any sulphur globules that are released by the breakdown of the bloom, may provide post-mortem precipitation nuclei for abiogenic precipitation in the water column.

In addition to purple sulphur bacteria, other members of the water column, such as Psychroflexus, may influence carbonate precipitation. Psychroflexus ALD_RP9 was isolated from the Thiohalocapsa bloom (Chapter C.4). Microscopic analysis showed that its cells are encased in a jelly-like layer of EPS. The strategy to produce large amounts of protective EPS has been described for other members of its genus, including the type-strain Psychroflexus torquis isolated from Antarctic sea ice (Bowman et al., 1998; Feng et al., 2015). Our genomic analysis revealed additional 
EPS genes encoded in regions absent from other Psychroflexus genomes, suggesting that this is an adaptation to the high salinity and sun exposure in Westpool D (Chapter C.4). The degradation of large quantities of EPS produced by Psychroflexus and other members of the water column and bloom community will release EPS-bound $\mathrm{Ca}^{2+}$ into the already saturated water column. The calcium release can induce spontaneous abiotic precipitation in the water column or on the randomly ordered, degraded EPS matrix (Figure 7).

Our data on the water geochemistry of Cinq Cases was potentially influenced by a downpour of rain on the day of sampling. The rain, as well as its runoff from the surrounding area will have pooled at Cinq Cases leading to a dilution of the water column. In addition, the bacterial community did not suggest that precipitation inducing taxa, i.e., cyanobacteria, were particularly abundant in the water column. Assuming that dilution was caused by the rain, any precipitation that occurred within the water column at Cinq Cases is of an abiotic nature. Potential nucleation sites could be provided by microbes, such as Pontibacillus sp. ALD_SL1. This moderately halophilic bacterium had a high relative abundance in the water column (Chapter C.3) and is able to thrive at salinities up to $20 \%$. Upon degradation its endospores may provide nuclei for abiotic precipitation in the water column (Chapter C.4).

\section{Sediment microbial communities and contamination}

Anthropogenic contamination is an important topic in sediments studies. This includes both contamination from a methodological and a diagnostic point of view. The first case tackles potential biases caused by wet and dry lab methods, as well as potential reagent contaminations. The second aspect focuses on microbial communities that are frequently used to determine the effects of an anthropogenic impact on sediments. They are used either in the context of pollutants, such has hydrocarbons from oil spills (Dell'Anno et al., 2020; Rodriguez-R et al., 2015), or heavy metal contamination (Gough and Stahl, 2011; Quero et al., 2015). The aim is to understand potential effects on the base of the food chain, or to determine the microbial remediation potential for the contaminants. The second type of community studies assesses the microbial load in sediments. They aim to determine the sediments' potential as reservoir for infectious agents or existing level of human and other potential faecal contaminants (Boehm, 
Yamahara and Sassoubre, 2014; Cui et al., 2013; Hatvani et al., 2018; Kopprio et al., 2020).

\subsection{Method-based biases and contaminations}

Field-based studies are never perfectly sterile. While cleanliness and purity of many aspects can be controlled for in a laboratory environment, it is virtually impossible to avoid small amounts of contamination in the field. These may be introduced by the equipment, researcher, or pre-existing reagent contamination from the manufacturers (Davis et al., 2018; Knight et al., 2018). Even when everything is sterilized and decontaminated, small amounts of amplifiable DNA may persist on tools and in reagents or through cross-contamination, particularly when a high number of PCR cycles is used (Salter et al., 2014). Most of the time low amounts of contamination are not a problem, as they are masked by the, in comparison, large amount of input material. In low-biomass samples, DNA contamination is more relevant than in highbiomass samples and can even result in misleading microbiomes (Goffau et al., 2018; Perez-Muñoz et al., 2017). The low-biomass problem particularly affects biomedical studies (Perez-Muñoz et al., 2017), but also environmental samples from, e.g.: the deep biosphere (Peoples et al., 2019; Suzuki et al., 2020). In order to cope with potential biases, different approaches have been established. One method is the utilization of a relative abundance cut-off of $0.25-0.3 \%$ to remove spurious or less abundant contaminating sequences (Reitmeier et al., 2021; Willner et al., 2012). Another method is the exclusion of "known contaminants" (Peoples et al., 2019). This means postsequencing filtering of reads associated with taxa from the reagent microbiome or atypical environments. In the case of environmental samples this means filtering of reads by taxonomic affiliation. Known human or faecal-associated contaminants, such as Escherichia-Shigella, Pseudomonas and Vibrio are thereby excluded. Alternatively, statistical tools have been developed to remove contaminant taxonomic units based on the logic, that their abundance increases in low biomass sediments, or on their presence in control samples (Davis et al., 2018).

In some cases, the sediments and water samples studied in this thesis also harboured a low biomass. However, removal of specific taxa by known association was counterintuitive as this may remove real members of the community. For instance, Pseudomonas have been associated with reagent contamination (Salter et al., 2014), 
but also form a large proportion of the bacterial community in both pristine (Chapter C.3) and anthropogenically contaminated sediments (Rodriguez-R et al., 2015). In the case of Escherichia and other Enterobacteriaceae, the taxonomy cannot be fully resolved using V3-V4 16S rRNA gene primers or even primers amplifying the full sequence (Jovel et al., 2016). Furthermore, a "natural input" by the gut microbiota of the surrounding fauna on Aldabra cannot be excluded. We therefore decided against a filtering of known contaminants and evaluated the samples by merging replicates and using abundance cut-offs to investigate abundant community members. In the case of rare-biosphere members, which may be lost using abundance cut-offs, samples were evaluated in the ecological context of their environment, as recommended by Goffau et al. (2018).

\subsection{Environmental pollution and microbial community response}

With increasing global pollution, a large number of studies focus on microbial communities in relation to pollutants. Common pollutants of interest are heavy metals, including mercury or lead (Quero et al., 2015; Sun et al., 2013), as well as polycyclic aromatic hydrocarbons (PAHs) from oil spills (Rodriguez-R et al., 2015) and factoryor urban-associated sediments (Obi et al., 2016; Sun et al., 2013). Generally, a high proportion of Gammaproteobacteria and Desulfobacterota are found in these studies. Gammaproteobacteria are mostly linked to the degradation of PAHs (Obi et al., 2016; Sun et al., 2013), and certain members of this phylum have been shown to harbour the ability to degrade these (Dell'Anno et al., 2020; Mason et al., 2014). Desulfobacterota and Chloroflexota (Anaerolineaceae) were found at higher relative abundances in heavy metal contaminated sediments. This was proposed to be linked to sulphate reduction and anaerobic oxidation of methane while using methane or iron (Sun et al., 2013). It should be noted that these genera are highly prevalent in most sediments worldwide, including the pristine sediments of Aldabra. Unless individual strains or consortia are tested, as in (Dell'Anno et al., 2020), any association to contamination is likely tenuous.

In many cases, studies on microbial populations in polluted environments use a closely situated sediment as reference for comparison but ignore their different sediment settings. As the availability of organic matter or connectivity to the ocean 
may impact the community, as shown in Chapter C.3, the sediment setting first needs to be taken into consideration when analysing these environments. In the case of Lake Neusiedl for instance, mercury has been found to be enriched in plants and fish. In Chapters C.1 and C.2 we also detected Chloroflexi members, which have been shown to be hydrocarbon degraders (Dombrowski et al., 2017) and organohalide respirers (Hug et al., 2013). Yet, it is unlikely that their abundance is related to pollution in the lake and is rather linked to the fermentation of plant matter that has accumulated in the sediments (Chapter C.1). One common feature of many polluted environments is a decreased species richness in comparison to their control environments. This indicates that pollution has an inhibitory effect on microbial growth, favouring highly specialized or resilient taxa. In eutrophic environments a decrease in diversity may be observed when these are dominated by highly adapted and fast-growing community members. One solution to further disentangle the main drivers of polluted sediment communities is to study metagenomes to discover potential pollution adaptations. Genes conveying resistance to heavy metals, for instance, should be more prevalent in the polluted microbial community. Alternatively, functional arrays, such as the GeoChip, may provide this information without the need for metagenomes (Shi et al., 2019).

\subsection{Clinically relevant microbial pollution}

A third focal point of sediment studies is the detection of clinically relevant microbes in recreational environments, such as beaches (Boehm, Yamahara and Sassoubre, 2014; Cui et al., 2013) or lakes (Hatvani et al., 2018), and urbanized areas, such as the Karnaphuli estuary (Kopprio et al., 2020). The main bacterial taxa of interest comprise potentially pathogenic and opportunistic pathogenic organisms, such as Aeromonas, Escherichia, Salmonella, Shigella, and Vibrio, amongst others (Abia, Ubomba-Jaswa and Momba, 2016; Kopprio et al., 2020; Zhang et al., 2015; Zhang et al., 2020). Initial assessment within the microbial community is often done using 16S rRNA gene analysis to estimate the overall pathogenic load in sediments. In addition, counts of colony forming units (CFUs) and species-specific markers are used to capture the most important members (Cui et al., 2013; Hatvani et al., 2018; Kopprio et al., 2020). Sediments are targeted, as they are regarded as bacterial reservoirs. They essentially 
seed the water column at the marine or aquatic sites and trigger bacterial blooms and outbreaks under the right conditions (Criminger et al., 2007; Whitman and Nevers, 2003). It is therefore necessary to monitor bathing and recreational sites on a regular basis.

Input of clinically relevant taxa and particularly of faecal contaminants in the environment can occur through efflux from wastewater treatment plants (Hatvani et al., 2018), sewage (Kopprio et al., 2020), or agricultural run-off (Abia et al., 2016). In addition, natural faecal input from local and visiting birds and animals can lead to increased amounts of gut-associated taxa. This applies to touristic environments, such as Lake Neusiedl where Vibrio species may be introduced by migrant birds (Pretzer et al., 2017), as well as protected environments, such as Aldabra, where we detected an increase in phosphate levels and Arcobacter in mangrove sediments in the proximity of a bird colony (Chapter C.3). While the monitoring of potentially pathogenic taxa is important, it should be noted, that often only a few strains within a bacterial species lead to infection. For instance, only a few specific serogroups of Vibrio cholerae cause the cholera disease (Pretzer et al., 2017), while other Vibrio spp. are common and even abundant in the environment, including sediments (Chapter C.3), surface seawater (Wietz et al., 2010), marine rhizosphere (Criminger et al., 2007) and corals (Chimetto et al., 2008). This also applies to Escherichia-Shigella, which are difficult to distinguish using 16S rRNA gene amplicons (Devanga Ragupathi et al., 2018). Their ubiquity, growth-rates and robustness has led to the idea, that they may represent microbial weeds together with taxa, such as Pseudomonas putida, Mycrocystis aeruginosa, Salinibacter ruber, fungal Saccharomyces cerevisiae and Aspergillus spp. (Cray et al., 2013). Using these taxa as indicators for human and animal faecal pollution should therefore be carefully considered. Screening for specific serotypes for verification becomes a necessity for the verification of these data.

\section{Conclusion \& Outlook}

This study demonstrates the breadth of microbial communities in lacustrine and marine carbonate sediments. The data are based on 16S rRNA genes and transcripts, metagenomes and bacterial isolates, highlighting different aspects of the communities. $16 \mathrm{~S}$ rRNA gene analysis showed the transition of bacterial communities along 
biogeochemical gradients at Lake Neusiedl and the Aldabra Atoll. The data was supported by metagenome analysis, indicating the metabolic capabilities of abundant community members. Lastly, two bacterial isolates were characterised from a physiological and genomic standpoint and placed into the overall context of Aldabra. Together with an extensive geochemical dataset, our data highlight changes in microbial communities and their potential involvement in biogeochemical cycling, carbonate precipitation and dissolution.

Although taxonomically a comprehensive assessment of the bacterial communities was performed, additional studies are needed to fully understand their metabolic activity. On the one hand, the metagenomes should be investigated in more detail to uncover the metabolic potential of currently uncultured taxa. On the other hand, further isolate-based studies or enumeration of the community and specific functional genes using cell counts and qPCR may provide further evidence for our taxonomy-based observations.

Currently growing amounts of plastic pollution are threatening the natural beauty of the Aldabra Atoll. Further studies may therefore quantitatively assess the load of microplastics on the sediments and how these affect structure, function, and adaptation of the microbial communities.

\section{References}

Abia, A.L.K. et al. (2016) 'Quantitative microbial risk assessment (QMRA) shows increased public health risk associated with exposure to river water under conditions of riverbed sediment resuspension', The Science of the Total Environment, 566-567, pp. 1143-1151. doi: 10.1016/j.scitotenv.2016.05.155.

Abia, A.L.K., Ubomba-Jaswa, E. and Momba, M.N.B. (2016) 'Competitive survival of Escherichia coli, Vibrio cholerae, Salmonella typhimurium and Shigella dysenteriae in riverbed sediments', Microbial Ecology, 72(4), pp. 881-889. doi: 10.1007/s00248-016-0784y.

Al Disi, Z.A. et al. (2017) 'Evidence of a role for aerobic bacteria in high magnesium carbonate formation in the evaporitic environment of Dohat Faishakh Sabkha in Qatar', Frontiers in Environmental Science, 5. doi: 10.3389/fenvs.2017.00001.

Alderkamp, A.C., Sintes, E. and Herndl, G.J. (2006) 'Abundance and activity of major groups of prokaryotic plankton in the coastal North Sea during spring and summer', Aquatic Microbial Ecology, 45, pp. 237-246. doi: 10.3354/ame045237. 
Anil Kumar, P. et al. (2009) 'Thiohalocapsa marina sp. nov., from an Indian marine aquaculture pond', International Journal of Systematic and Evolutionary Microbiology, 59(Pt 9), pp. 2333-2338. doi: 10.1099/ijs.0.003053-0.

Arp, G., Reimer, A. and Reitner, J. (2001) 'Photosynthesis-induced biofilm calcification and calcium concentrations in Phanerozoic oceans', Science, 292(5522), pp. 1701-1704. doi: $10.1126 /$ science. 1057204 .

Baker, B.J. et al. (2020) 'Diversity, ecology and evolution of Archaea', Nature Microbiology, 5(7), pp. 887-900. doi: 10.1038/s41564-020-0715-z.

Baumgartner, L.K. et al. (2006) 'Sulfate reducing bacteria in microbial mats: Changing paradigms, new discoveries', Sedimentary Geology, 185(3-4), pp. 131-145. doi: 10.1016/j.sedgeo.2005.12.008.

Baumgartner, L.K. et al. (2009) 'Microbial diversity in modern marine stromatolites, Highborne Cay, Bahamas', Environmental Microbiology, 11(10), pp. 2710-2719. doi: 10.1111/j.1462-2920.2009.01998.x.

Berger, W.H. and Wefer, G. (2009) 'Marine biogenic sediments', in Gornitz, V. (ed.) Encyclopedia of Paleoclimatology and Ancient Environments. (Encyclopedia of Earth Sciences Series). Dordrecht: Springer, pp. 525-533. doi: 10.1007/978-1-4020-4411-3_131.

Bertagnolli, A.D. and Stewart, F.J. (2018) 'Microbial niches in marine oxygen minimum zones’, Nature Reviews. Microbiology, 16(12), pp. 723-729. doi: 10.1038/s41579-018-0087$\mathrm{z}$.

Bickert, T. (2009) 'Carbonate compensation depth', in Gornitz, V. (ed.) Encyclopedia of Paleoclimatology and Ancient Environments. (Encyclopedia of Earth Sciences Series). Dordrecht: Springer Netherlands, pp. 136-138. doi: 10.1007/978-1-4020-4411-3 33.

Boehm, A.B., Yamahara, K.M. and Sassoubre, L.M. (2014) 'Diversity and transport of microorganisms in intertidal sands of the California coast', Applied and Environmental Microbiology, 80(13), pp. 3943-3951. doi: 10.1128/AEM.00513-14.

Böer, S.I. et al. (2009) 'Time- and sediment depth-related variations in bacterial diversity and community structure in subtidal sands', The ISME Journal, 3(7), pp. 780-791. doi: 10.1038/ismej.2009.29.

Boetius, A. et al. (2000) 'A marine microbial consortium apparently mediating anaerobic oxidation of methane', Nature, 407(6804), pp. 623-626. doi: 10.1038/35036572.

Boros, E. et al. (2014) 'Salinity and ionic composition of the shallow astatic soda pans in the Carpathian Basin', Annales de Limnologie - International Journal of Limnology, 50(1), pp. 59-69. doi: 10.1051/limn/2013068.

Bourn, D. et al. (1999) 'The rise and fall of the Aldabran giant tortoise population', Proceedings. Biological Sciences, 266(1424), pp. 1091-1100. doi: 10.1098/rspb.1999.0748.

Bowman, J. (2006) 'The Methanotrophs - The families Methylococcaceae and Methylocystaceae', in Dworkin M., Falkow S., Rosenberg E., Schleifer KH., Stackebrandt E. (eds.) The Prokaryotes, 3rd edn. New York: Springer, pp. 266-289. doi: 10.1007/0-38730745-1_15.

Bowman, J.P. et al. (1998) 'Psychroflexus torquis gen. nov., sp. nov., a psychrophilic species from Antarctic sea ice, and reclassification of Flavobacterium gondwanense (Dobson et al. 1993) as Psychroflexus gondwanense gen. nov., comb. nov', Microbiology, 144 (Pt 6), pp. 1601-1609. doi: 10.1099/00221287-144-6-1601. 
Braithwaite, C. et al. (1989) 'Recent stromatolites in landlocked pools on Aldabra, Western Indian Ocean', Palaeogeography, Palaeoclimatology, Palaeoecology, 69, pp. 145-165. doi: 10.1016/0031-0182(89)90162-4.

Braithwaite, C.J.R. (2020) 'Last Interglacial changes in sea level on Aldabra, western Indian Ocean', Sedimentology, 67(6), pp. 3236-3258. doi: 10.1111/sed.12738.

Braithwaite, C.J.R., Taylor, J.D. and Kennedy, W.J. (1973) 'The evolution of an atoll: the depositional and erosional history of Aldabra', Philosophical Transactions of the Royal Society of London. B, Biological Sciences, 266(878), pp. 307-340. doi: 10.1098/rstb.1973.0051.

Brinkhoff, T., Giebel, H.-A. and Simon, M. (2008) 'Diversity, ecology, and genomics of the Roseobacter clade: a short overview', Archives of Microbiology, 189(6), pp. 531-539. doi: 10.1007/s00203-008-0353-y.

Brown, M.V. et al. (2012) 'Global biogeography of SAR11 marine bacteria', Molecular Systems Biology, 8, p. 595. doi: 10.1038/msb.2012.28.

Bunbury, N. et al. (2018) 'Late stage dynamics of a successful feral goat eradication from the UNESCO World Heritage site of Aldabra Atoll, Seychelles', Biological Invasions, 20(7), pp. 1735-1747. doi: 10.1007/s10530-017-1657-0.

Burdorf, L.D. et al. (2016) 'Long-distance electron transport by cable bacteria in mangrove sediments', Marine Ecology Progress Series, 545, pp. 1-8. doi: 10.3354/meps11635

Burt, A.J. et al. (2020) 'The costs of removing the unsanctioned import of marine plastic litter to small island states', Scientific Reports, 10(1), p. 14458. doi: 10.1038/s41598-020-71444-6.

Casaburi, G. et al. (2016) 'Characterization of the stromatolite microbiome from Little Darby Island, The Bahamas using predictive and whole shotgun metagenomic analysis', Environmental Microbiology, 18(5), pp. 1452-1469. doi: 10.1111/1462-2920.13094.

Chamizo, S. et al. (2020) 'Exopolysaccharide features influence growth success in biocrustforming Cyanobacteria, moving from liquid culture to sand microcosms', Frontiers in Microbiology, 11, p. 568224. doi: 10.3389/fmicb.2020.568224.

Chen, Y.-J. et al. (2021) 'Metabolic flexibility allows bacterial habitat generalists to become dominant in a frequently disturbed ecosystem', The ISME Journal. 15(10), pp. 2986-3004. doi: 10.1038/s41396-021-00988-w.

Chimetto, L.A. et al. (2008) 'Vibrios dominate as culturable nitrogen-fixing bacteria of the Brazilian coral Mussismilia hispida', Systematic and Applied Microbiology, 31(4), pp. 312 319. doi: 10.1016/j.syapm.2008.06.001.

Couradeau, E. et al. (2012) 'An early-branching microbialite cyanobacterium forms intracellular carbonates', Science, 336(6080), pp. 459-462. doi: 10.1126/science.1216171.

Cray, J.A. et al. (2013) 'The biology of habitat dominance; can microbes behave as weeds?' Microbial Biotechnology, 6(5), pp. 453-492. doi: 10.1111/1751-7915.12027.

Criminger, J.D. et al. (2007) 'Nitrogen fixation by Vibrio parahaemolyticus and its implications for a new ecological niche', Applied and Environmental Microbiology, 73(18), pp. 5959-5961. doi: 10.1128/AEM.00981-07.

Cui, H. et al. (2013) 'Spatial and temporal variation in enterococcal abundance and its relationship to the microbial community in Hawaii beach sand and water', Applied and Environmental Microbiology, 79(12), pp. 3601-3609. doi: 10.1128/AEM.00135-13. 
Davis, N.M. et al. (2018) 'Simple statistical identification and removal of contaminant sequences in marker-gene and metagenomics data', Microbiome, 6(1), p. 226. doi: 10.1186/s40168-018-0605-2.

Decho, A.W. and Gutierrez, T. (2017) 'Microbial extracellular polymeric substances (EPSs) in ocean systems', Frontiers in Microbiology, 8, p. 922. doi: 10.3389/fmicb.2017.00922

Degenhardt, J. et al. (2020) 'Seasonal dynamics of microbial diversity at a sandy high energy beach reveal a resilient core community', Frontiers in Marine Science, 7, p. 573570. doi: $10.3389 /$ fmars.2020.573570.

Dell'Anno, F. et al. (2020) 'Degradation of hydrocarbons and heavy metal reduction by marine bacteria in highly contaminated sediments', Microorganisms, 8(9), p. 1402. doi: 10.3390/microorganisms8091402.

Devanga Ragupathi, N.K. et al. (2018) 'Accurate differentiation of Escherichia coli and Shigella serogroups: challenges and strategies', New Microbes and New Infections, 21, pp. 5862. doi: 10.1016/j.nmni.2017.09.003.

Diamond, A.W. (1971) 'The ecology of the sea birds of Aldabra', Philosophical Transactions of the Royal Society of London. B, Biological Sciences, 260(836), pp. 561-571. Available at: http://www.jstor.org/stable/2417076.

Diaz et al. (2013) 'Bacterial community of oolitic carbonate sediments of the Bahamas Archipelago', Marine Ecology Progress Series, 485, pp. 9-24. doi: 10.3354/meps10359.

Dickson, A.G. (1992) 'The development of the alkalinity concept in marine chemistry', Marine Chemistry, 40(1-2), pp. 49-63. doi: 10.1016/0304-4203(92)90047-E.

Dombrowski, N. et al. (2017) 'Genomic insights into potential interdependencies in microbial hydrocarbon and nutrient cycling in hydrothermal sediments', Microbiome, 5(1), p. 106. doi: 10.1186/s40168-017-0322-2.

Donaldson, A. (1978) Studies on the terrestrial and freshwater algae of aldabra atoll. Doctoral. Durham University. Available at: http://etheses.dur.ac.uk/8442/.

Donaldson, A. and Whitton, B.A. (1977) 'Chemistry of freshwater pools on Aldabra', Atoll Research Bulletin, 213, pp. 1-25. doi: 10.5479/si.00775630.213.1.

Drew, E.A. (1972) 'The biology and physiology of alga-invertebrate symbioses. I. Carbon fixation in Cassiopea sp. at Aldabra Atoll', Journal of Experimental Marine Biology and Ecology, 9(1), pp. 65-69. doi: 10.1016/0022-0981(72)90007-X.

Dupraz, C. et al. (2004) 'Microbe-mineral interactions: early carbonate precipitation in a hypersaline lake (Eleuthera Island, Bahamas)', Sedimentology, 51(4), pp. 745-765. doi: 10.1111/j.1365-3091.2004.00649.x.

Dupraz, C. et al. (2009) 'Processes of carbonate precipitation in modern microbial mats', Earth-Science Reviews, 96(3), pp. 141-162. doi: 10.1016/j.earscirev.2008.10.005

Dwulit-Smith, J.R. et al. (2018) 'acI Actinobacteria assemble a functional actinorhodopsin with natively synthesized retinal', Applied and Environmental Microbiology, 84(24), pp. e01678-18. doi: 10.1128/aem.01678-18.

Dyksma, S. et al. (2016) 'Ubiquitous Gammaproteobacteria dominate dark carbon fixation in coastal sediments', The ISME Journal, 10(8), pp. 1939-1953. doi: 10.1038/ismej.2015.257

Falkowski, P.G., Fenchel, T. and Delong, E.F. (2008) 'The microbial engines that drive Earth's biogeochemical cycles', Science, 320(5879), pp. 1034-1039. doi: 10.1126/science.1153213. 
Farrow, G.E. (1971) 'Back-reef and lagoonal environments of Aldabra Atoll distinguished by their crustacean burrows', in Stoddart, D.R. and Yonge, M. (eds.) Regional variation in Indian Ocean Coral Reefs. (Symposia of the zoological society of London, 28. London: Academic Press, pp. 455-500.

Feng, S. et al. (2015) 'Proteomic insight into functional changes of proteorhodopsincontaining bacterial species Psychroflexus torquis under different illumination and salinity levels', Journal of Proteome Research, 14(9), pp. 3848-3858. doi: 10.1021/acs.jproteome.5b00241.

Foti, M. et al. (2007) 'Diversity, activity, and abundance of sulfate-reducing bacteria in saline and hypersaline soda lakes', Applied and Environmental Microbiology, 73(7), pp. 2093-2100. doi: 10.1128/AEM.02622-06.

Frioux, C. et al. (2020) 'From bag-of-genes to bag-of-genomes: metabolic modelling of communities in the era of metagenome-assembled genomes', Computational and Structural Biotechnology Journal, 18, pp. 1722-1734. doi: 10.1016/j.csbj.2020.06.028.

Fryer, J.C.F. (1911) 'No. XIX.-The structure and formation of Aldabra and neighbouring islands - with notes on their flora and fauna', Transactions of the Linnean Society of London. 2nd Series: Zoology, 14(3), pp. 397-442. doi: 10.1111/j.1096-3642.1911.tb00536.x.

Fussmann, D. et al. (2020) 'Authigenic formation of $\mathrm{Ca}-\mathrm{Mg}$ carbonates in the shallow alkaline Lake Neusiedl, Austria', Biogeosciences, 17(7), pp. 2085-2106. doi: 10.5194/bg-17-20852020.

Gaillard, C., Bernier, P. and Gruet, Y. (1994) 'Le lagon d'Aldabra (Seychelles, Océan indien), un modèle pour le paléoenvironnement de Cerin (Kimméridgien supérieur, Jura méridional, France)', Geobios, 27, pp. 331-348. doi: 10.1016/S0016-6995(94)80050-2.

Gallagher, K.L. et al. (2012) 'Inside the alkalinity engine: the role of electron donors in the organomineralization potential of sulfate-reducing bacteria', Geobiology, 10(6), pp. 518-530. doi: 10.1111/j.1472-4669.2012.00342.x.

Galushko, A. and Kuever, J. (2015) 'Desulfovibrio', in Whitman, W.B. et al. (eds.) Bergey's Manual of Systematics of Archaea and Bacteria: Wiley, pp. 1-10. doi: 10.1002/9781118960608.gbm01035.pub2.

Garcia-Pichel, F., Ramírez-Reinat, E. and Gao, Q. (2010) 'Microbial excavation of solid carbonates powered by P-type ATPase-mediated transcellular $\mathrm{Ca}^{2+}$ transport', Proceedings of the National Academy of Sciences of the United States of America, 107(50), pp. 21749-21754. doi: 10.1073/pnas.1011884108.

Gibson, C. and Phillipson, J. (1983) 'The vegetation of Aldabra Atoll: preliminary analysis and explanation of the vegetation map', Philosophical Transactions of the Royal Society of London. B, Biological Sciences, 302(1109), pp. 201-235. doi: 10.1098/rstb.1983.0051.

Giovannoni, S.J. and Stingl, U. (2005) 'Molecular diversity and ecology of microbial plankton', Nature, 437(7057), pp. 343-348. doi: 10.1038/nature04158.

Gleason, F.H. et al. (2017) 'The roles of endolithic fungi in bioerosion and disease in marine ecosystems. I. General concepts', Mycology, 8(3), pp. 205-215. doi: 10.1080/21501203.2017.1352049.

Glunk, C. et al. (2011) 'Microbially mediated carbonate precipitation in a hypersaline lak., Big Pond (Eleuthera, Bahamas)', Sedimentology, 58(3), pp. 720-736. doi: 10.1111/j.13653091.2010.01180.x. 
Gobet, A. et al. (2012) 'Diversity and dynamics of rare and of resident bacterial populations in coastal sands', The ISME Journal, 6(3), pp. 542-553. doi: 10.1038/ismej.2011.132.

Goffau, M.C. de et al. (2018) 'Recognizing the reagent microbiome', Nature Microbiology, 3(8), pp. 851-853. doi: 10.1038/s41564-018-0202-y.

González-Domenech, C.M. et al. (2010) 'Denitrification as an important taxonomic marker within the genus Halomonas', Systematic and Applied Microbiology, 33(2), pp. 85-93. doi: 10.1016/j.syapm.2009.12.001.

Gough, H.L. and Stahl, D.A. (2011) 'Microbial community structures in anoxic freshwater lake sediment along a metal contamination gradient', The ISME Journal, 5(3), pp. 543-558. doi: 10.1038 /ismej.2010.132.

Griffin, D. (1974) 'The Aldabra research station', Notes and Records of the Royal Society of London, 29(1), pp. 111-119. doi: 10.1098/rsnr.1974.0008.

Grubb, P. (1971) 'The growth, ecology and population structure of giant tortoises on Aldabra', Philosophical Transactions of the Royal Society of London. B, Biological Sciences, 260(836), pp. 327-372. doi: 10.1098/rstb.1971.0018.

Hamylton, S. et al. (2018) Mapping the lagoon at aldabra atoll, western Indian Ocean, Atoll Research Bulletin, 619, pp. 45-59.

Hamylton, S., Spencer, T. and Hagan, A.B. (2012) 'Spatial modelling of benthic cover using remote sensing data in the Aldabra lagoon, western Indian Ocean', Marine Ecology Progress Series, 460, pp. 35-47. doi: 10.3354/meps09779.

Hamylton, S.M., Hagan, A.B. and Doak, N. (2012) 'Observations of dugongs at Aldabra Atoll, western Indian Ocean: lagoon habitat mapping and spatial analysis of sighting records', International Journal of Geographical Information Science, 26(5), pp. 839-853. doi: 10.1080/13658816.2011.616510.

Hatvani, I.G. et al. (2018) 'Hotspots and main drivers of fecal pollution in Neusiedler See, a large shallow lake in Central Europe', Environmental Science and Pollution Research International, 25(29), pp. 28884-28898. doi: 10.1007/s11356-018-2783-7.

Haupt, P. (2020) Reef fish associations with benthic habitats at a remote protected coral reef ecosystem in the Western Indian Ocean-Aldabra Atoll, Seychelles. Doctoral thesis. Rhodes University. Available at: http://hdl.handle.net/10962/141629.

Haverkamp, P.J. et al. (2017) 'Giant tortoise habitats under increasing drought conditions on Aldabra Atoll-Ecological indicators to monitor rainfall anomalies and related vegetation activity', Ecological Indicators, 80, pp. 354-362. doi: 10.1016/j.ecolind.2017.05.029.

He, J. et al. (2018) 'Insights into biomethane production and microbial community succession during semi-continuous anaerobic digestion of waste cooking oil under different organic loading rates', $A M B$ Express, 8(1), p. 92. doi: 10.1186/s13568-018-0623-2.

Hesse, R. and Schacht, U. (2011) 'Early diagenesis of deep-sea sediments', in Deep-Sea Sediments. (Developments in Sedimentology): Elsevier, 63, pp. 557-713. doi: 10.1016/B9780-444-53000-4.00009-3.

Hilairy E. H. (2018) 'Biogeochemistry', in Encyclopedia of Geochemistry (Encyclopedia of Earth Sciences): Springer, Cham, pp. 1-4. doi: 10.1007/978-3-319-39193-9_169-1. 
Hoyningen-Huene, A.J.E. von et al. (2019) 'Bacterial succession along a sediment porewater gradient at Lake Neusiedl in Austria', Scientific Data, 6(1), p. 163. doi: 10.1038/s41597-0190172-9.

Hubas, C. et al. (2017) 'A nanoscale study of carbon and nitrogen fluxes in mats of purple sulfur bacteria: Implications for carbon cycling at the surface of coastal sediments', Frontiers in Microbiology, 8, p. 1995. doi: 10.3389/fmicb.2017.01995.

Hug, L.A. et al. (2013) 'Community genomic analyses constrain the distribution of metabolic traits across the Chloroflexi phylum and indicate roles in sediment carbon cycling', Microbiome, 1, p. 22. doi: 10.1186/2049-2618-1-22.

Hug, L.A. et al. (2016) 'A new view of the tree of life', Nature Microbiology, 1, p. 16048. doi: 10.1038/nmicrobiol.2016.48.

Hughes, R.N. and Gamble, J.C. (1977) 'A quantitative survey of the biota of intertidal soft substrata on Aldabra Atoll, Indian Ocean', Philosophical Transactions of the Royal Society of London. B, Biological Sciences, 279(965), pp. 327-355. doi: 10.1098/rstb.1977.0093.

Imhoff, J.F. and Hiraishi, A. (2005) 'Aerobic bacteria containing bacteriochlorophyll and belonging to the Alphaproteobacteria', in Brenner D.J., Krieg N.R., Staley J.T., Garrity G.M. (eds.) Bergey's Manual of Systematic Bacteriology: Boston, Springer, pp. 1-7. doi: 10.1007/0387-28021-9_16.

Jirsa, F. et al. (2014) 'Total mercury in sediments, macrophytes, and fish from a shallow steppe lake in eastern Austria', Chemistry \& Biodiversity, 11(8), pp. 1263-1275. doi: $10.1002 / \mathrm{cbdv} .201400172$.

Jochum, L.M. et al. (2018) 'Single-cell genomics reveals a diverse metabolic potential of uncultivated Desulfatiglans-related Deltaproteobacteria widely distributed in marine sediment', Frontiers in Microbiology, 9, p. 2038. doi: 10.3389/fmicb.2018.02038.

Jørgensen, B.B. (2019) 'Unravelling the sulphur cycle of marine sediments', Environmental Microbiology, 21(10), pp. 3533-3538. doi: 10.1111/1462-2920.14721.

Jørgensen, B.B., Findlay, A.J. and Pellerin, A. (2019) 'The biogeochemical sulfur cycle of marine sediments', Frontiers in Microbiology, 10, p. 849. doi: 10.3389/fmicb.2019.00849.

Jørgensen, B.B. and Kasten, S. (2006) 'Sulfur cycling and methane oxidation', in Schulz, H.D. and Zabel, M. (eds.) Marine Geochemistry. Berlin/Heidelberg: Springer-Verlag, pp. 271-309. doi: 10.1007/3-540-32144-6_8.

Jovel, J. et al. (2016) 'Characterization of the gut microbiome using 16S or shotgun metagenomics', Frontiers in Microbiology, 7, p. 459. doi: 10.3389/fmicb.2016.00459.

Kartal, B. et al. (2013) 'How to make a living from anaerobic ammonium oxidation', FEMS Microbiology Reviews, 37(3), pp. 428-461. doi: 10.1111/1574-6976.12014.

Kazmierczak, J. and Kempe, S. (2006) 'Genuine modern analogues of Precambrian stromatolites from caldera lakes of Niuafo'ou Island, Tonga', Die Naturwissenschaften, 93(3), pp. 119-126. doi: 10.1007/s00114-005-0066-x.

Kennard, J.M. and James, N.P. (1986) 'Thrombolites and stromatolites: two distinct types of microbial structures', PALAIOS, 1(5), p. 492. doi: 10.2307/3514631.

Kensley, B. (1988) 'Preliminary observation on the isopod crustacean fauna of Aldabra Atoll', Bulletin of the Biological Society of Washington, 8, 80-44. 
Knight, R. et al. (2018) 'Best practices for analysing microbiomes', Nature Reviews. Microbiology, 16(7), pp. 410-422. doi: 10.1038/s41579-018-0029-9.

Kopprio, G.A. et al. (2020) 'Vibrio and bacterial communities across a pollution gradient in the Bay of Bengal: Unraveling their biogeochemical drivers', Frontiers in Microbiology, 11, p. 594. doi: 10.3389/fmicb.2020.00594.

Krachler, R. et al. (2018) 'Uranium concentrations in sediment pore waters of Lake Neusiedl, Austria', The Science of the Total Environment, 633, pp.981-988. doi: 10.1016/j.scitotenv.2018.03.259.

Kuever, J. (2014) 'The Family Syntrophobacteraceae', in Rosenberg, E., DeLong E.F., Lory S., Stackebrandt E., Thompson F. (ed.) The Prokaryotes, 4th edn. Berlin, Heidelberg: Springer, pp. 289-299. doi: 10.1007/978-3-642-39044-9_268.

Kuypers, M.M.M., Marchant, H.K. and Kartal, B. (2018) 'The microbial nitrogen-cycling network', Nature Reviews. Microbiology, 16(5), pp. 263-276. doi: 10.1038/nrmicro.2018.9.

Lalucat, J. et al. (2006) 'Biology of Pseudomonas stutzeri', Microbiology and Molecular Biology Reviews, 70(2), pp. 510-547. doi: 10.1128/mmbr.00047-05.

Littler, M.M. and Littler, D.S. (2011) 'Algae, blue-green boring', in Hopley, D. (ed.) Encyclopedia of modern coral reefs. (Encyclopedia of Earth Sciences Series). Dordrecht: Springer, pp. 18-20. doi: 10.1007/978-90-481-2639-2_173.

Liu, X. et al. (2020) 'Characterization of aerobic denitrification genome sequencing of Vibrio parahaemolyticus strain HA2 from recirculating mariculture system in China', Aquaculture, 526, p. 735295. doi: 10.1016/j.aquaculture.2020.735295.

Lloyd, K.G. et al. (2018) 'Phylogenetically novel uncultured microbial cells dominate Earth microbiomes', MSystems, 3, pp. e00055-18. doi: 10.1128/mSystems.00055-18.

Lloyd, K.G. (2021) 'Time as a microbial resource', Environmental Microbiology Reports, 13(1), pp. 18-21. doi: 10.1111/1758-2229.12892.

López-García, P. et al. (2005) 'Bacterial diversity and carbonate precipitation in the giant microbialites from the highly alkaline Lake Van, Turkey', Extremophiles: Life Under Extreme Conditions, 9(4), pp. 263-274. doi: 10.1007/s00792-005-0457-0.

Löscher, C.R. et al. (2016) 'Water column biogeochemistry of oxygen minimum zones in the eastern tropical North Atlantic and eastern tropical South Pacific oceans', Biogeosciences, 13(12), pp. 3585-3606. doi: 10.5194/bg-13-3585-2016.

Mackenzie, F.T. and Andersson, A.J. (2011) 'Biological control on diagenesis: Influence of bacteria and relevance to ocean acidification', in Reitner, J. and Thiel, V. (eds.) Encyclopedia of Geobiology. (Encyclopedia of Earth Sciences Series). Dordrecht: Springer, pp. 137-143. doi: 10.1007/978-1-4020-9212-1 73.

Magyar, N. et al. (2013) 'Application of multivariate statistical methods in determining spatial changes in water quality in the Austrian part of Neusiedler See', Ecological Engineering, 55, pp. 82-92. doi: 10.1016/j.ecoleng.2013.02.005.

Mann, S. (2001) Biomineralization: Principles and Concepts in Bioinorganic Materials Chemistry. (Oxford Chemistry Masters: 5). Oxford: Oxford University Press.

Marchant, H.K. et al. (2017) 'Denitrifying community in coastal sediments performs aerobic and anaerobic respiration simultaneously', The ISME Journal, 11(8), pp. 1799-1812. doi: 10.1038/ismej.2017.51. 
Martin, D. et al. (2013) 'Carbonate precipitation under pressure for bioengineering in the anaerobic subsurface via denitrification', Environmental Science \& Technology, 47(15), pp. 8692-8699. doi: 10.1021/es401270q.

Mason, O.U. et al. (2014) 'Metagenomics reveals sediment microbial community response to Deepwater Horizon oil spill', The ISME Journal, 8(7), pp. 1464-1475. doi: 10.1038/ismej.2013.254.

McCormack, J. et al. (2018) 'Controls on cyclic formation of quaternary early diagenetic dolomite', Geophysical Research Letters, 45(8), pp.3625-3634. doi: 10.1002/2018GL077344.

McIlroy, S.J. et al. (2017) 'Culture-independent analyses reveal novel Anaerolineaceae as abundant primary fermenters in anaerobic digesters treating waste activated sludge', Frontiers in Microbiology, 8, p. 1134. doi: 10.3389/fmicb.2017.01134.

Mobberley, J.M. et al. (2015) 'Inner workings of thrombolites: spatial gradients of metabolic activity as revealed by metatranscriptome profiling', Scientific Reports, 5, p. 12601. doi: $10.1038 /$ srep 12601 .

Monard, C. et al. (2016) 'Habitat generalists and specialists in microbial communities across a terrestrial-freshwater gradient', Scientific reports, 6(1). doi: 10.1038/srep37719.

Montañez, I.P. and Crossey, L.J. (2018) 'Diagenesis', in White, W.M. (ed.) Encyclopedia of Geochemistry. (Encyclopedia of Earth Sciences Series). Cham: Springer, pp. 353-362. doi: 10.1007/978-3-319-39312-4_35.

Monteil, C.L. et al. (2021) 'Intracellular amorphous Ca-carbonate and magnetite biomineralization by a magnetotactic bacterium affiliated to the Alphaproteobacteria', The ISME Journal, 15(1), pp. 1-18. doi: 10.1038/s41396-020-00747-3.

Moran, M.A. (2015) 'The global ocean microbiome', Science, 350(6266), aac8455. doi: $10.1126 /$ science.aac8455.

Müller, G., Irion, G. and Förstner, U. (1972) 'Formation and diagenesis of inorganic Ca-Mg carbonates in the lacustrine environment', Die Naturwissenschaften, 59(4), pp. 158-164. doi: 10.1007/BF00637354.

Musat, N. et al. (2006) 'Microbial community structure of sandy intertidal sediments in the North Sea, Sylt-Rømø Basin, Wadden Sea', Systematic and Applied Microbiology, 29(4), pp. 333-348. doi: 10.1016/j.syapm.2005.12.006.

Muynck, W. de et al. (2013) 'Influence of temperature on the effectiveness of a biogenic carbonate surface treatment for limestone conservation', Applied Microbiology and Biotechnology, 97(3), pp. 1335-1347. doi: 10.1007/s00253-012-3997-0.

Nelson, C.S., Keane, S.L. and Head, P.S. (1988) 'Non-tropical carbonate deposits on the modern New Zealand shelf', Sedimentary Geology, 60(1-4), pp. 71-94. doi: 10.1016/00370738(88)90111-X.

Obi, C.C. et al. (2016) 'Microbial communities in sediments of Lagos Lagoon, Nigeria: Elucidation of community structure and potential impacts of contamination by municipal and industrial wastes', Frontiers in Microbiology, 7, p. 1213. doi: 10.3389/fmicb.2016.01213.

Oceanlife S.r.1 (2017) Oceanlife Water Salinity Converter. Available at: https://www.oceanlife.it/index.php/en/19-notizie/370-water-salinity-converter-en (Accessed: 27 July 2021). 
O'Reilly, S.S. et al. (2017) 'Molecular biosignatures reveal common benthic microbial sources of organic matter in ooids and grapestones from Pigeon Cay, The Bahamas', Geobiology, 15(1), pp. 112-130. doi: 10.1111/gbi.12196.

Pederson, C.L. et al. (2019) 'Deposition and early diagenesis of microbial mud in the Florida Everglades', Sedimentology, 66(6), pp. 1989-2010. doi: 10.1111/sed.12569.

Peoples, L.M. et al. (2019) 'Microbial community diversity within sediments from two geographically separated hadal trenches', Frontiers in Microbiology, 10, p. 347. doi: 10.3389/fmicb.2019.00347.

Perez-Muñoz, M.E. et al. (2017) 'A critical assessment of the "sterile womb" and "in utero colonization" hypotheses: implications for research on the pioneer infant microbiome', Microbiome, 5(1), p. 48. doi: 10.1186/s40168-017-0268-4.

Perry, C.T. et al. (2011) 'Fish as major carbonate mud producers and missing components of the tropical carbonate factory', Proceedings of the National Academy of Sciences of the United States of America, 108(10), pp. 3865-3869. doi: 10.1073/pnas.1015895108.

Pester, M., Schleper, C. and Wagner, M. (2011) 'The Thaumarchaeota: an emerging view of their phylogeny and ecophysiology', Current Opinion in Microbiology, 14(3), pp. 300-306. doi: 10.1016/j.mib.2011.04.007.

Petriglieri, F. et al. (2018) 'In situ visualisation of the abundant Chloroflexi populations in full-scale anaerobic digesters and the fate of immigrating species', PloS One, 13(11), e0206255. doi: 10.1371/journal.pone.0206255.

Petryshyn, V.A. et al. (2021) 'Builders, tenants, and squatters: the origins of genetic material in modern stromatolites', Geobiology, 19(3), pp. 261-277. doi: 10.1111/gbi.12429.

Pohlner, M. et al. (2017) 'The biogeographical distribution of benthic Roseobacter group members along a Pacific transect is structured by nutrient availability within the sediments and primary production in different oceanic provinces', Frontiers in Microbiology, 8, p. 2550. doi: 10.3389/fmicb.2017.02550.

Potts, M. (1977) Studies on blue-green algae and photosynthetic bacteria in the lagoon of Aldabra Atoll. Doctoral thesis. Durham University.

Potts, M. and Whitton, B.A. (1977) 'Nitrogen fixation by blue-green algal communities in the intertidal zone of the lagoon of Aldabra Atoll', Oecologia, 27(4), pp. 275-283. doi: 10.1007/BF00345560.

Potts, M. and Whitton, B.A. (1979a) 'pH and Eh on Aldabra atoll 1. comparison of marine and freshwater environments', Hydrobiologia, 67(1), pp. 11-17. doi: 10.1007/BF00020872.

Potts, M. and Whitton, B.A. (1979b) ' $\mathrm{pH}$ and Eh on Aldabra Atoll 2. Intertidal photosynthetic microbial communities showing zonation', Hydrobiologia, 67(2), pp.99-105. doi: 10.1007/BF00126708.

Potts, M. and Whitton, B.A. (1980) 'Vegetation of the intertidal zone of the lagoon of Aldabra, with particular reference to the photosynthetic prokaryotic communities', Proceedings of the Royal Society of London. Series B. Biological Sciences, 208(1170), pp. 13-55. doi: 10.1098/rspb.1980.0041.

Pretzer, C. et al. (2017) 'High genetic diversity of Vibrio cholerae in the European lake Neusiedler See is associated with intensive recombination in the reed habitat and the longdistance transfer of strains', Environmental Microbiology, 19(1), pp.328-344. doi: $10.1111 / 1462-2920.13612$. 
Probandt, D. et al. (2017) 'Permeability shapes bacterial communities in sublittoral surface sediments', Environmental Microbiology, 19(4), pp. 1584-1599. doi: 10.1111/14622920.13676.

Probandt, D. et al. (2018) 'Microbial life on a sand grain: from bulk sediment to single grains', The ISME Journal, 12(2), pp. 623-633. doi: 10.1038/ismej.2017.197.

Quero, G.M. et al. (2015) 'Patterns of benthic bacterial diversity in coastal areas contaminated by heavy metals, polycyclic aromatic hydrocarbons (PAHs) and polychlorinated biphenyls (PCBs)', Frontiers in microbiology, 6, p. 1053. doi: 10.3389/fmicb.2015.01053.

Range to Reef Environmental (2016) Aldabra Atoll Management Plan. Available at: https://www.sif.sc/sites/default/files/downloads/Aldabra\%20Atoll\%20Management\%20Plan. pdf.

Reeburgh, W.S. (2007) 'Oceanic methane biogeochemistry', Chemical Reviews, 107(2), pp. 486-513. doi: 10.1021/cr050362v.

Reid, R.P. et al. (2000) 'The role of microbes in accretion, lamination and early lithification of modern marine stromatolites', Nature, 406(6799), pp. 989-992. doi: 10.1038/35023158.

Reimer, A. and Arp, G. (2011) 'Alkalinity', in Reitner, J. and Thiel, V. (eds.) Encyclopedia of Geobiology. (Encyclopedia of Earth Sciences Series). Dordrecht: Springer, pp. 20-24. doi: 10.1007/978-1-4020-9212-1_8.

Reitmeier, S. et al. (2021) 'Handling of spurious sequences affects the outcome of highthroughput 16S rRNA gene amplicon profiling', ISME Communications, 1, p. 31. doi: 10.1038/s43705-021-00033-z.

Riding, R. (1977) 'Calcified Plectonema (Blue-Green Algae), a recent example of Girvanella from Aldabra Atoll', Paleonotology, 20, pp. 33-46.

Riding, R. (2006) 'Cyanobacterial calcification, carbon dioxide concentrating mechanisms, and Proterozoic Cambrian changes in atmospheric composition', Geobiology, 4(4), pp. 299316. doi: 10.1111/j.1472-4669.2006.00087.x.

Riding, R.E. and Awramik, S.M. (eds.) (2000) Microbial Sediments. Berlin, Heidelberg: Springer Berlin Heidelberg.

Rinke, C. et al. (2019) 'A phylogenomic and ecological analysis of the globally abundant Marine Group II archaea (Ca. Poseidoniales ord. nov.)', The ISME Journal, 13(3), pp. 663675. doi: 10.1038/s41396-018-0282-y.

Rodriguez-R, L.M. et al. (2015) 'Microbial community successional patterns in beach sands impacted by the Deepwater Horizon oil spill', The ISME Journal, 9, pp. 1928-1940. doi: 10.1038/ismej.2015.5.

Rusch, A. and Gaidos, E. (2013) 'Nitrogen-cycling bacteria and archaea in the carbonate sediment of a coral reef', Geobiology, 11(5), pp. 472-484. doi: 10.1111/gbi.12048.

Russell, J.A. et al. (2014) 'Prokaryote populations of extant microbialites along a depth gradient in Pavilion Lake, British Columbia, Canada', Geobiology, 12(3), pp. 250-264. doi: 10.1111/gbi.12082.

Saghaï, A. et al. (2016) 'Comparative metagenomics unveils functions and genome features of microbialite-associated communities along a depth gradient', Environmental Microbiology, 18(12), pp. 4990-5004. doi: 10.1111/1462-2920.13456. 
Salter, S.J. et al. (2014) 'Reagent and laboratory contamination can critically impact sequencebased microbiome analyses', BMC Biology, 12, p. 87. doi: 10.1186/s12915-014-0087-z.

Schmitt, S. et al. (2019) 'Salinity, microbe and carbonate mineral relationships in brackish and hypersaline lake sediments: A case study from the tropical Pacific coral atoll of Kiritimati', The Depositional Record, 5(2), pp. 212-229. doi: 10.1002/dep2.71.

Schneider, D. et al. (2013) 'Phylogenetic analysis of a microbialite-forming microbial mat from a hypersaline lake of the Kiritimati atoll, Central Pacific', PloS One, 8(6), e66662. doi: 10.1371/journal.pone.0066662.

Schneider, D. et al. (2015) 'Metagenomic and metatranscriptomic analyses of bacterial communities derived from a calcifying karst water creek biofilm and tufa', Geomicrobiology Journal, 32(3-4), pp. 316-331. doi: 10.1080/01490451.2014.907376.

Schroll, E. and Wieden, P. (1960) 'Eine rezente Bildung von Dolomit im Schlamm des Neusiedler Sees', Tschermaks Mineralogische und Petrographische Mitteilungen, 7(3), pp. 286-289. doi: 10.1007/BF01127917.

Shi, Z. et al. (2019) 'Functional gene array-based ultrasensitive and quantitative detection of microbial populations in complex communities', MSystems, 4(4). doi: 10.1128/msystems.00296-19.

Smith, A.M. (1998) 'Carbonate sediments', in Geochemistry. (Encyclopedia of Earth Science). Dordrecht: Springer, pp. 73-75. doi: 10.1007/1-4020-4496-8_47.

Soja, G. et al. (2013) 'Climate impacts on water balance of a shallow steppe lake in Eastern Austria (Lake Neusiedl)', Journal of Hydrology, 480, pp. 115-124. doi: 10.1016/j.jhydrol.2012.12.013.

Starnawski, P. et al. (2017) 'Microbial community assembly and evolution in subseafloor sediment', Proceedings of the National Academy of Sciences of the United States of America, 114(11), pp. 2940-2945. doi: 10.1073/pnas.1614190114.

Stocks-Fischer, S., Galinat, J.K. and Bang, S.S. (1999) 'Microbiological precipitation of $\mathrm{CaCO}_{3}{ }^{3}$, Soil Biology and Biochemistry, 31(11), pp. 1563-1571. doi: 10.1016/S00380717(99)00082-6.

Stoddart, D. et al. (1971) 'Geomorphology of Aldabra Atoll', Philosophical Transactions of the Royal Society of London. B, Biological Sciences, 260(836), pp.31-66. doi: 10.1098/rstb.1971.0006.

Stoddart, D.R. (1968) 'The Aldabra affair', Biological Conservation, 1(1), pp. 63-69. doi: 10.1016/0006-3207(68)90021-9.

Strohm, T.O. et al. (2007) 'Growth yields in bacterial denitrification and nitrate ammonification', Applied and Environmental Microbiology, 73(5), pp. 1420-1424. doi: 10.1128/AEM.02508-06.

Sun, M.Y. et al. (2013) 'Core sediment bacteria drive community response to anthropogenic contamination over multiple environmental gradients', Environmental Microbiology, 15(9), pp. 2517-2531. doi: 10.1111/1462-2920.12133.

Sunagawa, S. et al. (2015) 'Ocean plankton. Structure and function of the global ocean microbiome', Science, 348(6237), p. 1261359. doi: 10.1126/science.1261359. 
Suzuki, Y. et al. (2020) 'Deep microbial proliferation at the basalt interface in 33.5-104 million-year-old oceanic crust', Communications Biology, 3(1), p. 136. doi: 10.1038/s42003020-0860-1.

Taylor, H.B. and Kurtz, H.D. (2020) 'Microbial community structure shows differing levels of temporal stability in intertidal beach sands of the grand strand region of South Carolina', PloS One, 15(2), e0229387. doi: 10.1371/journal.pone.0229387.

Teeling, H. et al. (2012) 'Substrate-controlled succession of marine bacterioplankton populations induced by a phytoplankton bloom', Science, 336(6081), pp. 608-611. doi: $10.1126 /$ science. 1218344 .

Thompson, J.B. et al. (1997) 'Whiting events: biogenic origin due to the photosynthetic activity of cyanobacterial picoplankton', Limnology and Oceanography, 42(1), pp. 133-141. doi: 10.4319/1o.1997.42.1.0133.

Thomson, J., Walton and A. (1972) 'Redetermination of chronology of Aldabra Atoll by 230Th/234U dating', Nature, 240(5377), pp. 145-146. doi: 10.1038/240145a0.

Torti, A., Lever, M.A. and Jørgensen, B.B. (2015) 'Origin, dynamics, and implications of extracellular DNA pools in marine sediments', Marine Genomics, 24(Pt 3), pp. 185-196. doi: 10.1016/j.margen.2015.08.007.

Trojan, D. et al. (2016) 'A taxonomic framework for cable bacteria and proposal of the candidate genera Electrothrix and Electronema', Systematic and Applied Microbiology, 39(5), pp. 297-306. doi: 10.1016/j.syapm.2016.05.006.

Urbanczyk, H., Ast, J.C. and Dunlap, P.V. (2011) 'Phylogeny, genomics, and symbiosis of Photobacterium', FEMS Microbiology Reviews, 35(2), pp. 324-342. doi: 10.1111/j.15746976.2010.00250.x.

van de Crommenacker, J. et al. (2016) 'Long-term monitoring of landbirds on Aldabra Atoll indicates increasing population trends', Bird Conservation International, 26(3), pp. 337-349. doi: $10.1017 /$ S0959270915000143.

Visscher, P.T. and Stolz, J.F. (2005) 'Microbial mats as bioreactors: populations, processes, and products', Palaeogeography, Palaeoclimatology, Palaeoecology, 219(1-2), pp. 87-100. doi: 10.1016/j.palaeo.2004.10.016.

Wagner, M. et al. (2005) 'Functional Marker Genes for Identification of Sulfate-Reducing Prokaryotes', in Environmental Microbiology. (Methods in Enzymology): Academic Press, 397, pp. 469-489. doi: 10.1016/S0076-6879(05)97029-8.

Waite, D.W. et al. (2020) 'Proposal to reclassify the proteobacterial classes Deltaproteobacteria and Oligoflexia, and the phylum Thermodesulfobacteria into four phyla reflecting major functional capabilities', International Journal of Systematic and Evolutionary Microbiology, 70(11), pp. 5972-6016. doi: 10.1099/ijsem.0.004213.

Wang, W. et al. (2020) 'Contrasting bacterial and archaeal distributions reflecting different geochemical processes in a sediment core from the Pearl River Estuary', AMB Express, 10(1), p. 16. doi: 10.1186/s13568-020-0950-y.

Warden, J.G. et al. (2016) 'Characterization of microbial mat microbiomes in the modern thrombolite ecosystem of Lake Clifton, Western Australia using shotgun metagenomics', Frontiers in Microbiology, 7, p. 1064. doi: 10.3389/fmicb.2016.01064. 
Warnecke, F., Amann, R. and Pernthaler, J. (2004) 'Actinobacterial 16S rRNA genes from freshwater habitats cluster in four distinct lineages', Environmental Microbiology, 6(3), pp. 242-253. doi: 10.1111/j.1462-2920.2004.00561.x.

Wasmund, K., Mußmann, M. and Loy, A. (2017) 'The life sulfuric: microbial ecology of sulfur cycling in marine sediments', Environmental Microbiology Reports, 9(4), pp. 323-344. doi: $10.1111 / 1758-2229.12538$.

Watson, J. et al. (2000) 'Reductively debrominating strains of Propionigenium maris from burrows of bromophenol-producing marine infauna', International Journal of Systematic and Evolutionary Microbiology, 50(Pt 3), pp. 1035-1042. doi: 10.1099/00207713-50-3-1035.

Wemheuer, B. et al. (2015) 'The green impact: bacterioplankton response toward a phytoplankton spring bloom in the southern North Sea assessed by comparative metagenomic and metatranscriptomic approaches', Frontiers in Microbiology, 6, p. 805. doi: 10.3389/fmicb.2015.00805.

Wemheuer, F. et al. (2019) 'Primary production in the water column as major structuring element of the biogeographical distribution and function of Archaea in deep-sea sediments of the Central Pacific Ocean', Archaea, 2019, p. 3717239. doi: 10.1155/2019/3717239.

Wemheuer, F. et al. (2020) 'Tax4Fun2: prediction of habitat-specific functional profiles and functional redundancy based on 16S rRNA gene sequences', Environmental Microbiome, 15(1), p. 11. doi: 10.1186/s40793-020-00358-7.

Whitman, R.L. and Nevers, M.B. (2003) 'Foreshore sand as a source of Escherichia coli in nearshore water of a Lake Michigan beach', Applied and Environmental Microbiology, 69(9), pp. 5555-5562. doi: 10.1128/AEM.69.9.5555-5562.2003.

Wiegand, S., Jogler, M. and Jogler, C. (2018) 'On the maverick Planctomycetes', FEMS Microbiology Reviews, 42(6), pp. 739-760. doi: 10.1093/femsre/fuy029.

Wietz, M. et al. (2010) 'Latitudinal patterns in the abundance of major marine bacterioplankton groups', Aquatic Microbial Ecology, 61(2), pp. 179-189. doi: $10.3354 / \mathrm{ame} 01443$.

Willis, A. and Woodhouse, J.N. (2020) 'Defining cyanobacterial species: Diversity and description through genomics', Critical Reviews in Plant Sciences, 39(2), pp. 101-124. doi: $10.1080 / 07352689.2020 .1763541$.

Willner, D. et al. (2012) 'Comparison of DNA extraction methods for microbial community profiling with an application to pediatric bronchoalveolar lavage samples', PloS One, 7(4), e34605. doi: 10.1371/journal.pone.0034605.

Wong, H.L. et al. (2015) 'Niche differentiation of bacterial communities at a millimeter scale in Shark Bay microbial mats', Scientific Reports, 5, p. 15607. doi: 10.1038/srep15607.

Xia, Y. et al. (2016) 'Cellular adhesiveness and cellulolytic capacity in Anaerolineae revealed by omics-based genome interpretation', Biotechnology for Biofuels, 9, p. 111. doi: 10.1186/s13068-016-0524-z.

Zhang, B. et al. (2020) 'Sediment microbial communities and their potential role as environmental pollution indicators in Xuande Atoll, South China Sea', Frontiers in Microbiology, 11, p. 1011. doi: 10.3389/fmicb.2020.01011.

Zhang, C.L. et al. (2015) 'Marine Group II Archaea, potentially important players in the global ocean carbon cycle', Frontiers in Microbiology, 6, p. 1108. doi: 10.3389/fmicb.2015.01108. 
Zhang, Y. et al. (2014) 'Drivers shaping the diversity and biogeography of total and active bacterial communities in the South China Sea', Molecular Ecology, 23(9), pp. 2260-2274. doi: $10.1111 / \mathrm{mec} .12739$.

Ziels, R.M. et al. (2015) 'Monitoring the dynamics of syntrophic $\beta$-oxidizing bacteria during anaerobic degradation of oleic acid by quantitative PCR', FEMS Microbiology Ecology, 91(4). doi: 10.1093/femsec/fiv028. 


\section{E. APPENDIX}

\section{Supplement}

\subsection{Supplementary Data Chapter B.1 Figure 1}

Sampling information and most abundant bacterial phyla in all studies used in the generation of Figure 1. The data is based on studies using 16S rRNA amplicons, which are referenced underneath the table. The table can also be found on the enclosed CD and zip folder: Supplement|Chapter_B_1|Supplementary_Data_B_1_Figure_1.docx.

\subsection{Supplementary Data Chapter D.1 Figure 6}

Metabolic assignment of abundant orders, relative abundances and summed metabolism based on metabolic features of cultured bacteria in each order. Page 1: Categories Aldabra: Abundant bacterial orders ( $>5 \%$ relative abundance), their metabolic affiliation, source of metabolic information and relative abundance table. Page 2: Categories Neusiedl: Abundant bacterial orders ( $>1 \%$ relative abundance), their metabolic affiliation, source of metabolic information and relative abundance table. Metabolic assignments and sources are adapted from Fussman et al. (2020). Page 3: Relative abundances summed by sample in the Aldabra and Neusiedl sediment cores.

The table can be found on the enclosed $C D$ and zip folder:

Supplement|Chapter_D_1|Supplementary_Data_D_1_Figure_6.xIsx. 
Supplementary Data Figure 1. Sampling information and most abundant bacterial phyla in all studies used in Figure 1. The data is based on studies using 16S rRNA amplicons, which are referenced underneath the table.

\begin{tabular}{|c|c|c|c|c|c|c|c|c|c|c|c|c|}
\hline Sampling site & Country & Latitude & Longitude & Category & $\begin{array}{c}\alpha- \\
\text { Proteo }\end{array}$ & $\begin{array}{c}\text { V- } \\
\text { Proteo }\end{array}$ & $\begin{array}{c}\delta- \\
\text { Proteo }\end{array}$ & $\begin{array}{l}\text { Bacte- } \\
\text { roidetes }\end{array}$ & $\begin{array}{l}\text { Chloro- } \\
\text { flexota }\end{array}$ & $\begin{array}{l}\text { Plancto- } \\
\text { mycetes }\end{array}$ & Other & Source \\
\hline $\begin{array}{l}\text { Arctic Mid- } \\
\text { Ocean Ridge }\end{array}$ & Atlantic & 73.21 & 7.34 & seafloor & 0 & 0 & 1 & 0 & 1 & 1 & 4 & 1 \\
\hline Pigeon Cay & Bahamas & 24.53 & -75.61 & intertidal & 1 & 1 & 1 & 1 & 0 & 0 & 3 & 2 \\
\hline Cananeia & Brazil & -25.05 & -47.57 & mangrove & 1 & 1 & 1 & 0 & 0 & 0 & 4 & 3 \\
\hline Plymouth & England & 50.34 & -4.148 & seafloor & 0 & 1 & 1 & 1 & 1 & 1 & 2 & 4 \\
\hline Cedar Key & Florida & 29.75 & -83.18 & mangrove & 1 & 1 & 1 & 0 & 1 & 1 & 2 & 5 \\
\hline Spiekeroog & Germany & 53.78 & 7.71 & intertidal & 0 & 1 & 0 & 1 & 0 & 1 & 4 & 6 \\
\hline Godthåbsfjord & Greenland & 64.29 & -50.42 & seafloor & 0 & 1 & 1 & 1 & 1 & 0 & 3 & 7 \\
\hline Gloucester & $\begin{array}{l}\text { Virginia, } \\
\text { USA }\end{array}$ & 37.25 & -76.51 & intertidal & 0 & 1 & 1 & 0 & 1 & 1 & 3 & 8 \\
\hline Caspian Sea & Eurasia & 39.99 & 51.5 & seafloor & 0 & 1 & 1 & 0 & 1 & 1 & 3 & 9 \\
\hline Xuande Atoll & China & 16.57 & 112.14 & atoll & 1 & 1 & 1 & 1 & 0 & 0 & 3 & 10 \\
\hline Yap Trench & China & 8.05 & 137.6 & $\begin{array}{c}\text { deep sea/ } \\
\text { seafloor }\end{array}$ & 1 & 1 & 0 & 0 & 1 & 1 & 3 & 11 \\
\hline Beilun & China & 21.31 & 108 & mangrove & 0 & 1 & 1 & 1 & 1 & 1 & 2 & 12 \\
\hline $\begin{array}{c}\text { Jiaolong } \\
\text { Methane Seep }\end{array}$ & China & 22.7 & 119.17 & seafloor & 0 & 1 & 1 & 0 & 1 & 0 & 4 & 13 \\
\hline Potrok Aike & Argentina & -51.96 & -70.38 & lake/river & 0 & 0 & 1 & 0 & 1 & 1 & 4 & 14 \\
\hline Lake Neusiedl & Austria & 47.48 & 16.42 & lake/river & 0 & 1 & 1 & 0 & 1 & 0 & 4 & 15 \\
\hline Pavilion Lake & Canada & 50.51 & -121.44 & lake/river & 1 & 0 & 0 & 1 & 0 & 0 & 5 & 16 \\
\hline Kinneret & Israel & 32.83 & 35.59 & lake/river & 0 & 1 & 0 & 1 & 1 & 0 & 4 & 17 \\
\hline Australia & Australia & -33.62 & 115.12 & intertidal & 1 & 1 & 1 & 1 & 0 & 0 & 3 & 18 \\
\hline Bhitarkanika & India & 20.4 & 86.54 & mangrove & 1 & 1 & 1 & 1 & 0 & 0 & 3 & 19 \\
\hline Goa & India & 15.3 & 73.52 & mangrove & 1 & 1 & 1 & 0 & 0 & 0 & 4 & 20 \\
\hline Aldabra & Seychelles & -9.44 & 46.39 & atoll & 1 & 1 & 1 & 0 & 0 & 0 & 4 & $\begin{array}{c}\text { Chapter } \\
\text { C.3 }\end{array}$ \\
\hline
\end{tabular}




\begin{tabular}{|c|c|c|c|c|c|c|c|c|c|c|c|c|}
\hline Serrana Bank & Colombia & 14.27 & -80.15 & atoll & 1 & 1 & 0 & 0 & 0 & 0 & 5 & 21 \\
\hline Spermonde & Indonesia & -5.02 & 119.3 & atoll & 1 & 1 & 1 & 0 & 0 & 0 & 4 & 22 \\
\hline Kiritimati & Kiribati & 1.9 & -157.4 & atoll & 0 & 0 & 0 & 1 & 1 & 1 & 4 & 23 \\
\hline $\begin{array}{c}\text { Kermadec } \\
\text { trench }\end{array}$ & $\begin{array}{c}\text { New } \\
\text { Zealand }\end{array}$ & -35.9 & -178.96 & $\begin{array}{l}\text { deep sea/ } \\
\text { seafloor }\end{array}$ & 1 & 1 & 0 & 1 & 1 & 1 & 2 & 24 \\
\hline Hydrate Ridge & $\begin{array}{l}\text { Oregon, } \\
\text { Canada }\end{array}$ & 44.4 & -125.06 & seafloor & 1 & 1 & 1 & 0 & 1 & 1 & 2 & 25 \\
\hline $\begin{array}{l}\text { Dorado } \\
\text { Outcrop }\end{array}$ & Pacific & 9.5 & -87.5 & seafloor & 1 & 1 & 1 & 0 & 1 & 1 & 2 & 26 \\
\hline $\begin{array}{l}\text { South Pacific } \\
\text { Gyre, Pacific }\end{array}$ & Pacific & -27.54 & -123.1 & seafloor & 1 & 1 & 0 & 0 & 0 & 0 & 5 & 27 \\
\hline $\begin{array}{c}\text { Mariana } \\
\text { trench }\end{array}$ & USA & 12.63 & 144.72 & $\begin{array}{l}\text { deep sea/ } \\
\text { seafloor }\end{array}$ & 1 & 1 & 0 & 1 & 1 & 1 & 2 & 24 \\
\hline $\begin{array}{c}\text { Mertz Glacier } \\
\text { Plynya }\end{array}$ & Antarctica & -66.312 & 143.38 & seafloor & 1 & 1 & 1 & 1 & 0 & 1 & 2 & 28 \\
\hline California & USA & 37.096 & -122.279 & intertidal & 1 & 1 & 1 & 1 & 0 & 1 & 2 & 29 \\
\hline
\end{tabular}

\section{Sources}

1. Jorgensen, S. L. et al. Correlating microbial community profiles with geochemical data in highly stratified sediments from the Arctic Mid-Ocean Ridge. Proceedings of the National Academy of Sciences of the United States of America 109, E2846-55; 10.1073/pnas.1207574109 (2012).

2. O'Reilly, S. S. et al. Molecular biosignatures reveal common benthic microbial sources of organic matter in ooids and grapestones from Pigeon Cay, The Bahamas. Geobiology 15, 112-130; 10.1111/gbi.12196 (2017)

3. Andreote, F. D. et al. The microbiome of Brazilian mangrove sediments as revealed by metagenomics. PloS one 7, e38600; 10.1371/journal.pone.0038600 (2012).

4. Laverock, B. et al. Bioturbating shrimp alter the structure and diversity of bacterial communities in coastal marine sediments. The ISME journal 4, 15311544; 10.1038/ismej.2010.86 (2010).

5. Green-García, A. M. \& Engel, A. S. Bacterial diversity of siliciclastic sediments in a Thalassia testudinum meadow and the implications for Lucinisca nassula chemosymbiosis. Estuarine, Coastal and Shelf Science 112, 153-161; 10.1016/j.ecss.2012.07.010 (2012). 
6. Degenhardt, J. et al. Seasonal dynamics of microbial diversity at a sandy high energy beach reveal a resilient core community. Front. Mar. Sci. 7; 10.3389/fmars.2020.573570 (2020).

7. Pelikan, C. et al. Glacial runoff promotes deep burial of sulfur cycling-associated microorganisms in marine sediments. Frontiers in microbiology 10, 2558; 10.3389/fmicb.2019.02558 (2019).

8. Hong, Y., Wu, J., Wilson, S. \& Song, B. Vertical stratification of sediment microbial communities along geochemical gradients of a subterranean estuary located at the Gloucester Beach of Virginia, United States. Frontiers in microbiology 9, 3343; 10.3389/fmicb.2018.03343 (2018).

9. Mahmoudi, N. et al. Microbial community composition and diversity in Caspian Sea sediments. FEMS microbiology ecology 91, 1-11; 10.1093/femsec/fiu013 (2015).

10. Zhang, B. et al. Sediment microbial communities and their potential role as environmental pollution indicators in Xuande Atoll, South China Sea. Frontiers in Microbiology 11, 1011; 10.3389/fmicb.2020.01011 (2020).

11. Fu, L. et al. Characteristics of the archaeal and bacterial communities in core sediments from Southern Yap Trench via in situ sampling by the manned submersible Jiaolong. The Science of the total environment 703, 134884; 10.1016/j.scitotenv.2019.134884 (2020).

12. Wu, P. et al. Bacterial communities in the rhizospheres of three mangrove tree species from Beilun Estuary, China. PloS one 11, e0164082; 10.1371/journal.pone.0164082 (2016).

13. Li, H., Yang, Q. \& Zhou, H. Niche differentiation of sulfate- and iron-dependent anaerobic methane oxidation and methylotrophic methanogenesis in deep sea methane seeps. Frontiers in microbiology 11, 1409; 10.3389/fmicb.2020.01409 (2020).

14. Vuillemin, A., Ariztegui, D., Horn, F., Kallmeyer, J. \& Orsi, W. D. Microbial community composition along a 50000 -year lacustrine sediment sequence. FEMS microbiology ecology 94; 10.1093/femsec/fiy029 (2018).

15. Hoyningen-Huene, A. J. E. von et al. Bacterial succession along a sediment porewater gradient at Lake Neusiedl in Austria. Scientific data 6, 163; 10.1038/s41597-019-0172-9 (2019).

16. Russell, J. A. et al. Prokaryote populations of extant microbialites along a depth gradient in Pavilion Lake, British Columbia, Canada. Geobiology 12, 250264; 10.1111/gbi.12082 (2014).

17. Bar-Or, I., Ben-Dov, E., Kushmaro, A., Eckert, W. \& Sivan, O. Methane-related changes in prokaryotes along geochemical profiles in sediments of Lake Kinneret (Israel). Biogeosciences 12, 2847-2860; 10.5194/bg-12-2847-2015 (2015).

18. Dyksma, S. et al. Ubiquitous Gammaproteobacteria dominate dark carbon fixation in coastal sediments. The ISME journal 10, 1939-1953; 10.1038/ismej.2015.257 (2016). 
19. Behera, P. et al. Spatial and temporal heterogeneity in the structure and function of sediment bacterial communities of a tropical mangrove forest. Environmental science and pollution research international 26, 3893-3908; 10.1007/s11356-018-3927-5 (2019).

20. Fernandes, S. O., Kirchman, D. L., Michotey, V. D., Bonin, P. C. \& LokaBharathi, P. A. Bacterial diversity in relatively pristine and anthropogenicallyinfluenced mangrove ecosystems (Goa, India). Brazilian journal of microbiology : [publication of the Brazilian Society for Microbiology] 45, 1161-1171; 10.1590/s1517-83822014000400006 (2014).

21. Alvarez-Yela, A. C., Mosquera-Rendón, J., Noreña-P, A., Cristancho, M. \& López-Alvarez, D. Microbial diversity exploration of marine hosts at Serrana Bank, a coral atoll of the Seaflower Biosphere Reserve. Front. Mar. Sci. 6; 10.3389/fmars.2019.00338 (2019).

22. Cleary, D. F. R., Voogd, N. J. de, Polónia, A. R. M., Freitas, R. \& Gomes, N. C. M. Composition and predictive functional analysis of bacterial communities in seawater, sediment and sponges in the Spermonde Archipelago, Indonesia. Microbial ecology 70, 889-903; 10.1007/s00248-015-0632-5 (2015).

23. Schmitt, S. et al. Salinity, microbe and carbonate mineral relationships in brackish and hypersaline lake sediments: A case study from the tropical Pacific coral atoll of Kiritimati. Depositional Rec 5, 212-229; 10.1002/dep2.71 (2019).

24. Peoples, L. M. et al. Microbial community diversity within sediments from two geographically separated hadal trenches. Frontiers in microbiology 10,347 ; 10.3389/fmicb.2019.00347 (2019).

25. Marlow, J. J. et al. Microbial abundance and diversity patterns associated with sediments and carbonates from the methane seep environments of Hydrate Ridge, OR. Front. Mar. Sci. 1; 10.3389/fmars.2014.00044 (2014).

26. Zinke, L. A. et al. Sediment microbial communities influenced by cool hydrothermal fluid migration. Frontiers in microbiology 9,1249 ; 10.3389/fmicb.2018.01249 (2018).

27. Morono, Y. et al. Aerobic microbial life persists in oxic marine sediment as old as 101.5 million years. Nature communications 11, 3626; 10.1038/s41467020-17330-1 (2020).

28. Bowman, J. P. \& McCuaig, R. D. Biodiversity, community structural shifts, and biogeography of prokaryotes within Antarctic continental shelf sediment. Applied and environmental microbiology 69, 2463-2483; 10.1128/AEM.69.5.2463-2483.2003 (2003).

29. Boehm, A. B., Yamahara, K. M. \& Sassoubre, L. M. Diversity and transport of microorganisms in intertidal sands of the California coast. Applied and environmental microbiology 80, 3943-3951; 10.1128/AEM.00513-14 (2014). 


\section{Publications \& Conference participations}

1. Fussmann, Dario; Hoyningen-Huene, Avril Jean Elisabeth von; Reimer, Andreas; Schneider, Dominik; Babková, Hana; Peticzka, Robert et al. (2020): 'Authigenic formation of $\mathrm{Ca}-\mathrm{Mg}$ carbonates in the shallow alkaline Lake Neusiedl, Austria'. In Biogeosciences 17 (7), pp. 2085-2106. doi: 10.5194/bg17-2085-2020.

2. von Hoyningen-Huene, A.J.E., Schneider, D., Fussmann, D., Reimer, A., Arp, G., Daniel, R. (2019) 'The microbial world of the Aldabra Atoll'. Functional Metagenomics, Trondheim, Norway. Oral presentation.

3. Hoyningen-Huene, Avril Jean Elisabeth von; Schneider, Dominik; Fussmann, Dario; Reimer, Andreas; Arp, Gernot; Daniel, Rolf (2019): 'Bacterial succession along a sediment porewater gradient at Lake Neusiedl in Austria'. In Scientific data 6 (1), p. 163. doi: 10.1038/s41597-019-0172-9.

4. Wemheuer, Franziska; Hoyningen-Huene, Avril Jean Elisabeth von; Pohlner, Marion; Degenhardt, Julius; Engelen, Bert; Daniel, Rolf; Wemheuer, Bernd (2019) 'Primary production in the water column as major structuring element of the biogeographical distribution and function of Archaea in deepsea sediments of the Central Pacific Ocean'. In Archaea, 2019, p. 3717239. doi: $10.1155 / 2019 / 3717239$.

5. von Hoyningen-Huene, A.J.E., Schneider, D., Fussmann, D., Reimer, A., Arp, G., Daniel, R. (2018) 'Microbiome of the Aldabra Atoll - Insights into microbial communities and their influence on their carbonate environment'. ISME, Leipzig, Germany. Poster.

6. Pohlner, Marion; Degenhardt, Julius; Hoyningen-Huene, Avril J. E. von; Wemheuer, Bernd; Erlmann, Nora; Schnetger, Bernhard et al. (2017) 'The biogeographical distribution of benthic Roseobacter group members along a Pacific transect is structured by nutrient availability within the sediments and primary production in different oceanic provinces'. In Frontiers in Microbiology 8, p. 2550. doi: 10.3389/fmicb.2017.02550.

7. von Hoyningen-Huene, A.J.E., Wemheuer, B., Daniel, R. (2017) 'Structural and functional characterization of microbial communities within the biogeographical provinces of the Pacific Ocean'. ProkaGENOMICS, Göttingen, Germany. Poster.

8. Voget, Sonja; Díaz Valerio, Stefani Maria; Hoyningen-Huene, Avril Jean Elisabeth von; Nattramilarasu, Praveen Kumar; Vollheyde, Katharina; Xiao, Shengbin; Daniel, Rolf (2015) 'Genome Sequence of Jannaschia aquimarina GSW-M26, a Member of the Roseobacter Clade'. In Genome announcements 3 (2). doi: 10.1128/genomeA.00353-15. 


\section{Acknowledgements}

This thesis would not have been possible without the support from lots of people who I can't all mention by name. I want you to know, that I really appreciate all you have done for me, even if it was the tinies thing and I didn't mention you here.

My first thank you goes out to Prof. Dr. Rolf Daniel who gave me the opportunity to learn about microbial communities and see the most remote and fascinating places in the world. Thank you for all the support and advice readily given throughout the past couple of years. I had a great time chatting to you about work, football and Brexit.

I would also like to thank PD Dr. Michael Hoppert for being my second examiner and giving advice in- and outside my thesis committee meetings. Thank you also to Prof. Dr. Gernot Arp, who was not only a member on my thesis committee, but also the leader of our Aldabra expedition. Your guidance, advice, and patience during my personal expedition into biogeochemistry have been of great value to me.

I would also like to thank the remaining members of my examination board Prof. Dr. Stefanie Pöggeler, Prof. Dr. Kai Heimel and Prof. Dr. Jan DeVries for agreeing to partake in reading and evaluating this thesis and approaching defence.

Dear Dominik, as "Master of the Dominikans" and expedition coach you have played a large part in the success of this thesis. Thank you for your advice, open ear, Takamaka, and letting me bounce my confused thoughts off of you.

Thank you to the entire AG Daniel, present and past. Particularly the Post-Docs, technical assistants, secretaries, and workshop who are managing life, lab, and students. Anja, Bernd, Birgit, HeikoN and HeikoL, Jacqueline and Robert, for their ready support in all situations. Mechthild, Christiane, Melanie and Sarah for their excellent technical assistance and expertise. Petra, Nicole, and Angela for their support with the paperwork and organisation. Anja thank you also for your incredible management of the sequencing platform, patience, and advice.

To my fellow PhD Students, I wouldn't have made it without you! Thank you, Amelie, Dirk, Genis, Inka, Kristin, Randi, Richard, Simone for welcoming me into "The Office". A big thank you also to the present cast of PhDs: Alex, Ines, Miri, Stefi, Tati and Tim. You have kept me going during the ups and downs of the last years and are 
pretty cool. I will never forget the paper-sword fights, random road trips to buy sausages, girls' nights, motivational gifs and gossip, and generally great time.

Thank you also to all past and present Master and Bachelor students who have made this department so enjoyable. Especially the students who let me teach them and enabled me to pursue all my side projects: Lukas, Max, Nils and Tabea.

Dominik, Dario, Andreas, and Gernot. Our sampling team was pretty amazing. Even in the most gruelling times the mood remained great due to the inordinate amount of self-irony and sarcasm. Dario, my Co-PhD student, thank you for all the work and time you have invested in this. We finally did it! Andreas, thank you for your great expertise and ready advice in all things porewater geochemistry. Speaking of the sampling team, this work would not have been possible without the dedicated SIF Team (Cheryl, April, Frauke, Nancy, Chef, Marc and many more) including Ronny Marie. Without him we probably would have died of thirst in some champignon crevasse next to a tortoise cadaver. Keep on loving nature and living the Gren!

Next, I would like to thank my support network. Julian may the dark DNA be ever in your favour and the home-brew never explode. The SchleFaZ crew for booze, banter, and bad movies. Ines and Tati for supportive walks, gifs, and all-round advice. Thanks to Ilona for the emotional-support-sport-replacement-walks. Isa and Katrina for brainless TV evenings with high quality trash TV, prosecco, and tea. Thank you to the Tuspo Weende women and mixed teams for the fun times. Thanks goes to the Pomodoro PhD's who saved me from isolation and worked alongside me in the past months. You'll also get it done! Gina Hawkins thank you for always being there for me, despite the long distance between us. Thank you for introducing me to the right kind of Tea. Tim, thank you for keeping me balanced and getting me through the toughest bits of this thesis with cake deliveries and Nordic excursions.

Dear Mama, Papa, Alex, and the rest of the family. Thank you for always supporting me, raising me to be inquisitive and nerdy, and patiently answering my many questions. This wouldn't have been possible without your trust in me and the constant support messages. 